MÁRCIA REGINA GAMA

\title{
DESENVOLVIMENTO E ESTUDO COMPARATIVO DE LISTAS DE PALAVRAS PARA USO NA MEDIDA DO LIMIAR DE RECONHECIMENTO DA FALA EM CRIANÇAS DE 5 A 7 ANOS DE IDADE
}

\author{
São Paulo
}

2004 


\title{
MÁRCIA REGINA GAMA
}

\section{DESENVOLVIMENTO E ESTUDO COMPARATIVO DE LISTAS DE PALAVRAS PARA USO NA MEDIDA DO LIMIAR DE RECONHECIMENTO DA FALA EM CRIANÇAS DE 5 A 7 ANOS DE IDADE}

Tese apresentada ao Instituto de Psicologia da Universidade São Paulo como parte dos requisitos para obtenção do titulo de

Doutor em Psicologia

\author{
Área de Concentração: Neurociências e \\ Comportamento \\ Orientador: Prof Dr Klaus Tiedemann
}

São Paulo 


\section{Ficha Catalográfica preparada pelo Serviço de Biblioteca e Documentação do Instituto de Psicologia da USP}

\section{Gama, M. R.}

Desenvolvimento e estudo comparativo de listas de palavras para uso na medida do limiar de reconhecimento da fala em crianças de 5 a 7 anos de idade./ Márcia Regina Gama. - São Paulo: s.n., 2004. - 207p.

Tese (doutorado) - Instituto de Psicologia da Universidade de São Paulo. Núcleo de Pesquisa em Neurociências e Comportamento.

Orientador: Klaus Tiedemann.

1. Audiometria da fala 2. Crianças 3. Percepção da fala 4. Percepção auditiva I. Título. 
Desenvolvimento e estudo comparativo de listas de palavras para uso na medida do limiar de reconhecimento da fala em crianças de 5 a 7 anos de idade

\section{Márcia Regina Gama}

\section{BANCA EXAMINADORA}

(nome e assinatura)

(nome e assinatura)

(nome e assinatura)

(nome e assinatura)

(nome e assinatura)

Tese defendida e aprovada em _23_/_09_/2004 


\section{DEDICATÓRIA}

Ao meu marido Paulo,
por proporcionar a vivência das palavras amor, respeito,
companheirismo e amizade.

À minha querida irmã Aglael por seu profissionalismo, conhecimento e encorajamento. obrigada! 


\section{AGRADECIMENTOS}

Ao meu orientador Prof Dr Klaus Tiedemann por sua orientação e pela oportunidade de desenvolver meu doutorado no Nec.

A Profa Dra Maria Teresa Momenshon dos Santos pela co-orientação no trabalho.

Às ex-alunas da Universidade São Francisco: Gislene e Ana Claudia pela ajuda no levantamento do corpus, à Rose pela ajuda na qualificação e fase final da coleta dos dados e à Marina ( espero que você esteja bem juntinho d'Ele).

À secretaria de educação do município de Itatiba e as escolas participantes pelo apoio e confiança.

À Universidade São Francisco, pelo uso do espaço da clinica-escola de fonoaudiologia e em especial, a Ednéia por sua ajuda.

À Fga. Aline Wolf por suas horas de locução.

Ao Estudio Vibe, em especial, ao Eduardo, por seu profissionalismo e cuidado com o material.

Ao Orlandi e André (AcústicaOrlandi) por seu total apoio nas questões técnicas e metodológicas.

À Profa. Valeria Almeida por sua ajuda e dedicação na correção do texto.

À Sandra Malagutti pelo tratamento estatístico dos dados. 
À minha sócia-mamãe Tatiana por sua paciência na minha ausência.

À Fga. Dra. Fátima Branco por compartilhar os momentos de angústia.

À amiga Leila Sandra pelo eterno companheirismo.

Em especial,

Aos meus pais a quem devo muito.

E por fim, as crianças motivo maior deste trabalho. 
"FELIZ É O HOMEM QUE SE OCUPA DE ALGUMA COISA QUE O PRESERVE DA OCIOSIDADE E QUE SABE DESFRUTAR AS DOÇURAS DO TRABALHO PORQUE LHE É AGRADÁ YEL O EXERCÍCIO DE SUA ATIVIDADE" BORDOGNS 


\section{SUMÁRIO}

Lista de Quadros

Lista de Figuras

Lista de Tabelas

Lista de Abreviaturas e Siglas

Resumo

Abstract

i

i

ii

iv

$\mathrm{V}$

vi

1. Introdução

1.1 Audiometria da Fala: Conceituação Geral

2

1.2 Objetivo

9

2. Revisão da Literatura

2.1- A Avaliação da Audição e os Testes Para Uso na Audiometria da Fala

2.1.1 -A Medida do Limiar de Reconhecimento

De Fala

2.1.2 - Testes Desenvolvidos para a Medida do LRF

2.1.3 - Testes para a Medida do LRF em Português

Brasileiro

2.2 - Desenvolvendo Testes para audiometria de Fala: Pressupostos 40 sobre a Percepção da Fala

2.3 - Critérios para Desenvolvimento de Testes

3. Método

3.1 Sujeitos

3.1.1 - Critérios de Inclusão

3.1.2 - Amostra da População no Projeto Piloto:

Primeira e Segunda Fase

3.2 - Material

3.2.1 - Desenvolvimento das Listas LE e LRS 73

3.2.2 - Gravação Do Material $\quad 75$

3.3 Procedimento $\quad 77$

3.3.1 - Procedimento para Obtenção do Limiar $\quad 80$

De Reconhecimento da Fala: LRF

3.3.2 - Analise Estatística dos Resultados $\quad 82$

\begin{tabular}{ll} 
4. Resultados & 82 \\
\hline
\end{tabular}

4.1 Resultados do Estudo Piloto: Primeira Fase 85

4.1.2 Resultados do Estudo Piloto: Segunda Fase $\quad 90$

4.2 Fase Experimental: Análise do Desempenho dos Sujeitos no 94 Resultado do Limiar de Reconhecimento da Fala (dBNS), por Faixa Etária,em Relação à Lista e à Orelha Avaliada 
4.3 Análise Comparativa entre es Listas LE e LRS Segundo a

97 Análise do Desempenho dos Sujeitos em Relação aos Valores Obtidos no LRF, em dBNs, por Faixa Etária e Orelha

Avaliada

4.4 Análise Comparativa Entre as Faixas Etárias no Desempenho 99 dos Sujeitos para as Listas LE e LRS

4.5 Análise de Efeito de Ordem de Aplicação das Listas LE e LRS nas Orelhas para todas as Faixas Etárias

4.6 Análise do Desempenho dos Sujeitos por Faixa Etária em Relação à Lista e Orelha Avaliada em Relação ao Sexo

4.7 Análise da Distribuição dos Resultados do LRF (dBNS) em 105 Relação ao Total de Orelhas nas Faixas Etárias

4.8 Análise do Desempenho Individual dos Sujeitos em Relação ao 109 Resultado do LRF (dBNs) em cada Faixa Etária

4.9 Avaliação Quantitativa e Qualitativa de Erros por Palavra na Lista LE1

5.0 Discussão

5.1 Sobre os Desempenhos dos Sujeitos em Relação as Variáveis Faixa Etária, Lista e Orelha Avaliada

5.2 Sobre a Análise Qualitativa das Respostas Obtidas nas PalavrasAlvo apresentadas

5.3 Sobre as Listas de Palavras Elaboradas para o Experimento

5.4 Sobre a Gravação e a Edição do Material da Fala

7. Anexos

8. Referências Bibliográficas 


\section{LISTA DE QUADROS}

Quadro

página

Quadro 1: Testes desenvolvidos para uso na audiometria da fala

Quadro 2: testes gravados em CD, em língua inglesa e espanhola, para uso na 32 audiometria de fala

Quadro 3: forma de apresentação das listas LE na fase piloto 81

Quadro 4: forma de apresentação das listas LE e LRS na fase experimental 81

Quadro 5. Número total de erros por palavra na lista LE1 em ordem 92 decrescente.

Quadro 6: Análise descritiva do tipo de erro por palavra na LE em todas as

faixas etárias, quando o sujeito apresentou resposta. 0s números à frente das palavras indicam quando o tipo de erro ocorreu mais que uma vez

\section{LISTA DE FIGURAS}

\section{FIGURA}

\section{PAGINA}

Figura 1. Média dos resultados do LRF em relação ao número total de 106 orelhas avaliadas nas três faixas etárias para a lista LE

Figura 2. Média dos resultados do LRF em relação ao número total de orelhas avaliadas nas três faixas etárias a lista LRS

Figura 3 : Dispersão entre a média tonal e as diferenças entre o resultado da aplicação do LRF para as orelhas direitas dos sujeitos do grupo de 5 anos.

Figura 4 : Dispersão entre a média tonal e as diferenças entre o resultado da aplicação do LRF para as orelhas esquerdas dos sujeitos do grupo de 5 anos. Figura 5 : Dispersão entre a média tonal e as diferenças entre o resultado da aplicação do LRF para as orelhas direitas dos sujeitos do grupo de 6 anos. Figura 6 : Dispersão entre a média tonal e as diferenças entre o resultado da aplicação do LRF para as orelhas esquerdas dos sujeitos do grupo de 6 anos. Figura 7 : Dispersão entre a média tonal e as diferenças entre o resultado da aplicação do LRF para as orelhas direitas dos sujeitos do grupo de 7 anos. Figura 8: Dispersão entre a média tonal e as diferenças entre o resultado da aplicação do LRF para as orelhas esquerdas dos sujeitos do grupo de 7 anos. Figura 9. Gráfico de dispersão do número de erros encontrados nas palavras 


\section{LISTA DE TABELAS}

Tabela

página

Tabela 1. Distribuição da amostra segundo a faixa etária e sexo na fase 171

do piloto

Tabela 2. Distribuição da população segundo o sexo e a faixa etária na 72

segunda fase do piloto

Tabela 3 . Distribuição da população segundo o sexo e a faixa etária no grupo 72

experimental

Tabela 4: distribuição da ocorrência do LRF em dBNS, para as variáveis lista, orelha e faixa etária no estudo piloto fase 1

Tabela 5: Média da ocorrência número de degraus para o estabelecimento do

LRF para as orelhas direita e esquerda no estudo piloto fase 1

Tabela 6: distribuição da ocorrência do LRF, em dBNS, para as variáveis lista 91 orelha e faixa etária no estudo piloto fase 2

Tabela 7 . Média do LRF, em dBNS, para as variáveis lista aplicada, orelha avaliada para a faixa etária de 5 anos. Não houve diferença estatisticamente significante do desempenho entre os sujeitos verificado pelo teste U de MannWhitney

Tabela 8 . Média do LRF, em dBNS, para as variáveis lista aplicada, orelha avaliada para a faixa etária de 6 anos. Não houve diferença estatisticamente significante do desempenho entre os sujeitos verificado pelo teste U de MannWhitney

Tabela 9 . Média do LRF, em dBNS, para as variáveis lista aplicada, orelha avaliada para a faixa etária de 7 anos. Não houve diferença estatisticamente significante do desempenho entre os sujeitos verificado pelo teste U de MannWhitney

Tabela 10. Média dos resultados do LRF, em dBNS, para as variáveis lista, LE e LRS, e faixa etária. Não houve diferença estatisticamente significante do desempenho entre os sujeitos verificado pelo teste U de Mann-Whitney.

Tabela.11. Médias dos resultado do LRF em dBNS para as variáveis lista

LE, faixa etária e orelha avaliada.,verificada pela Prova de Kruskal-Wallis para LE na OD e OE.

Tabela. 12. Média dos resultado do LRF em dBNS para as variáveis lista

LRS, faixa etária e orelha avaliada. verificados pela Prova de Kruskal-Wallis para LRS na OD. Houve diferença estatisticamente significante do desempenho entre os sujeitos na LRS na OE.

Tabela 13 . Média dos resultados do LRF, em dBNS, para as variáveis ordem

de aplicação das listas LE e LRS, orelha e faixa etária. Não houve diferença estatisticamente significante $(\mathrm{p}<0,05)$ no desempenho entre os sujeitos, verificada pelo teste $\mathrm{U}$ de Mann-Whitney

Tabela.14 . Média dos resultados do LRF em dBNS para as variáveis sexo,

listas LE e LRS e faixa etária. Houve diferença estatisticamente significante $(\mathrm{p}<0,05)$, verificado pelo teste $\mathrm{U}$ de Mann-Whitney, no desempenho entre o sexo feminino e masculino, no grupo de 5 anos, na lista LRS, na OE. .

Tabela 15 Correlação entre a média tonal e o LRF (dBNA) para as variáveis faixa etária, lista e orelha avaliada. 
Tabela 16. Resultados dos sujeitos que obtiveram valores do LRF( dBNS)

110 negativos em, pelo menos, uma das apresentações na LE ou LRS para a faixa etária de 5 anos

Tabela 17. Resultados dos sujeitos que obtiveram valores de LRF positivos e maiores que 10dBNS em, pelo menos, uma das apresentações na LE ou LRS para a faixa etária de 5 anos

Tabela 18. Resultados dos sujeitos que obtiveram valores de LRF negativos em, pelo menos, uma das apresentações na LE ou LRS para a faixa etária de 6 anos

Tabela 19. Média dos resultados entre os sujeitos que obtiveram valores de LRF positivos e maiores que 10dBNS em, pelo menos, uma das apresentações na LE ou LRS para a faixa etária de 6 anos

Tabela 20. Média dos resultados entre os sujeitos que obtiveram valores de LRF negativos em, pelo menos, uma das apresentações na LE ou LRS para a faixa etária de 7 anos

Tabela 21. Média dos resultados entre os sujeitos que obtiveram valores de LRF positivos e maiores que 10dBNS em, pelo menos, uma das apresentações na LE ou LRS para a faixa etária de 7 anos

Tabela 22. Número total dos erros por palavras na lista LE em ordem decrescente e a porcentagem de erros sobre o número total de apresentações de cada palavra (112 vezes).

Tabela 23 Distribuição das palavras na lista LE e LRS por categoria gramatical 


\section{LISTA DE ABREVIATURAS E SIGLAS}

IRF: índice de reconhecimento da fala

LDF: limiar de detecção da fala

LRF: limiar de reconhecimento da fala

Hz: Hertz

dB: decibel

SRT: Speech recognition threshold

NS: nível de sensação

IEL: Instituto de estudos lingüísticos

UNICAMP: Universidade de Campinas

PI: performance-intensity

ASHA: association of speech-hearing American

NPS: nível de pressão sonora

ANSI: American National Standard Method for Coupler

Calibration of Earphones

CID-W : Instituto Central para o Surdo

VV: viva voz

CD: compact disc

S/R: sinal/ruido

NU: Northwestern University

ISO: International Organization for Standardization

\footnotetext{
${ }^{2}$ Baseado em Cervo e Bervian (2002) e NBR 6029 (ABNT,2000)
} 


\section{RESUMO}

Gama, M.R. Desenvolvimento e estudo comparativo de listas de palavras para uso na medida do limiar de reconhecimento da fala em crianças de 5 a 7 anos de idade. São Paulo, 2004, 207p. Tese (Doutorado). Instituto de Psicologia, Universidade de São Paulo.

O trabalho teve como objetivo geral discutir a construção de listas de palavras para uso na medida do teste de Limiar de Reconhecimento da Fala (LRF) em crianças com idade entre 5 e 7 anos. O grupo de sujeitos foi constituído por alunos de pré-escola e da $1^{\mathrm{a}}$ série do ensino fundamental de escolas da rede pública da cidade de Itatiba, São Paulo, otologicamente normais. O trabalho foi estruturado em 3 etapas. A primeira etapa relacionou-se com a construção das listas de palavras experimentais trissilábicas paroxítonas denominadas de LE1 e 2, constituídas a partir de um levantamento feito com programas e filmes infantis de maior audiência pelos grupos etários estudados. Das 673 palavras obtidas, 35 trissílabas paroxítonas foram selecionadas, formando duas listas em ordem aleatória. As listas LRS 1 e 2 foram utilizadas para comparação e retiradas de Russo e Santos (1993), seguindo os mesmos critérios de elaboração. Na segunda etapa, as listas de palavras foram gravadas em estúdio profissional, por um locutor do sexo feminino nativo do português brasileiro. Na terceira etapa o material desenvolvido foi aplicado em um grupo de 94 crianças de 5 a 7 anos de ambos os sexos.. Os resultados, na análise quantitativa, não mostraram diferenças estatisticamente significantes entre as variáveis listas, orelhas, faixa etária, ordem de apresentação e sexo. Os resultados do LRF (em deciBel Nível de Sensação) obtidos com as listas LE e LRS situaram-se entre -10 e $+15 \mathrm{dBNS}$ com média de 4,3dBNS para orelha direita e 4,4dBNS para orelha esquerda. Os dados indicaram que as listas desenvolvidas para a obtenção do LRF, em crianças na faixa etária do estudo, são válidas para este fim. A análise qualitativa indicou algumas das estratégias utilizadas pelos sujeitos no reconhecimento auditivo das palavras da lista E1.

Palavras-chaves: criança, audiometria da fala, percepção da fala, audição. 


\begin{abstract}
GAMA, M. R. Development and comparative study of word lists to use in the speech recognition threshold research in 5 to 7 year-old children.
\end{abstract}

This study provides a discussion about a word list construction to use in the speech recognition threshold. The chosen subjects are pre and first year school children from the Basic Education at public schools in Itatiba, São Paulo - Brazil, otologically normal. The study comprises three stages. The first one was the construction of paroxytone trisyllabic word lists called LE1 e 2, consisted of a survey done with juvenile programs and films of bigger audience by the aged studied groups. From the 672 words, 35 paroxytone trisyllables were selected, forming two lists in a random order. The LRS 1 and 2 were used for comparison and they were got from Russo e Santos (1993), following the same criteria. In the second stage, the word lists were recorded in a professional studio by a native speaker. In the third stage, the developed material was applied in a group with 94 children. The results didn't show differences statistically significant among the varied list, the ear, the aged group, the presentation order and the sex. The SRT (dBNS) results obtained with the LE and the LRS lists were placed among -10 and +15 dBNS. The data indicated that the developed lists to obtain the SRT in these children are valid.

Key-words:childhood, audiometry speech, speech perception, hearing. 


\section{1 - INTRODUÇÃO}

\section{1 - Audiometria da Fala: Conceituação Geral}

Com objetivos clínicos ou de diagnóstico a avaliação da percepção da fala teve seu início por volta de 1910. Essa avaliação, desde então, vêm apresentando um grande desenvolvimento com a introdução de diferentes técnicas de avaliação, tipos de testes e formas de resposta do avaliado.

Segundo Lively, Pisoni e Goldinger (1994) as metodologias mais utilizadas para avaliar a percepção da fala advêm dos estudos de reconhecimento visual. Baseadas nestas metodologias, foram desenvolvidas formas de avaliação da percepção auditiva, e hoje, há inúmeros testes de percepção da fala que compõem a bateria logoaudiométrica utilizada como procedimento de rotina em qualquer avaliação audiológica. Como a logoaudiometria avalia aspectos da recepção da fala e da linguagem, esses testes são também chamados de testes de reconhecimento ou inteligibilidade da fala (Penrod, 1999). ${ }^{3}$

A audiometria da fala ou logoaudiometria é uma modalidade de avaliação da percepção da fala através de instrumentos calibrados como o audiômetro. O objetivo principal é avaliar uma ou mais habilidades auditivas do indivíduo, utilizando sons da fala como estímulo, evocando uma resposta verbal ou não. Os testes componentes da audiometria da fala utilizam formas diferenciadas de apresentação

\footnotetext{
${ }^{3}$ as referências bibliográficas estão baseadas na ABNT NBR 10520 (2002).
} 
(com e sem ruído em competição, aceleração, compressão e filtragem) e tipos de itens-estímulo como palavras monossilábicas, dissilábicas, trissilábicas e sentenças, dentre outros (Sherwood e Fuller, 1997).

A audiometria da fala também tem papel importante no diagnóstico diferencial das mais variadas alterações auditivas. A importância destes testes na audiometria da fala é indiscutível do ponto de vista do diagnóstico, previsibilidade do desempenho comunicativo e informações quanto à qualidade das habilidades auditivas do indivíduo como suporte ao processo da reabilitação auditiva e da linguagem (Evans, 1997).

A função auditiva adequada é condição essencial para o bom desenvolvimento da linguagem oral. Não havendo possibilidade de recuperação da audição, em termos fisiológicos, é necessário um processo de intervenção terapêutica e educacional. Assim sendo, a audiometria da fala é um importante instrumento para a confirmação dos dados da audiometria tonal e diagnóstico diferencial, merecendo grande atenção.

A audiometria da fala é constituída por três testes básicos, aplicados de acordo com as possibilidades auditivas, lingüísticas e cognitivas do avaliado. São eles: o índice de reconhecimento da fala (IRF), o limiar de detecção da fala (LDF) e o limiar de reconhecimento da fala (LRF) (Evans, 1997; Kruger e Kruger, 1997).

A audiometria da fala avalia a habilidade de compreensão da fala relacionada à intensidade do sinal em que ela é apresentada. Sabe-se que é possível detectar a presença de estímulos da fala em nível muito baixo, como o limiar auditivo, embora não seja possível reconhecer, discriminar e compreender tais estímulos. 
O IRF tem por objetivo quantificar a habilidade auditiva em termos percentuais do desempenho do avaliado na tarefa de repetição de palavras. O LDF é utilizado quando o indivíduo não apresenta condições auditivas, lingüísticas ou cognitivas suficientes à aplicação dos testes IRF e LRF.

A medida do limiar de reconhecimento da fala (também conhecido sob a sigla SRT - speech recognition threshold) é utilizada como medida da relação entre os limares de tom puro em determinadas frequiências e a intensidade mínima na qual o indivíduo tem condições de repetir corretamente o estímulo em 50\% das apresentações realizadas. Utiliza-se, geralmente, como parâmetro de resposta, a diferença entre o LRF e a média dos limares tonais nas freqüências de $500 \mathrm{~Hz}, 1 \mathrm{KHz}$ e $2 \mathrm{KHz}$ em torno de $6 \mathrm{~dB}$ nível de sensação (NS), podendo chegar em até 10dBNS, segundo Olsen e Matkin (1979). O LRF pode ser utilizado como medida de referência para outros testes supra-liminares.

Os mesmos autores sugeriram que a relação entre a inteligibilidade da fala e a sensibilidade para tom puro tem sido utilizada como uma fórmula para prever o desempenho comunicativo a partir do audiograma, de modo a representar o indivíduo em condições de comunicação no dia-a-dia. Em especial, a medida do LRF tem sido utilizada como medida de confirmação dos limiares auditivos tonais obtidos, já que, tanto a audiometria tonal quanto a medida do LRF são testes subjetivos que podem sofrer influências da motivação, atenção e condições cognitivas do sujeito (como rebaixamento mental), além de condições acústicas na realização do teste (como nível de ruído da sala) bem como condições do equipamento (calibração).

Os resultados dos estudos com testes de percepção de fala têm demonstrado a dificuldade em avaliar-se a relação da perda auditiva 
e o prejuízo causado por ela pois a relação entre o grau da perda e o prejuízo não é linear.

Penrod (1999) sugeriu que muitos dos estudos realizados entre 1930 e 1960 já demonstravam a forte relação entre a porcentagem de palavras reconhecidas corretamente e os níveis de intensidade na apresentação dos estímulos da fala. Estudos sobre a relação entre a intensidade de apresentação do estímulo e os tipos de estímulo utilizados para a avaliação logoaudiométrica têm mostrado que não só a intensidade é importante, mas também o tipo de estímulo da fala selecionado e o nível de processamento da percepção da fala (como detecção, reconhecimento, discriminação ou compreensão) que se deseja avaliar (Machado, 1988; Gama, 1994; Meyer e Bilger, 1997; Penrod, 1999).

Os testes de audiometria da fala têm se diferenciado para uso em populações distintas, em especial, de crianças e adultos. Esta diferenciação é devido à necessidade de escolha dos tipos de materiais da fala que são utilizados, além de outros critérios como a familiaridade do estímulo na língua pela população estudada e o nível de complexidade lingüística exigido no teste (Mendel; Danhauer, 1997). Os testes de fala, na língua inglesa, são em grande número e variedade, estando disponíveis comercialmente para serem utilizados na prática clínica audiológica, segundo Mendel e Danhauer (op.cit.). No Brasil, os testes logoaudiométricos utilizam diferentes estímulos da fala, mas preferencialmente palavras monossilábicas no teste de Índice de Reconhecimento da Fala e palavras trissilábicas na medida do Limiar de Reconhecimento da fala .

Assim, a partir de 1990, no Brasil, houve uma grande evolução nos testes para avaliar a percepção da fala, com o objetivo 
principal de utilizá-los nas baterias de testes de diagnóstico diferencial de alterações do processamento auditivo e de avaliar as habilidades de recepção da fala em indivíduos portadores de implante coclear. Em especial, o teste da medida do IRF recebeu várias formas alternativas de tipos de materiais (monossílabos, dissílabos, espondeus e sentenças) e formas de apresentação (com e sem ruído), mas há um número restrito de estudos sobre o teste da medida do Limiar de Reconhecimento da Fala (LRF), tanto em adultos como em crianças.

As listas de palavras, atualmente utilizadas no Brasil, apresentam questões discutíveis quanto aos dados disponíveis acerca dos critérios de escolha do material, dados de avaliação de sensibilidade e validade e desenvolvimento específico para população de crianças ou adulto, conforme os trabalhos mais conhecidos e utilizados em língua portuguesa do Brasil.

Costa (1998 a e b) atualizou o levantamento, anteriormente feito por Gama em 1991, das listas para IRF mais utilizadas nos principais centros de audiologia de São Paulo e obteve os mesmos resultados que Gama (op.cit.), no qual não foi possível localizar com precisão a metodologia de desenvolvimento destas listas e seus estudos de validação e normatização.

Silva, Gama-Rossi, Albano, Moreira e Kakinohama (1995), Silva, Gama-Rossi e Albano (1997) e Gama-Rossi e Silva (2000) contribuíram para estas discussões através da análise de vários trabalhos recentemente desenvolvidos em português e avaliados no Laboratório de Fonética Acústica e Psicolingüística Experimentais do IEL, UNICAMP, em especial, solicitações por parte dos pesquisadores da área para avaliar o balanceamento fonético de listas para este fim. 
Os autores citados, então, realizaram um estudo sobre o desenvolvimento de listas de palavras para a logoaudiometria em outras línguas, que não o inglês, e observaram que os trabalhos mais recentes tendem a abandonar o modelo da língua inglesa, em especial o americano, com balanceamento fonético, e a utilizar um modelo mais psico-sócio-lingüístico para a elaboração dessas listas.

Esses trabalhos propõem outras formas de escolha dos itensestímulos das listas de modo a refletir melhor as características das línguas avaliadas quando na falta de grande ocorrência de monossílabos ou outros tipos de palavras na língua. Outras palavras, de maior incidência na língua, são utilizadas como no caso da língua Bantu, que utiliza palavras quase-monossílábicas (Nsamba, 1979) ou da língua árabe, que utiliza monossílabos, mas sem o balanceamento fonético, optando por palavras mais familiares em qualquer contexto sócioeconômico-cultural de sua língua. Também observado nos estudos de Ashoor e Prochazcka (1982); Zubick, Irizarry, Rosen, Feudo, Kelly e Strome (1983) ou ainda, como no estudo de Mukari e Said (1991), para o malaio, que utilizou como critério a familiaridade e a ocorrência na língua, além do balanceamento fonético.

Em relação aos trabalhos mais recentes, em português brasileiro, visando o estudo exclusivo da medida do limiar de reconhecimento de fala, há os trabalhos de Lacerda (1976), Fragoso (1986), Camargo et al. (1989), Russo e Santos (1993) e Harris, Goffy, Pedalini, Gygi e Merril. (2001).

Harris et al. (2001) forneceram uma importante contribuição ao estudo destes testes, em português, com o desenvolvimento de listas de palavras para o LRF, especialmente para 
adultos. Destes estudos somente Fragoso (1986) pesquisou o LRF em crianças a partir de listas de palavras dissílabas.

A avaliação da audição em crianças, em especial, a recepção da fala, torna-se uma tarefa difícil devido a fatores como a idade cronológica e mental, presença de alterações da fala e da linguagem em diferentes níveis, e a associação destes com uma perda auditiva ou alterações neurológicas e emocionais, além da motivação da criança à tarefa.

O desenvolvimento de testes para a avaliação de uma população infantil não é tarefa fácil, pois muitos fatores, como já citados anteriormente, estão envolvidos tanto na formulação dos testes como na cautela em avaliar as respostas das crianças.

Como proposto por Mendel e Danhauer (1997) há uma série de variáveis que devem ser consideradas: as variáveis internas, que dizem respeito à competência do vocabulário, à idade cronológica, às habilidades cognitivas e do desenvolvimento adequado da linguagem.

No grupo das variáveis externas estão aquelas que envolvem a resposta à tarefa, a utilização de reforço e o uso da memória de trabalho ou curto-prazo. Outros fatores, chamados por Mendel (op. cit.) de metodológicos dizem respeito à forma de apresentação do material e ao nível ou habilidade da fala que se deseja avaliar no teste.

A partir do levantamento bibliográfico realizado, não foi possível encontrar trabalhos que se dedicassem à construção, ao desenvolvimento e à avaliação de materiais para uso na medida do LRF em crianças no Brasil, em especial, na faixa etária do início do processo de escolarização entre 5 a 7 anos. 


\subsection{Objetivo}

Esse trabalho tem como objetivo geral a construção de listas de palavras para uso na medida do Limiar de Reconhecimento da Fala em crianças com idade entre 5 e 7 anos.

Os objetivos específicos são: construir uma lista de palavras trissilábicas a partir do universo lingüístico da criança; avaliar o desempenho de crianças entre 5 e 7 anos para essas listas na medida do LRF, em dB nível de audição e dB nível de sensação; avaliar, em termos comparativos, os resultados obtidos das listas desenvolvidas e outra lista atualmente utilizada em setores de audiologia clínica e avaliar se os desempenhos das listas são equivalentes e válidos aos objetivos propostos para serem utilizadas na medida do LRF. 
2 - REVISÃO DA LITERATURA 


\section{1 - A Avaliação da Audição e os Testes para uso na Audiometria da Fala}

A avaliação da audição pode ser realizada através de duas formas básicas. A primeira forma é a avaliação objetiva, realizada através da avaliação eletrofisiológica da via auditiva ou por procedimentos que não necessitam da resposta direta do sujeito à estimulação. A segunda forma de avaliação é a subjetiva realizada através da resposta comportamental da reação do sujeito à estimulação auditiva.

Nas diferentes possibilidades de avaliação da audição subjetiva pode-se utilizar modalidades de estímulos variados, como tom puro, ruído filtrado, clicks ou tone bursts, sons verbais (fonemas, sílabas, palavras e sentenças) e sons ambientais. A escolha da forma de avaliação e do tipo de estímulo varia de acordo com o objetivo e natureza da avaliação que pode ocorrer em diferentes níveis de processamento auditivo da informação, desde um nível mais sensorial e periférico até os níveis mais complexos, corticais, envolvendo não só habilidades de reconhecimento, mas também de inteligibilidade do estímulo (Gama, 1994). 
Dentre as opções para se avaliar a audição de modo subjetivo, a audiometria tonal é uma delas. Através dela obtêm-se os níveis mínimos de audição, isto é, o limiar auditivo, e se utiliza como forma de estimulação mais comum, o tom puro. A avaliação dos limiares auditivos obtidos com tons puros é realizada nas frequiências de $250 \mathrm{~Hz}$ a $8 \mathrm{kHz}$ e é considerada a etapa inicial da bateria de testes que compõem a avaliação da audição. Speaks et al. (1966) considerou que este tipo de avaliação mostra-se muito restrita para avaliar a percepção da fala devido às características do próprio estímulo, pois o tom puro é formado por uma única frequêencia e visa auxiliar mais na detecção de perdas auditivas.

A natureza da perda auditiva é complexa devido a dois aspectos que a compõem: a extensão que se refere à perda da sensibilidade auditiva e a natureza das estruturas envolvidas e danificadas. O decréscimo na sensibilidade auditiva provoca uma perda na redundância intrínseca da fala que compromete, em grau variado, o desempenho do indivíduo para ouvir em condições desfavoráveis de redundância extrínseca. Essas distorções são bem mais acentuadas quando temos uma perda auditiva sensório-neural onde o desempenho auditivo-liguístico é muito mais prejudicado do que na presença de uma perda na condução do som (Bellis, 2003).

Assim, a audiometria da fala tem por objetivo medir a habilidade do indivíduo, com ou sem perda auditiva, de modo a complementar a audiometria tonal. Essa avaliação é utilizada para vários fins como, a confirmação dos resultados da audiometria tonal, a determinação do campo dinâmico de audição (isto é, a audição residual) necessária ao processo de indicação de um aparelho auditivo e a um programa de reabilitação. 
A fala é um sinal que apresenta mudanças rápidas no tempo, na freqüência e na intensidade sonora, muito mais complexa que um tom puro, clicks ou tone bursts.

A intensidade média de uma conversação normal está em torno de 60 a $65 \mathrm{~dB}$, nível de pressão sonora (NPS) a uma distância de um metro entre os falantes, podendo variar de 50 a 80dBNPS. Um indivíduo com perda auditiva, mesmo próximo ao falante e sob condições favoráveis de escuta, poderá apresentar algum nível de dificuldade no entendimento da fala (Penrod, 1999).

A importância dos diferentes espectros de frequiências para o entendimento em uma conversação comum, a partir de diferentes falantes, em diversas línguas, foi demonstrado por Studebaker, Pavlovic e Sherbecoe (1987). Eles apontaram que a informação mais importante para a inteligibilidade da fala está acima do espectro de frequiência de $4000 \mathrm{~Hz}$ onde, em contrapartida, há menor concentração de energia na produção da fala.

Os resultados dos estudos de testes para avaliar a percepção da fala têm demonstrado a dificuldade em avaliar-se a relação da perda auditiva e o prejuízo causado por ela, pois a relação entre o grau da perda e o prejuízo não é linear. As teorias de percepção da fala tentam exatamente definir e prever estas dificuldades, mas ainda não conseguiram defini-las por completo.

Testes foram desenvolvidos para uso na audiometria da fala de modo a obterem-se dados mais precisos sobre a percepção auditiva da fala. Estes testes têm o objetivo de fornecer uma medida de como o ouvinte está compreendendo a fala numa situação controlada, de modo a refletir como é seu desempenho nas situações do dia-a-dia e avaliam o impacto desta perda auditiva na qualidade de captação de informação 
fundamental, em especial, a da fala através de seus variados componentes como a frequiência, intensidade, duração, resolução temporal e outros.

O desenvolvimento desses testes iniciou-se com a necessidade de avaliar-se sistemas de transmissão de comunicação e eles foram denominados de "índice de articulação". O resultado da avaliação foi colocado em um gráfico onde na ordenada está descrito a porcentagem de respostas corretas e na abscissa o nível da intensidade de apresentação. Assim, à medida que se aumenta a intensidade, o índice de articulação também será maior, isto é, ocorrerá um aumento na porcentagem de acerto dos itens. A função deste desempenho varia de acordo com o tipo de material da fala apresentado, segundo Harris (1965) citado por Penrod (1999), Marshal e Bacon (1981), Machado (1988), Meyer e Bilger (1997) e Costa (1998b).

Esta medida da função auditiva é uma função psicométrica que identifica a porcentagem de estímulos identificados corretamente na fala em função do nível da intensidade do estímulo. Segundo Evans (1997) esta função foi denominada de "função desempenhointensidade" (PI-performance-intensity). A média resultante das curvas da PI deve refletir a melhor curva de desempenho do sujeito num dado nível de intensidade, utilizando-se determinado tipo de estímulo. O limiar de reconhecimento da fala (LRF) é o ponto na PI que mostra o nível de intensidade em decibéis onde o individuo identifica corretamente o estimulo da fala em função da porcentagem de acerto, isto é, no caso do LRF identificando 50\% dos estímulos apresentados.

Segundo Penrod (1999), os estudos clássicos de Fletcher e Steinberg (1930), Hudgins (1947), Licklider e Miller (1951), Miller, Heise e Linchten (1951), Hirsch (1952) e Traul e Black (1965) já 
demonstravam a forte relação entre a porcentagem de palavras corretas e os níveis de intensidade na apresentação dos estímulos, através das curvas de inteligibilidade. Estes trabalhos demonstraram que entre 30 a 40 dBNS o ouvinte normal acerta 80 a $100 \%$ das palavras apresentadas.

A curva ou índice de inteligibilidade se propõe a espelhar a relação entre a detectabilidade e o máximo de inteligibilidade da fala. Quando o valor obtido é zero indica que nenhuma característica da fala foi detectada e quando o valor for um, indica que todos os componentes da fala foram detectados, sendo esta uma medida da forma como a informação auditiva é avaliada pelo processamento do sistema auditivo (Evans, 1997).

O estudo sobre a relação entre a intensidade de apresentação do estímulo e os tipos de estímulo utilizados na audiometria da fala têm mostrado que não só a intensidade é importante, mas também o próprio estímulo da fala selecionado e o nível de processamento da percepção da fala que se deseja avaliar (Machado, 1988; Gama, 1994; Meyer e Bilger, 1997; Penrod, 1999).

Os testes de audiometria da fala foram sendo modificados, ao longo do tempo, através da adição de artifícios para distorcer o estímulo da fala, tais como aceleração, compressão, filtragem de frequiência, competição com outro estímulo e outros tipos. A esses testes convencionou-se chamar de audiometria da fala sensibilizada, uma vez que eles utilizam sinais de fala "sensibilizados", ou seja, modificados. As pistas acústicas da fala são controladas de forma que a resposta do paciente é dada por sua capacidade de decodificar e codificar integrando as informações do estímulo da fala apresentado, mesmo quando ele está degradado. 
Essas modificações foram introduzidas a partir das observações de indivíduos que possuíam limiares tonais dentro da normalidade, mas apresentavam dificuldades de reconhecimento e compreensão da fala em determinadas situações onde a fala era apresentada em condições de difícil escuta, como por exemplo, fala e ruídos ambientais juntos. Esta forma de escuta afeta diretamente a habilidade de compreender a fala, pois afeta a redundância presente no sinal de fala. Bocca e Callearo (1963) citado por Muller e Bright (1999), observaram que a capacidade do indivíduo em perceber a fala está diretamente ligada às redundâncias extrínsecas do sinal de fala e à redundância intrínseca que é o próprio sistema auditivo como um todo.

Entende-se por redundância as pistas presentes em excesso para a compreensão da fala podendo ser diminuídas através de artifícios e, assim, realizar-se uma avaliação mais específica dos níveis centrais da audição. Segundo Webster (1999), a redundância intrínseca refere-se às diferentes possibilidades das vias e conexões dentro do sistema auditivo, as sinapses entre os neurônios, o uso de variados tipos de células que formam um ambiente de alta redundância interna. A redundância externa é a informação presente no sinal acústico (de fala ou não) como as pistas acústicas, lingüísticas, sintáticas, semânticas e prosódicas.

Dependendo da condição de escuta (monótica ou dicótica), do tipo da distorção e do tipo de estímulo da fala (palavras, sentenças), diferentes aspectos do processamento do sinal acústico pela via auditiva, podem ser degradados como a resolução temporal, a resolução de frequiência, a ordenação temporal dentre outros aspectos (Bellis, 2003).

No Brasil há várias versões de testes para audiometria da fala sensibilizada, com diferentes estímulos da fala e distorções, em especial, citamos os trabalhos de Almeida, Campos e Almeida (1978a, 1988b); 
Schochat (1997), Costa (1998a), Pereira (1993), Machado (1996), dentre outros. E ainda, os testes para audiometria da fala (sem distorção) em especial, os endereçados à medida do Limiar de Reconhecimento da Fala.

\subsubsection{A Medida do Limiar de Reconhecimento da Fala}

O resultado da medida do LRF é a intensidade onde o indivíduo repete $50 \%$ dos estímulos apresentados. O objetivo é medir a recepção da fala do sujeito nesta intensidade, de modo a predizer suas dificuldades comunicativas no dia-a-dia, além de seu resultado ser utilizado para confirmar os limiares tonais obtidos na média das frequiências de $500 \mathrm{~Hz}, 1000 \mathrm{~Hz}$ e $2000 \mathrm{~Hz}$, e também, no auxilio da seleção e indicação de aparelhos auditivos e implante coclear (Penrod, 1999).

Há várias razões que podem provocar o aparecimento de uma discrepância entre a média dos limiares do tom puro e o Limiar de Reconhecimento da Fala. As mais comuns são a deficiência auditiva funcional, problemas no equipamento, alterações auditivas centrais, a idade do paciente, não entendimento da instrução da tarefa pelo paciente ou problemas cognitivos e de linguagem associados e configurações audiométricas irregulares (Coren, 1994).

A relação entre o LRF e a média do limiar tonal de duas ou mais freqüências é o critério mais freqüentemente utilizado como 
indicativo de fidedignidade da média dos limiares de tom puro (Olsen; Maktin, 1979), podendo-se utilizar a média de $500 \mathrm{~Hz}, 1000 \mathrm{~Hz}$ e $2000 \mathrm{~Hz}$, ou a média de $500 \mathrm{~Hz}$ e $1000 \mathrm{~Hz}$ ou a média dos menores limiares de duas freqüências entre as de $500 \mathrm{~Hz}, 1000 \mathrm{~Hz}$ e $2000 \mathrm{~Hz}$. Carhart (1971) sugeriu que a média de 500, 1000 e 2000Hz é um ótimo guia para se prever o LRF, exceto em casos de perda auditiva descendente, com grandes inclinações em altas freqüências. Nesses casos ele sugere o uso da média de 500 e $1000 \mathrm{~Hz}$.

Hirsch et al.(1952) desenvolveram a técnica da medida do LRF como a utilizamos hoje. Estudos posteriores de Chaiklyn (1959), e Chaiklyn e Ventry (1964) mostraram que não há diferenças significativas se utilizarmos passos de 2 em $2 \mathrm{dBs}$ ou 5 em $5 \mathrm{dBs}$ na determinação do LRF.

Em 1979, a ASHA publicou o primeiro guia de recomendações para a realização do limiar do reconhecimento da fala. Nesse guia eram propostos critérios para realizá-lo, sugerindo como estímulo da fala, o espondeu. Também sugeria que o limiar fosse obtido em técnica ascendente com passos de $5 \mathrm{dBs}$.

A partir de observações feitas por vários pesquisadores, como Ventry (1976) e Olsen e Maktin (1979) verificou-se que não era possível obter os $50 \%$ de acerto com esta técnica ascendente e que estas propostas não tinham bases experimentais sólidas. Assim, baseados em estudos que se sucederam, a ASHA publicou um novo guia em 1988.

Atualmente a definição e método para a medida do LRF mais utilizado tanto nos Estados Unidos como no Brasil é o proposto pela ASHA em 1988 segundo Bess e Humes (1998) . O guia aponta os procedimentos, além do equipamento e calibração, propondo que o LRF deverá ser aplicado via audiômetro com padrão de calibração ANSI 
S3.6-1996. Quanto ao local do teste, a sala deve ser tratada acusticamente com padrão ANSI S3.1-1991. Em relação ao material da fala, o guia propõe uma lista de 36 espondeus gravados (lista do CID W1 por Young, Dudley e Gunter (1982)) que possuem versões para adultos e crianças entre 5 a 12 anos. Quanto ao modo de resposta do examinado, sugerem a repetição oral do estimulo, podendo também ser utilizadas figuras para o apontamento. Se desejado, as respostas podem ser gravadas. Em relação à forma de apresentação, o guia sugere que o material seja preferencialmente gravado, mas podendo também ser apresentado à viva-voz.

O uso do mascaramento deve ser utilizado na medida do LRF quando o valor obtido exceder em $40 \mathrm{dBs}$ ou mais a média dos limiares das freqüências de 500,1000, 2000 e $4000 \mathrm{~Hz}$ da orelha contralateral não-avaliada. Pode-se utilizar ruído branco ou ruído de espectro da fala.

Também se podem introduzir pequenas adaptações no método de determinação do LRF dependendo da população avaliada e para crianças menores que 6 anos, podendo ser realizado com ordens simples ou apontamento de figuras. A ASHA (1988) sugeriu o uso de uma lista especial para crianças entre 6 a 12 anos.

Nesta recomendação há duas propostas de formas para se obter o LRF: os métodos ascendentes e descendentes.

No método ascendente inicia-se a medida do LRF com menor a intensidade de atenuação do equipamento que é aumentada em 10 em $10 \mathrm{~dB}$ apresentando-se uma palavra. Quando houver resposta correta, a intensidade é diminuída em $15 \mathrm{~dB}$ e duas palavras são apresentadas com aumentos de $5 \mathrm{~dB}$ até a obtenção de $50 \%$ de respostas corretas. Devem ser realizadas duas séries ascendentes, no mínimo, para 
a confirmação das medidas. Esta técnica é muito pouco empregada na prática clínica podendo ser utilizada com crianças e pacientes difíceis de serem avaliados como no caso de simuladores, isto é, pacientes que tentam manipular o resultado real de sua capacidade auditiva para mais ou para menos.

Para a determinação do limiar no método descendente, o guia da ASHA (1988) propõe o seguinte procedimento básico: a instrução, a familiarização com os itens da lista, séries descendentes de determinação do limiar e um cálculo do limiar da fala.

$\mathrm{Na}$ instrução deve-se orientar o paciente de modo claro e objetivo, especificar o modo de resposta, indicar qual o material do teste e insistir que ele deve ser encorajado a responder mesmo sem entender, isto é, ele pode adivinhar. Para a fase de familiarização, o audiologista deve ler a lista e o paciente respondê-la. $\mathrm{Na}$ fase de determinação do limiar com técnica descendente, o procedimento sugerido foi de Wilson et al.(1973) que prevê a fase preliminar e a fase de teste.

A FASE PRELIMINAR: inicia-se o teste a 30 ou $40 \mathrm{~dB}$ acima do limiar estimado para a fala. Apresenta-se uma palavra: se correto, diminui-se em $10 \mathrm{~dB}$, apresentando uma palavra até que ela não seja mais respondida. Neste ponto, apresenta-se mais uma palavra e continua-se diminuindo a intensidade de 10 em $10 \mathrm{~dB}$ até que os dois itens não sejam mais repetidos corretamente. Neste ponto, eleva-se a intensidade em $10 \mathrm{~dB} \quad \mathrm{e}$ inicia-se $\mathrm{o}$ teste.

A FASE DO TESTE: apresentando-se duas palavras e diminuindo a intensidade de $2 \mathrm{em} 2 \mathrm{~dB}$ até que, as últimas cinco das seis palavras apresentadas, foram repetidas incorretamente.

O cálculo do limiar deve ser feito a partir da subtração do número total de respostas corretas do nível de início e adicionado o fator 
de correção. Este cálculo é baseado em um precedente estatístico para estimar o limiar no ponto de 50\% na curva psicométrica em Spearman (1908) citado por ASHA (1988)

$$
\text { T50\% }=i+1 / 2(d)-\underline{d(r)}
$$

n

onde T: limiar; $\mathrm{d}=$ valor de aumento (passos 2 ou $5 \mathrm{dBs}$ ); $\mathrm{r}=$ respostas corretas; $\mathrm{n}=$ número de palavras por passos em $\mathrm{dB}$. Ou ainda $\mathrm{LRF}=$ nível de início - número de respostas corretas + fator de correção.

Wilson, Morgan e Dirks (1973) mostraram que o limiar obtido quando cinco espondeus são apresentados em cada nível e utilizada a atenuação de $5 \mathrm{~dB}$ no inicio do teste é essencialmente o mesmo resultado quando o LRF é obtido quando são apresentados dois espondeus com atenuação em cada nível de $2 \mathrm{~dB}$.

Há diferentes padrões de normalidade do LRF dependendo do estudo em função do tipo de estímulo utilizado e também pela técnica empregada.

O reconhecimento da fala não ocorre antes de 8 a 9 decibéis acima do nível mínimo do limiar auditivo para tons puros (a média dos limiares auditivos de $500 \mathrm{~Hz}, 1000 \mathrm{~Hz}$ e $2000 \mathrm{~Hz}$ ) segundo Mendel e Danhauer (1997).

Segundo Olsen e Matkin (1979) o LRF é obtido ao redor de 6dB nível de sensação (NS), podendo chegar em até 10dBNS. O padrão de normalidade se utilizada a versão do teste CID W1 de Hirsch et al. (1952) é de 8 dB acima do limiar de detecção para palavras do tipo espondeu (duas sílabas tônicas).

Para Keith (1984) o LRF deve se situar numa variação de mais ou menos $6 \mathrm{~dB}$ da média tonal de três freqüências $(500,1000$ e $2000 \mathrm{~Hz})$. 
Segundo Jahner et al. (1994) com a utilização do procedimento proposto pela ASHA (1988) é possível obter-se valores de LRF de -10 a +10 dbNS em adultos, com média de $-6,4$ e desvio padrão de 5,3 dBNS para sentenças.

Lebel e Picard (1997) em um estudo com crianças entre 6 e 11 anos, não encontraram resultados com diferenças estatisticamente significantes nos valores do LRF (dBNS), para a tarefa de repetição de palavras, nas crianças entre 6 e 7 anos de idade, somente para faixa etárias maiores, acima de 9 anos.

O estudo de Lebel e Lefrebvre (1991), segundo Picard Banville, Barbaroise e Manolache_(1998), apontou em crianças de 4 anos e 6 meses a 5 anos e 6 meses otologicamente normais, LRF sem competição de 3,5 a 5,1dBNS em relação à média tonal, mas os autores também referira ter encontrado resultados de LRF menores do que a média tonal.

Picard et al. (1998) avaliaram o LRF em indivíduos adultos expostos a ruído e encontraram que $25 \%$ dos casos com valores menores de LRF em relação à média tonal, entre 8 a 16 dBNS . Eles sugeriram cuidado no uso do LRF para medidas clinico-terapêuticas diante destes resultados. Nesse estudo, com trabalhadores expostos à ruído, os autores concluíram que, neste grupo com respostas do LRF abaixo da média tonal, o efeito do contexto do léxico adicionado à informação fonológica da palavra, em sujeitos proficientes em sua língua, pode ter facilitado a tarefa e, assim, obteve-se valores negativos no LRF, não necessariamente indicando uma perda auditiva funcional.

Em um estudo de correlação de tom puro e LRF, Letowiski et al. (1992) utilizaram ruído branco e não estímulo de fala para a relação com a média das freqüências de 500, 1000 e $2000 \mathrm{~Hz}$ 
com tons puros, isto é, o Limiar de Detecção para Ruído (LDR). Eles obtiveram uma correlação de $\Gamma=0,97$ (nível de confidência de limite) e as diferenças entre o LRF (com palavras) e o LDR, em relação à média tonal, foi de 2,3dB com um desvio-padrão de 4,3dB.

No estudo de Versfeld, Davaler, Festen e Houtgast (2000) utilizando sentenças, o resultado do LRF foi de -1,8dBNS comparável aos resultados de Nilsson et al. (1994) de -2,9dBNS. No estudo de Wagener, Josvassen e Ardenkjaer (2003) para o dinamarquês utilizando sentenças com ruído, o LRF foi de -8,43dBNS. Em Rabin e Rosenhouse (2000) o LRF foi obtido em 22,2 dB nível de pressão sonora com desvio padrão de 3dBNPS.

Martin e Sides (1985) realizaram um levantamento sobre as formas de uso dos testes da audiometria da fala em vários aspectos, em especial, destacam os resultados referentes às práticas audiológicas na realização do LRF. O primeiro deles refere-se à freqüência com que os audiologistas americanos utilizam materiais gravados ou à viva-voz (VV). Descobriram que $90 \%$ utilizam VV mas os autores consideram que este quadro se modificou de modo mais intenso, a partir do guia da ASHA em 1988, que indica as duas possibilidades de uso mas dá mais preferência ao material gravado. Martin et al. (1994) também levantaram em pesquisa, qual a forma mais comum de obtenção do limiar auditivo, em especial nos passos de incremento e descobriram que $87 \%$ dos clínicos utilizam passos de $5 \mathrm{~dB}$ e $40 \%$ dizem utilizar o critério de duas a 3 respostas corretas para determinar o LRF.

Em relação ao item familiaridade com o estímulo, apesar da ASHA indicar a necessidade do uso da familiarização como forma de diminuir o estresse do avaliado, Martin (op.cit.), levantaram que somente $49 \%$ dos entrevistados utilizam esta metodologia da 
familiarização, pois consideram que essa fase eleva muito o tempo de administração do teste, além do efeito do conhecimento prévio do estimulo, considerando que o limiar obtido pode ser melhor após esta fase de apresentação prévia.

Quanto ao uso de frase inicial ou veículo, eles observaram que ela não é freqüentemente utilizada.

Quanto ao método para obtenção do limiar, a técnica descendente é a mais freqüente. O teste inicia-se num nível acima do esperado para o LRF e a intensidade é subtraída de 5 em $5 \mathrm{~dB}$, apresentando-se de uma a três palavras em cada nível, até que uma não seja mais respondida. Quando ela é perdida, sobe-se $10 \mathrm{~dB}$, apresentando-se três a seis palavras . Se a resposta for correta em $50 \%$, este é o LRF, se mais de $50 \%$ das palavras forem corretas continua-se a subtração em degraus de $5 \mathrm{~dB}$.

Estes achados demonstraram que há muitas variações nos procedimentos propostos na recomendação da ASHA (1988).

Nas publicações brasileiras, as citações também se baseiam nas recomendações da ASHA (op.cit.), como a definição de LRF e a proposta de uso de técnica descendente. Não há levantamentos oficiais no Brasil mas percebe-se na prática clinica que os audiologistas adotam as mesmas variações no procedimento encontradas nos estudos de Martin et al. citados acima.

Os textos que tratam do assunto foram publicados por Lacerda (1976), Machado (1988), Russo e Santos (1993), Zeigelbonm et al. (1994), Camargo et al. (1989), Redondo e Lopes Fo. (1997), Sacaloski (1997), Frota e Sampaio (2000), Fraza et al.(2000) e Harris et al. (2001). 
Destes estudos somente Machado (1988), Russo e Santos (1993) e Harris et al. (2001) propuseram listas de palavras próprias para a avaliação do LRF.

\subsection{2 - Testes Desenvolvidos para a Medida do LRF}

Segundo Mendell e Danhauer (1997), os testes para avaliar a percepção da fala tiveram seu início por volta de 1910, em especial, nos Estados Unidos. Grande parte destes testes foram financiados pelo exército americano após as duas Grandes Guerras e por empresas de telefonia e comunicação.

No quadro 1 pode-se acompanhar a cronologia do desenvolvimento destes testes observando-se o tipo de estímulo utilizado e os variados artifícios que foram se incorporando ao longo do tempo. Os testes estão organizados em ordem cronológica, e estão em destaque os nomes do teste e autores, os tipos de estímulo utilizado, a informação se a apresentação está gravada ou não, a população a que se destina e dados de padronização disponíveis. Os testes foram agrupados a partir das informações colhidas em Konkle e Rintelmann (1983), Mendell e Danhauer (1997), Martin (1997) e Penrod (1999) além da fonte dos próprios autores. 
Quadro 1: Testes desenvolvidos para uso na audiometria da fala

\begin{tabular}{|c|c|c|c|c|c|}
\hline ano & Autor & $\begin{array}{l}\text { Teste } \\
\text { Nome/Estímulo }\end{array}$ & Artifícios & População & $\begin{array}{l}\text { Dados de } \\
\text { padronização }\end{array}$ \\
\hline 1910 & Campbell & $\begin{array}{l}\text { Silabas sem sentido } \\
\text { via canal telefônico }\end{array}$ & & Não há & Não há \\
\hline 1929 & $\begin{array}{l}\text { Fletcher e } \\
\text { Steimberg }\end{array}$ & $\begin{array}{l}\text { Palavras com significado e } \\
\text { sentenças }\end{array}$ & & $\begin{array}{l}\text { Deficientes } \\
\text { auditivos }\end{array}$ & Não há \\
\hline 1947 & $\begin{array}{l}\text { Hudgins } \\
\text { et al. }\end{array}$ & $\begin{array}{l}\text { Para determinação dos } \\
\text { limiares de reconhecimento } \\
\text { da fala } \\
\text { PAL } 8 \text { monossílabos } \\
\text { PAL } 12 \text { sentenças }\end{array}$ & $\begin{array}{l}1^{\circ} \text { teste } \\
\text { gravado }\end{array}$ & $\begin{array}{l}\text { Ouvintes e } \\
\text { deficientes } \\
\text { auditivos }\end{array}$ & Sim \\
\hline 1947 & $\begin{array}{l}\text { Hudgins et } \\
\text { al. }\end{array}$ & $\begin{array}{l}\text { Para determinação dos } \\
\text { limiares do reconhecimento } \\
\text { da fala } \\
\text { PAL } 9 \text { espondeus } \\
\text { PAL } 14 \text { dissílabos }\end{array}$ & $\begin{array}{l}1^{\circ} \text { teste } \\
\text { gravado }\end{array}$ & $\begin{array}{l}\text { Ouvintes e } \\
\text { Deficientes } \\
\text { auditivos }\end{array}$ & Sim \\
\hline 1948 & Egan & $\begin{array}{l}\text { Para IRF } \\
\text { PAL PB } 50 \\
\text { Palavras monossilábicas }\end{array}$ & $\begin{array}{l}\text { Gravado } \\
\text { ou viva } \\
\text { voz }\end{array}$ & Ouvintes & Sim \\
\hline 1949 & Haskins & $\begin{array}{l}\text { PBK } 50 \\
\text { Palavras monossilábicas } \\
\text { balanceados foneticamente } \\
\text { representativos da } \\
\text { linguagem de crianças } \\
\text { entre } 3 \text { a } 5 \text { anos }\end{array}$ & $\begin{array}{l}\text { Gravado } \\
\text { ou viva } \\
\text { voz }\end{array}$ & Crianças & Não há \\
\hline 1952 & Hirsch. et al. & $\begin{array}{l}\text { CID W-1, W2, W22 } \\
\text { Listas de palavras } \\
\text { monossilábicas }\end{array}$ & $\begin{array}{l}\text { Gravado } \\
\text { ou viva } \\
\text { voz }\end{array}$ & Ouvintes & Sim \\
\hline 1955 & Silverman e & CID- CHABA & Gravado & Ouvintes & Sim \\
\hline
\end{tabular}




\begin{tabular}{|lllll|}
\hline & Hirsch & Sentenças do dia-a-dia & $\begin{array}{l}\text { ou viva } \\
\text { voz }\end{array}$ & \\
\hline 1957 & Black & Teste de inteligibilidade de & Ouvintes & Sim \\
& & & \\
& & & \\
& múltipla escolha: & & \\
& de fonecimento através de & & \\
& palavras monossilábicas & & \\
& & \\
\end{tabular}

\begin{tabular}{|c|c|c|c|c|c|}
\hline 1958 & Fairbanks & $\begin{array}{l}\text { Teste de rima: } \\
\text { utilizado em sistemas de } \\
\text { comunicação }\end{array}$ & & & Não \\
\hline 1959 & $\begin{array}{l}\text { Lehiste e } \\
\text { Peterson }\end{array}$ & $\begin{array}{l}\text { Consoante/núcleo/ } \\
\text { consoante } \\
\text { (CNC) } \\
\text { Listas de palavras } \\
\text { monossilábicas }\end{array}$ & Gravado & $\begin{array}{l}\text { Ouvintes e } \\
\text { deficientes } \\
\text { Auditivos }\end{array}$ & Sim \\
\hline 1962 & $\begin{array}{l}\text { Peterson e } \\
\text { Lehiste }\end{array}$ & CNC revisado & & $\begin{array}{l}\text { Ouvintes e } \\
\text { deficientes } \\
\text { auditivos }\end{array}$ & Sim \\
\hline 1965 & $\begin{array}{l}\text { Speaks e } \\
\text { Jerger }\end{array}$ & $\begin{array}{l}\text { SSI } \\
\text { Sentenças sintéticas }\end{array}$ & $\begin{array}{l}\text { Ruído } \\
\text { competi } \\
\text { tivo } \\
\text { gravado }\end{array}$ & Ouvintes & Sim \\
\hline 1965 & House et al. & $\begin{array}{l}\text { MRT } \\
\text { Teste de rima modificado } \\
\text { utilizado em sistemas de } \\
\text { comunicação }\end{array}$ & & Ouvintes & Sim \\
\hline 1966 & $\begin{array}{l}\text { Tillman e } \\
\text { Carhart }\end{array}$ & $\begin{array}{l}\text { NU } 6 \\
\text { Para IRF } \\
\text { Listas de palavras } \\
\text { Monossilábicas }\end{array}$ & $\begin{array}{l}\text { Gravado } \\
\text { ou viva } \\
\text { voz }\end{array}$ & ouvintes & Sim \\
\hline 1967 & Griffiths & $\begin{array}{l}\text { Contraste mínimo de rimas } \\
\text { Listas de palavras } \\
\text { monossilábicas }\end{array}$ & & Ouvintes & Sim \\
\hline 1968 & Kreul et al. & $\begin{array}{l}\text { MRT } \\
\text { Teste de rima modificado }\end{array}$ & & Ouvintes & Sim \\
\hline 1968 & Boothroyd & $\begin{array}{l}\text { Listas de palavras } \\
\text { isofonêmicas }\end{array}$ & $\begin{array}{l}\text { Gravado } \\
\text { ou viva }\end{array}$ & $\begin{array}{l}\text { Ouvintes e } \\
\text { deficientes }\end{array}$ & Sim \\
\hline
\end{tabular}




\begin{tabular}{|c|c|c|c|c|c|}
\hline & & monossilábicas & voz & auditivos & \\
\hline 1969 & $\begin{array}{l}\text { Schultz e } \\
\text { Schubert }\end{array}$ & $\begin{array}{l}\text { Teste de discriminação de } \\
\text { múltipla escolha: } \\
\text { palavras monossilabicas }\end{array}$ & Gravado & Ouvintes & Sim \\
\hline 1970 & $\begin{array}{l}\text { Ross E } \\
\text { Lerman }\end{array}$ & $\begin{array}{l}\text { WIPI } \\
\text { Identificação de palavras } \\
\text { em figurs:resposta } \\
\text { fechada } \\
\text { Para } 4 \text { ou + anos }\end{array}$ & & & Não há \\
\hline
\end{tabular}

\begin{tabular}{|c|c|c|c|c|c|}
\hline 1971 & Gardner & $\begin{array}{l}\text { Lista de palavras de alta } \\
\text { frequiência }\end{array}$ & & & Não há \\
\hline 1972 & $\begin{array}{l}\text { Pederson e } \\
\text { Studebacker }\end{array}$ & $\begin{array}{l}\text { Oklahoma teste: } \\
\text { resposta fechada }\end{array}$ & & Ouvintes & Sim \\
\hline 1975 & Pascoe & $\begin{array}{l}\text { Lista de palavras de alta } \\
\text { Freqüência }\end{array}$ & & $\begin{array}{l}\text { Deficientes } \\
\text { auditivos }\end{array}$ & Não há \\
\hline 1977 & $\begin{array}{l}\text { Kalikov } \\
\text { et al. }\end{array}$ & Teste de percepção & $\begin{array}{l}\text { Ruído } \\
\text { competi } \\
\text { tivo } \\
\text { gravado }\end{array}$ & $\begin{array}{l}\text { Ouvintes e } \\
\text { deficientes } \\
\text { auditivos }\end{array}$ & Sim \\
\hline 1977 & $\begin{array}{l}\text { Owens e } \\
\text { Schubert }\end{array}$ & $\begin{array}{l}\text { Califórnia teste consonantal } \\
\text { CCT } \\
\text { Palavras monossilábicas }\end{array}$ & $\begin{array}{l}\text { Ruído } \\
\text { competi } \\
\text { tivo } \\
\text { gravado }\end{array}$ & $\begin{array}{l}\text { Ouvintes e } \\
\text { deficientes } \\
\text { auditivos }\end{array}$ & Sim \\
\hline 1978 & $\begin{array}{l}\text { Levitt e } \\
\text { Resnick }\end{array}$ & $\begin{array}{l}\text { Teste de sílaba sem sentido } \\
\text { de resposta fechada }\end{array}$ & $\begin{array}{l}\text { Ruído } \\
\text { competi } \\
\text { tivo } \\
\text { gravado }\end{array}$ & $\begin{array}{l}\text { Ouvintes e } \\
\text { deficientes } \\
\text { auditivos }\end{array}$ & Não há \\
\hline 1978 & $\begin{array}{l}\text { Katz e } \\
\text { Elliott }\end{array}$ & $\begin{array}{l}\text { NU CHIPS } \\
\text { Monossílabos, resposta } \\
\text { fechada com figuras }\end{array}$ & & $\begin{array}{l}\text { Para } \\
\text { crianças de } \\
3 \text { anos }\end{array}$ & Não há \\
\hline 1979 & $\begin{array}{l}\text { Edgerton e } \\
\text { Danhauer }\end{array}$ & Teste de sílaba sem sentido & & $\begin{array}{l}\text { Ouvintes e } \\
\text { deficientes } \\
\text { auditivos }\end{array}$ & Sim \\
\hline 1979 & $\begin{array}{l}\text { Mc Pherson } \\
\text { e Pang- } \\
\text { Ching }\end{array}$ & $\begin{array}{l}\text { Teste de discriminação de } \\
\text { características distintivas }\end{array}$ & & & Não há \\
\hline 1986 & Plomp & $\begin{array}{l}\text { Sentenças para avaliar o } \\
\text { LRF }\end{array}$ & Gravado & & Sim \\
\hline
\end{tabular}




\begin{tabular}{|lllll|}
\hline 1980 & $\begin{array}{l}\text { Wilson e } \\
\text { Antablin }\end{array}$ & $\begin{array}{l}\text { Tarefa de identificação de } \\
\text { figuras } \\
\text { Listas de palavras } \\
\text { monossilábicas }\end{array}$ & Não há \\
\hline 1982 & $\begin{array}{l}\text { Feeney e } \\
\text { Franks }\end{array}$ & $\begin{array}{l}\text { Teste de diferenças de } \\
\text { característica distintivas }\end{array}$ & Ouvintes & Sim \\
& & & & \\
\hline
\end{tabular}

\begin{tabular}{|c|c|c|c|c|c|}
\hline 1984 & $\begin{array}{l}\text { Causey } \\
\text { et al. }\end{array}$ & $\begin{array}{l}\text { Maryland } \\
\text { Listas CNC }\end{array}$ & Gravado & $\begin{array}{l}\text { Ouvintes e } \\
\text { deficientes } \\
\text { auditivos } \\
\text { com perda } \\
\text { em altas } \\
\text { freqüências }\end{array}$ & Sim \\
\hline 1985 & $\begin{array}{l}\text { Martin e } \\
\text { Jansen }\end{array}$ & $\begin{array}{l}\text { Espondeus de alta } \\
\text { freqüência }\end{array}$ & Gravado & & Não há \\
\hline 1985 & $\begin{array}{l}\text { Boothroyd } \\
\text { et al. }\end{array}$ & Teste de sentença & Gravado & & Não há \\
\hline 1986 & $\begin{array}{l}\text { Bochner et } \\
\text { al. }\end{array}$ & $\begin{array}{l}\text { Teste de discriminação de } \\
\text { padrão de sons da fala: } \\
\text { Sentenças }\end{array}$ & & & Não \\
\hline 1987 & Cox et al. & $\begin{array}{l}\text { Teste de fala conectada } \\
\text { Sentenças }\end{array}$ & Gravado & & $\begin{array}{l}\text { Sim com } \\
\text { ouvintes e } \\
\text { deficientes } \\
\text { auditivos }\end{array}$ \\
\hline 1994 & $\begin{array}{l}\text { Nilsson et } \\
\text { al. }\end{array}$ & $\begin{array}{l}\text { Teste da audição em ruído } \\
\text { (HINT): } \\
\text { Espondeus } \\
\text { sentenças }\end{array}$ & $\begin{array}{l}\text { Gravado } \\
\text { em CD }\end{array}$ & $\begin{array}{l}\text { Deficientes } \\
\text { auditivos } \\
\text { com perda } \\
\text { em alta } \\
\text { freqüência }\end{array}$ & Sim \\
\hline 1995 & Laitakari & $\begin{array}{l}\text { SRTN } \\
\text { Teste de fala no ruído para } \\
\text { LRF } \\
\text { (baseado em Plomp, 1986) }\end{array}$ & $\begin{array}{l}\text { Palavras + } \\
\text { ruído } \\
\text { Gravado } \\
\text { em CD }\end{array}$ & $\begin{array}{l}\text { Ouvintes e } \\
\text { deficientes } \\
\text { auditivos }\end{array}$ & $\begin{array}{l}\text { Sim } \\
\text { com ouvintes } \\
\text { e deficientes } \\
\text { auditivos }\end{array}$ \\
\hline 1999 & $\begin{array}{l}\text { Ardle, } \\
\text { Hazan e } \\
\text { Prasher }\end{array}$ & $\begin{array}{l}\text { Adaptação dos testes: } \\
\text { Manchester Junior Word } \\
\text { lists; } \\
\text { Speech Pattern audiometry } \\
\text { (com figuras). }\end{array}$ & $\begin{array}{l}\text { Sentenças } \\
\text { e palavras } \\
\text { isofonêmi } \\
\text { cas } \\
\text { Gravados } \\
\text { em CD }\end{array}$ & $\begin{array}{l}\text { Ouvintes e } \\
\text { deficientes } \\
\text { auditivos }\end{array}$ & $\begin{array}{l}\text { Sim } \\
\text { com ouvintes } \\
\text { e deficientes } \\
\text { auditivos }\end{array}$ \\
\hline
\end{tabular}




\begin{tabular}{|clllll}
\hline 2003 & Wagener, & Teste de sentença no ruído & Sentenças & Ouvintes e & Sim \\
& Josvassen e & para o dinamarquês & Gravados & deficientes & com ouvintes \\
& Ardenkjaer & & em CD & auditivos & \\
& & &
\end{tabular}

A grande maioria destes testes não apresenta dados suficientes sobre seus processos de validação e padronização, e até hoje recebem inúmeras críticas, apesar de sua extensa utilização clínica.

Em destaque, sobre o uso de palavras monossilábicas, alguns autores baseados nas colocações de Carhart (1965) citado por Mendell e Danhauer (1997) questionaram o uso deste estímulo como válido para avaliar e prever o desempenho do indivíduo em situações de conversação diária, devido a sua curta extensão e características lingüísticas, não apresentando grande ocorrência em várias línguas, por isso, apresentam maior dificuldade de reconhecimento ou compreensão. Diante destas críticas, muitos destes testes receberam versões com outros tipos de materiais da fala como os espondeus, e atualmente, a grande tendência tem sido o desenvolvimento de testes com sentenças.

A seguir, será apresentada uma revisão dos testes desenvolvidos exclusivamente para uso na medida do limiar do reconhecimento da fala, com ênfase nos testes que foram inicialmente desenvolvidos e não nas pesquisas que se seguiram. Esses testes foram utilizados em diferentes populações e situações de avaliação.

O primeiro teste foi desenvolvido por Hudgins et al. (1947) utilizando como estímulo espondeus e sentenças. Este teste apresentou como inovação ser gravado em fita cassete. A versão PAL 90 foi composta por duas listas de 24 espondeus em 12 formas diferentes.

O decréscimo da intensidade na pesquisa do LRF foi feito de 4 em $4 \mathrm{~dB}$ em intervalos de 6 segundos. Os autores propuseram a 
utilização de frase veículo antes de cada palavra. A versão PAL 140 foi composta por duas listas de 24 dissílabos cada com 12 formas equivalentes. A medida do LRF se dá da mesma forma que a versão anterior.

Estes mesmos autores desenvolveram uma versão utilizando sentenças (PAL 12). O teste foi composto por oito listas de 28 itens. São sentenças curtas e simples. O decréscimo da intensidade foi feito de 4 em 4 dB. Não há a utilização de frase carreadora e há a possibilidade dele ser apresentado à viva-voz ou gravado.

A seguir foi desenvolvido o CID W 1 por Hirsh et al. (1952). Nesse teste a medida do limiar do reconhecimento da fala foi proposta do modo como a entendemos hoje, isto é, o limiar do reconhecimento da fala é o ponto em que o indivíduo repete $50 \%$ dos estímulos apresentados. $\mathrm{O}$ teste foi formado por espondeus familiares, numa lista de 36, gravados num nível constante e com frase introdutória gravada a $10 \mathrm{~dB}$ acima do estímulo.

Outra versão foi desenvolvida por Plomp (1979) que propôs dez listas de 13 sentenças compostas por oito a nove sílabas cada uma. Não há frase carreadora e a versão é gravada.

Uma das versões mais recentes foi a desenvolvida por Nilsson et al. (1994) que propuseram o uso de sentenças apresentadas sem e com ruído competitivo, com versões para adultos e crianças. O teste foi formado por 240 sentenças de mesmo comprimento (de seis a oito sílabas) e baixo nível de dificuldade. Os grupos de sentenças foram balanceados foneticamente em listas de 10 ou 20 sentenças. Eles não propuseram o uso de frase carreadora e o teste foi gravado em compact disc. 
Os materiais de fala passaram a ser gravados com mais frequiência a partir de 1970, e em compact disc a partir de 1980. Dentre os materiais gravados em língua inglesa e espanhola para a medida do LRF, os mais utilizados na clínica audiológica, estão resumidamente descritos na quadro 2 abaixo, sendo todos gravados em CD. Nele estão citadas as populações a que se destinam, o nome do teste, o tipo de locutor, o intervalo de gravação entre os estímulos e dados de padronização disponíveis.

Quadro 2: testes gravados em CD, em língua inglesa e espanhola, para uso na audiometria de fala

\begin{tabular}{|c|c|c|c|c|c|}
\hline $\begin{array}{l}\text { Teste } \\
\text { Audtec } \\
\text { of Saint Louis } \\
\text { (EU) } \\
\text { versão em } \\
\text { inglês e } \\
\text { espanhol }\end{array}$ & $\begin{array}{l}\text { população } \\
\text { Crianças } \\
\text { adultos }\end{array}$ & $\begin{array}{l}\text { subtestes } \\
\text { CID } \\
\text { W1 } \\
\text { CIDW22 } \\
\text { NU6 } \\
\text { WIPI } \\
\text { Ruídos } \\
\text { competitivos } \\
\text { Múltiplos }\end{array}$ & $\begin{array}{l}\text { Tipo de } \\
\text { locutor } \\
\text { locutor: } \\
\text { masculino }\end{array}$ & $\begin{array}{l}\text { Tempo de } \\
\text { intervalo } \\
\text { Intervalo de } \\
\text { apresentação } \\
\text { dos } \\
\text { estímulos: } \\
4 \text { a } 5 \mathrm{~s} .\end{array}$ & $\begin{array}{l}\text { padronização } \\
\text { disponíveis }\end{array}$ \\
\hline $\begin{array}{l}\text { Brigham } \\
\text { Young } \\
\text { University } \\
\text { (Inglaterra) }\end{array}$ & $\begin{array}{l}\text { Crianças } \\
\text { adultos }\end{array}$ & $\begin{array}{l}\text { CIDW1 e W22 } \\
\text { Listas de } \\
\text { consoantes de } \\
\text { alta frequiência } \\
\text { PBK/ WIPI }\end{array}$ & $\begin{array}{l}\text { locutor: } \\
\text { masculino } \\
\text { e } \\
\text { feminino }\end{array}$ & $\begin{array}{l}\text { Intervalo } \\
\text { médio de } \\
3,5 \mathrm{~s} \text {. }\end{array}$ & disponíveis \\
\hline $\begin{array}{l}\text { Departamento } \\
\text { de veteranos } \\
\text { (EU) }\end{array}$ & $\begin{array}{l}\text { Crianças } \\
\text { adultos }\end{array}$ & $\begin{array}{l}\text { Maryland lists, } \\
\text { CIDW1, } \\
\text { identificação } \\
\text { de figuras } \\
\text { NU6 /SSI } \\
\text { ruídos } \\
\text { competitivos } \\
\text { múltiplos }\end{array}$ & $\begin{array}{l}\text { locutor: } \\
\text { masculino } \\
\text { e } \\
\text { feminino }\end{array}$ & $\begin{array}{l}\text { Intervalos } 4 \\
\text { a } 7 \mathrm{~s} .\end{array}$ & disponíveis \\
\hline $\begin{array}{l}\text { (Instituto } \\
\text { Auditivo } \\
\text { Espanhol) }\end{array}$ & $\begin{array}{l}\text { Crianças e } \\
\text { adultos }\end{array}$ & $\begin{array}{l}\text { Palavras } \\
\text { polissilábicas } \\
\text { para LRF e } \\
\text { monossilábicas } \\
\text { para IRF }\end{array}$ & $\begin{array}{l}\text { não } \\
\text { disponível }\end{array}$ & $\begin{array}{l}\text { não } \\
\text { disponível }\end{array}$ & $\begin{array}{l}\text { não } \\
\text { disponível }\end{array}$ \\
\hline
\end{tabular}




\begin{tabular}{|llllll|}
\hline National & Crianças e & palavras & falantes & intervalo 5 a disponível \\
Acoustic & adultos & isofonemicas & com & $7 \mathrm{~s}$. & \\
Laboratories & & NU CHIPS & diferentes \\
(Australia) & & ruídos & dialetos, & \\
& & multiplos & masculino & \\
& & e & \\
& & feminino & \\
\hline
\end{tabular}

Além destes trabalhos, há aqueles desenvolvidos em outras línguas, o de Zubick et al. (1983) em língua espanhola e o de Rabin e Rosenhouse (2000) em língua árabe.

Segundo Zubick et al. (1983), os trabalhos mais utilizados em língua espanhola são os desenvolvidos por Cancel-Ferrer (1952) citado por Zubick op.cit. e as listas da Auditec. Sendo assim eles propuseram um novo teste $\mathrm{O}$ teste se intitula "Boston College Auditory Test" e é formado por um grupo de oito listas contendo 50 itens, que foram gravados por falante nativo da língua espanhola, não treinado, com um mínimo de dialeto, voz clara e articulação inteligível. Para a medida do LRF utiliza-se frase veículo antes de cada item. O teste foi padronizado em sujeitos de 20 a 32 anos, ouvintes otologicamente normais.

Os critérios utilizados para o desenvolvimento deste teste foram: o uso de palavras com a acentuação mais freqüente em língua espanhola, predominantemente paroxítonas dissilábicas e trissilábicas, o uso de palavras familiares para não haver interferência da competência do vocabulário ou nível de inteligência do sujeito. Para este item foram utilizados juízes para julgar quais seriam as palavras mais frequientes. Estas palavras foram colhidas do dicionário de palavras mais familiares em espanhol de Juilland e Chang-Rodriguez (1964) citado por Zubick (op.cit.). 
Outro item utilizado como critério foi o de dissimilaridade fonética, isto é, todas as palavras escolhidas não são foneticamente similares para eliminarem possíveis pistas auditivas fornecidas por palavras similares ou rimas. Ainda utilizaram o critério da homogeneidade de audibilidade das palavras, sendo a gravação de todas as palavras no mesmo nível de intensidade. E por fim, o critério de nível de dificuldade médio entre as palavras e a composição da lista de forma não balanceada foneticamente, pois a familiaridade foi considerada um critério mais importante do que o balanceamento.

Kishon-Rabin e Rosenhouse (2000) propuseram um teste para avaliar a percepção da fala de crianças árabes, pois julgavam que os testes desenvolvidos até então não atendiam às necessidades e as especificidades da língua árabe, principalmente em relação aos contrastes fonológicos. A grande crítica aos trabalhos anteriores verificase no sentido de eles importarem modelos de balanceamento fonético do inglês e que não correspondem às características do árabe, também salientados por Ashoor e Prochazka (1982). E ainda, muitos dos indivíduos avaliados falam hebreu como sua segunda língua que contém sistemas fonético e fonológico diferentes. Os autores salientam ainda a grande necessidade de testes que avaliem a percepção auditiva devido ao grande número de deficientes auditivos na população de Israel, segundo os autores.

O teste foi constituído por listas de palavras monossilábicas. Os critérios para seleção das palavras foram: a familiaridade na língua onde as palavras foram retiradas de livros utilizados nas escolas, jornais e livros de estória infantil; a homogeneidade com respeito a inteligibilidade; a similaridade morfológica e o balanceamento fonético. 
Inicialmente, as palavras foram avaliadas em seu aspecto de familiaridade por 37 estudantes universitários. Após a exclusão das palavras pouco familiares, formou-se uma lista de 120 palavras, divididas em 6 grupos de 20 palavras cada. O material foi gravado em compact disc. O teste foi aplicado em 74 estudantes de 20 a 35 anos.

Outros estudos também têm utilizado como critério principal, a familiaridade da palavra na língua, associado ou não ao balanceamento fonético, como nos trabalhos de Turrini et al. (1993) que desenvolveram listas de palavras dissílabas em italiano ou Nsamba (1979) que desenvolveu listas de palavras dissílabas e quasemonossilábicas no indú, segundo o autor e, ainda, Mukari e Said (1991) para o malaio com palavras dissílabas.

\subsection{3 - Testes para a Medida do LRF em Português Brasileiro.}

No Brasil há um número restrito de pesquisas que se dedicaram ao estudo do LRF. Os trabalhos serão citados em ordem cronológica.

Lacerda (1976) publicou a primeira lista de palavras trissilábicas para uso na pesquisa do LRF, contendo 50 itens. Ele baseouse em 4 critérios para a montagem das várias listas propostas para LRF e IRF: familiaridade, vocábulos concretos, representação de todos os fonemas da língua e distribuição entre palavras fáceis e difíceis. Ele também propôs listas de dissílabos para 5 a 7 anos e de trissílabos para 8 e 9 anos. 
Russo e Santos (1993) publicaram uma lista com 49 palavras trissilábicas, mas não há informações sobre dados de validade e fidedignidade das listas. O princípio de sua concepção foi a utilização de palavras trissilábicas familiares, elaboradas a partir do quadro fonético de aquisição dos sons da língua. As autoras sugeriram como valores de normalidade para o LRF de 5 a $10 \mathrm{~dB}$ nível de sensação, acima da média dos limiares tonais das frequiências de $500 \mathrm{~Hz}, 1000 \mathrm{~Hz}$ e $2000 \mathrm{~Hz}$.

A técnica descrita para a pesquisa do LRF foi a descendente. A proposta foi de apresentação de uma palavra em cada nível de intensidade, subtraindo-se a intensidade de 10 em 10dBNA, até que não haja repetição correta. Neste ponto apresenta-se mais uma palavra, se correta a resposta, subtrai-se a intensidade em mais $10 \mathrm{~dB}$. Se não houver repetição correta aumenta-se em $5 \mathrm{~dB}$ e apresenta-se quatro palavras. Se houver $50 \%$ de acerto é considerado o LRF, se houver mais de 50\%, diminui-se 5dB. Se houver menos de 50\%, aumenta-se $5 \mathrm{~dB}$ e apresenta-se novamente mais quatro palavras.

Outras publicações nacionais que se dedicaram ao assunto reproduziram as listas publicadas em Russo e Santos (op. cit.) e definiram a técnica para obtenção do LRF como em Osterne (1997), Fraza, Silva, Munhoz, Caovilla e Ganança (2000) e Frota e Sampaio (2000).

A primeira pesquisa sobre a medida do LRF foi realizada por Fragoso (1986) que avaliou os resultados do LRF com uma lista de palavras dissilábicas, aplicada em 318 crianças, entre 5 a 14 anos de idade. Ela não obteve em seus resultados diferenças estatisticamente significantes entre sexo e faixa etária.

Machado (1988) desenvolveu listas de palavras com espondeus ou expressões da língua, com características de espondeus, 
para futuro uso em logoaudiometria sensibilizada. As listas foram concebidas a partir da gravação de conversa espontânea entre crianças e adultos em que foram retirados os monossílabos mais freqüentes, a partir de um corpus e combinados entre si, formando 1156 expressões. Destas expressões, após julgamento de quatro juízes, foram selecionados os 265 mais frequientes. Para medir a eficiência das listas, Machado realizou a curva logoaudiométrica em 20 sujeitos jovens ouvintes e encontrou o LRF a 12dB nível de audição.

Camargo et al. (1989) avaliaram os resultados do LRF para diferentes médias tonais, utilizando as médias de $250 \mathrm{~Hz}, 500 \mathrm{~Hz}, 1000$ $\mathrm{Hz}$ e $2000 \mathrm{~Hz}$, a de $500 \mathrm{~Hz}, 1000 \mathrm{~Hz}$ e $2000 \mathrm{~Hz}$ e a de $500 \mathrm{~Hz}, 1000 \mathrm{~Hz}$, $2000 \mathrm{~Hz}$ e $4000 \mathrm{~Hz}$. Em seu trabalho utilizaram adultos com alterações condutivas e mistas e os resultados apontaram que a média que incluí a frequiência de $250 \mathrm{~Hz}$, mostrou-se mais próxima do LRF para o português. As listas utilizadas na pesquisa foram as publicadas em Russo e Santos (1993).

Zeigelbonm, Borges e Pereira (1994) realizaram um estudo com o objetivo de avaliar a utilização de um equipamento (Zenith 11) para triagem auditiva em escolares. Foram avaliadas 31 crianças, de 4 a 7 anos, sem e com evidência de alteração auditiva. As autoras apenas a descreveram a lista como composta por 12 palavras dissilábicas gravadas, sem informações sobre critérios de seu desenvolvimento. No grupo sem evidência de alteração auditiva, os resultados apontaram uma média de LRF em 19dBNA para orelha direita e esquerda, para o sexo masculino e de 18dBNA para o sexo feminino.

Sacaloski (1997) avaliou o LRF em 60 indivíduos do sexo feminino com idade entre 18 a 24 anos com audição normal. Os indivíduos foram divididos em dois grupos com e sem experiência 
auditiva prévia em testes de fala. Eles foram submetidos à apresentação de quatro listas de palavras a uma intensidade fixa de 10dBNA. As listas foram compostas por palavras dissilábicas oxítonas, dissilábicas paroxítonas, trissílabicas paroxítonas e espondeus. Todas as listas foram gravadas por locutor feminino e masculino.

Os resultados não apontaram diferenças estatisticamente significantes quanto ao tipo de locutor para todas as listas. Os indivíduos apresentaram desempenho superior com as listas de trissílabos, com diferenças estatisticamente significantes com as demais listas.

Kumabe (1999) avaliou a interferência de diferentes materiais de fala (listas de palavras monossilábicas, dissilábicas e espondeus) na presença de ruído $(\mathrm{S} / \mathrm{R}=+5 \mathrm{~dB})$ em 67 ouvintes de 5 a 6 anos. As listas de palavras desenvolvidas pela autora obtiveram $97,1 \%$ de acerto contra $80,9 \%$ de acerto para listas de monossílabos de Russo e Santos (1993) e 78,5\% de acerto para os espondeus de Machado (1988).

Quanto à idade e sexo não houve diferenças estatisticamente significantes entre os sujeitos no desempenho com as três listas. Quanto à ordem da orelha iniciada, a segunda orelha apresentou desempenho melhor que a primeira.

Harris et al. (2001) desenvolveram uma lista de palavras para uso na medida do LRF. Nesta publicação, eles descrevem o desenvolvimento do material, como a estruturação das listas de palavras, os resultados de sua aplicação em diferentes intensidades e locutores com voz masculina e feminina e os resultados da curva psicométrica de cada palavra.

Para a estruturação das listas, os autores partiram de um corpus de 5.000.000 de palavras, e dele foram selecionadas 1.500 .000 de palavras dentre as mais utilizadas na língua portuguesa, segundo 
Borba e Ramsey (1998) citado por Harris et al. (2001). O referido trabalho não está publicado, impossibilitando o acesso aos critérios utilizados na escolha das palavras mais freqüentes da língua.

Destas 1.500.000 de palavras foram selecionadas 89 palavras trissilábicas paroxítonas, mas também o critério para este filtro não foi devidamente descrito. Apesar deste critério, nota-se na lista a presença de nove palavras que não são paroxítonas como: atenção, criação, general, posição, militar, natural dentre outras.

A lista de 89 palavras foi gravada por três falantes masculinos e três femininos nativos do Estado de São Paulo. Essas gravações foram avaliadas por 12 juízes que escolheram um falante masculino e um feminino levando à versão final da gravação do teste.

A metodologia empregada na medida do LRF foi a seguinte: inicialmente ocorreu uma fase para familiarização das palavras à 50dBNA. A seguir, toda a lista foi apresentada em 15 diferentes intensidades, entre $-10 \mathrm{~dB}$ a $18 \mathrm{~dB}$ NA, em intervalos de $2 \mathrm{~dB}$. A ordem de apresentação das listas foi aleatória e também, o tipo de locução.

Para se obter as curvas logoaudiométricas de cada palavra foi aplicada uma equação de inclinação de regressão a fim de que fosse possível estimar a porcentagem de acerto em qualquer nível de intensidade. A porcentagem encontrada para cada palavra manteve-se entre -10 a $18 \mathrm{dBNA}$. Os limiares de reconhecimento da fala variaram de -3,5dBNA a 14,3 dBNA com média de 0,9dBNA para o falante masculino e - 0,9 a 13,1 dBNA com média de 5,4 dBNA para falante feminino. Para a montagem da versão final das listas, com 30 palavras, foram escolhidas aquelas em que no índice de $50 \%$ de acerto, não houve uma inclinação maior que $9,2 \% / \mathrm{dB}$. 
Segundo os autores todos esses cuidados foram tomados para produzir medidas de LRF consistentes, independentes do método utilizado, isto é, significando que quando o clinico muda a intensidade da apresentação, de 5 em $5 \mathrm{~dB}$, isto resulta em uma mudança drástica de desempenho, uma mudança de $5 \mathrm{~dB}$ deve resultar em uma melhora de até $60 \%$ no desempenho.

Harris et al. (2001) não explicitaram neste trabalho os resultados obtidos em dBNA ou dBNS do LRF dos indivíduos, apenas o resultado da curva psicométrica de cada palavra.

\section{2 - Desenvolvendo Testes para a Audiometria da Fala: Pressupostos sobre Percepção da Fala}

O estudo da percepção da fala apresenta-se como uma difícil tarefa, com interfaces entre diferentes áreas do conhecimento, demandando o trabalho de vários pesquisadores, como fonoaudiólogos, lingüistas, neuropsicólogos, engenheiros e outros.

Esta interface representa a compreensão de várias questões, dentre elas, de que modo ocorre efetivamente a percepção auditiva, como um indivíduo traduz a onda sonora em um evento lingüístico e qual a interferência da memória e dos processos cognitivos, a via descendente (top-down).

Perceber é identificar algo conhecido, é um processo psíquico interno que pressupõe existência de um objeto real que atua imediata e diretamente sobre nossos órgãos sensoriais; é sempre perceber algo material produzido sob certas condições reais (Rubinstein, 1972). Perceber é um processo tão natural que nem nos damos conta de seu acontecimento.

A percepção é o produto final das influências interativas entre os estímulos apresentados e as hipóteses internas, as expectativas e 
o conhecimento, isto é, a entrada da informação é a base para a elaboração de hipóteses sobre ela mesma. A percepção é um processo ativo e construtivista, implicando na discriminação e compreensão do que se torna conhecimento para aprender a reconhecer um objeto e identificá-lo de forma a apreender seu significado, sendo necessário passar por experiências repetidas e respostas motoras ao ambiente (Eysenk; Keane, 1990).

O fator bottom-up (via ascendente) é crítico para a habilidade de perceber e entender a fala, mas não é suficiente, mesmo que haja um processamento de entrada adequado, se algo não funcionar corretamente na via top-down, haverá prejuízo da compreensão da mensagem verbal (Bellis, 2003).

Sensação e percepção, apesar de interagirem funcionalmente, se diferenciam na medida em que a sensação implica em circuitos neuronais mais simples e diretos entre o órgão sensorial e o cérebro. O comportamento resultante da sensação é mais simples, mais reflexivo e mais previsível. Em contraste, a percepção embora iniciada pela sensação, implica em circuitos neuronais mais complexos, desde os órgãos dos sentido até o cérebro (Gama, 1994). Mas tal diferenciação hoje se aponta como meramente didática.

Muitos têm se dedicado ao entendimento do processamento auditivo. O que se sabe é que o sinal acústico é transformado nas vias auditivas e o resultado final é uma representação equivalente ao evento sensorial recebido. Os sinais acústicos da fala não conduzem mensagens em si, conduzem informações que serão reconstituídos pelo ouvinte (Gama, 1994).

Ouvir é muito mais que detectar a presença de um som pois há a participação de vários outros processos e mecanismos 
neurocognitivos que contribuem para uma decodificação adequada, isto é, reconhecimento e interpretação do sinal acústico de entrada. Mesmo um evento auditivo simples é influenciado por níveis mais altos cognitivos como a memória, a atenção e a aprendizagem (Bellis, 2003).

A fala é um sinal que varia muito e pode ser definida como um grupo finito de parâmetros acústico-fonéticos. Essas propriedades caracterizam todas as formas de sons de fala das línguas no mundo. Essas propriedades auxiliam o ouvinte a identificar a fala em uma língua e em relação a diferentes falantes e situações de comunicação.

Os fonemas que compõem os sons de fala são o resultado de três dimensões físicas: a intensidade, a frequiência e a duração. A interação dessas dimensões é que forma a cadeia da fala. Existem características nestas dimensões que nunca variam e fornecem a identidade do fonema como tal. Esses modelos acústicos invariantes para as características do fonema se mantêm mesmo variando o falante, o contexto fonético-fonológico em que ocorrem, a prosódia (ritmo e entonação) e a co-articulação, além da memória auditiva e da atenção (Gama, 1994; Machado, 2003).

Muitos trabalhos tentaram explicar como se dá a conversão da fala, um fenômeno físico e concreto, em um fenômeno mental, subjetivo e lingüistico (Jakobson et al., 1963; Stevens e House, 1972; Lierberman, 1975; Fant, 1977; Sanders, 1977). A visão psicolingüística foca no processo em como a percepção auditiva influencia a compreensão da linguagem oral. Neste ponto de vista, o processamento fonêmico não depende somente da entrada dos níveis mais baixos, isto é a codificação das caracterisitcas acústicas, mas o processamento fonêmico é influenciado também pela exposição e experiência com os sons da língua, a memória de trabalho e a co-articulação. A influência na 
percepção de ordem mais alta terá um efeito significativo no que é percebido, mesmo num nível fonêmico (top-down). Mas, a competência lingüística e a experiência do ouvinte, o contexto da mensagem e o evento comunicativo servem diretamente ao processamento auditivo. Assim, mesmo com uma entrada idêntica, o que um ouvinte ouve é um pouco diferente do que o outro ouve.

Seguindo-se a esses trabalhos, a tendência atual dos estudos em percepção da fala é a tarefa de se definir a invariância, a constância e a unidade perceptual mínima. A invariância é o conjunto de caracterísitcas mínimas que proporcionam a identidade do fonema e que são altamente influenciadas pela co-articulação. Segundo a Teoria Motora da Percepção da Fala considera-se que a fala é percebida através do gesto articulatório usado para produzí-la (Albano, 2001). A constância é a permanência das características do fonema apesar da enorme variabilidade entre os falantes. E por fim, as unidades perceptuais mínimas da fala que permanecem diante da ampla variedade de formas e produção de um mesmo fonema, segundo Jusczyk e Luce (2002). Quanto a este último refere-se não haver um consenso dentre os estudos na área da psicolingüística que tem demonstrado que diferentes processos podem ser utilizados para o reconhecimento auditivo, utilizando desde pistas do traço, informações acústicas do fonema, morfema, pedaços da palavra, relações semânticas e lexicais, dentre outras (Barbosa, 1999; Bisol; 2002; Scliar-Caral, 2003).

Segundo Sanders (1977), a percepção auditiva da fala é um processo de interpretação de instruções impressas pelo falante sobre a onda sonora em um determinado período de tempo. Blumstein e Stevens (1979) demonstraram que há dois modos de processamento auditivo: um categórico (limitado ao contexto da fala) e outro contínuo (sons não 
verbais). Eles acreditam que há dois mecanismos sendo o primeiro inato, o qual corresponde às propriedades invariantes de alguns estímulos da fala e o segundo correspondente aos atributos acústicos dependentes do contexto. Acreditam, também, que esses atributos são apreendidos pela associação com as pistas invariantes ou pelos processos top-down em que se utilizam dos conhecimentos do sistema fonológico da língua já apreendido. E ainda que o sistema auditivo trabalha através de detectores neurais específicos para extrair as características dos fonemas.

Eysenk e Keane (1990) sugeriram que há duas vias de organização perceptual auditiva primária. A primeira organiza os componentes acústicos em uma seqüência. A segunda funde esses componentes acústicos em freqüência e intensidade, baseada nas características espectrais do som. Eles sugerem que estas vias utilizam mecanismos neurofisiológicos separados.

Para avaliar-se a inteligibilidade da fala há vários fatores que estão inter-relacionados, o falante, o ouvinte, a tarefa de resposta, o tipo de estímulo e, sobretudo o que se deseja avaliar (Silverman; Hirsh, 1956), além da combinação dos efeitos de redundância extrínseca e intrínseca. A redundância intrínseca é o mapeamento do sistema auditivo, a representação bilateral de cada orelha em cada hemisfério, e as projeções nas áreas corticais auditivas. A redundância extrínseca tem relação com a faixa de freqüência do fonema, a intensidade, o tempo e a duração, pistas semânticas e sintáticas e a familiaridade com o léxico. Assim, a redundância é a resultante da interação de fatores ambientais, da mensagem e do ouvinte.

Um fator direto de influência sobre as respostas em tarefas de reconhecimento de palavras é o funcionamento intrínseco do sistema 
auditivo que atua de modo diferenciado para as descargas das fibras nervosas para tons puros em regiões de frequêencia específicas e para sons de fala (complexo) com descargas múltiplas (Pickles, 1989).

Os estudos sugeriram que cada córtex auditivo governa as respostas ao estímulo na orelha contralateral mas, de modo muito mais intenso, em tarefas na presença de estímulo em competição na orelha oposta a avaliada. Nesse caso, da vantagem da orelha direita, Efron (1985) sugeriu que esta vantagem poderia ser observada também na estimulação com tons puros.

O processo de neuromaturação está diretamente relacionado com o processo de mielinização do sistema nervoso central auditivo que ocorre ao longo do desenvolvimento da criança. $\mathrm{Na}$ avaliação de crianças, em tarefas auditivas dicóticas, observou-se naquelas de 5 anos um desempenho significantemente melhor na orelha direita que vai desaparecendo com o aumento da idade, podendo atingir um desempenho equivalente ao adulto por volta dos 9 anos de idade (Pinheiro e Musiek, 1985; Pereira, 1993; Bellis, 2003). Dos 5 aos 7 anos ocorre o processo de mielinização completo até as regiões talâmicas. Outros estudos na área da aquisição de aspectos intrínsecos da língua como o voice-onset-time (tempo de ataque na produção do fonema) e a duração no português demonstraram que o processo de neuro-maturação motora, ainda, está em desenvolvimento em crianças até 6/7 anos, o que pode provocar nos resultados de estudos nessa faixa etária, uma maior variabilidade e relações de não significância entre os grupos etários, como de Aquino (1997), Albano (1999), Gama-Rossi (1999, 2000).

No trabalho de Zaidan (2001), com uma bateria de testes para triagem do processamento auditivo, nas faixas etárias de 6,7 e 8 anos, se observou uma diminuição da variabilidade do desempenho 
(com testes de fala em competição) em função do aumento da idade, mas sem relações de significância entre elas.

Bellis (2003) sugeriu que há implicações clínicas na avaliação auditiva devido à maturação do processamento top-down . Sugere que os protocolos de avaliação tenham diferentes parâmetros de respostas (padrão de normalidade) até 11/12 anos de idade, em que se espera que o padrão de resposta se iguale ao adulto. Sugere, também, que haja parâmetros de normalidade para crianças abaixo de 7 anos e que devem ser analisados com cautela pois, até esta idade, deve ocorrer uma grande variedade de respostas nos grupos etários. Por isso, Northern e Downs (1990) consideraram que os valores dos limiares tonais estariam iguais aos limiares dos adultos somente após os 6 anos de idade.

Bellis (2003) sugeriu que o processamento perceptual auditivo não consiste simplesmente na construção de propriedades globais (fonema, palavra, sentença) ou seja, a simples análise e síntese de caracterísitcas num nível local (anatômico) mais baixo (bottom-up). Mas, muito além disso, o acesso às propriedades globais por elas mesmas (incluindo familiaridade com os sons da fala da língua e outros aspectos de ordem mais elevados) influênciaria e facilitaria o processamento refinado dos detalhes do nível mais baixo da via auditiva.

Boothroyd e Nittrouer (1988) referiram que em qualquer teste de percepção da fala haveria dois tipos de informação para determinar como o estímulo será percebido, são elas, as características do estímulo em si e as características do contexto no qual o estímulo é apresentado. A percepção da fala envolveria vários processos, periféricos e centrais, do sistema nervoso auditivo. Uma das questões que mais influenciaria o processo de reconhecimento de uma palavra, além de suas características acústico-fonéticas, seria a sua freqüência e familiaridade, 
isto é, qual seu lugar no universo do léxico do grupo avaliado. Os estudos sugeriram que o desempenho nas diferentes faixas etárias, desde crianças muito pequenas (ao redor de 2 anos), até crianças maiores (entre 5 a 10 anos) e adultos, variando com o tipo de estímulo que é utilizado (palavras freqüentes ou não, palavras e não-palavras).

Frauenfelder e Tyler (1987) sugeriram que o ouvinte não necessita ouvir completamente a palavra para entendê-la, sendo que o ponto exato do reconhecimento de uma palavra depende de fatores como as propriedades físicas (freqüência, intensidade e duração), o número e natureza das palavras dentre outras pré-existentes no léxico, similares ou não. Eles sugerem que o contexto no qual o indivíduo está inserido tem influência sobre seu desempenho de reconhecimento.

Lahiri e Marseln-Wilson (1991) apontaram em seu modelo de percepção de fala que o indivíduo pode identificar uma palavra ouvindo somente a primeira sílaba. Quando o início da palavra é ouvido, o indivíduo ativa um sistema do léxico que separa todas as palavras com o mesmo início. Assim, quanto mais palavras similares armazenadas, mais tempo de processamento para o reconhecimento, tornando necessário ouvir mais pedaços do estímulo. Deste modo, não é necessário ouvir a palavra toda para reconhecê-la sendo, possível, prever seu grau de familiaridade no léxico. Eles destacaram que esta tarefa é facilitada pela informação retirada da prosódia da palavra, isto é, a identificação da sílaba tônica.

Marslen-Wilson (1996) segundo Welsh (1978) propuseram a Teoria de Cohort como forma de explicar o reconhecimento da palavra falada em contraposição às pesquisas que utilizaram estudos com base no reconhecimento visual da palavra. Eles descreveram que o reconhecimento aconteceria a partir da entrada da palavra que ativaria 
um grupo de palavras similares na memória com inícios iguais a palavraalvo. Por exemplo, a palavra elefante ativaria as palavras eco, elegante, elevador, dentre outras. Uma vez ativado, o reconhecimento é feito através de processos bottom-up (acústico-fonêmico) e top-down (sintático-semântico), até que reste somente uma palavra.

Charles-Luce e Luce (1990) e Walley (1988) argumentaram que a criança faz uso da informação inicial da palavra para o acesso ao léxico, somente após ter adquirido um léxico substancial. Esta visão é apoiada pelas pesquisas com escolares, mostrando que crianças são menos capazes de realizar a identificação de palavras familiares do que o adulto. E que as crianças menores teriam uma representação lexical mais "holística" da palavra . Outra questão levantada por estes autores, é que a velocidade e a precisão no reconhecimento da palavra estão relacionados com o crescimento do vocabulário, isto é, quanto maior o vocabulário, mais rápida é a tarefa de identificação. Eles referem que como o léxico nas crianças jovens aumenta rapidamente, erros no reconhecimento da palavra são freqüentes quando baseados somente na informação inicial.

Boothroyd e Nittrouer (1988) e Nittrouer e Boothroyd (1990) sugeriram que quando o material de fala para avaliação tem um alto grau de familiaridade e homogeneidade, ele irá facilitar a tarefa de reconhecimento e influenciar o processo top-down, tanto para o reconhecimento do fonema como para o reconhecimento da palavra. A influência no reconhecimento da fala, pelos fatores top-down para crianças, tem sido reportada de acordo com a proficiência dela com a linguagem e sua habilidade em utilizar-se das pistas contextuais (Jerger, 1984). Olsen e Maktin (1979) sugeriram que os resultados obtidos durante um teste de fala com crianças refletem, muito mais o seu 
interesse e sua motivação, do que realmente indica suas habilidades de discriminação e reconhecimento. Assim, a percepção da fala não pode ser medida diretamente, mas somente inferida pela resposta do indivíduo. Se ele não tem habilidade cognitiva para entender a tarefa ou apresenta déficit na produção articulatória ou déficit de atenção, então se observará uma diferença entre o desempenho no teste e as suas verdadeiras habilidades perceptuais.

Warren e Marslen-Wilson (1988) avaliaram a importância da co-articulação como facilitadora no processo de reconhecimento da palavra baseado em resultados de indivíduos que "adivinharam" o final da palavra somente a partir de fragmentos iniciais. Eles sugeriram que estes indivíduos seriam sujeitos com maiores capacidades em perceber nuances mais sutis do detalhes acústico-fonéticos da palavra. Mas estudos recentes de Marslen-Wilson (1996) mostraram que o uso da entonação e prosódia seriam os facilitadores para tornar estes indivíduos mais proficientes.

Luce, Pisoni e Goldinger (1990) reportaram que palavras de alta freqüência requerem menos informação fonético-acústica para seu reconhecimento, e em tarefas de tempo de decisão lexical, elas são reconhecidas muito mais rapidamente que outras palavras. Eles sugeriram que a densidade de palavras vizinhas, no arquivo do léxico, refere-se ao número de palavras no léxico que compartilham fonemas com a palavra alvo, isto é, com todas as combinações em fonemas que determinam o reconhecimento da palavra. Assim, palavras que compartilham muitos fonemas com muitas outras palavras são referenciadas, no léxico, como tendo alta densidade de vizinhas e, essas palavras são mais difíceis de serem reconhecidas que as palavras com 
pouca densidade de vizinhas. O reconhecimento seria diretamente afetado pela frequiência das palavras-alvo.

Jusczyk e Luce (2002) definiram a similaridade de vizinhança como uma coleção de palavras que são mais parecidas com a palavra-alvo, por exemplo, janela, panela, canela, favela, etc. Essa vizinhança varia na densidade e na freqüência das palavras. Aquelas com vizinhanças mais populosas de alta freqüência interferem no tempo de processamento e na rapidez da decisão lexical auditiva e na identificação perceptual. As palavras que estão em vizinhanças mais populosas são consideradas de maior competição lexical e são processadas mais lentamente.

Fallon, Thelub e Schneider (2000) realizaram um estudo com crianças de 5, 9 e 11 anos e também com adultos entre 19 e 28 anos, com sentenças com e sem ruído de fundo para a medida do LRF. Eles obtiveram resultados estatisticamente significantes na melhora do desempenho de crianças de 5, 9 e 11 anos, para o LRF, de acordo com o aumento da idade. Sugerem que o Limiar de Reconhecimento da Fala em crianças menores é mais alto do que em crianças mais velhas e, com o aumento do vocabulário, as palavras tornam-se mais familiares e, menor quantidade de informação acústica é necessária para seu reconhecimento, resultando em uma diminuição dos limiares do LRF.

Fallon (op. cit.) sugeriram que crianças jovens têm limiares tonais auditivos mais altos que crianças mais velhas e que adultos mas, essa relação entre sensibilidade auditiva e LRF em silêncio ou com ruído, ainda não é totalmente clara pois as diferenças relacionadas à idade na sensitividade poderiam espelhar as dificuldades dessas crianças em identificar fala em ruído. Eles apontaram que a partir de 5 anos há mudanças nos limiares absolutos por banda de oitava de ruído que 
espelham as mudanças nos limiares de reconhecimento mascarados por ruído.

Eles sugeriram, ainda, que o desempenho das crianças, em geral, é influenciado por suas experiências de linguagem mais limitadas que o adulto e, por isso, necessitam de mais informação acústica pois não poderiam utilizar completamente suas informações vindas do processo top-down limitadas. Por fim, eles salientaram que as respostas de testes com crianças são influenciadas por outros fatores como, a atenção e a motivação. Schneider e Trehub (1992) também apontaram que a atenção à tarefa de tom puro (detecção) e fala (reconhecimento) é um dos fatores de maior influência nos resultados entre crianças e adultos.

Elliot et al. (1979) e Mills (1975) obtiveram melhor desempenho com o aumento da idade, entre crianças de 5 a 7 anos e sugeriram que estes resultados foram influenciados pela freqüência de uso das palavras na língua, isto é, as crianças mais velhas tiveram desempenho melhor por conhecerem mais as palavras do teste. Os autores também sugerem que este desempenho das crianças foi afetado pelo grau de redundância do tipo de estímulo de fala (no caso espondeus), sendo maior para adultos do que para crianças, valendo o mesmo entre crianças menores e maiores

Os estudos de Owens (1961); Lovrininc et al. (1968) e Schwartz e Goldman (1974) apoiaram a idéia que quanto mais familiar é a palavra mais fácil é seu reconhecimento e, portanto, menor será o número de erros. Estudos de Fernald et al. (2001) mostraram que quanto maior o léxico da criança mais eficiente será seu processamento de fala.

Outra questão envolvida no processo de reconhecimento é a forma de funcionamento da memória fonológica de curto prazo. 
Gathercole, Willis, Emslie e Baddeley (1992) reportaram achados na relação entre o conhecimento do vocabulário e a habilidade de memória fonológica em crianças com 4,5 até 8 anos de idade. $\mathrm{O}$ estudo de Baddeley e Wilson (1993) aprofundou estes conhecimentos e afirma a importância do armazenador fonológico diretamente relacionado à percepção da fala e uma alça referente ao processo articulatório ligada à produção da fala.

Gathercole et al. (1992) indicaram que, após os 5 anos de idade, o conhecimento lingüístico indexado à palavra exerce menor influência no desempenho das medidas de memória de curto prazo. $\mathrm{O}$ estudo apontou que o aumento do conhecimento do vocabulário torna-se um marcador do desempenho da memória fonológica, a partir dos 5 anos, indicando que a influência do conhecimento do léxico torna-se menor nos primeiros anos de escola.

Todo este processo e seus diferentes níveis, além da memória, dependeriam de um processo anterior e, também, simultâneo ao evento perceptual, a atenção.

A atenção pode ser definida como a capacidade de selecionar parte do estímulo que está entrando para um processamento mais intenso, mais detalhado, podendo também ser chamada de concentração ou estado mental. Para Luria (1981), a atenção é uma força de caráter mental, implicando em que o comportamento perceptual, sempre contenha um aspecto de seletividade e de intensificação, ou seja, a atenção é a base para a organização destes processos cogntivos.

Eysenk e Keane (1990) sugeriram que a atenção pode ser dividida em dois tipos: a atenção focalizada entre dois ou mais estímulos e a atenção dividida em que realiza-se várias tarefas ao mesmo tempo. Broadbent (1954) sugeriram que as diferentes entradas sensoriais 
passariam por um filtro de atenção e que somente a entrada focalizada seria processada, os demais poderiam ser totalmente dispensadas.

Para Geert (1983), a atenção é um processo bipolar, intra e inter subjetivo. A atenção ocorre por focos que podem estar nas zonas proximais ou periféricas e esses focos são selecionados através de vários fatores ligados ao estímulo e ao sujeito.

$\mathrm{O}$ ato de prestar atenção envolve a capacidade de processamento múltiplo de uma função executiva como áreas múltiplas sub-corticais como os gânglios da base, o tálamo, o lobo frontal, o lobo parietal e o lobo temporal, além de entradas da vias visuais associadas (Bellis, 2003).

Uma questão muito discutida refere-se aos estudos da percepção auditiva terem sua origem relacionada aos estudos de reconhecimento visual. Para Lively, Pisoni e Goldinger (1994), a compreensão e estudo dos processos auditivos estaria relacionada e baseada nos conhecimentos obtidos nos estudos do reconhecimento visual da palavra. Uma das metodologias mais utilizadas nestes estudos foi a identificação perceptual, em que o sujeito ouve palavras isoladas e identifica-as do melhor modo possível, podendo ser uma tarefa open set (tarefa de resposta aberta) ou closed set (tarefa de resposta fechada).

Mas, sabe-se que há diferenças fundamentais entre estes dois processos, visual e auditivo, não se permitindo generalizações dos estudos visuais para o auditivo. Os fatos auditivos na percepção da fala ocorrem em função do tempo, em sequiências temporais, o que não é fundamental na modalidade visual, onde os fatos ocorrem em função dos campos visuais e, portanto, organizados espacialmente, e que podem ser retomados sem haver repetição na maioria das vezes. 
Este fato não ocorre com os eventos auditivos, que se acabam no tempo, só podendo ser repetidos quando houver disposição do falante (ou reproduzidos se for gravação). Apesar disso, é comum na literatura aplicar-se o mesmo conceito de discriminação e memória nas duas modalidades, desconsiderando inclusive que a organização das vias nervosas do cérebro é diferente para cada uma delas. (Machado, 2003).

Deste modo o processamento temporal que difere de modo decisivo do processamento visual, dificulta o uso destes procedimentos para sua análise. O processamento temporal é a decodificação de informações de padrões acústicos temporais (Domitz e Schow, 2000). Para que ocorra o processamento temporal exige-se o cumprimento de algumas etapas em níveis de processamento. São elas: a detecção do evento sensorial acústico, o reconhecimento dos componentes do evento e a discriminação destes componentes com outros da língua falada. Este processamento só poderá ocorrer se o evento sonoro estiver num nível acima do limiar de detecção do sujeito. Para esta tarefa, outras habilidades ou processamentos devem estar presentes e íntegros. São elas: a habilidade de resolução, a habilidade de sequenciação e a habilidade de organização temporal.

A resolução temporal é a capacidade do sistema auditivo em detectar a ocorrência de dois eventos auditivos consecutivos e evitar que eles sejam ouvidos como um só, permitindo ao individuo identificar pequenas variações acústicas que ocorrem na fala, realizando distinções segmentais, silábicas e das palavras na fala contínua (Grose, Hall e Gibbs, 1993). A sequenciação e organização dos itens no evento da fala determinariam a percepção correta de um enunciado (as combinações temporais e seqüenciais). 


\section{3 - Critérios para desenvolvimento de testes de fala.}

Muitos critérios devem ser utilizados no desenvolvimento de testes para avaliar a percepção da fala. A terminologia aqui utilizada, sobre testes de percepção da fala, está baseada na definição proposta por Mendel e Danhauer (1997) a percepção da fala é utilizada num sentido genérico e inclue a percepção dos aspectos supra-segmentais da fala, de estímulos sem sentido, monossílabos e polissílabos e avalia a percepção auditiva e da leitura labial para sentenças e discurso. Geralmente estes testes estão classificados em níveis. O primeiro deles se relaciona à inteligibilidade que mede o grau de compreensão do enunciado que é entendido pelo ouvinte. $\mathrm{O}$ segundo se relaciona à articulação que avalia a qualidade da repetição de partes do enunciado da fala e o terceiro se relaciona a discriminação que avalia a capacidade do indivíduo em distinguir entre sons diferentes e iguais.

Há grande variabilidade metodológica para desenvolver, aplicar e avaliar a resposta de um teste de percepção da fala. Alguns 
passos devem ser seguidos pelo pesquisador desde a sua concepção até a padronização (Lyregaard, 1997; Mendel e Danhauer, 1997; Martin, 1997) .

Primeiro passo, estabelecer o nível de percepção da fala que se deseja avaliar (deteç̧ão, discriminação, reconhecimento, compreensão). Após a opção pela tarefa perceptual, deve-se escolher o estímulo que melhor seria representativo para a tarefa (fonema, sílaba com ou sem sentido, palavras de diferentes extensões, sentenças e discurso) de acordo com a língua estudada. Para a escolha do estímulo, alguns critérios devem ser eleitos como: a familiaridade ou não dos itens na língua da população estudada, a presença de diferentes fonemas representativos de sua ocorrência na língua, isto é, o balanceamento fonético e fonêmico e a homogeneidade ou não dos itens em termos de características auditivas (Epstein et al., 1968; Gama, 1994; Penrod, 1999).

Martin, Chaplin e Perez (2000) desenvolveram um estudo para avaliar a importância do balanceamento fonético nos testes de percepção da fala. Avaliaram 20 sujeitos com audição normal e 15 com perda sensório-neural moderada. Utilizaram quatro listas balanceadas do teste NU6 e quatro listas com palavras escolhidas aleatoriamente no dicionário. Os resultados não mostraram diferenças significantes entre os grupos de sujeitos e o tipo das listas. Eles citaram os estudos de Egan (1948) e Lehiste e Peterson (1959) que sugeriram que, através de um levantamento de palavras, a partir de uma conversação, seria possível montar listas que tem uma freqüência de ocorrência dos fonemas na média da fala da sua real distribuição na língua, pois o som da fala varia dependendo do som ao seu redor (co-articulação) sendo quase 
impossível se obter uma lista de palavras realmente balanceada foneticamente.

Martin (op.cit.) sugeriram que o teste deveria estar baseado na familiaridade dos itens para a população estudada pois, também consideram que seja difícil balancear completamente uma lista, pois o som da fala varia dependendo do contexto em que o fonema ocorre (coarticulação), mas sugerem que seria possível aproximar-se da freqüência e ocorrência do som na média da ocorrência na língua. Os autores sugeriram, também, como forma de minimizar o efeito de ordem da apresentação, que a orelha avaliada e a lista deveriam ser apresentadas de forma balanceada.

Segundo Tarallo (1985) a relação entre a língua e a sociedade estaria baseada num "caos" onde se configura uma batalha entre várias formas de se dizer uma mesma coisa, sendo a língua falada heterogênea e sistematizada. Essa língua falada seria um meio de comunicação de situações do dia-a-dia, onde na fala de uma comunidade existiriam as variantes lingüísticas que também deveriam ser consideradas.

Assim, como descrever e analisar essas variantes lingüísticas? Tarallo (op. cit.) sugeriu alguns passos, dentre eles a seleção aleatória da amostragem, o tamanho da amostra que dependerá do que se deseja estudar e os critérios de escolha dos grupos (sexo, idade, grupo sócio-econômico) para garantir a representatividade da amostra. Ele também sugeriu, como forma de colher os dados, a seleção de textos a partir de jornais, televisão, novela ou programas de rádio, através de um corte transversal na amostra. Por isso, os materiais lingüísticos utilizados deveriam ser permanentemente modificados de acordo com o atual contexto histórico e lingüístico em que se inserem. 
Lyregaard (1997) apontou uma lista de variáveis independentes que devem ser consideradas para o desenvolvimento de testes com o intuito de avaliar a percepção da fala. A primeira delas seria o material ou estímulo utilizado, podendo ser desde o nível fonêmico até a sentença. A escolha deveria estar relacionada com o grau de redundância que se deseja no material de teste, tendo a sentença o maior grau de redundância. E ainda, se o teste desejaria refletir uma situação de comunicação diária ou apenas avaliar aspectos mais intrínsecos do processamento da informação. Neste ponto, ele levantou a questão sobre a necessidade do material estar ou não balanceado no nível fonético e fonêmico. Para que isso ocorra, seria necessário um conhecimento suficiente da língua para que se possa avaliar se este item pode ser atingido e de que modo. $\mathrm{O}$ autor considerou que o balanceamento fonético não deveria ser critério único ou mais importante quando estes testes são utilizados para fins de diagnóstico.

A segunda variável independente relacionar-se-ia com o tipo de resposta que é solicitada do sujeito, podendo ser verbal, escrita, apontar figuras, dentre outras. A terceira variável relaciona-se à forma de computação das respostas e emissão da análise dos resultados de forma oral ou escrita. A quarta variável se relacionaria ao tempo de duração para administração do teste devendo ser clinicamente viável. E por último, a variável que diz respeito ao locutor do teste, pode ter ou não experiência em locução e a escolha do sexo do locutor.

Soorenburg e Bosman (1992) sugeriram que o locutor deveria possuir um timbre ou freqüência fundamental de qualidade vocal específica, de modo, a possibilitar o uso do material para avaliação com indivíduos com perda auditiva, do tipo sensório-neural, que tenham ênfase de perda em regiões de frequiência mais agudas. Esse padrão 
poderia proporcionar menor interferência nas tarefas de reconhecimento da fala de tais indivíduos

Entre outros estudos já citados há o trabalho desenvolvido por Peerce e Fowler (1992) que avaliaram o desempenho de 215 orelhas na medida do LRF com locutores femininos e masculinos, não encontrando diferenças significantes para os dois tipos. Young, Dudeley e Gunter (1982) sugeriram que o efeito do locutor é menor quando o estímulo é uma palavra trissilábica ou palavras maiores que monossílabos, nos testes da medida do LRF, concordando com Beattie et al (1975)

Mendel e Danhauer (1997) concordaram com Lyregaard (1997) e apontaram ainda outras questões. A primeira delas em relação ao sujeito, devendo-se levar em consideração sua familiaridade com o estímulo e a tarefa a ser realizada, seu nível sócio-cultural e sua idade cronológica e mental, e ainda, a presença ou não de alterações de linguagem, auditivas e neurológicas, e por último, sua motivação para o desempenho da tarefa. Todos estes fatores deveriam ser analisados tanto na variabilidade intra, como também, inter sujeitos.

Quanto ao examinador dever-se-ia considerar sua habilidade na aplicação do teste e na computação e análise dos resultados. Quanto ao teste em si, sugeriram considerar: o nível de intensidade da apresentação, se a apresentação é gravada ou a viva voz, o número de estímulos e as formas alternativas do mesmo teste. Também se deveria observar a forma de instrução à tarefa e o tipo de resposta solicitada ao sujeito, uso ou não de ruído de fundo ou outros artifícios para distorção do estímulo/sinal, além da calibração do equipamento e o uso de uma frase carreadora antes da apresentação de cada estímulo. 
Kreul, Bell e Nixon (1969) desenvolveram um estudo sobre a importância das listas gravadas para a avaliação da percepção da fala já naquela época. Eles apontaram a preocupação dos audiologistas em padronizar listas balanceadas foneticamente, mas não a preocupação com a forma de apresentação das listas. Eles também encontraram que a presença de frase carreadora ou veículo afetou significantemente o desempenho dos sujeitos, sendo que as palavras são mais facilmente entendidas.

Outra questão quanto aos critérios de desenvolvimento de material de fala relaciona-se à familiarização do estímulo antes do início do teste. Conn, Danver e Ventry (1975) estudaram a influência da familiarização dos estímulos antes do início da medida do LRF. Aplicaram listas em 48 sujeitos com e sem familiarização. Os resultados indicaram que há diferença entre os grupos com e sem familiarização em 5dB nível de sensação. Estudos anteriores de Chaiklin e Ventry (1964) mostraram que os resultados são mais fidedignos quando há familiarização dos estímulos. Mas na prática, tem sido pouco utilizada por aumentar o tempo clínico de administração para o início do teste propriamente dito. Conforme atestado por Martin e Pennington (1971) dentre os audiologistas americanos, apenas 50\%, deles utilizava a familiarização conforme posteriormente indicado pelo guia da ASHA (1988).

Quanto ao número de estímulos, Punch e Howard (1985) estudaram a influência do tamanho da lista sobre a obtenção do LRF. Eles apontaram que muitos autores sugeririam a diminuição para 36 palavras, a partir da proposta do CID W1, para melhor aplicabilidade na clínica (tempo de realização do teste). Mas tal técnica, segundo pesquisadores, pode retirar o efeito de homogeneidade que estas listas 
apresentam. 0s resultados do seu estudo revelaram uma diferença significante no resultado do LRF de acordo com o tamanho das listas, sendo que o limiar do LRF aumenta sistematicamente quando o tamanho da lista é reduzido e o intervalo de valores de resposta do LRF variou em $7 \mathrm{~dB}$ quando a lista era composta por 3 a 36 palavras.

Meyer e Bilger (1997) também estudaram a influência do tamanho da lista na obtenção do LRF , com ruído branco, concluindo que quando se utilizava uma técnica livre, não descrita pela ASHA, o limiar era dependente do tamanho da lista, quando se utilizava o método descrito pela ASHA (1988) o limiar obtido era independente, podendo utilizar uma lista com menos de 36 palavras. O limiar de reconhecimento de fala obtido variou de 3 a 7 dBNS de acordo com a técnica utilizada. Tais dados também suportaram os achados de Punch e Howard (1985) e ainda os estudos de Beattie et al. (1975) .

Martin (1997) estabeleceu alguns princípios de escolha dos critérios para a composição dos testes de fala. Sugeriu que o material de fala deve ser configurado em termos de suas características acústicas e fonéticas para ser apropriadamente sensível ao prejuízo auditivo provocado pela perda auditiva, e ainda, quando se avalia um processo de intervenção/reabilitação, o material de fala deve ter as características acústicas e fonéticas necessárias para avaliar essa intervenção e em qual grau. Sugeriu, também, que o grupo de indivíduos avaliados deve representar o grupo a que se destina o teste desenvolvido. $O$ tipo do material de fala, o ruído de fundo de competição e o nível de apresentação deveriam ser representativos das condições acústicas do dia a dia. E por fim, o teste deveria ser replicável, isto é, deveria conter alta fidedignidade de resposta. 
Ele ainda apontou vários outros itens a serem contemplados como a forma de administração e o formato da resposta solicitada, bem como o método de contagem das respostas, a possibilidade de formas alternativas do mesmo teste e o tempo necessário de administração para aplicá-lo.

Wilson (1993a, 1997b) descreveu as vantagens da utilização de materiais gravados para uso em teste de percepção da fala:

- alta fidelidade na relação sinal / ruído;

- separação entre os canais de gravação e apresentação;

- manutenção da qualidade na reprodução do material;

- gravação em CD: longa durabilidade, acesso rápido às faixas.

- mostra a faixa e o tempo de execução, acesso por controle remoto.

Wilson (1997) ainda apontou a escolha do nível de apresentação do teste associado à presença de ruído de fundo (fatores a serem considerados no uso de ruído: o nível de apresentação, relação sinal /ruído, apresentação ipsilateral ou contralateral e o tipo de ruído) e, por fim, os cuidados na calibração do equipamento.

Quanto ao nível de intensidade de apresentação do material de fala e a monitoração no $V U$ meter calibrado Green, Williams e Kiuter (1959) e Lilly (1967) reforçaram a importância do tom de calibração estar gravado na faixa 1 do CD. Eles sugeriram que, em geral, há alta variabilidade entre achados de um mesmo estudo, quando aplicados à viva-voz comparado com material gravado. $\mathrm{O}$ tom de calibração de $1000 \mathrm{hz}$ deveria refletir precisamente o pico do material de fala no VU meter. De acordo com Sherwood e Fuller (1997) e a norma 
ISO 8253-3 o tom deveria ser gravado em -3dB do pico do material de fala.

Segundo Walden (1984) dois itens apresentaram maior número de falhas nos testes de fala. São eles: a validade e a fidedignidade. A validade de um teste é comprovar que ele mede o que se propõe a medir e a fidedignidade é a administração repetida do teste, num mesmo sujeito e a média de respostas corretas, obtidas nas retestagens, deve se manter dentro da média de acertos do teste, medido numa determinada população, indicando assim, a confiabilidade do teste.

Todos os autores citados acima são unânimes em enfatizar a necessidade de se estabelecer a padronização de um teste de fala e seu nível de confiabilidade nas diferentes formas equivalentes do teste.

Linquist (1953) já apontava quais deveriam ser os passos para o desenvolvimento de um teste e sua padronização. Em primeiro lugar, definir o teste e preparar uma larga amostragem de itens. Em segundo lugar, realizar uma pré-testagem nesta amostragem aplicandose em um grande número de sujeitos. Em seguida, conduzir uma avaliação psicométrica utilizando dados de parte da amostragem e construir uma ou mais formas do teste.

Ele sugeriu que a validação seja feita utilizando-se os dados obtidos com a última amostra comparada com a primeira amostra. Para uma padronização mais refinada deveria-se observar os resultados de cada item para retirar aqueles que não contribuem para o estudo do que se deseja.

McCauley e Swisher (1984) propuseram 10 critérios psicométricos para avaliar se um teste pode ser considerado válido e adequado a seus objetivos. Eles deveriam conter a descrição dos dados 
normativos da amostra, o tamanho da amostra, a análise dos itens, o desvio padrão, a validade concorrente, a validade preditiva, a fidedignidade do teste-reteste, a fidedignidade entre examinadores (correlação de 0,9), a descrição dos procedimentos e a descrição da qualificação do teste.

Jerger (1983) indicou 4 itens que deveriam ser considerados na avaliação de fala de crianças. $O$ primeiro seria a possível restrição no desempenho da criança imposta pelo vocabulário a partir dos critérios de escolha dos itens. O segundo seria a limitação das respostas dadas dependendo se a tarefa é de resposta aberta ou fechada. O terceiro seria a necessidade de controlar a influência das habilidades de linguagem receptiva no desempenho do teste e, por último, a necessidade de se considerar a influência de efeitos não-auditivos, como, por exemplo, o nível cognitivo.

Lyregaard (1997) agrupou os erros na audiometria de fala e apontou que eles, geralmente, apresentam quatro características. A primeira tendência de erro seria a substituição do item-estímulo por uma palavra com o mesmo número de silabas. A segunda tendência seria o erro, a palavra respondida, tenderia a ser foneticamente similar ao item-estímulo. A terceira tendência de erro seria a substituição do item-estímulo por uma palavra com significado diferente e freqüente na língua. A quarta e última tendência seria a perda de informações acústicas das consoantes mais facilmente do que as vogais, por isso, a palavra respondida tenderia a preservar as vogais de sua constituição e substituir a consoantes.

No português brasileiro, os trabalhos de Gama (1991), Machado (1996) e Costa (1998a) se propuseram a estudar e debater alguns aspectos destes critérios citados. 
Costa (1998a) atualizou o levantamento, anteriormente feito por Gama em 1991, das listas utilizadas para medida do Índice de Reconhecimento da Fala. Costa obteve os mesmos resultados que Gama, em que não foi possível localizar com precisão a metodologia de desenvolvimento destas listas e seus estudos de validação e normatização.

Costa (1998a) também solicitou uma avaliação do balanceamento fonético dessas listas no Laboratório de Fonética da Unicamp que foi realizada por Silva e Gama-Rossi (2000). Concluíram que estas listas apresentavam baixa distribuição da freqüência de ocorrência dos fonemas em comparação à freqüência de ocorrência deles na língua portuguesa, sendo difícil obter uma correlação satisfatória em relação à distribuição da frequiência de ocorrência dos fonemas no português, uma vez que cada lista continha apenas 25 monossílabos, conforme Albano et.al. (1995) e Silva, Gama-Rossi e Albano (1995, 1997)

Para que as listas pudessem ser consideradas balanceadas foneticamente, elas deveriam obter um índice de correlação próximo de $100 \%$. As listas que apresentaram melhor índice de correlação foram as publicadas em Russo e Santos (p. 87, 1993) sendo a lista 2 de monossílabos para orelha direita e a lista proposta por Pen e Mangabeira-Albernaz (1973) com 55\% de correlação cada.

Para as listas de dissílabos, esta correlação mostrou-se melhor com três das listas obtendo os índices: 72\% (p.87, lista 2 , orelha esquerda), 66\% (p.88, lista 3, orelha direita) e 66\% (p.88, lista 4, orelha direita) respectivamente em Russo e Santos (1993).

Constatou-se a ausência de fonemas de grande ocorrência na língua, como os fonemas /r/, /g/, /f/, /z/, /v/, /u/ em 7 das 9 listas 
analisadas. Após esta análise, Costa (1998) modificou alguns vocábulos existentes nas próprias listas para melhor garantir o equilíbrio fonêmico, mas não realizou nova análise do balanceamento fonético. Após estas modificações, Costa aplicou as listas em 21 sujeitos adultos, ouvintes normais, com o objetivo final de traçar as curvas de articulação na situação de escuta, sem e com ruído competidor.

Observou-se, no trabalho de Costa (1998), que das 9 listas analisadas, o índice de reconhecimento geral da fala, sem ruído, foi de $80 \%$ de acerto a $30 \mathrm{dBNS}, 85 \%$ de acerto a $35 \mathrm{dBNS}$ e $89 \%$ de acerto a 40dBNS. Para os valores de LRF, o índice de 50\% de reconhecimento das palavras foi a $19,1 \mathrm{dBNS}$.

Este ponto também foi abordado por Gama-Rossi, Silva e Albano (1997a, 2000b). Eles agruparam todos os monossílabos das listas compostas por um mesmo autor para verificar como se comportaria o índice do balanceamento fonético, e obtiveram um novo índice de $70 \%$ para Russo e Santos (1993) com monossílabos e 82\% para dissílabos, sendo que agora cada lista seria composta por 100 palavras.

Assim, esses achados apontaram que para se desenvolver listas de palavras numa dada língua, não só o critério de balanceamento fonético e familiaridade poderiam ser seguidos, mas outras variáveis interfeririam de modo decisivo na qualidade da lista em termos de sua validade e fidediginidade.

Esses aspectos têm sido pouco apreciados nos testes desenvolvidas no Brasil, em geral. A preocupação principal tem sido a presença do balanceamento fonético, além da forma de sua apresentação. Mas, as listas citadas anteriormente não apresentaram dados de validação e padronização apesar de serem aplicadas em larga escala e em diferentes populações. 
Gama-Rossi e Silva (2000) deram uma contribuição a estas discussões, pois muitos dos trabalhos citados, recentemente desenvolvidos em português, foram analisados por elas no Laboratório de Fonética acústica e Psicolinguística experimentais da UNICAMP através do pedido para que as listas desenvolvidas fossem balanceadas foneticamente.

Realizaram, então, um estudo sobre o desenvolvimento de listas de palavras para logoaudiometria em outras línguas, que não o inglês, e observaram que os trabalhos mais recentes, tendem a abandonar o modelo inglês de uso de monossílabos com balanceamento fonético e passam a utilizar um modelo mais psicolingüístico e sociolingüístico para a elaboração destas listas, conforme vimos nos itens anteriores deste capítulo.

Os autores sugeriram critérios de formas para refletir melhor a característica das línguas avaliadas. Por exemplo, na falta de grande ocorrência de monossílabos, outras palavras de maior incidência na língua são utilizadas, como no caso das línguas Bantu que utilizam palavras quasi-monossílábicas, ou no árabe que utilizam monossílabos, mas sem o balanceamento fonético, optando pelas palavras mais familiares em qualquer contexto sócio-econômico-cultural ou ainda como no caso do malaio que utilizaram como critério a familiaridade e a ocorrência na língua além do balanceamento fonético. (Nsamba, 1979; Ashoor e Prochazcka, 1982; Mukarii e Said ,1991; Gama-Rossi e Silva, 2000), e ainda outros trabalhos já citados 


\section{MÉTODO}

\section{1 - Sujeitos}

A casuística desta pesquisa foi composta por 130 sujeitos na faixa etária de 5 a 7 anos, do sexo masculino e feminino que atenderam os critérios de inclusão.

A coleta dos dados foi realizada no período de julho de 2002 a agosto de 2003, tendo sido recrutados um total de 200 crianças estudantes regularmente matriculadas na pré-escola e 1a série da rede de escolas públicas do município de Itatiba, SP. Deste total de crianças, 150 pais assinaram o termo de consentimento sendo que somente 130 crianças satisfizeram os critérios de inclusão. ${ }^{4}$

\subsubsection{Critérios de inclusão}

\footnotetext{
${ }^{4}$ Este trabalho foi aprovado pelo comitê de ética do Instituto de Ciências Biomédicas da Universidade de São Paulo em 13 de dezembro de 2002 (anexo 15).
} 
Baseado nos dados obtidos no procedimento de avaliação para inclusão na pesquisa: os questionários aos pais e professores, a avaliação audiológica e a aplicação do teste de linguagem ABFW, adotou-se os seguintes critérios de inclusão para a formação dos grupos de sujeitos a serem avaliados:

- aceitação e assinatura do termo de consentimento;

- ser falante nativo do português brasileiro;

- não apresentar alteração auditiva em qualquer dos testes aplicados: inspeção visual do meato acústico externo, a audiometria tonal, timpanometria e pesquisa do reflexo do músculo do estapédio;

- não apresentar desvio na fala ou outras alterações em seu desenvolvimento de linguagem oral aquém de sua idade cronológica;

- não apresentar dificuldade de desempenho acadêmico, segundo a análise do professor.

\subsubsection{Amostra da População no Estudo Piloto: primeira e segunda fase}

Após a utilização desses critérios, a amostra para o estudo piloto constituiu-se de 16 sujeitos, na primeira fase, que formaram 3 grupos etários de: 5 anos a 5 anos e 11 meses, 6 anos a 6 anos e 11 meses e 7 anos a 7 anos e 11 meses, sendo 12 (75\%) do sexo feminino e 4 (25\%) do sexo masculino. A tabela 1 descreve a amostra quanto à faixa etária e sexo. 


\begin{tabular}{|c|c|c|c|c|c|c|}
\hline & \multicolumn{2}{|c|}{ FEMININO } & \multicolumn{2}{|c|}{ MASCULINO } & \multicolumn{2}{|c|}{ TOTAL } \\
\hline $\begin{array}{l}\text { Faixa } \\
\text { Etária }\end{array}$ & $\mathbf{N}$ & $\%$ & $\mathbf{N}$ & $\%$ & $\mathbf{N}$ & $\%$ \\
\hline (anos) & & & & & & \\
\hline $51-6$ & 2 & 16,6 & 1 & 31,5 & 3 & 18,7 \\
\hline $61-7$ & 7 & 58,3 & 2 & 50,0 & 9 & 56,2 \\
\hline 7 I- 8 & 3 & 25,0 & 1 & 31,5 & 4 & 25,0 \\
\hline total & 12 & 100 & 4 & 100 & 16 & 100 \\
\hline
\end{tabular}

Tabela 1. Distribuição da amostra segundo a faixa etária e sexo na fase 1 do estudo piloto.

Os sujeitos excluídos da pesquisa por apresentarem alguma alteração audiológica, de linguagem ou queixas escolares foram encaminhados para o atendimento na clínica-escola da Universidade São Francisco ou no setor de otorrinolaringologia da Santa Casa. 
$\mathrm{Na}$ segunda fase do estudo piloto foram avaliados 23 sujeitos. Na tabela 2 observa-se a distribuição de sexo e faixa etária. Diferentemente do primeiro grupo, este apresenta um número maior de meninos na faixa etária de 6 anos.

Tabela 2. Distribuição da população segundo o sexo e a faixa etária na segunda fase do estudo piloto.

\begin{tabular}{|c|c|c|c|c|c|c|}
\hline & \multicolumn{2}{|c|}{ FEMININO } & \multicolumn{2}{|c|}{ MASCULINO } & \multicolumn{2}{|c|}{ TOTAL } \\
\hline $\begin{array}{l}\text { Faixa } \\
\text { Etária } \\
\text { (anos) }\end{array}$ & $\mathbf{n}$ & $\%$ & $\mathbf{n}$ & $\%$ & $\mathbf{n}$ & $\%$ \\
\hline $5 \mid-6$ & 1 & 9,0 & 2 & 15,3 & 3 & 12,5 \\
\hline $61-7$ & 5 & 45,5 & 10 & 84,6 & 15 & 66,6 \\
\hline $71-8$ & 5 & 45,5 & $\mathbf{0}$ & $\mathbf{0 , 0}$ & 5 & 20,8 \\
\hline total & 11 & 100 & 12 & 100 & 23 & 100 \\
\hline
\end{tabular}

Após o estudo piloto foram, então, avaliados 94 sujeitos do grupo experimental, entre 5 anos a 7 anos e 11 meses, caracterizados a partir dos critérios de inclusão explicitados anteriormente. 
Os sujeitos formaram 3 grupos etários distribuídos conforme a tabela 3 .

Tabela 3 . Distribuição da população segundo o sexo e a faixa etária no grupo experimental

\begin{tabular}{c|c|c|c|c|c|c}
\hline & \multicolumn{2}{|c|}{ MASCULINO } & \multicolumn{2}{c|}{ FEMININO } & \multicolumn{2}{c}{ TOTAL } \\
\hline Faixa & $\mathbf{n}$ & $\mathbf{\%}$ & $\mathbf{n}$ & $\mathbf{\%}$ & $\mathbf{n}$ & $\%$ \\
etária & & & & & & \\
\hline 5 I -6 & $\mathbf{1 5}$ & $\mathbf{3 4 , 8}$ & $\mathbf{1 8}$ & $\mathbf{3 5 , 2}$ & 33 & 35,1 \\
6 I- 7 & $\mathbf{1 8}$ & $\mathbf{4 1 , 8}$ & $\mathbf{1 4}$ & $\mathbf{2 7 , 4}$ & 32 & 34,0 \\
7 I- 8 & $\mathbf{1 0}$ & $\mathbf{2 3 , 2}$ & $\mathbf{1 9}$ & $\mathbf{3 7 , 2}$ & 29 & 30,8 \\
total & 43 & 100 & 51 & 100 & 94 & 100 \\
\hline
\end{tabular}

\subsection{Material}

\subsubsection{Desenvolvimento das listas LE e LRS}

O desenvolvimento das listas foi baseado nos critérios já descritos por Mendel e Danhauer (1997), Martin (1997) e Lyregaard (1997) e obedeceu aos princípios de :

1. frequiência das palavras, coletadas a partir de um corpus significativo à faixa etária do estudo;

2. homogeneidade de audibilidade das palavras: todas as palavras foram gravadas no mesmo nível de intensidade;

3. tipo de resposta solicitada do sujeito: oral;

4. forma de computação das respostas: por escrito, pelo avaliador, no momento da resposta do sujeito; 
5. tempo de duração para administração do teste: clinicamente viável, de 3 a 4 minutos por lista;

6. a locução no CD: locutor não-treinado, do sexo feminino;

7. gravação em CD: para garantir os critérios de reprodutibilidade e homogeneidade da apresentação inter e intra teste;

8. forma de apresentação dos itens da lista: técnica descendente. O número de estímulos da lista é de 35 palavras cada e as formas alternativas do teste são duas, lista 1 e 2;

9. forma de instrução à tarefa: gravada no CD na faixa 2;

10. tom de calibração: gravado segundo a norma ISO R389 (1993).

O desenvolvimento das listas de palavras experimentais (LE) foi feito a partir de um levantamento de ocorrência de um conjunto de palavras trissilábicas e paroxítonas, uma vez que elas constituem as de maior ocorrência na língua, segundo Gama-Rossi e Silva (2000).

Este levantamento foi realizado a partir de programas e filmes infantis, selecionados entre àqueles de maior audiência pelos grupos etários a serem estudados. Trata-se de três programas infantis de TV (Eliana, da Rede Record; Angélica, da Rede Globo e Jaqueline, do SBT), gravados no período de março a agosto de 2000 e ainda dois filmes de longa metragem exibidos no cinema e na televisão (Castelo Rá-tim-bum e o Tigrão). No total foram analisados 25 horas de vídeo para o levantamento de todas as palavras trissilábicas paroxítonas existentes nos programas e filmes.

Inicialmente, formou-se uma lista com 673 palavras paroxítonas trissilábicas (anexo 1). A partir dela foi estruturada uma lista composta das 50 palavras mais freqüentes, obtidas nos programas de TV e filmes. Destas 50 primeiras, foram selecionadas 35 que compuseram a lista final. 
Para a elaboração final desta lista de trissílabos, as 35 palavras foram sorteadas para compor a ordem da lista E1 e novamente sorteadas, para compor a ordem da lista E2. Assim, as listas diferem entre si apenas quanto à ordem de apresentação das palavras (anexo $2 \mathrm{~A}$ e B).

Após esta etapa, organizou-se uma segunda lista de palavras, a partir do material publicado por Russo e Santos (1993). A escolha desta lista ocorreu após o levantamento bibliográfico sobre as propostas de listas para uso em LRF, em especial para crianças, publicadas em português, de amplo acesso à comunidade fonoaudiológica. Tal levantamento indicou exclusivamente as listas publicadas por Russo e Santos (LRS).

A lista original LRS é composta por 57 palavras sendo que 8 não foram consideradas, pois não são trissilábicas e paroxítonas. Assim, das 49 palavras restantes foram sorteadas 35 palavras que formaram a lista RS1 e novamente sorteadas para formarem a lista RS2 (anexo $3 \mathrm{~A}$ e B).

\subsubsection{Gravação do Material}

$\mathrm{Na}$ terceira etapa, as listas de palavras trissilábicas foram gravadas em estúdio profissional, por uma locutora, falante nativa do português brasileiro. As características de sua voz foram analisadas através do programa VOXMETRIA e indicaram padrões de normalidade para todos os itens avaliados, como a freqüência fundamental, a intensidade, o jitter, o shimmer e a proporção ruído/harmônico (anexo 4).

Para a gravação foi utilizado um microfone modelo AKG

414 BTL II posicionado a um palmo de distância da locutora com 
anteparo antipuff. (anexo 5 A e B). O microfone estava conectado a um pré-amplificador modelo Focus Rite Red 7. O sinal foi conduzido a uma interface Digidesign 96 que converteu o sinal analógico para digital. O sinal digitalizado foi armazenado em um hardware no sistema Pro-Tools. O compact disc (CD) foi gravado em um drive de gravação para CD modelo Yamaha CDR 400, no padrão mundial 16bits a 44.1 KHz. O CD foi gravado através do software 5.1 Pro-Tools.

A masterização foi feita dentro do programa Pro-Tools sendo utilizado um limiter (com razão de compressão infinita). Desta forma, pode-se obter uma locução mais uniforme, sem que houvesse variação dinâmica de volume (intensidade). Esse programa redesenha os picos de maior amplitude da onda que ultrapassem o nível préestabelecido, com um artefato mínimo audível, fornecendo limitação absoluta desses picos. Assim, o material da fala apresenta-se com uma faixa dinâmica mais estreita, sem afetar as características psicoacústicas da fala da locutora, além de permitir a eliminação de qualquer artefato audível (ruído).

A amostragem do sinal foi armazenada em 24 bits para efeito das edições. Ao final da gravação foi utilizado um ditter no PROTOOLS em forma de plug in para converter a gravação de 24 para 16 bits. As palavras foram gravadas em intervalos de 4 segundos.

Durante as sessões de gravação, a locutora pronunciava de 3 a 6 vezes cada palavra e 3 juizes brasileiros nativos de São Paulo ( duas fonoaudiólogas e um advogado, com idade entre 25 e 39 anos) classificaram cada palavra pela percepção de clareza da produção; a melhor produção foi, então, selecionada em termos de articulação e intensidade média. Se não houvesse uma produção satisfatória de uma determinada palavra, ela era gravada uma segunda vez, segundo os 
mesmos critérios. Após a seleção das palavras, a intensidade de cada palavra foi editada para fornecer uma intensidade equilibrada (realizado pelo limiter). Além disso, foi gravado um tom de calibração de $1000 \mathrm{~Hz}$ de modo que o $V U$ meter $^{5}$ do audiômetro, quando ajustado em $0 \mathrm{~dB}$, produzisse aproximadamente a mesma intensidade em todas as palavras.

O CD foi organizado da seguinte maneira:

faixa 1: tom de calibração

faixa 2: instrução

faixa 3: LE1

faixa 4: LE2

faixa 5: LRS1

faixa 6: LRS2.

A partir dos resultados do estudo piloto, a lista experimental LE foi regravada em $4 \mathrm{~dB}$ de atenuação do pico máximo de saída da mesa para evitar distorção, alteradando-se o modelo do discman para um modelo com saídas de fone e line out separadas, a ordem das palavras na lista e regravando-se aquelas que apresentaram distorções de produção em termos de clareza de articulação do locutor bem como de distorção de tonicidade, mantendo-a essencialmente como paroxítonas.

\footnotetext{
${ }^{5}$ O V U Meter (medidor de unidade de volume) é um instrumento de referência de sinal tanto para os testes de logoaudiometria com microfone, como fita cassete ou outro sistema de emissão de som enviado ao audiômetro para depois ser enviado ao paciente, VU Meter é usado para ajustar o sinal e mantê-lo sempre igual na saída para o paciente, portanto quando se faza calibração do sinal de entrada através do VU Meter e ajusta-se o mesmo para Zero (0)dB no VU Meter, significa que todos os sinais enviados ao paciente estarão com uma intensidade aproximada a selecionada no Dial de intensidade em dB no audiômetro.
} 


\subsection{Procedimento}

A aplicação das listas ocorreu em duas etapas: um estudo piloto e a fase experimental. O estudo piloto abrange vários objetivos. $\mathrm{O}$ primeiro objetivo foi determinar se os instrumentos utilizados para a pré-seleção (critérios de inclusão) foram eficazes na separação entre sujeitos com alteração de audição ou fala dos sem alteração. E também, avaliar aspectos relacionados com os instrumentos e procedimentos escolhidos, como o nível de dificuldade na aplicação do material em termos do tempo de aplicação, manuseio dos equipamentos envolvidos (audiômetro e disc man), calibração dos equipamentos e entendimento dos sujeitos à tarefa solicitada.

Além disso, o estudo piloto permitiu avaliar as respostas do LRF com as listas desenvolvidas, avaliar os itens-estímulo da lista em termos de seu nível de dificuldade e avaliar a qualidade da gravação da lista em relação à qualidade de articulação do locutor, intervalo entre os estímulos e nível de intensidade da gravação.

O procedimento se iniciou com a assinatura do termo de consentimento pelos pais ou responsáveis (anexo 6) e a resposta a um questionário de 5 questões (anexo 7) . Posteriormente outro questionário foi entregue aos professores contendo 3 questões (anexo 8). O objetivo foi o de obter informações sobre o nível atual de desenvolvimento da linguagem oral e escrita, informação sobre o histórico otológico e outras

alterações associadas e, por último, informações sobre o nível de entendimento dos sujeitos à tarefa de ordens verbais, indicando a presença de dificuldades de atenção .

Em seguida, foi aplicado um protocolo de avaliação de linguagem oral, mais especificamente de nível fonológico, o ABFW 
desenvolvido por Wertzner et al. (2000) (anexo 9). Selecionou-se o teste de imitação de palavras que apresenta tarefa análoga àquela exigida pelo LRF. O objetivo da aplicação deste protocolo foi o de realizar um levantamento do inventário fonológico da criança a fim de confrontar com os dados obtidos nos questionários, respondidos pelos pais e professores, e não aceitar os sujeitos que apresentavam qualquer desvio na fala. Cabe ressaltar que nos casos onde o ABFW apontou alterações do tipo "regionalismos", as crianças foram consideradas como sem alteração.

A avaliação audiológica constou dos seguintes procedimentos. Primeiramente foi realizada a inspeção visual do meato acústico externo em ambas as orelhas para certificar-se que nada impedia a realização da avaliação da audição. Nos casos em que ocorreram alterações, os sujeitos foram enviados para avaliação otorrinolaringológica e retorno para a avaliação da audição.

A seguir foi realizada a medida da imitância acústica composta pelos testes de timpanometria que avalia a mobilidade da membrana timpânica e das condições funcionais da orelha média e a pesquisa dos reflexos acústicos do músculo do estapédio que verifica, através da contração do músculo estapédio, as funções auditivas da orelha média e a via auditiva de tronco cerebral baixo (Lopes $\mathrm{F}^{\circ}$, 1997).

Para análise dos resultados no teste da timpanometria, adotou-se o critério de acordo com Jerger et al. (1972), sendo a Curva tipo A caracterizada por um pico máximo ao redor de -100 a +50 pressão em mm de água, considerada como padrão de normalidade.

$\mathrm{Na}$ pesquisa do reflexo acústico do músculo estapédio, os sujeitos foram considerados normais, quando todos os reflexos 
realizados nas frequiências $500 \mathrm{~Hz}, 1000 \mathrm{~Hz}$ e $2000 \mathrm{kHz}$ estiveram presentes (Lopes $\mathrm{F}^{\mathrm{o}}$, 1997).

$\mathrm{Na}$ audiometria tonal, por via aérea, os sujeitos realizaram o teste com fones supra-aurais. A ordem de teste das freqüências foi de 1000, 2000, 3000, 4000, 6000, 8000, 500 e 250Hz. Em seguida, testouse o lado oposto na mesma sucessão de freqüências. A técnica utilizada para a obtenção dos limiares auditivos foi a descendente. O critério de normalidade é o proposto pela BIAP (1996) sendo limiares normais na média de 500, 1000, 2000 e $4000 \mathrm{~Hz}$ de até $20 \mathrm{dBNA}$.

\subsubsection{Procedimento para Obtenção do Limiar de Reconhecimento da Fala: LRF}

A medida do limiar de reconhecimento da fala (LRF), através da aplicação das listas de palavras desenvolvidas, foi realizada após a avaliação da audição.

$\mathrm{Na}$ medida do limiar do reconhecimento da fala, o LRF foi obtido, utilizando-se o método descendente. Para iniciar, obteve-se a média tonal, por via aérea, nas frequiências 500,1000 e $2000 \mathrm{~Hz}$ para cada orelha. Obtendo-se a média, acrescentou-se $30 \mathrm{~dB}$ e iniciou-se a medida do LRF, apresentando-se uma frase inicial com a seguinte explicação da tarefa: 
"Você vai ouvir várias palavras. Preste atenção e repita cada uma delas. Você deve repeti-las do jeito como as entendeu. Tudo bem? Podemos começar?"

A seguir apresentou-se uma palavra, se correta, subtraía-se a intensidade em degraus de $5 \mathrm{~dB}$ e nova palavra foi apresentada. Quando a palavra não foi respondida corretamente, apresentou-se um grupo com quatro palavras, se obtido 50\% de acerto, este foi considerado o LRF. Se obtido mais de $50 \%$ acerto, a intensidade foi atenuada em $2 \mathrm{~dB}$ e novas quatro palavras foram apresentadas. Se obtido $50 \%$ de respostas corretas, considerou-se este o LRF, se ainda houve mais do que $50 \%$ de acerto, novamente a intensidade foi atenuada em 2dB. Se mesmo assim, não foi possível obter $50 \%$ de acerto, considera-se como o LRF a última intensidade onde ocorreu $50 \%$ de acerto ou mais. No estudo piloto os degraus de intensidade foram de apenas $5 \mathrm{~dB}$.

A forma de apresentação das listas seguiu os seguintes critérios para a fase piloto (quadro 3).

Quadro 3: forma de apresentação das listas LE na fase do estudo piloto.

\begin{tabular}{|c|c|c|c|c|c|c|c|c|}
\hline $\begin{array}{c}\text { Ordem de } \\
\text { apresentação }\end{array}$ & $\mathbf{1}^{\circ}$ & $\mathbf{1}^{\circ}$ & $\mathbf{2}^{\circ}$ & $\mathbf{2}^{\circ}$ & $\mathbf{1}^{\circ}$ & $\mathbf{1}^{\circ}$ & $\mathbf{2}^{\circ}$ & $\mathbf{2}^{\circ}$ \\
\hline Orelha & OD & OE & OD & OE & OE & OD & OD & OE \\
\hline lista & LE1 & LE1 & LE2 & LE2 & LE2 & LE2 & LE1 & LE1 \\
\hline
\end{tabular}

$\mathrm{Na}$ fase experimental adotou-se o critério abaixo para a apresentação das listas LE e LRS (quadro 4).

Quadro 4: forma de apresentação das listas LE e LRS na fase experimental. 


\begin{tabular}{|c|c|c|c|c|c|c|c|c|}
\hline $\begin{array}{c}\text { Ordem de } \\
\text { apresen- } \\
\text { taçãa }\end{array}$ & $\mathbf{1}^{\circ}$ & $\mathbf{1}^{\circ}$ & $\mathbf{2}^{\circ}$ & $\mathbf{2}^{\circ}$ & $\mathbf{1}^{\circ}$ & $\mathbf{1}^{\circ}$ & $\mathbf{2}^{\circ}$ & $\mathbf{2}^{\circ}$ \\
\hline Orelha & OD & OE & OD & OE & OD & OE & OD & OE \\
\hline lista & $\begin{array}{c}\text { LE1 } \\
\text { LRS1 }\end{array}$ & $\begin{array}{c}\text { LE1 } \\
\text { LRS1 }\end{array}$ & $\begin{array}{c}\text { LE1 } \\
\text { LRS1 }\end{array}$ & $\begin{array}{c}\text { LE1 } \\
\text { LRS1 }\end{array}$ & $\begin{array}{c}\text { LE2 } \\
\text { LRS2 }\end{array}$ & $\begin{array}{c}\text { LE2 } \\
\text { LRS2 }\end{array}$ & $\begin{array}{c}\text { LE2 } \\
\text { LRS2 }\end{array}$ & $\begin{array}{c}\text { LE2 } \\
\text { LRS2 }\end{array}$ \\
\hline
\end{tabular}

A escolha para avaliação das orelhas foi na ordem aleatória de avaliação, bem como a ordem de apresentação das listas, segundo sugestão de Martin et al. (2000).

Quando não houve concordância entre o LRF (dBNA) e a média tonal, conforme a literatura já citada, adotou-se o procedimento de refazer primeiro o LRF naquela determinada orelha. Na eventualidade de continuar não havendo concordância, a medida do limiar tonal, nas freqüências de 500, 1000 e $2000 \mathrm{~Hz}$, foi refeita.

Os exames foram realizados em uma sala com baixo nível de ruído (medido através de calibração biológica da pesquisadora) e uma cabina acústica. Os equipamentos utilizados foram um otoscópio HEINE, um audiômetro clínico de dois canais modelo - CE 10, marca Interacoustics e um imitanciômetro Interacoustics modelo - AZ- 7R e um disc man marca Panasonic.

A calibração dos equipamentos foi realizada por técnico especializado segundo as normas (padrão ISO 8253-3 e ANSI 3.6, 1996). A calibração foi feita antes do início da primeira fase do estudo piloto, segunda fase do piloto e da fase experimental.

\subsubsection{Análise Estatística dos Resultados}


As análises quantitativas foram realizadas a partir da seguinte metodologia estatística: a distribuição das variáveis foi representada por freqüências absolutas e relativas (\%) e por média e desvio padrão (dp). As diferenças entre os limiares do LRF e a média tonal foram calculadas e analisadas entre as listas LE e LRS .

Testes não paramétricos foram utilizados devido à ausência de distribuição normal dos dados. A presença de efeito da ordem de aplicação das listas e da ordem das palavras, dentro de cada lista, foi avaliada pela Prova de Mann-Whitney nas amostras independentes dentro de cada grupo etário. Dentro de cada grupo etário foram comparadas as diferenças apresentadas por sujeitos do sexo feminino e masculino pela Prova de Mann-Whitney nas amostras independentes.

As diferenças obtidas com as listas LE e LRS foram comparadas pela Prova de Wilcoxon nas amostras relacionadas dentro de cada grupo etário.

Os grupos etários foram comparados entre si, em relação às diferenças em cada lista, pela Prova de Kruskal-Wallis.

A presença de correlação entre a idade e as diferenças em cada lista, entre a média tonal e os resultados da LRF, e entre a incidência das palavras no corpus e o número de erros nas palavras foi avaliada pelo coeficiente de correlação por postos de Spearman, sendo sua significância testada.

Adotou-se o nível de significância de $0,05(\alpha=5 \%)$ e níveis descritivos (p) inferiores a esse valor foram considerados significantes e representados por *.

A avaliação qualitativa das respostas foi realizada somente com a lista LE1, desenvolvida pela autora e aplicada sempre na orelha direita em três diferentes níveis de intensidade de apresentação à 5dBNS, 
10dBNS e 15 dBNS. Iniciou-se a apresentação de menor intensidade, isto é, a 5dBNS, de modo a garantir a atenção e motivação da criança nas intensidades mais baixas que demandam maior atenção à tarefa. 


\section{RESULTADOS}

\subsubsection{Resultados do Estudo Piloto: primeira fase}

Inicialmente, foram avaliados 16 sujeitos entre 5 a 7 anos de idade, sendo $12(75 \%)$ do sexo feminino e 4 (25\%) do sexo masculino.

Os questionários para determinar os sujeitos de inclusão foram aplicados e as respostas obtidas mostraram-se coincidentes, entre a entrevista com os pais e professores, em 94\% das vezes, isto é, somente um pai respondeu dizendo que seu filho não tinha alterações de fala, mas o questionário do professor e o teste $\mathrm{ABFW}$ indicaram que havia alteração. Não foi observado qualquer nível de dificuldade no entendimento ou preenchimento dos questionários. 
$\mathrm{Na}$ prova de imitação (nível fonológico) do teste ABFW não foi constatada dificuldades tanto na aplicação como na avaliação das respostas. Os achados demonstraram efetividade tanto dos questionários quanto do $\mathrm{ABFW}$ para diferenciar as crianças com e sem alteração de fala.

No anexo 13 estão apresentadas as respostas dadas aos questionários e ao ABFW em relação à indicação de fala alterada ou não.

No procedimento de avaliação da audição, através da inspeção visual do meato acústico externo, não houve casos de impedimento para a realização da avaliação audiológica.

$\mathrm{Na}$ avaliação da audição uma das crianças apresentou perda auditiva moderada na orelha direita do tipo condutiva, confirmada pela curva timpanométrica tipo B e ausência na medida do reflexo acústico do músculo do estapédio no ouvido contra lateral esquerdo na via aferente.

$\mathrm{Na}$ bateria de testes de imitância acústica somente uma criança apresentou curva tipo $\mathrm{C}$ na orelha esquerda e uma criança apresentou curva tipo Ad em ambas as orelhas, mas 100\% das crianças apresentaram presença na medida do reflexo acústico do músculo do estapédio entre 70 a 90dBNS.

Sendo assim, neste estudo piloto, as duas crianças que apresentaram curvas $\mathrm{C}$ e Ad não foram retiradas da amostra já que seus limiares tonais estavam dentro da normalidade além da presença do reflexo do músculo do estapédio. Sendo retirada, somente, a criança que apresentou alteração nos limiares tonais.

Os resultados obtidos na medida do limiar de reconhecimento de fala (LRF), através da aplicação das listas LE desenvolvidas, estão descritos na tabela 4 . Nas respostas obtidas para as listas experimentais (E1 e E2) considerou-se que o limiar de 
reconhecimento de fala apresentou-se no limite máximo aceitável ou acima dele, isto é, a maior porcentagem de respostas para as listas, tanto para orelha direita como para esquerda, apresentaram valores entre 0 a 20dB nível de sensação.

Tabela 4: distribuição da ocorrência do LRF em dBNS, para as variáveis lista, orelha e faixa etária no estudo piloto fase 1

\begin{tabular}{c|c|c|c|c|c|c|c|c}
\hline & \multicolumn{2}{|c|}{5 anos } & \multicolumn{2}{c|}{6 anos } & \multicolumn{2}{c|}{7 anos } & \multicolumn{2}{c}{ Total } \\
\hline $\begin{array}{c}\text { LRF } \\
(\mathrm{dBNS})\end{array}$ & OD & OE & OD & OE & OD & OE & $\mathbf{n}$ & $\%$ \\
\hline 0 & 0 & 1 & 0 & 2 & 2 & 1 & 6 & 19 \\
\hline 5 & 0 & 1 & 3 & 2 & 1 & 1 & 8 & 25 \\
\hline 10 & 1 & 0 & 2 & 2 & 1 & 2 & 8 & 25 \\
\hline 15 & 0 & 0 & 4 & 2 & 0 & 0 & 6 & 19 \\
\hline 20 & 2 & 1 & 0 & 1 & 0 & 0 & 4 & 12 \\
\hline total & 3 & 3 & 9 & 9 & 4 & 4 & 32 & 100 \\
\hline
\end{tabular}

Os achados foram considerados inadequados, em especial os $31 \%$ acima de $10 \mathrm{dBNS}$, isto é, acima dos valores citados na literatura que propõem que o LRF deve situar-se aproximadamente em 6dBNS da 
média tonal ou até 10dBNS segundo Olsen e Maktin (1979) e Russo e Santos (1993).

No geral, não foram constatadas dificuldades dos sujeitos no entendimento e execução da tarefa do LRF. As dificuldades se restringiram à própria obtenção do LRF, isto é, nas intensidades próximas ao limiar do LRF, a criança tende a cometer mais erros e se mostra mais dispersa à tarefa.

Quanto à atenção ao teste, a pesquisadora observou comportamentos como: perguntando se iria demorar muito ainda para acabar, a criança olhava para vários lados dentro e fora da cabina acústica ou parava repentinamente de responder, assim tais comportamentos foram classificados como cansaço e dispersão resultando numa possível diminuição de atenção à tarefa solicitada. Tal comportamento foi mais acentuado nos sujeitos de 5 anos, o que pode ter influenciado no aparecimento de LRF altos, isto é, 20dBNS.

Outro dado analisado foi relativo ao número de passos necessários para a obtenção do LRF. Neste estudo piloto, foram utilizados degraus descendentes de $10 \mathrm{em} 10 \mathrm{dBs}$ e aumentos sucessivos de 5 em 5 dBs. Na tabela 5 observa-se que 4 a 6 mudanças no valor da intensidade, tanto para cima quanto para baixo, foram suficientes para que o LRF fosse obtido.

Tabela 5: Média do número de degraus para o estabelecimento do LRF para as orelhas direita e esquerda no estudo piloto fase 1.

\begin{tabular}{c|c|c|c|c|c}
\hline & \multicolumn{2}{|c|}{ OD } & \multicolumn{2}{c|}{ OE } & total \\
\hline $\begin{array}{c}\text { No de } \\
\text { passos }\end{array}$ & $\mathbf{N}$ & $\mathbf{\%}$ & $\mathbf{N}$ & $\mathbf{\%}$ & $\mathrm{N} \%$ \\
\hline 4 & 6 & 37,5 & 5 & 31,2 & 1134,3 \\
\hline 5 & 3 & 18,7 & 5 & 31,2 & 825
\end{tabular}




\begin{tabular}{c|c|c|c|c|c}
6 & 5 & 31,2 & 5 & 31,2 & 1031,2 \\
\hline 7 & 2 & 12,5 & 1 & 6,2 & 309,9 \\
\hline Total & 16 & 100 & 16 & 100 & 32100 \\
\hline
\end{tabular}

Quanto à avaliação do tempo de aplicação do material, foram gastos, em média, 2 a 4 minutos por orelha para a medida do LRF, tempo este considerado clinicamente viável.

Em relação ao manuseio dos equipamentos envolvidos, o conjunto audiômetro e discman, também não foram encontradas dificuldades, sendo de fácil acesso e visualização a seleção e troca das faixas das listas a serem apresentadas e da orelha a ser avaliada.

Os sujeitos, no geral, foram instruídos pela orientação gravada no CD. Poucos foram os casos (quatro crianças) em que foi necessário fornecer nova orientação, desta vez, a viva-voz pela pesquisadora.

Como os resultados esperados para o LRF poderiam ser melhores, isto é, LRF com valores menores dos que os encontrados, vários outros itens foram reavaliados. Inicialmente, foi solicitado ao técnico responsável uma nova checagem na calibração, que se encontrava adequada.

A seguir, o modelo de discman utilizado foi reavaliado, pois este modelo não apresentava saídas diferenciadas entre fones e saída externa (line out) e optou-se para, a próxima fase, a troca do modelo pois a indiferenciação das saídas poderia acarretar mudanças na intensidade do sinal se movimentado o controle de volume, como sugerido pelo técnico responsável.

Três aspectos referentes à gravação das listas foram avaliados. O primeiro aspecto referia-se à qualidade da articulação do 
locutor, onde novamente os três juizes re-avaliaram a produção das palavras em termos de qualidade de articulação e entonação. Assim, decidiu-se gravar novamente nove palavras que apresentavam pequenas distorções na acentuação tônica, sendo elas: agora, espera, amigo, estranho, cidade, embora, socorro, cansado e comigo.

Foi necessária, também, a modificação da ordem de algumas palavras na lista, sendo, retiradas da LE1 e LE2 as palavras iniciais, pois na LE1 a primeira palavra era "espera", assim, a criança não iniciava a tarefa aguardando pela segunda palavra. Na LE2, a primeira palavra era "cansado" e algumas crianças tenderam a interpretar como uma pergunta, respondendo à ela. A ordem de apresentação, também, foi modificada pois algumas palavras que apresentavam estrutura fonêmica bastante similar, apareciam seguidamente na lista, então foi realizado novo sorteio, para que estas palavras não aparecessem tão próximas como: ainda/aonde, bolinha/sozinho.

O terceiro aspecto avaliado foi o intervalo de gravação, de 4 segundos entre os itens da lista, que se mostrou suficiente para a resposta das crianças. Observou-se, no geral, até uma sobra de tempo, isto é, quando as crianças entendiam a palavra, elas tenderam a respondê-la imediatamente entre 1 a 2 segundos da apresentação. Quando as crianças não entendiam a palavra, no geral, não apresentavam respostas, o que dificultou a avaliação dos itens-estímulo individualmente.

\subsubsection{Resultados do Estudo Piloto: Segunda Fase}

Na segunda fase do piloto, após as modificações, as listas LE1 e LE2 foram avaliadas em um grupo de 23 crianças. Neste grupo 
houve concordância de $100 \%$ das vezes, na aplicação do questionário aos pais e professores e sua correlação com o ABFW (critérios de inclusão). Nesta fase foram avaliadas somente as crianças com avaliação da audição dentro do padrão de normalidade descrito.

Na tabela 6 estão os resultados obtidos na medida do LRF (dBNS) para o grupo de sujeitos nesta segunda fase. Observa-se que após as modificações (mudança do discman, re-gravação de palavras) obteve-se um LRF com valores entre 5 e 10dBNS. Estes resultados foram considerados mais adequados de acordo com a literatura já citada.

Tabela 6: distribuição da ocorrência do LRF, em dBNS, para as variáveis lista orelha e faixa etária no estudo piloto segunda fase

\begin{tabular}{c|c|c|c|c|c|c|c|c}
\hline & \multicolumn{2}{|c|}{5 anos } & \multicolumn{2}{c|}{6 anos } & \multicolumn{2}{c|}{7 anos } & \multicolumn{2}{c}{ Total } \\
\hline $\begin{array}{c}\text { LRF } \\
(\mathrm{dBNS})\end{array}$ & OD & OE & OD & OE & OD & OE & $\mathbf{n}$ & $\%$ \\
\hline 0 & 1 & 0 & 2 & 1 & 0 & 2 & 6 & 13,0 \\
\hline 5 & 0 & 1 & 7 & 7 & 2 & 1 & 18 & 39,5 \\
\hline 10 & 2 & 2 & 5 & 5 & 2 & 2 & 18 & 39,5 \\
\hline 15 & 0 & 0 & 1 & 2 & 1 & 0 & 4 & 8,0 \\
\hline 20 & 0 & 0 & 0 & 0 & 0 & 0 & 0 & 0,0 \\
\hline 25 & 0 & 0 & 0 & 0 & 0 & 0 & 0 & 0,0 \\
\hline 30 & 0 & 0 & 0 & 0 & 0 & 0 & 0 & 0,0 \\
\hline total & 3 & 3 & 15 & 15 & 5 & 5 & 46 & 100 \\
\hline
\end{tabular}


Nesta segunda fase foi realizada, num grupo de 12 sujeitos (52\% do total), a medida da curva psicométrica (função desempenhointensidade) em três intensidades à $5 \mathrm{dNS}, 10 \mathrm{dBNS}$ e $15 \mathrm{dBNS}$ com o objetivo de avaliar o desempenho geral dos grupos em relação à lista e observar variação de desempenho de modo a inferir sobre a qualidade dos itens da lista. Não foi possível avaliar as 23 crianças que compõem o grupo desta segunda fase pois muitas delas não cooperaram em, pelo menos, uma das apresentações prejudicando assim o total da avaliação.

O quadro 5 mostra a distribuição total de erros de cada palavra, na lista LE1, somados os resultados de erro por palavra. No geral, quando foi possível a avaliação em 15dBNS, as crianças apresentaram índices de acerto próximos a 90\% para toda a lista LE1 apresentada.

Quadro 5. Distribuição do número total de erros por item na lista LE1 em ordem decrescente. 


\begin{tabular}{|c|c|}
\hline LISTA E1 & Total de erros \\
\hline Idéia & 23 \\
\hline Menina & 21 \\
\hline Caminho & 21 \\
\hline Primeiro & 20 \\
\hline Ainda & 17 \\
\hline Cidade & 13 \\
\hline Teatro & 12 \\
\hline Pessoas & 12 \\
\hline Desculpe & 12 \\
\hline Pedido & 11 \\
\hline Estranho & 11 \\
\hline Querido & 10 \\
\hline Porteiro & 10 \\
\hline Certeza & 10 \\
\hline Aquela & 10 \\
\hline Presente & 9 \\
\hline Crianças & 9 \\
\hline Cansado & 9 \\
\hline Abelha & 8 \\
\hline Sozinho & 7 \\
\hline Socorro & 7 \\
\hline Moeda & 7 \\
\hline Embora & 7 \\
\hline Alguma & 7 \\
\hline Espera & 6 \\
\hline Comigo & 6 \\
\hline Vergonha & 5 \\
\hline Direito & 5 \\
\hline Bolinha & 5 \\
\hline Verdade & 4 \\
\hline Aonde & 4 \\
\hline Problema & 3 \\
\hline Castelo & 3 \\
\hline Amigo & 1 \\
\hline Agora & 0 \\
\hline total & 325 \\
\hline avaliç & $t e n d$ \\
\hline
\end{tabular}

A avaliação da tendência de respostas apontou algumas palavras que parecem ter maior dificuldade de reconhecimento por parte 
das crianças, em especial, quando da situação de apresentação a 5dBNS. Esta situação não foi tomada como base final para avaliar as palavras pois algumas crianças que apresentaram maior índice de erros neste nível, apresentaram seu LRF, em geral em 10dbNS ou mais. Mas, mesmo assim, houve uma tendência de erros, em 4 palavras, como as palavras idéia, menina, caminho e primeiro, com alto índice de erros também em todos os níveis avaliados.

Estas palavras não foram substituídas para a fase experimental porque se desejou avaliá-las melhor do ponto de vista do reconhecimento auditivo, além de possíveis interferências ligadas à parte semântica e lexical, e também porque algumas delas aparecem em posição final da lista experimental (idéia e primeiro), sendo pouco utilizadas para a medida do LRF onde, geralmente, utiliza-se, no máximo, 15 palavras para a medida.

\subsection{Fase Experimental: Análise do Desempenho dos Sujeitos no Resultado do Limiar de Reconhecimento da Fala (dBNS), por Faixa Etária, em Relação à cada Lista e à Orelha Avaliada}


Para avaliar o desempenho dos sujeitos em relação a todas as listas aplicadas, em termos do resultado do Limiar de Reconhecimento da Fala e a média tonal, em dBNS, foi aplicado o teste não-paramétrico de Mann-Whitney, adotando-se o índice de significância menor que $\mathrm{p}=0,05$.

Tabela 7 . Média do LRF, em dBNS, para as variáveis lista aplicada, orelha avaliada para a faixa etária de 5 anos verificado pelo teste $U$ de Mann-Whitney adotando-se o índice de significância menor que p=0,05. Os valores em parênteses indicam o desvio-padrão.

\begin{tabular}{|c|c|c|c|c|}
\hline \multicolumn{5}{|c|}{ Média do LRF em dBNS (dp) } \\
\hline $\begin{array}{l}\text { Lista de } \\
\text { palavras }\end{array}$ & LE1 & LE2 & LRS1 & LRS2 \\
\hline OD & $\begin{array}{c}4,1 \\
(4,8)\end{array}$ & $\begin{array}{c}5,2 \\
(2,8)\end{array}$ & $\begin{array}{c}3,9 \\
(5,6)\end{array}$ & $\begin{array}{c}4,1 \\
(3,9)\end{array}$ \\
\hline Teste U & \multicolumn{2}{|c|}{$\mathrm{p}=0,758$} & \multicolumn{2}{|c|}{$\mathrm{p}=0,877$} \\
\hline $\mathrm{OE}$ & $\begin{array}{c}3,6 \\
(5,8)\end{array}$ & $\begin{array}{c}4,0 \\
(6,3)\end{array}$ & $\begin{array}{c}1,0 \\
(6,0)\end{array}$ & $\begin{array}{c}3,3 \\
(4,7)\end{array}$ \\
\hline Teste U & \multicolumn{2}{|c|}{$p=0,899$} & \multicolumn{2}{|c|}{$p=0,204$} \\
\hline
\end{tabular}

Como mostrado na tabela 7 , na faixa etária de 5 anos não foi encontrada diferença estatisticamente significante entre as listas LE1 e LE2 (da autora) em relação à diferença do resultado do LRF e a média tonal nas orelhas direitas $(\mathrm{p}=0,758)$ e esquerdas $(\mathrm{p}=0,899)$, ocorrendo os mesmos resultados não significativos entre as listas LRS1 e LRS2 (de Russo e Santos) para orelha direita $(\mathrm{p}=0,877)$ e a orelha esquerda $(\mathrm{p}=0,204)$. 
Tabela 8. Média do LRF, em dBNS, para as variáveis lista aplicada, orelha avaliada para a faixa etária de 6 anos verificado pelo teste $U$ de Mann-Whitney adotando-se o índice de significância menor que $p=0,05$. Os valores em parênteses indicam o desvio-padrão.

\begin{tabular}{c|c|c|c|c}
\hline \multicolumn{5}{c}{$\begin{array}{c}\text { Média do LRF } \\
\text { em dBNS (dp) }\end{array}$} \\
\hline $\begin{array}{c}\text { Lista de } \\
\text { palavras }\end{array}$ & LE1 & LE2 & LRS1 & LRS2 \\
& & & & \\
OD & 4,2 & 3,9 & 5,8 & 4,0 \\
& $(2,9)$ & $(4,9)$ & $(3,0)$ & $(3,8)$ \\
\hline Teste U & \multicolumn{2}{|c|}{$p=0,766$} & \multicolumn{2}{c}{$p=0,216$} \\
\hline \multirow{2}{*}{ OE } & 4,0 & 5,8 & 4,9 & 6,8 \\
& $(4,0)$ & $(4,7)$ & $(5,4)$ & $(5,5)$ \\
\hline Teste U & \multicolumn{3}{c|}{$\mathbf{p = 0 , 1 7 6}$} & \multicolumn{2}{c}{$\mathbf{p = 0 , 3 3 1}$} \\
\hline
\end{tabular}

$\mathrm{Na}$ faixa etária de 6 anos também não foi encontrada diferença estatisticamente significante entre as listas LE1 e LE2 em relação à diferença do resultado do LRF e a média tonal nas orelhas direitas $(\mathrm{p}=0,766)$ e esquerdas $(\mathrm{p}=0,176)$ ocorrendo o mesmo em relação às listas LRS1 e LRS2 para a orelha direita $(\mathrm{p}=0,216)$ e a orelha esquerda $(\mathrm{p}=0,331)$, conforme a tabela 8 .

Tabela 9. Média do LRF, em dBNS, para as variáveis lista aplicada, orelha avaliada para a faixa etária de 7 anos verificado pelo teste $U$ de Mann-Whitney adotando-se o índice de significância menor que $p=0,05$. Os valores em parênteses indicam o desvio-padrão. 


\begin{tabular}{|c|c|c|c|c|}
\hline \multicolumn{5}{|c|}{$\begin{array}{l}\text { Média do LRF } \\
\text { em dBNS (dp) }\end{array}$} \\
\hline $\begin{array}{l}\text { Lista de } \\
\text { palavras }\end{array}$ & LE1 & LE2 & LRS1 & LRS2 \\
\hline OD & $\begin{array}{c}4,9 \\
(4,0)\end{array}$ & $\begin{array}{c}5,7 \\
(5,8)\end{array}$ & $\begin{array}{c}3,6 \\
(4,3)\end{array}$ & $\begin{array}{c}4,0 \\
(4,9)\end{array}$ \\
\hline Teste U & \multicolumn{2}{|c|}{$\mathrm{p}=0,512$} & \multicolumn{2}{|c|}{$\mathrm{p}=0,874$} \\
\hline $\mathrm{OE}$ & $\begin{array}{c}4,9 \\
(4,2)\end{array}$ & $\begin{array}{c}5,2 \\
(4,0)\end{array}$ & $\begin{array}{c}4,3 \\
(4,9)\end{array}$ & $\begin{array}{c}5,4 \\
(3,4)\end{array}$ \\
\hline Teste U & \multicolumn{2}{|c|}{$p=0,751$} & \multicolumn{2}{|c|}{$p=0,455$} \\
\hline
\end{tabular}

Na faixa etária de 7 anos, novamente, não foi encontrada diferença estatisticamente significante entre LE1 e LE2 em relação à diferença do resultado do LRF e a média tonal nas orelhas direitas $(\mathrm{p}=$ 0,512) e esquerdas $(\mathrm{p}=0,751)$ e também para entre LRS1 e LRS2 para a orelha direita $(\mathrm{p}=0,874)$ e a orelha esquerda $(\mathrm{p}=0,455)$, conforme a tabela 9 . 


\section{Valores Obtidos no LRF, em dBNS, por Faixa Etária e Orelha Avaliada.}

Diante da inexistência de diferença estatisticamente significante para os resultados do LRF em dBNS, entre as listas LE1 e LE2 e também entre as listas LRS1 e LRS2 (tabela 7,8,9), nas orelhas direitas e esquerdas, as listas foram reunidas por tipo (LE e LRS) e comparadas em relação às diferenças encontradas, aplicando-se o teste não-paramétrico de Mann-Whitney.

Nesta condição, não foi encontrada diferença estatisticamente significante entre os limiares do LRF (dBNS) nas listas LE e LRS em relação à diferença do resultado do LRF e a média tonal nas orelhas direitas e esquerdas, indicando que os resultados, para ambas as orelhas, são semelhantes aplicando-se a lista LE ou LRS, conforme a tabela 10 . 
Tabela 10. Média dos resultados do $\mathrm{LRF}$, em dBNS, para as variáveis lista, LE e LRS, orelha avaliada e faixa etária verificado pelo teste $U$ de Mann-Whitney adotando-se o índice de significância menor que $p=0,05$. Os valores em parênteses indicam o desvio-padrão e abaixo os valores da mediana

\begin{tabular}{|c|c|c|c|c|c|c|}
\hline \multirow[b]{3}{*}{$\begin{array}{l}\text { Lista de } \\
\text { palavras }\end{array}$} & \multicolumn{2}{|c|}{5 anos } & \multicolumn{2}{|c|}{6 anos } & \multicolumn{2}{|c|}{7 anos } \\
\hline & \multicolumn{2}{|c|}{$\begin{array}{l}\text { Média do LRF } \\
\text { (dp) }\end{array}$} & \multicolumn{2}{|c|}{$\begin{array}{l}\text { Média do LRF } \\
\text { (dp) }\end{array}$} & \multicolumn{2}{|c|}{$\begin{array}{c}\text { Média do LRF } \\
\text { (dp) }\end{array}$} \\
\hline & LE & LRS & LE & LRS & LE & LRS \\
\hline OD & $\begin{array}{c}4,1 \\
(3,9) \\
5,0\end{array}$ & $\begin{array}{c}4,0 \\
(4,9) \\
5,0\end{array}$ & $\begin{array}{c}4,1 \\
(3,9) \\
5,0\end{array}$ & $\begin{array}{c}4,9 \\
(4,4) \\
5,0\end{array}$ & $\begin{array}{c}5,2 \\
(4,7) \\
5,0\end{array}$ & $\begin{array}{c}3,7 \\
(4,5) \\
5,0\end{array}$ \\
\hline Teste $\mathbf{U}$ & & & & & & \\
\hline $\mathbf{O E}$ & $\begin{array}{c}3,2 \\
(6,0) \\
4,0\end{array}$ & $\begin{array}{c}2,4 \\
(5,3) \\
3,0\end{array}$ & $\begin{array}{c}5,0 \\
(3,5) \\
5,0\end{array}$ & $\begin{array}{c}5,9 \\
(5,4) \\
7,0\end{array}$ & $\begin{array}{c}5,1 \\
(4,0) \\
5,0\end{array}$ & $\begin{array}{c}5,0 \\
(4,0) \\
5,0\end{array}$ \\
\hline Teste U & & & & & & \\
\hline
\end{tabular}

Apesar dos resultados gerais terem sido não significativos em suas relações de idade, orelha e lista, observa-se ligeira tendência de valores mais baixos no LRF, para o grupo de 5 anos, na OE. Mas, também se observa uma tendência de maior variabilidade nas respostas nesse grupo do que no grupo de crianças de 6 e 7 anos. 


\subsection{Análise Comparativa entre as Faixas Etárias no Desempenho dos Sujeitos para as Listas LE e LRS e orelha avaliada.}

Para a avaliação comparativa do desempenho dos sujeitos entre as três faixas etárias estudadas em relação às listas e às orelhas foi aplicada a Prova de Kruskal-Wallis.

Tabela 11. Médias dos resultados do LRF em dBNS para as variáveis lista LE, faixa etária e orelha avaliada verificada pela Prova de Kruskal-Wallis. Adotando-se o índice de significância menor que $\mathrm{p}=0,05$. Os valores em parênteses indicam o desvio-padrão

\begin{tabular}{|c|c|c|c|}
\hline & 5 anos & 6 anos & 7 anos \\
\hline & $\begin{array}{l}\text { Média do LRF } \\
\text { (dp) }\end{array}$ & $\begin{array}{l}\text { Média do LRF } \\
\text { (dp) }\end{array}$ & $\begin{array}{l}\text { Média do LRF } \\
\text { (dp) }\end{array}$ \\
\hline $\begin{array}{c}\text { Diferença do } \\
\text { LRF (LE) e } \\
\text { a média tonal } \\
\text { OD }\end{array}$ & $4,5(4,1)$ & $4,1(3,9)$ & $5,2(4,7)$ \\
\hline Teste U & & $\mathrm{p}=0,618$ & \\
\hline $\begin{array}{l}\text { Diferença do } \\
\text { LRF (LE) e } \\
\text { a média tonal } \\
\text { OE }\end{array}$ & $3,9(6,0)$ & $4,9(4,4)$ & $5,1(4,0)$ \\
\hline Teste $\mathbf{U}$ & & $\mathrm{p}=0,751$ & \\
\hline
\end{tabular}


Tabela 12. Média dos resultados do LRF em dBNS para as variáveis lista LRS, faixa etária e orelha avaliada verificado pela Prova de Kruskal-Wallis para LRS na OD. Houve diferença estatisticamente significante do desempenho entre os sujeitos na LRS na OE. Adotou-se o índice de significância menor que p=0,05. Os valores em parênteses indicam o desvio-padrão

\begin{tabular}{|c|c|c|c|}
\hline & 5 anos & 6 anos & 7 anos \\
\hline & $\begin{array}{l}\text { Média do LRF } \\
\text { (dp) }\end{array}$ & $\begin{array}{l}\text { Média do LRF } \\
\text { (dp) }\end{array}$ & $\begin{array}{l}\text { Média do LRF } \\
\text { (dp) }\end{array}$ \\
\hline $\begin{array}{l}\text { Diferença do } \\
\text { LRF (LRS) e a } \\
\text { média tonal } \\
\text { OD }\end{array}$ & $4,0(4,9)$ & $5,0(3,5)$ & $3,7(4,5)$ \\
\hline Teste U & & $\mathrm{P}=0,588$ & \\
\hline $\begin{array}{l}\text { Diferença do } \\
\text { LRF (LRS) e a } \\
\text { média tonal } \\
\text { OE }\end{array}$ & $2,4(5,3)^{*}$ & $5,9(5,4)$ & $5,0(4,0)$ \\
\hline Teste U & & $p=0,024 *$ & \\
\hline
\end{tabular}

Prova de Kruskal-Wallis: $p=0,024 *(5$ anos $\neq 6$ anos $)$

Nas listas LE na OD ( $\mathrm{p}=0,618)$ e na $\mathrm{OE}(\mathrm{p}=0751)$ não foram encontradas diferenças significantes entre os grupos etários em relação à diferença do resultado do LRF da lista LE e a média tonal, conforme a tabela 11.

Nas listas LRS, na OD não foram encontradas diferença estatisticamente significante entre os grupos etários em relação à diferença do resultado do LRF da lista LRS e a média tonal $(\mathrm{p}=0,588)$, conforme a tabela 12 .

Somente na lista LRS, na OE, foram encontradas diferenças estatisticamente significantes entre os grupos etários de 5 e 6 anos em relação à diferença do resultado do LRF da lista LRS e a média tonal ( $\mathrm{p}=$ 0,024), onde o grupo de crianças de 5 anos apresentou LRFs 
significantemente menores do que o grupo de crianças de 6 anos. $\mathrm{O}$ grupo de 5 anos apresentou diferenças menores devido alguns sujeitos com valores de LRF mais baixos que a média geral do seu grupo. Tais achados serão apresentados de modo mais individualizado no item 4.8.

\subsection{Análise do Efeito de Ordem de Aplicação das Listas LE e LRS nas Orelhas para todas as Faixas Etárias.}

Com o objetivo de verificar a existência de diferenças no desempenho das faixas etárias, para cada lista proposta, segundo a ordem de apresentação, foi aplicada a prova de Mann-Whitney, conforme a tabela 13. 
Tabela 13. Média dos resultados do LRF, em dBNS, para as variáveis ordem de aplicação das listas LE e LRS, orelha e faixa etária verificado pelo teste $U$ de Mann-Whitney adotando-se o índice de significância menor que $\mathbf{p = 0 , 0 5}$. Os valores em parênteses indicam o desvio-padrão

\begin{tabular}{|c|c|c|c|c|c|c|}
\hline & \multicolumn{2}{|c|}{5 anos } & \multicolumn{2}{|c|}{6 anos } & \multicolumn{2}{|c|}{7 anos } \\
\hline & Primeira & Segunda & Primeira & Segunda & Primeira & Segunda \\
\hline & $\begin{array}{l}\text { Média do } \\
\text { LRF } \\
\text { (dp) }\end{array}$ & $\begin{array}{c}\text { Média } \\
\text { do LRF } \\
\text { (dp) }\end{array}$ & $\begin{array}{c}\text { Média do } \\
\text { LRF } \\
\text { (dp) }\end{array}$ & $\begin{array}{c}\text { Média } \\
\text { do LRF } \\
\text { (dp) }\end{array}$ & $\begin{array}{l}\text { Média } \\
\text { do LRF } \\
\text { (dp) }\end{array}$ & $\begin{array}{c}\text { Média do } \\
\text { LRF } \\
\text { (dp) }\end{array}$ \\
\hline $\begin{array}{l}\text { Ordem de } \\
\text { aplicação } \\
\text { da LE na } \\
\text { OD }\end{array}$ & $5,1(3,7)$ & $4,0(4,4)$ & $5,5(2,4)$ & $2,8(4,6)$ & $5,0(4,5)$ & $5,4(5,0)$ \\
\hline Teste U & $\mathrm{p}=0$ & 510 & $p=($ & 164 & $\mathrm{p}=$ &, 843 \\
\hline $\begin{array}{c}\text { Ordem de } \\
\text { aplicação } \\
\text { da LE na } \\
\text { OE }\end{array}$ & $3,4(5,6)$ & $4,3(6,5)$ & $4,1(3,8)$ & $5,9(5,0)$ & $5,9(4,2)$ & $4,3(3,9)$ \\
\hline Teste U & $\mathrm{p}=0$ & 488 & $\mathrm{p}=\mathrm{c}$ & 165 & $\mathrm{p}=$ & 0,253 \\
\hline $\begin{array}{c}\text { Ordem de } \\
\text { aplicação } \\
\text { da LRS } \\
\text { na OD }\end{array}$ & $4,7(4,6)$ & $3,2(5,3)$ & $5,7(2,8)$ & $4,3(4,0)$ & $4,4(4,1)$ & $3,0(4,8)$ \\
\hline Teste U & $\mathrm{p}=0$ & 599 & $p=($ & 295 & $\mathrm{p}=$ &, 227 \\
\hline $\begin{array}{c}\text { Ordem de } \\
\text { aplicação } \\
\text { da LRS } \\
\text { na OE }\end{array}$ & $2,7(5,6)$ & $2,1(5,1)$ & $5,4(5,8)$ & $6,4(5,2)$ & $5,3(4,5)$ & $4,7(3,5)$ \\
\hline Teste U & $\mathrm{p}=($ & ,94 & $p=($ & 478 & $\mathrm{p}=$ &, 455 \\
\hline
\end{tabular}


Não foi encontrada diferença estatisticamente significante no efeito de ordem de aplicação, na diferença do resultado do LRF e na média tonal, para todas as orelhas e listas, indicando que nas orelhas direita e esquerda, os resultados são semelhantes aplicando-se a lista LE ou LRS em primeiro ou em segundo lugar, mostrando que não houve efeito de aprendizagem ou outro efeito temporal.

\subsection{Análise do Desempenho dos Sujeitos por Faixa Etária em Relação à Lista e Orelha Avaliada em Relação ao Sexo}

Com o objetivo de verificar a existência de diferenças no desempenho das faixas etárias, em relação ao sexo, foi aplicada a prova de Mann-Whitney. Na tabela 14 são apresentados os resultados para todas as faixas etárias, e relação à lista LE e LRS e a orelha avaliada. 
Tabela 14. Média dos resultados do LRF em dBNS para as variáveis sexo, listas LE e LRS e faixa etária verificado pelo teste $U$ de Mann-Whitney

\begin{tabular}{|c|c|c|c|c|c|c|c|c|c|c|c|c|}
\hline & \multicolumn{4}{|c|}{5 anos } & \multicolumn{4}{|c|}{6 anos } & \multicolumn{4}{|c|}{7 anos } \\
\hline & \multicolumn{2}{|c|}{$\mathbf{L E}$} & \multicolumn{2}{|c|}{ LRS } & \multicolumn{2}{|c|}{$\mathbf{L E}$} & \multicolumn{2}{|c|}{ LRS } & \multicolumn{2}{|c|}{ LE } & \multicolumn{2}{|c|}{ LRS } \\
\hline & FEM & MASC & FEM & MASC & FEM & MASC & FEM & MASC & FEM & MASC & FEM & MASC \\
\hline OD & $\begin{array}{c}5,0 \\
(4,3)\end{array}$ & $\begin{array}{c}3,9 \\
(3,8)\end{array}$ & $\begin{array}{c}3,9 \\
(4,5)\end{array}$ & $\begin{array}{c}4,1 \\
(5,5)\end{array}$ & $\begin{array}{c}4,2 \\
(4,5)\end{array}$ & $\begin{array}{c}3,9 \\
(3,4)\end{array}$ & $\begin{array}{c}6,1 \\
(3,1)\end{array}$ & $\begin{array}{c}4,1 \\
(3,6)\end{array}$ & $\begin{array}{c}4,1 \\
(4,9)\end{array}$ & $\begin{array}{c}7,3 \\
(3,5)\end{array}$ & $\begin{array}{c}3,6 \\
(4,1)\end{array}$ & $\begin{array}{c}4,0 \\
(5,3)\end{array}$ \\
\hline Teste $\mathbf{U}$ & &, 456 & &, 792 & &, 604 & & 0,121 & &, 106 & & 908 \\
\hline $\mathbf{O E}$ & $\begin{array}{c}3,6 \\
(6,2)\end{array}$ & $\begin{array}{c}4,1 \\
(5,9)\end{array}$ & $\begin{array}{c}0,5 \\
(6,0)\end{array}$ & $\begin{array}{c}4,5 \\
(3,4)\end{array}$ & $\begin{array}{c}4,6 \\
(4,4)\end{array}$ & $\begin{array}{c}5,2 \\
(4,5)\end{array}$ & $\begin{array}{c}5,5 \\
(5,7)\end{array}$ & $\begin{array}{c}6,2 \\
(5,3)\end{array}$ & $\begin{array}{c}4,3 \\
(4,1)\end{array}$ & $\begin{array}{c}6,6 \\
(3,6)\end{array}$ & $\begin{array}{c}4,3 \\
(4,1)\end{array}$ & $\begin{array}{c}6,3 \\
(3,6)\end{array}$ \\
\hline Teste $\mathbf{U}$ & &, 870 & $\mathrm{p}=0$ & $028 *$ & &, 731 & & 0,954 & &, 152 & & 239 \\
\hline
\end{tabular}

$\mathrm{p}=0,028 * \mathrm{p}<0,05$ 
Nas faixas etárias de 6 e 7 anos não foram encontradas diferenças estatisticamente significantes, na aplicação das listas LE, entre os sexos masculino e feminino, em relação à diferença do resultado do limiar do LRF e dos limiares das médias tonais nas orelhas direita e esquerda, indicando que ambas apresentam resultados semelhantes entre os sexos. Na faixa etária de 5 anos foi encontrada diferença estatisticamente significante, somente na situação de aplicação da lista LRS, na OE. Esses resultados com limiares de LRF baixos nesta condição, já haviam sido evidenciados na tabela 12 entre as faixas etárias de 5 e 6 anos.

\subsection{Distribuição dos Resultados do LRF (dBNS) para a lista LE e LRS em Relação ao Total de Orelhas nas Faixas Etárias.}

A figura 1 mostra a distribuição de todos os resultados obtidos no LRF (dBNS) em relação ao total de orelhas avaliadas nas três faixas etárias para a lista LE e a figura 2 para a lista LRS. 


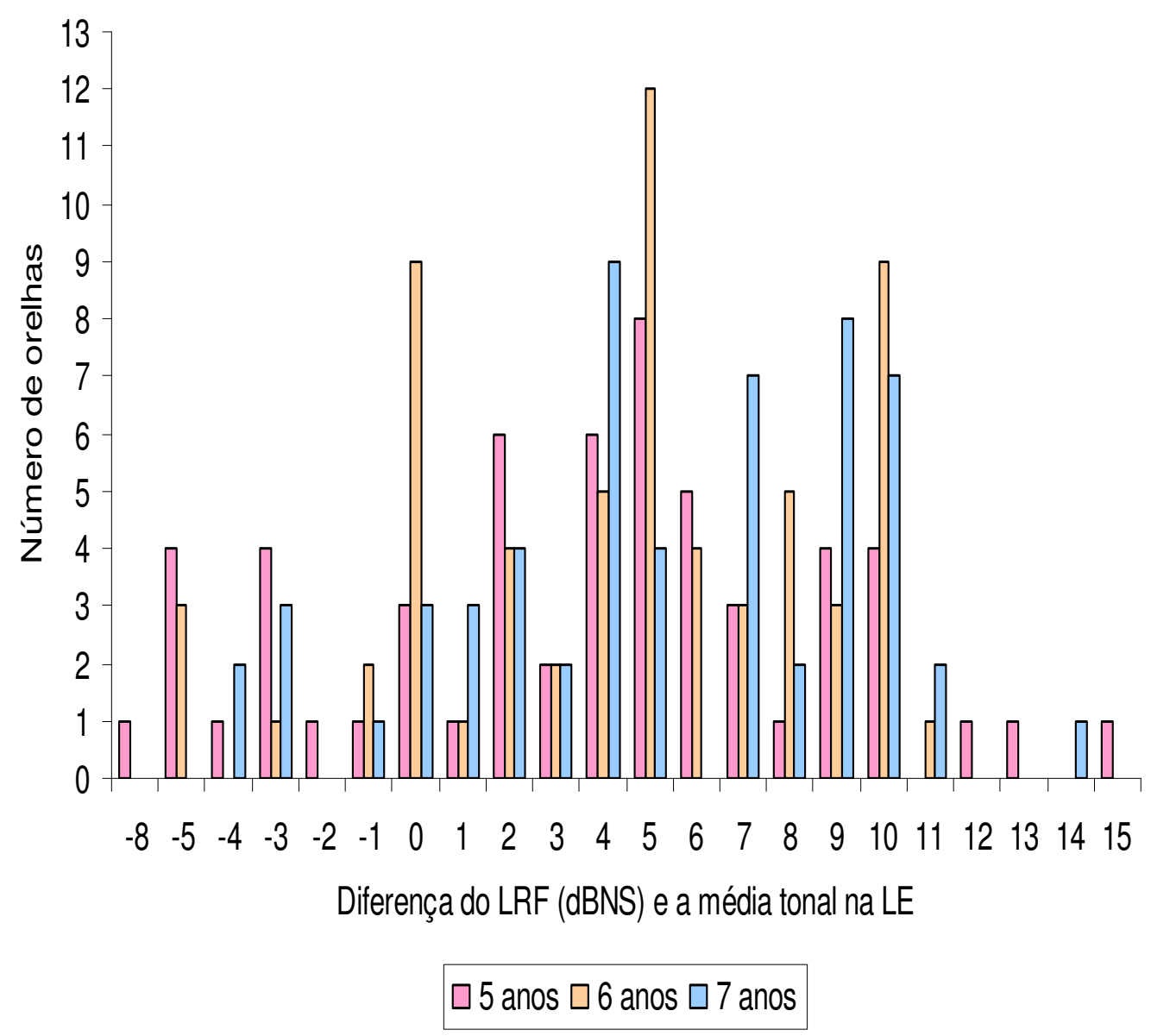

Figura 1. Resultados do LRF (dBNS) em relação ao número total de orelhas avaliadas nas três faixas etárias para a lista $\mathbf{L E}$

Na figura 1 observa-se a distribuição dos resultados do LRF (dBNS) e relação ao número total de orelhas avaliadas nas três faixas etárias para a lista LE. Os resultados variaram entre -8 e 15 dBNS. 


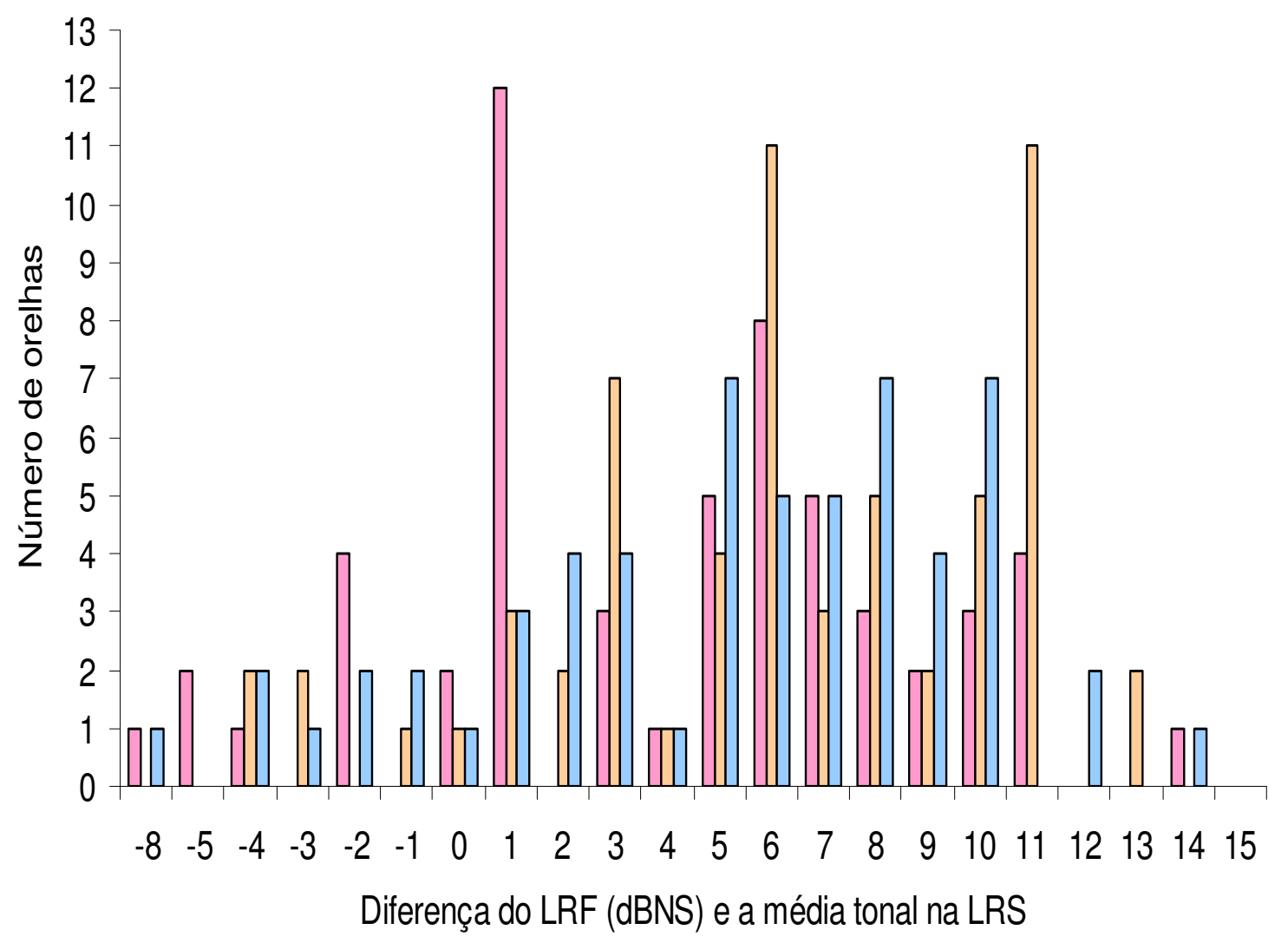

$\square 5$ anos $\square 6$ anos $\square 7$ anos

Figura 2. Resultados do LRF (dBNS) em relação ao número total de orelhas avaliadas nas três faixas etárias a lista LRS

Na figura 2 observa-se a distribuição dos resultados do LRF (dBNS) em relação ao número total de orelhas avaliadas nas três faixas etárias para a lista LRS. Os resultados variaram entre -10 e 14dBNS. A partir dos dados obtidos nesta figura estabeleceu-se que os valores abaixo de OdBNS e acima de 10dBNS seriam considerados fora dos resultados esperados de acordo com a literatura. 
Na tabela 15 estão os valores de correlação entre os resultados de LRF (dBNA) e os valores da média tonal indicando que a tendência do LRF maior está associado a médias tonais maiores com correlação estatisticamente significante para as três faixas etárias, tanto para as listas LE como para as listas LRS e também em relação às orelhas direitas e esquerdas.

Tabela 15. Correlação entre a média tonal e o LRF (dBNA) para as variáveis faixa etária, lista e orelha avaliada

\begin{tabular}{c|c|c|c|c|c|c} 
& \multicolumn{2}{|c|}{5 anos } & \multicolumn{2}{c|}{6 anos } & \multicolumn{2}{c}{7 anos } \\
\hline & $\mathbf{L E}$ & $\mathbf{L R S}$ & $\mathbf{L E}$ & $\mathbf{L R S}$ & $\mathbf{L E}$ & $\mathbf{L R S}$ \\
\hline $\mathrm{O}$ & $\mathrm{r}=0,71$ & $\mathrm{r}=0,86$ & $\mathrm{r}=0,70$ & $\mathrm{r}=0,67$ & $\mathrm{r}=0,49$ & $\mathbf{r}=\mathbf{0 , 5 7}$ \\
$\mathrm{D}$ & $\mathbf{p}<\mathbf{0 , 0 0 1} *$ & $\mathbf{p}<\mathbf{0 , 0 0 1}$ & $\mathbf{p}<\mathbf{0 , 0 0 1} *$ & $\mathbf{p}<\mathbf{0 , 0 0 1} *$ & $\mathbf{p}=\mathbf{0 , 0 0 7} *$ & $\mathrm{p}=0,001^{*}$ \\
& & & & & & \\
\hline $\mathrm{O}$ & $\mathrm{r}=0,54$ & $\mathrm{r}=0,48$ & $\mathrm{r}=0,57$ & $\mathrm{r}=0,54$ & $\mathrm{r}=0,60$ & $\mathbf{r}=\mathbf{0 , 6 7}$ \\
$\mathrm{E}$ & $\mathbf{p}=\mathbf{0 , 0 0 1}$ & $\mathbf{p}=\mathbf{0 , 0 0 9}$ & $\mathbf{p}=\mathbf{0 , 0 0 1} *$ & $\mathbf{p}=\mathbf{0 , 0 0 2} *$ & $\mathbf{p}=\mathbf{0 , 0 0 1} *$ & $\mathrm{p}<0,001^{*}$ \\
& & & & & \\
\hline
\end{tabular}

A correlação da média tonal e do LRF situou-se entre $\Gamma=0,86$ e 0,71 para $\mathrm{OD}$ e entre $\Gamma=0,48$ e 0,54 para $\mathrm{OE}$ na faixa etária de 5 anos, com média de 0,785 na OD e 0,510 na OE.

A correlação para os sujeitos de 6 anos situou-se entre $\Gamma=0,70$ e 0,67 para OD e entre $\Gamma=0,57$ e 0,54 para OE , com média de 0,685 na OD e 0,555 na OE.

A correlação para os sujeitos de 7 anos situou-se entre $\Gamma=0,57$ e 0,49 para OD e entre $\Gamma=0,57$ e 0,54 para $\mathrm{OE}$, com média de 0,530 na OD e 0,635 na OE. 


\subsection{Análise do Desempenho Individual dos Sujeitos em Relação ao Resultado do LRF (dBNS) em Cada Faixa Etária}

A seguir, será avaliado o desempenho dos sujeitos, de modo mais individualizado, em cada faixa etária a partir da análise dos resultados do LRF, em especial, o desempenho dos sujeitos do grupo etário de 5 anos, que apresentaram valores de LRF menores que os sujeitos de 6 e 7 anos em várias situações analisadas.

No anexo 10 (A e B) estão apresentados os resultados obtidos em relação à idade, o sexo, os valores da média tonal dos limiares de $500 \mathrm{~Hz}, 1000 \mathrm{~Hz}$ e $2000 \mathrm{~Hz}$ em dBNA para orelha direita (OD) e esquerda (OE) e os valores do LRF em dBNS para as listas LE1, LE2, LRS1 e LRS2 no grupo etário de 5 anos.

Os resultados demonstraram variabilidade do LRF em dBNS entre valores negativos a positivos, de -10 a 15 dBNS (figura $1 \mathrm{e}$ 2).

Os valores negativos indicam que as crianças, nesta situação, apresentaram resultados do LRF (dBNA) menores do que a média tonal. Tais achados são observados nos sujeitos 10, 11, 12, 13, 15, $18,19,20$ e 28 , conforme a tabela 16 . 
Tabela 16. Resultados dos sujeitos que obtiveram valores do LRF (dBNS) negativos em, pelo menos, uma das apresentações na LE ou LRS para a faixa etária de 5 anos.

\begin{tabular}{c|c|c|c|c|c|c} 
& \multicolumn{2}{|c|}{ LRF LE } & \multicolumn{2}{c|}{ LRF LRS } & \multicolumn{2}{c}{ MÉDIA TONAL } \\
\hline Sujeito & $\begin{array}{c}\text { OD } \\
\text { (dBNS) }\end{array}$ & $\begin{array}{c}\text { OE } \\
(\mathbf{d B N S})\end{array}$ & $\begin{array}{c}\text { OD } \\
(\mathbf{d B N S})\end{array}$ & $\begin{array}{c}\text { OE } \\
(\mathbf{d B N S})\end{array}$ & $\begin{array}{c}\text { OD } \\
\text { (dBNA) }\end{array}$ & $\begin{array}{c}\text { OE } \\
(\mathbf{d B N A})\end{array}$ \\
\hline 10 & -2 & -4 & -3 & -3 & 5 & 5 \\
\hline 11 & 0 & -5 & 0 & -8 & 0 & 10 \\
\hline 12 & 0 & -3 & 6 & -5 & 0 & 5 \\
\hline 13 & 3 & -1 & -1 & -3 & 5 & 10 \\
\hline 15 & -3 & -5 & -8 & 0 & 15 & 5 \\
\hline 18 & 4 & -8 & 0 & -10 & 10 & 10 \\
\hline 19 & -3 & 2 & 0 & 2 & 10 & 10 \\
\hline 20 & -3 & -5 & -3 & 5 & 5 & 5 \\
\hline 28 & 2 & -5 & 0 & -1 & 5 & 10 \\
\hline
\end{tabular}

Nos sujeitos 11, 12, 13 e 28 observa-se que há um aumento da média tonal na $\mathrm{OE}$ em relação à média tonal da $\mathrm{OD}$, o que pode estar relacionado com o aparecimento de valores negativos no LRF (dBNS), isto é, o LRF (NA) obtido foi menor que a média tonal, sendo que a OE foi sempre a segunda orelha avaliada na medida do limiar tonal. Tal relação também foi observada no sujeito 15 em relação à OD com valor de média tonal maior que a $\mathrm{OE}$. Nos sujeitos 10 e 21 não há diferenças entre as médias tonais, mas há resultados de LRF (dBNS) também negativos.

Para o sujeito 18 observou-se um desempenho, com limares altos na primeira lista aplicada (LE na OD: 14dB) e com diminuição dos limiares à medida que as listas foram sendo apresentadas, como para ODLRS (10dB), OELE (2dB) e OELRS (0 dB)NA. Não sendo esta relação observada nos demais sujeitos. 
Tabela 17. Média dos resultados entre os sujeitos que obtiveram valores de LRF positivos e maiores que 10dBNS em, pelo menos, uma das apresentações na LE ou LRS para a faixa etária de 5 anos

\begin{tabular}{c|c|c|c|c|c|c} 
& \multicolumn{2}{|c|}{ LRF LE } & \multicolumn{2}{c|}{ LRF LRS } & \multicolumn{2}{c}{ MÉDIA TONAL } \\
\hline Sujeito & $\begin{array}{c}\text { OD } \\
(\mathbf{d B N S})\end{array}$ & $\begin{array}{c}\text { OE } \\
(\mathbf{d B N S})\end{array}$ & $\begin{array}{c}\text { OD } \\
(\mathbf{d B N S})\end{array}$ & $\begin{array}{c}\text { OD } \\
(\mathbf{d B N S})\end{array}$ & $\begin{array}{c}\text { OD } \\
\text { (dBNA) }\end{array}$ & $\begin{array}{c}\text { OE } \\
(\mathbf{d B N A})\end{array}$ \\
\hline 5 & 9 & 13 & 9 & 9 & 5 & 5 \\
\hline 14 & 6 & 12 & 7 & 5 & 10 & 10 \\
\hline 23 & 5 & 10 & 10 & 13 & 10 & 10 \\
\hline 33 & 10 & 15 & 15 & 10 & 10 & 15 \\
\hline
\end{tabular}

Os sujeitos 5, 14, 23 e 33 apresentaram valores maiores que 10dBNS conforme tabela 17. Com exceção do sujeito 33 , todos os demais apresentarem valores maiores de LRF (NS) na OE, em especial, para a lista LE.

Todos os outros sujeitos, deste grupo de 5 anos, apresentaram valores de LRF, em dBNS, entre 0 e 10dBNS.

$\mathrm{Na}$ OD o valor de LRF muito baixo (negativos) como -8, aparece com a média tonal em 15dBNA. No caso da OE, o valor de LRF muito baixo, como -5 a -10 , aparece com a média tonal em 10dBNA, conforme figura 3 e 4 .

Os resultados destes sujeitos (valores de LRF muito baixos) provocaram o aparecimento de relações de significância no grupo e entre grupos como na avaliação dos itens 4.4 e 4.6 . 


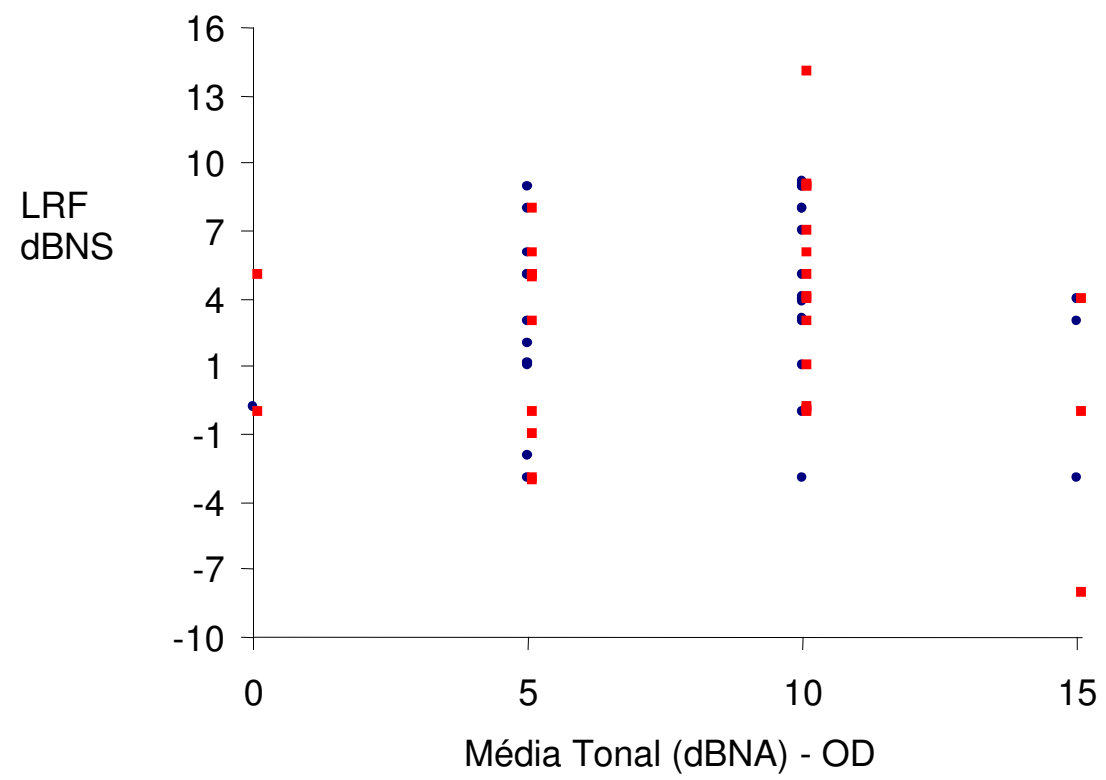

Figura 3 - Dispersão entre média tonal e as diferenças entre o resultado da aplicação da LRF ( $\bullet$ LE e $\bullet$ LRS) para orelhas direitas dos sujeitos do grupo etário de 5 anos

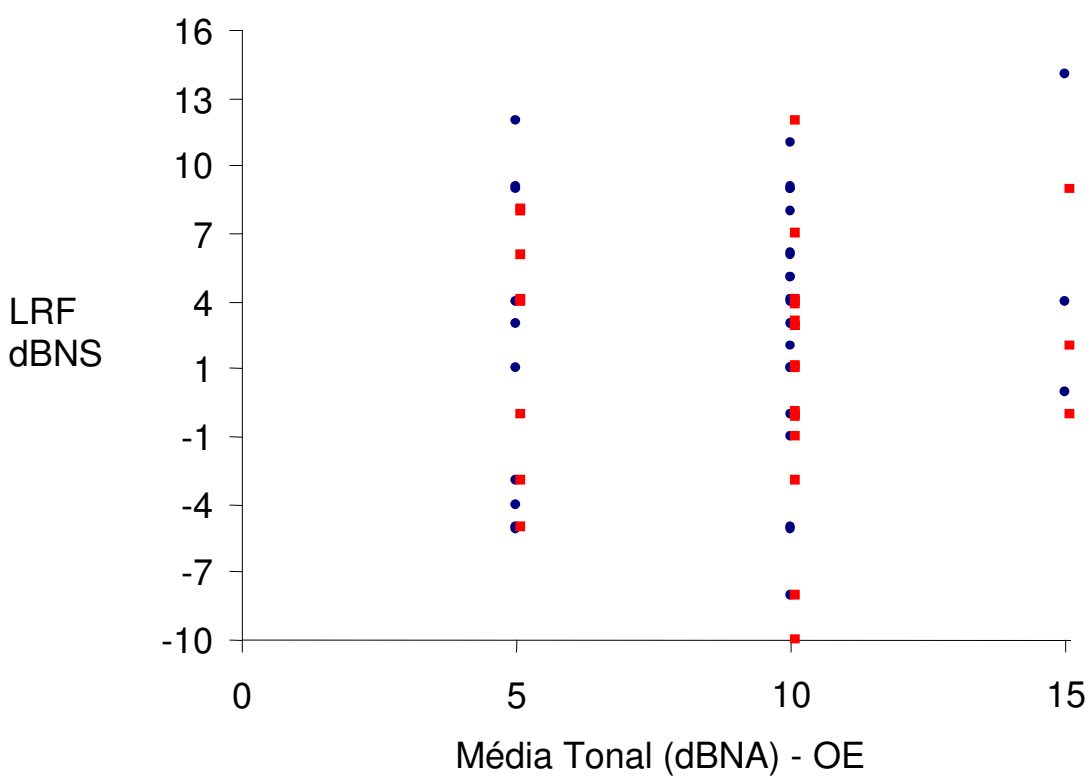

Figura 4 - Dispersão entre média tonal e as diferenças entre o resultado da aplicação da LRF (• LE e $\square$ LRS) e a média tonal para orelhas esquerdas das crianças do grupo etário de 5 anos 
No anexo 11 (A e B) estão apresentados os resultados obtidos em relação à idade, o sexo, os valores da média tonal dos limiares de $500 \mathrm{~Hz}, 1000 \mathrm{~Hz}$ e $2000 \mathrm{~Hz}$ em dBNA para orelha direita (OD) e esquerda (OE) e os valores do LRF em dBNS para as listas LE1, LE2, LRS1 e LRS2 no grupo etário de 6 anos.

Neste grupo, a variabilidade das respostas, tanto para os valores negativos como para aqueles maiores que $10 \mathrm{dBNS}$, é menor do que no grupo de 5 anos. Os valores negativos variaram entre -5 e $-1 \mathrm{~dB}$ (figura 1 e 2) e são encontrados com maior incidência na $\mathrm{OE}$, tanto para a lista LE como para a lista LRS, conforme apresentado na tabela 18.

Tabela 18. Média dos resultados entre os sujeitos que obtiveram valores de LRF negativos em, pelo menos, uma das apresentações na LE ou LRS no grupo etário de 6 anos

\begin{tabular}{c|c|c|c|c|c|c} 
& \multicolumn{2}{|c|}{ LE } & \multicolumn{2}{c|}{ LRS } & \multicolumn{2}{c}{ MÉDIA TONAL } \\
\hline Sujeito & $\begin{array}{c}\text { OD } \\
\text { (dBNS) }\end{array}$ & $\begin{array}{c}\text { OE } \\
\text { (dBNS) }\end{array}$ & $\begin{array}{c}\text { OD } \\
\text { (dBNS) }\end{array}$ & $\begin{array}{c}\text { OE } \\
\text { (dBNS) }\end{array}$ & $\begin{array}{c}\text { OD } \\
\text { (dBNA) }\end{array}$ & $\begin{array}{c}\text { OE } \\
\text { (dBNA) }\end{array}$ \\
\hline 1 & -5 & -1 & -5 & -1 & 10 & 15 \\
\hline 5 & 3 & -1 & 1 & -4 & 15 & 15 \\
\hline 21 & -5 & 4 & 4 & -4 & 5 & 5 \\
\hline 22 & 7 & -3 & 9 & -5 & 5 & 5 \\
\hline 23 & 5 & -5 & 5 & -2 & 10 & 10 \\
\hline
\end{tabular}

Em cinco casos, os sujeitos apresentaram valores maiores que 10dBNS como nos sujeitos 6, 16, 18, 27 e 29, somente na condição da LRS na OE, com exceção do sujeito 6 que apresentou valores maiores somente na OE na LE (11dBNS) de acordo com a tabela 19. 
Tabela 19. Média dos resultados entre os sujeitos que obtiveram valores de LRF positivos e maiores que 10dBNS em, pelo menos, uma das apresentações para LE ou LRS no grupo etário de 6 anos

\begin{tabular}{c|c|c|c|c|c|c} 
& \multicolumn{2}{|c|}{ LE } & \multicolumn{2}{c|}{ LRS } & \multicolumn{2}{c}{ MÉDIA TONAL } \\
\hline Sujeito & $\begin{array}{c}\text { OD } \\
\text { (dBNS) }\end{array}$ & $\begin{array}{c}\text { OE } \\
\text { (dBNS) }\end{array}$ & $\begin{array}{c}\text { OD } \\
\text { (dBNS) }\end{array}$ & $\begin{array}{c}\text { OE } \\
\text { (dBNS) }\end{array}$ & $\begin{array}{c}\text { OD } \\
\text { (dBNA) }\end{array}$ & $\begin{array}{c}\text { OE } \\
\text { (dBNA) }\end{array}$ \\
\hline 6 & 4 & 11 & 2 & 7 & 10 & 5 \\
\hline 16 & 0 & 10 & 10 & 15 & 15 & 10 \\
\hline 18 & 5 & 10 & 5 & 15 & 10 & 10 \\
\hline 27 & 0 & 10 & 2 & 12 & 10 & 5 \\
\hline 29 & 8 & 10 & 8 & 12 & 5 & 5 \\
\hline
\end{tabular}

Com exceção dos sujeitos acima, todos os outros deste grupo, apresentaram valores de LRF em dBNS entre 0 e 10dBNS. Na OD os valores de LRF muito baixo (negativos) como $-5 \mathrm{~dB}$, estão relacionados com a média tonal em 10dBNA, onde há somente 3 ocorrências. Na OE, os valores de LRF muito baixo, como -5 a -1dBNS, estão distribuídos por todas as médias tonais, conforme figura 5 e 6 . De qualquer modo, neste grupo há menor ocorrência de valores negativos e conseqüentemente menor variabilidade quando comparado ao grupo de 5 anos. 


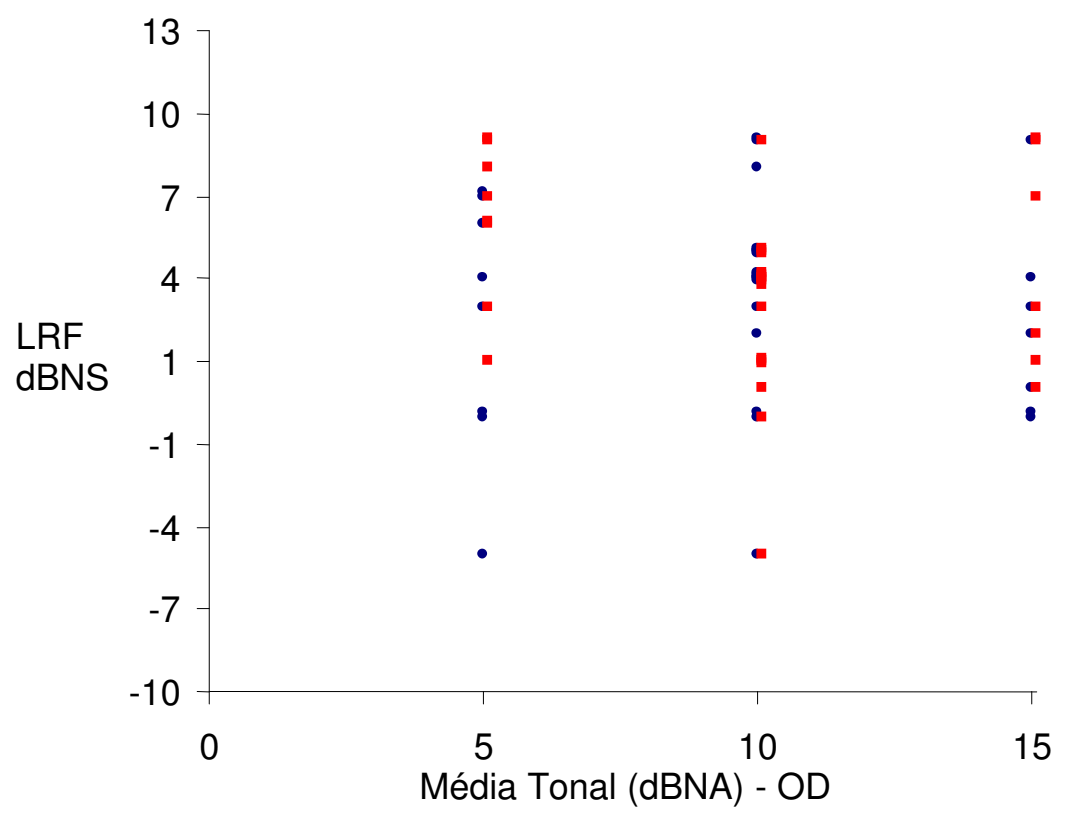

Figura 5 - Dispersão entre média tonal e as diferenças entre o resultado da aplicação da LRF (• LE e — LRS) para orelhas direitas das crianças do grupo etário de 6 anos

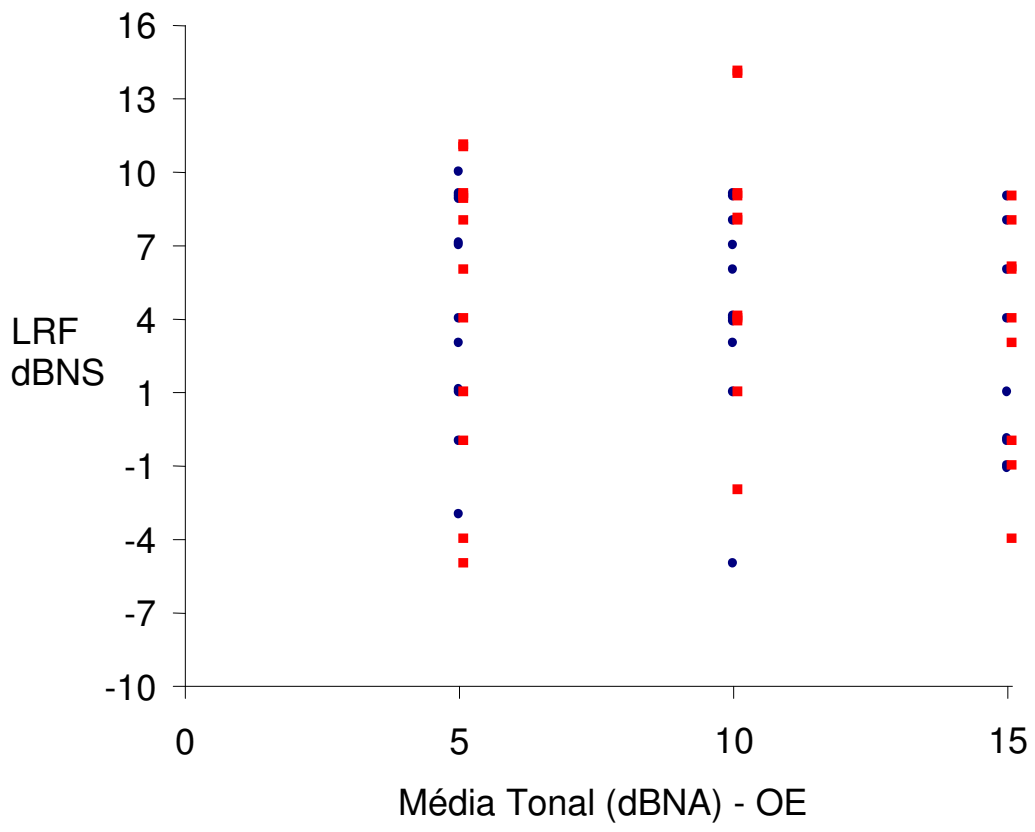

Figura 6 - Dispersão entre média tonal e as diferenças entre o resultado da aplicação da LRF (• LE e $\bullet$ LRS) para orelhas esquerdas das crianças do grupo etário de 6 anos 
No anexo 12 (A e B) estão apresentados os resultados obtidos em relação à idade, o sexo, os valores da média tonal dos limiares de $500 \mathrm{~Hz}, 1000 \mathrm{~Hz}$ e $2000 \mathrm{~Hz}$ em dBNA para orelha direita (OD) e esquerda (OE) e os valores do LRF em dBNS para as listas LE1, LE2, LRS1 e LRS2 no grupo etário de 7 anos.

Os resultados obtidos demonstraram variabilidade do LRF em dBNS entre valores negativos e positivos de -5 a $14 \mathrm{dBNS}$. Tais achados são observados nos sujeitos 9,11, 17, 23, 24, 25, 28 e 29. Todos os sujeitos apresentaram diferenças entre -1 e -5dBNS, e mesmo havendo valores negativos essa diferença em relação ao LRF é menor do que nas crianças de 5, tanto na lista LE como na LRS, conforme a tabela 20.

Tabela 20. Média dos resultados entre os sujeitos que obtiveram valores de LRF negativos em, pelo menos, uma das apresentações na LE ou LRS no grupo etário de 7 anos.

\begin{tabular}{c|c|c|c|c|c|c} 
& \multicolumn{2}{|c|}{ LE } & \multicolumn{2}{c|}{ LRS } & \multicolumn{2}{c}{ MÉDIA TONAL } \\
\hline Sujeito & $\begin{array}{c}\text { OD } \\
\text { (dBNS) }\end{array}$ & $\begin{array}{c}\text { OE } \\
\text { (dBNS) }\end{array}$ & $\begin{array}{c}\text { OD } \\
\text { (dBNS) }\end{array}$ & $\begin{array}{c}\text { OE } \\
\text { (dBNS) }\end{array}$ & $\begin{array}{c}\text { OD } \\
\text { (dBNA) }\end{array}$ & $\begin{array}{c}\text { OE } \\
\text { (dBNA) }\end{array}$ \\
\hline 9 & -3 & -3 & -3 & -5 & 10 & 10 \\
\hline 11 & 4 & 1 & 1 & -1 & 10 & 15 \\
\hline 17 & 7 & 10 & -5 & 7 & 5 & 0 \\
\hline 23 & 2 & 1 & -2 & -2 & 10 & 10 \\
\hline 24 & 10 & 10 & 5 & -5 & 5 & 0 \\
\hline 25 & 3 & 4 & -3 & -4 & 5 & 10 \\
\hline 28 & -3 & 0 & 1 & 1 & 10 & 10 \\
\hline 29 & -4 & 2 & -4 & 0 & 5 & 10 \\
\hline
\end{tabular}

Os sujeitos que apresentaram valores negativos o fizeram na lista LRS, com exceção do sujeito 9 que apresentou valores negativos em ambas orelhas e listas. E ainda, o sujeito 28 e 29 que apresentou valores negativos somente na condição OD na LE e LRS. 
Em dois casos, os sujeitos apresentaram valores maiores que 10dBNS, como nos sujeitos 3 e 19. Nesta situação, também, ocorreu menor incidência de casos que nos grupos anteriores, conforme a tabela 21.

Tabela 21. Média dos resultados entre os sujeitos que obtiveram valores de LRF positivos e maiores que 10dBNS em, pelo menos, uma das apresentações na LE ou LRS

\begin{tabular}{c|c|c|c|c|c|c} 
& \multicolumn{2}{|c|}{ LE } & \multicolumn{2}{c|}{ LRS } & \multicolumn{2}{c}{ MÉDIA TONAL } \\
\hline Sujeito & $\begin{array}{c}\text { OD } \\
\text { (dBNS) }\end{array}$ & $\begin{array}{c}\text { OE } \\
\text { (dBNS) }\end{array}$ & $\begin{array}{c}\text { OD } \\
\text { (dBNS) }\end{array}$ & $\begin{array}{c}\text { OE } \\
\text { (dBNS) }\end{array}$ & $\begin{array}{c}\text { OD } \\
\text { (dBNA) }\end{array}$ & $\begin{array}{c}\text { OE } \\
\text { (dBNA) }\end{array}$ \\
\hline 3 & 11 & 11 & 8 & 11 & 5 & 10 \\
\hline 19 & 14 & 9 & 13 & 11 & 5 & 5 \\
\hline
\end{tabular}

Com exceção dos sujeitos acima, todos os outros deste grupo, apresentaram valores de LRF em dBNS entre 0 e 10dBNS. Na OD, o aparecimento de LRF muito baixo (negativos) como $-5 \mathrm{~dB}$, aparece relacionado com a média tonal de 5dBNA. Na OE, o aparecimento de LRF muito baixo, como -5dBNS, aparece relacionado a média tonal de 0 e $10 \mathrm{dbNS}$, conforme figura 7 e 8 . De qualquer modo, neste grupo há menor variabilidade quando comparado ao grupo de 5 e 6 anos. 


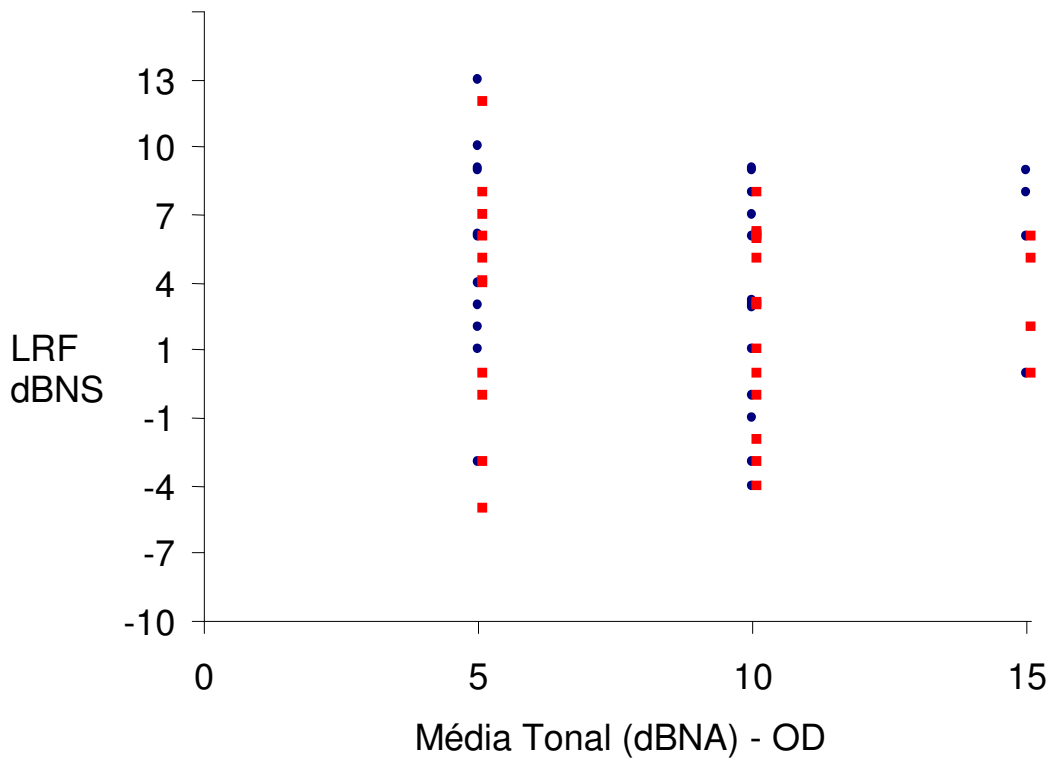

Figura 7 - Dispersão entre média tonal e as diferenças entre o resultado da aplicação da LRF (• LE e $\bullet$ LRS) para orelhas direitas das crianças do grupo etário de 7 anos

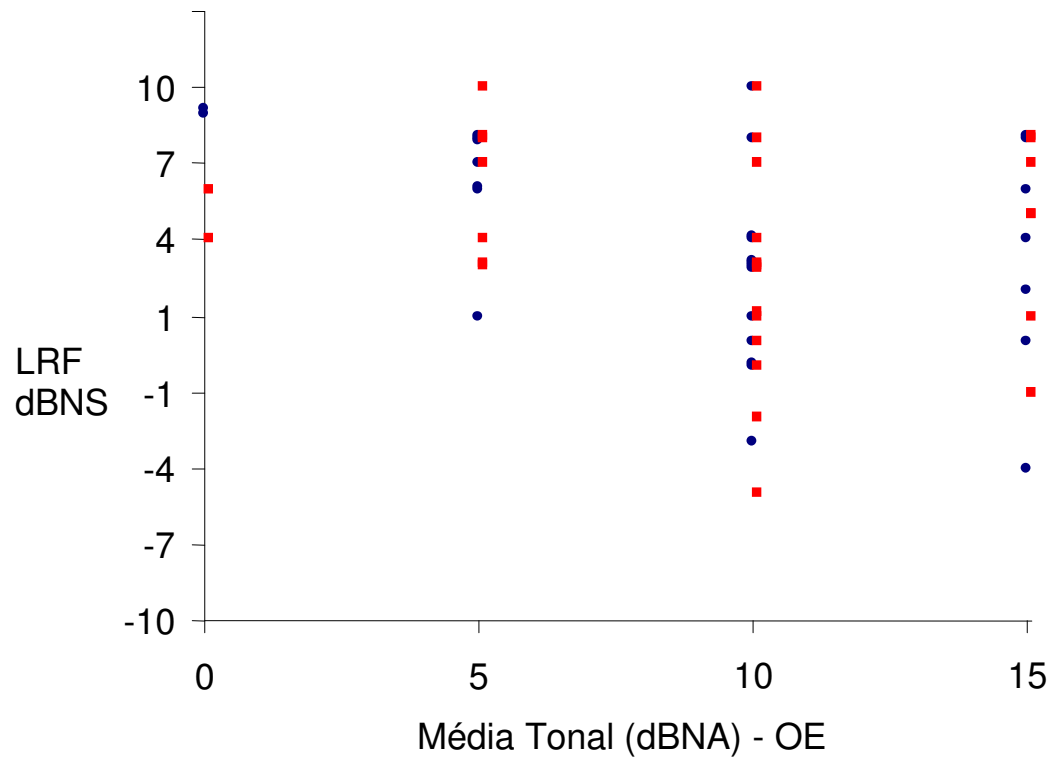

Figura 8 - Dispersão entre média tonal e as diferenças entre o resultado da aplicação da LRF (• LE e — LRS) para orelhas esquerdas das crianças do grupo etário de 7 anos 


\subsection{Avaliação Quantitativa e Qualitativa de Erros por Palavra na Lista LE1}

Na tabela 22 observa-se o número total de erros de cada palavra na lista LE, ordenadas de forma decrescente, por número de erros. Somando-se os erros totais de cada palavra, em todos os níveis de apresentação, observa-se que as palavras: idéia, menina, ainda, caminho, porteiro, primeiro, certeza, cansado, querido e vergonha apresentaram os maiores números de erros, com índices entre $54 \%$ a $30 \%$ do total, consistentemente em todas as faixas etárias.

A aplicação da lista completa foi realizada em parte dos

sujeitos da amostra total devido a problemas de cooperação, como já citado no estudo piloto. Um outro fator de interferência pode estar relacionado com a opção de aplicação das listas numa única sessão. Sendo assim, do total de 33 sujeitos de 5 anos, somente 17 (51,5\%) participaram desta fase; do total de 32 sujeitos de 6 anos, somente 20 $(62,5 \%)$ e do total de 29 sujeitos de 7 anos, somente $15(51,7 \%)$ participaram, perfazendo um total de 52 sujeitos. O total de apresentação de cada palavra é a somatória do total de apresentações, em três níveis de intensidade (à 5dBNS, à 10dBNS e à 15dBNS), em todos os sujeitos, totalizando 112 apresentações de cada palavra. 
Tabela 22. Número total dos erros, em ordem decrescente ,por item da lista experimental LE1 nos três níveis de apresentação, por faixa etária. $O$ total de erros está baseado no número total de apresentações de cada palavra

(112 vezes)

\begin{tabular}{c|c|c|c|c|c}
\hline LISTA E1 & $\mathbf{5}$ anos & $\mathbf{6}$ anos & $\mathbf{7}$ anos & \multicolumn{2}{|c}{ Total de erros } \\
\hline Idéia & 23 & 26 & 12 & 61 & 54,4 \\
Menina & 20 & 14 & 14 & 48 & 42,8 \\
Ainda & 13 & 15 & 17 & 45 & 40,1 \\
Caminho & 15 & 14 & 14 & 43 & 38,3 \\
Porteiro & 17 & 11 & 10 & 38 & 33,9 \\
Primeiro & 19 & 11 & 7 & 37 & 33,0 \\
Certeza & 15 & 12 & 10 & 37 & 33,0 \\
Cansado & 17 & 9 & 9 & 35 & 31,0 \\
Vergonha & 12 & 12 & 10 & 34 & 30,5 \\
Querido & 12 & 11 & 11 & 34 & 30,5 \\
Alguma & 10 & 7 & 14 & 31 & 27,6 \\
Socorro & 12 & 8 & 10 & 30 & 26,7 \\
Pessoas & 11 & 10 & 9 & 30 & 26,7 \\
Desculpe & 11 & 12 & 7 & 30 & 26,7 \\
Estranho & 13 & 7 & 8 & 28 & 25,0 \\
Teatro & 11 & 12 & 4 & 27 & 24,1 \\
Moeda & 6 & 8 & 13 & 27 & 24,1 \\
Pedido & 11 & 13 & 1 & 25 & 22,3 \\
Cidade & 10 & 6 & 8 & 24 & 21,3 \\
Aquela & 8 & 9 & 7 & 24 & 21,3 \\
Crianças & 8 & 6 & 9 & 23 & 20,5 \\
Verdade & 7 & 7 & 8 & 22 & 19,6 \\
Problema & 7 & 8 & 7 & 22 & 19,6 \\
Presente & 8 & 8 & 5 & 21 & 17,7 \\
Abelha & 8 & 8 & 5 & 21 & 18,7 \\
Direito & 11 & 3 & 5 & 19 & 16,9 \\
Embora & 9 & 4 & 4 & 17 & 15,1 \\
Bolinha & 4 & 7 & 6 & 17 & 15,1 \\
Sozinho & 6 & 3 & 5 & 14 & 12,5 \\
Espera & 6 & 6 & 2 & 14 & 12,5 \\
Castelo & 4 & 4 & 6 & 14 & 12,5 \\
Comigo & 4 & 5 & 4 & 13 & 11,6 \\
Amigo & 1 & 2 & 4 & 7 & 6,2 \\
Aonde & 3 & 0 & 0 & 3 & 2,6 \\
Agora & 2 & 1 & 0 & 3 & 2,6 \\
\hline Total de & $\mathbf{3 5 4}$ & $\mathbf{2 9 9}$ & $\mathbf{2 6 5}$ & $\mathbf{9 1 8}$ & \\
erros & & & & & \\
\hline & & & & & $n$ \\
\hline
\end{tabular}


Os resultados indicaram que os sujeitos de 5 anos, em geral, apresentaram maior número de erros do que os de 6 anos e estes, maior número que os sujeitos de 7 anos. Na distribuição total dos erros por item, da lista experimental LE, por faixa etária, não foi encontrada diferença estatisticamente significante entre os grupos em relação à faixa etária com $\mathrm{p}=0,119$ (coeficiente de correlação de Spearman $(\mathrm{p}<0,005))$.

A análise entre o número de erros cometidos nas palavras e a incidência das mesmas no corpus não foi estatisticamente significante $(r=-0,15 / p=0,394)$, conforme os dados da tabela 22 e o anexo 1 .

Na figura 9 estão dispostos os resultados da dispersão dos erros nas palavras e a incidência das palavras no corpus, isso que dizer que em uma palavra com incidência no corpus de 20 vezes, os erros variaram entre 20 a 60 vezes, portanto não ocorrendo relação entre a sua incidência de aparecimento no corpus e o número de erros na tarefa, somados os três níveis de intensidade de apresentação. 


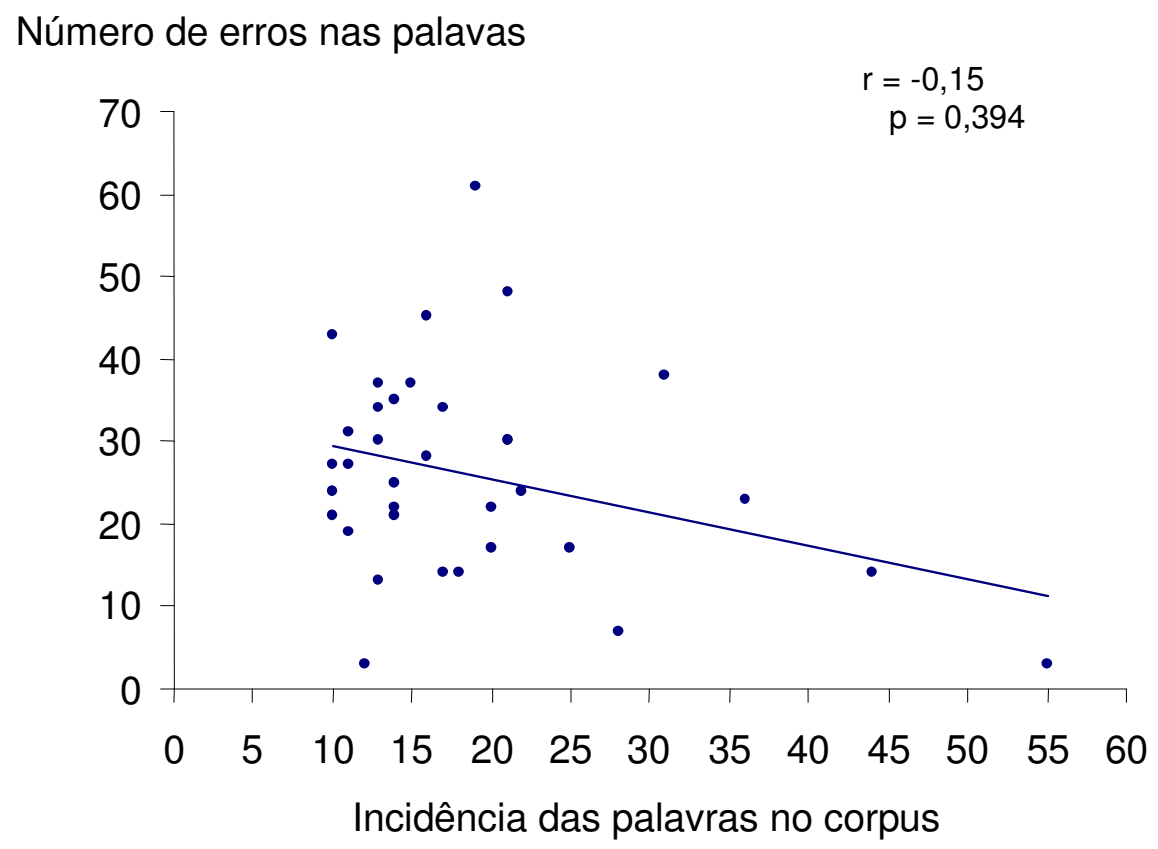

Figura 9. Gráfico de dispersão do número de erros encontrados nas palavras e incidência das palavras no corpus

No quadro 6 estão descritas as respostas dos sujeitos, para cada uma das palavras, nas três faixas etárias. Os números, à frente de alguns itens, indicam que o tipo de resposta ocorreu mais de uma vez. Na maioria das vezes, o sujeito avaliado não apresentou resposta, quando a palavra apresentada não foi reconhecida. Esta estratégia, também foi observada na própria pesquisa do LRF, com as listas LE e LRS, portanto, nesta tabela não estão computados os números de erros totais de cada palavra, apenas demonstrando o tipo de resposta quando ela ocorreu. 
Quadro 6. Descrição do tipo de resposta por palavra na LE em todas as faixas etárias, quando o sujeito apresentou resposta. Os números à frente das palavras indicam quando o tipo de resposta ocorreu mais que uma vez

\begin{tabular}{|c|c|c|c|}
\hline LISTA E1 & $\begin{array}{c}\text { Todos os níveis de } \\
\text { apresentação } \\
5 \text { anos }\end{array}$ & $\begin{array}{c}\text { Todos os níveis de } \\
\text { apresentação } \\
6 \text { anos }\end{array}$ & $\begin{array}{c}\text { Todos os níveis de } \\
\text { apresentação } \\
7 \text { anos }\end{array}$ \\
\hline Castelo & Castanha & & $\begin{array}{c}\text { Castanha } \\
\text { Telefone }\end{array}$ \\
\hline Comigo & Bolinha & Camisa & Comida \\
\hline Alguma & $\begin{array}{l}\text { Algencia } \\
\text { Calguma }\end{array}$ & $\begin{array}{l}\text { Abelha } \\
\text { Almoço } \\
\text { Amigo }\end{array}$ & $\begin{array}{c}\text { Sozinho } \\
\text { Alguto }\end{array}$ \\
\hline Direito & $\begin{array}{l}\text { Espelho } \\
\text { Silencio }\end{array}$ & & $\begin{array}{l}\text { Comida } \\
\text { Cliente } \\
\text { Diego }\end{array}$ \\
\hline Verdade & $\begin{array}{l}\text { Cidade } \\
\text { Soldado } \\
\text { Em Fase } \\
\text { Não Dá }\end{array}$ & $\begin{array}{l}\text { Cidade } \\
\text { Fechado }\end{array}$ & $\begin{array}{l}\text { Pesade } \\
\text { Perdão }\end{array}$ \\
\hline Bolinha & $\begin{array}{c}\text { Olho } \\
\text { Faz De Mim }\end{array}$ & Galinha & $\begin{array}{l}\text { Sozinho } \\
\text { Zoinho }\end{array}$ \\
\hline Amigo & & $\begin{array}{l}\text { Palito } \\
\text { Arroz }\end{array}$ & $\begin{array}{l}\text { A Perigosa } \\
\text { Figo }\end{array}$ \\
\hline Sozinho & $\begin{array}{c}\text { Cociguinha } \\
\text { Com Ninguem } \\
\text { Orelhinha }\end{array}$ & Bolinha & Só Amigo \\
\hline Querido & $\begin{array}{c}\text { Perigo } 3 \\
\text { Ferido } \\
\text { Prestigio } \\
\text { Coelhinho } \\
\end{array}$ & $\begin{array}{c}\text { Perigo } \\
\text { Comigo } \\
\text { Livro }\end{array}$ & $\begin{array}{c}\text { Perigo } 3 \\
\text { Ferido } \\
\text { Felipe } \\
\text { Pêssego }\end{array}$ \\
\hline Problema & $\begin{array}{c}\text { Coelho } \\
\text { Surpresa } \\
\text { Espelho } \\
\text { Novela } \\
\text { Governo }\end{array}$ & $\begin{array}{c}\text { Ovelha } \\
\text { Dosmundo }\end{array}$ & $\begin{array}{c}\text { Torvão } \\
\text { Programa } \\
\text { Cobrera } \\
\text { Eu Creio }\end{array}$ \\
\hline Desculpe & $\begin{array}{c}\text { Escrito } 2 \\
\text { Pescoço } \\
\text { Banquismo } \\
\text { Existe }\end{array}$ & $\begin{array}{c}\text { Escuro } 2 \\
\text { Pescoço } \\
\text { Biscoito } \\
\text { Cantinho } \\
\text { Pestico }\end{array}$ & $\begin{array}{l}\text { Escova } \\
\text { Tristeza } \\
\text { Esconde }\end{array}$ \\
\hline Caminho & $\begin{array}{c}\text { Amigo } 5 \\
\text { Camelo } \\
\text { Camisa } \\
\text { Mamãe } \\
\text { Amem }\end{array}$ & $\begin{array}{c}\text { Amigo } \\
\text { Camelo } \\
\text { Caminha } \\
\text { Camisa } \\
\text { Tamanho }\end{array}$ & $\begin{array}{c}\text { Amigo } 12 \\
\text { Camelo }\end{array}$ \\
\hline
\end{tabular}




\begin{tabular}{|c|c|c|c|}
\hline Porteiro & $\begin{array}{l}\text { Vocês } \\
\text { Oicente } \\
\text { Porte } \\
\text { Ursinho } \\
\text { Portão } \\
\text { Miojo }\end{array}$ & $\begin{array}{c}\text { Você } \\
\text { Ponteiro } \\
\text { Perfume }\end{array}$ & $\begin{array}{c}\text { Vocêe } \\
\text { Confete } \\
\text { Purseina } \\
\text { Cozinha }\end{array}$ \\
\hline Vergonha & $\begin{array}{c}\text { Legume } \\
\text { Cebola } 2 \\
\text { Mordida } \\
\text { Problema } 2\end{array}$ & $\begin{array}{l}\text { Senhor } \\
\text { Cebola } \\
\text { Pernora }\end{array}$ & $\begin{array}{l}\text { Legume } 2 \\
\text { Perfume } 2 \\
\text { Eu Vou Ai }\end{array}$ \\
\hline Socorro & $\begin{array}{c}\text { Chuveiro } \\
\text { Sucrilho } \\
\text { Suco } \\
\text { Surpresa } 2 \\
\text { Xampu } \\
\end{array}$ & $\begin{array}{c}\text { Sufoco } 2 \\
\text { Fogão } \\
\text { Castelo } \\
\text { Sofrendo } \\
\text { Escova } \\
\end{array}$ & $\begin{array}{c}\text { Sufoco } 2 \\
\text { Sucure } \\
\text { Demonio } \\
\text { Chupeta } \\
\text { Pestonha }\end{array}$ \\
\hline Aonde & $\begin{array}{c}\text { Aranha } \\
\text { Ao } 2 \\
\end{array}$ & & \\
\hline Espera & $\begin{array}{l}\text { Desculpe } \\
\text { Castelo } 2\end{array}$ & $\begin{array}{c}\text { Desculpe } \\
\text { Esfera } \\
\text { Estela } \\
\text { Escola }\end{array}$ & \\
\hline Menina & $\begin{array}{c}\text { Emilia } 2 \\
\text { Lindinha } \\
\text { Bom Dia } \\
\text { Aninha } \\
\text { Melancia } \\
\text { Uniao } \\
\text { Comigo 2 }\end{array}$ & $\begin{array}{c}\text { Emilia } \\
\text { É Minha } 2 \\
\text { Bom Dia } \\
\text { Amigo }\end{array}$ & $\begin{array}{c}\text { Emilia } 4 \\
\text { Envia } \\
\text { Vem Vindo } \\
\text { Tristeza }\end{array}$ \\
\hline Presente & Pergunte & $\begin{array}{l}\text { Ninquende } \\
\text { Elefante }\end{array}$ & Pringuente \\
\hline Estranho & $\begin{array}{c}\text { Espera } \\
\text { Estrela } 2 \\
\text { Gostoso } \\
\text { Respondo } \\
\text { Esconde }\end{array}$ & $\begin{array}{c}\text { Espera } \\
\text { Esteira } \\
\text { Escola } 2 \\
\text { Espelho } \\
\text { Estrile } \\
\text { Desculpe } \\
\text { Verdade }\end{array}$ & $\begin{array}{c}\text { Espere } 2 \\
\text { Estrela } 2 \\
\text { Espremo } \\
\text { Espelho } \\
\text { Despreme }\end{array}$ \\
\hline Cidade & $\begin{array}{c}\text { Idade } 2 \\
\text { Verdade } 2\end{array}$ & $\begin{array}{c}\text { Unidade } \\
\text { Verdade } 2\end{array}$ & $\begin{array}{l}\text { Estrada } \\
\text { Verdade } \\
\text { Pedade }\end{array}$ \\
\hline Abelha & $\begin{array}{l}\text { Avião } \\
\text { Azedo } \\
\text { Amigo } \\
\text { Abrigo } \\
\text { Abule } \\
\text { Abuso } \\
\end{array}$ & $\begin{array}{c}\text { Avião } \\
\text { Amelha } \\
\text { Cadeira } \\
\text { Abiba }\end{array}$ & $\begin{array}{c}\text { Abordo } \\
\text { Amigo } 3\end{array}$ \\
\hline
\end{tabular}




\begin{tabular}{|c|c|c|c|}
\hline Moeda & Cueca 2 & $\begin{array}{l}\text { Cueca } \\
\text { Espera }\end{array}$ & $\begin{array}{c}\text { Avião } \\
\text { Me Leva } \\
\text { Castelo } \\
\text { Cebulha } \\
\text { Moranga }\end{array}$ \\
\hline Aquela & $\begin{array}{l}\text { Raquel } \\
\text { Aviao } \\
\text { Castelo } \\
\text { A Vela }\end{array}$ & $\begin{array}{l}\text { Acela } \\
\text { Neda } \\
\text { Abelha } \\
\text { Amigo } \\
\text { Aqué }\end{array}$ & $\begin{array}{c}\text { A Menos } \\
\text { Acela } \\
\text { Atleta }\end{array}$ \\
\hline Idéia & $\begin{array}{c}\text { Jose } \\
\text { Ipsei } \\
\text { Presente } \\
\text { Inverno } \\
\text { Vitela } \\
\text { Quisela } \\
\end{array}$ & $\begin{array}{c}\text { Espelho } \\
\text { Icomo } \\
\text { Email }\end{array}$ & $\begin{array}{c}\text { Inveja } \\
\text { Velho } \\
\text { Ivete } \\
\text { Ninguem }\end{array}$ \\
\hline Teatro & $\begin{array}{c}\text { Prova } \\
\text { Tea } 3 \\
\text { Tearpe } \\
\text { Teaste } \\
\text { Iago } \\
\end{array}$ & $\begin{array}{c}\text { Pea } \\
\text { Veado } \\
\text { Tea } \\
\text { Viagem }\end{array}$ & $\begin{array}{c}\text { Tea } \\
\text { Toalha }\end{array}$ \\
\hline Agora & & Vassoura & \\
\hline Primeiro & $\begin{array}{c}\text { Cheiro Verde } \\
\text { Pimenta } \\
\text { Não Tem Ninguem } \\
\text { Dinehiro } \\
\text { Silencio } \\
\end{array}$ & $\begin{array}{c}\text { Email } 3 \\
\text { Milene } \\
\text { Amigo } \\
\text { No Meio }\end{array}$ & Imente \\
\hline Embora & $\begin{array}{c}\text { Ideia } \\
\text { Em Volta } \\
\text { Engola } \\
\text { Janela } \\
\end{array}$ & Depois & Em Volta \\
\hline Ainda & $\begin{array}{l}\text { Amigo } \\
\text { Ai } 2 \\
\text { Socorro }\end{array}$ & $\begin{array}{c}\text { Amiga } \\
\text { Ai } 3 \\
\text { Rainha }\end{array}$ & $\begin{array}{c}\text { Amigo } 4 \\
\text { Ai } 4\end{array}$ \\
\hline Crianças & Brilhante & $\begin{array}{l}\text { Triangulo } \\
\text { Fiat }\end{array}$ & $\begin{array}{c}\text { Brilhante } 2 \\
\text { Peão } \\
\text { Primeiro }\end{array}$ \\
\hline Pessoas & $\begin{array}{l}\text { Tesoura } 2 \\
\text { Perfume } \\
\text { Gostoso } \\
\text { Porsundo }\end{array}$ & $\begin{array}{c}\text { Biscoito } \\
\text { Perfume } \\
\text { Escola } \\
\text { É Sujo }\end{array}$ & $\begin{array}{c}\text { Tesoura } 3 \\
\text { Perfume } \\
\text { Desmossa }\end{array}$ \\
\hline Certeza & $\begin{array}{c}\text { Tesoura } \\
\text { Cerveja } \\
\text { Suco } \\
\text { Surpresa } 2\end{array}$ & $\begin{array}{l}\text { Tesoura } \\
\text { Criança } \\
\text { Abelha } \\
\text { Vermelho } \\
\text { Sempressa }\end{array}$ & $\begin{array}{c}\text { Tesoura } \\
\text { Serviço } \\
\text { Tereza }\end{array}$ \\
\hline
\end{tabular}




\begin{tabular}{|c|c|c|c|}
\hline Cansado & Sentado & Sentado & Quem Fala \\
& Sapato & & Privada \\
& Quensar 2 \\
& & & Pinga \\
\hline \multirow{2}{*}{ Pedido } & Perdido 5 & Perdido & Perdido 3 \\
& Aprendido & Eu Tive & Figo \\
& Vendido & & Tretini \\
& Mendigo & & Setigui \\
\hline
\end{tabular}

As palavras foram analisadas quanto a sua origem de categoria gramatical, sendo que, tanto na lista LE como na lista LRS, há maior número substantivos. Na lista LE há maior diversidade de categorias como advérbios, conjunções e adjetivos, e na lista LRS somente substantivos e adjetivos. Na tabela 23 estão dispostas as palavras por categorias das listas LE e LRS. Comparando-se com o quadro 19, dentre as cinco primeiras palavras de maior incidência de erros, há 4 substantivos e um advérbio, demonstrando que a origem de montagem das listas influenciou no uso de diferentes palavras da língua. 
Tabela 23: Distribuição das palavras das listas LE e LRS por categoria gramatical

\begin{tabular}{|c|c|c|c|c|c|c|}
\hline & substantivo & adjetivo & advérbio & pronome & verbo & conjunção \\
\hline & $\mathrm{N} \quad \%$ & $\mathbf{N} \%$ & $\mathbf{N} \%$ & $\mathrm{~N} \quad \%$ & $\mathbf{N}$ & $\mathbf{N}$ \\
\hline $\mathrm{LE}$ & $22 \quad 41,5$ & $\begin{array}{ll}4 & 50\end{array}$ & $\begin{array}{ll}3 & 100\end{array}$ & $\begin{array}{ll}3 & 100\end{array}$ & $\begin{array}{ll}2100 \\
\end{array}$ & $\begin{array}{ll}11 & 100\end{array}$ \\
\hline LRS & $\begin{array}{ll}31 & 58,4\end{array}$ & $4 \quad 50$ & $\begin{array}{ll}0,0 & 0,0\end{array}$ & $\begin{array}{ll}0,0 & 0,0\end{array}$ & $\begin{array}{ll}0,0 & 0,0\end{array}$ & $0,0 \quad 0,0$ \\
\hline total & $\begin{array}{ll}53 & 100\end{array}$ & $\begin{array}{ll}8 & 100\end{array}$ & $\begin{array}{ll}3 & 100\end{array}$ & 3100 & 2100 & 1100 \\
\hline
\end{tabular}


5.0 DISCUSSÃO 


\subsection{Sobre os Desempenhos dos Sujeitos em Relação às Variáveis Faixa Etária, Lista e Orelha Avaliada}

Os resultados dos desempenhos dos sujeitos na medida do Limiar de Reconhecimento da Fala foram semelhantes quando comparadas as listas experimentais LE, desenvolvidas por este trabalho, às listas LRS de Russo e Santos (1993), tanto em relação à orelha avaliada como em relação às faixas etárias, conforme descrito nas tabelas $7,8,9$ e 10 .

Os resultados dos sujeitos, na média geral das listas, indicam valores de LRF de 4,3 dBNS para a OD e 4,4 dBNS para a OE (tabela 10) e variabilidade total entre -10 a $15 \mathrm{dBNS}$. Segundo alguns trabalhos da literatura, os valores de LRF para crianças, encontram-se em uma faixa variável entre 3,5 e 5,1dBNS para Lebel e Lefebvre (1991) para crianças entre 4,5 e 5,5 aos de idade.. Para adultos, as respostas situam-se em 3,8dBNA para o CID10 conforme Mendell e Danhauer (1997) e 8dBNS conforme Young et.al. (1982); para Olsen e Matkin (1979) os resultados devem situar-se entre +/- 6 dBNS, não devendo ultrapassar a 10dBNS do limiar de detecção para a fala e, por fim, Russo e Santos (1993) apontam os valores de LRF em torno de 5 dBNS até $10 \mathrm{dBNS}$.

Como sugerido por Linquist (1953), os resultados do estudo experimental foram comparados aos resultados obtidos na segunda fase do estudo piloto. Apesar do estudo piloto ser restrito em número de sujeitos, os resultados foram comparados para avaliar-se os dados obtidos nestas duas fases, observar as tendências de resposta e compará-las à literatura acima. Ao fazer isto, neste trabalho, encontrouse que a maior incidência das respostas do LRF, em média, 
independentemente da lista e orelha, foi obtida entre 5 e $10 \mathrm{dBNS}$ no estudo piloto, uma vez que neste, os degraus de intensidade foram de 5 dBNS, coincidentes com os degraus de intensidade que usualmente são utilizados na prática clínica audiológica. $\mathrm{Na}$ fase experimental, a média dos valores do LRF foi de 4,4dBNS, sendo que nesta, os degraus foram de $2 \mathrm{dBNS}$. Os valores obtidos na segunda fase do estudo piloto foram semelhantes àqueles citados por Olsen e Matkin (1979) e Russo e Santos (1993). Ao passo que na fase experimental os valores médios coincidem com Lebel e Lefebvre (1991).

O presente estudo está, também, de acordo com Fragoso (1986) que avaliou o LRF em crianças de 5 a 14 anos e do mesmo modo não encontrou diferenças significativas entre as faixas etárias. Os achados de Kumabe (1999), com crianças de 5 e 6 anos, também não apresentaram essas diferenças significativas, apesar de utilizar tarefa monoaural competitiva.

O estudo de Lebel e Picard (1997), com crianças entre 6 e 11 anos, também não encontrou resultados com diferenças estatisticamente significantes nos valores do LRF (dBNS), para a tarefa de repetição de palavras, nas crianças entre 6 e 7 anos de idade, somente para faixa etárias maiores, acima de 9 anos. Os autores sugeriram que uma maior variabilidade na faixa de resultados pode ocorrer até os 10 anos de idade, quando as respostas tornam-se estatisticamente significativas entre os grupos etários e se equipararão às respostas do adulto.

Sendo assim, esses resultados indicam que as listas LE e LRS são adequadas para o uso na medida do LRF nas faixas etárias propostas. 
$\mathrm{Na}$ variabilidade dos valores de LRF negativos a positivos (de -10dBNS a +15dBNS), neste estudo, observa-se uma pequena diminuição na faixa de resultados com o aumento da idade, sendo encontrado para as crianças de 5 anos, resultados entre -10 e $+15 \mathrm{dBNS}$; nas crianças de 6 e 7 anos, entre -5 e 14dBNS, conforme figura 3 a 8 . Zaidan (2001) também constatou em seu estudo, com faixas etárias de 6 a 11 anos, uma diminuição da variabilidade do desempenho em função do aumento da idade (com testes de fala monóticos e dicóticos), com diferenças não significativas entre as idades.

Diferenças não estatisticamente significativas e a diminuição da variabilidade de respostas, a partir das faixas etárias acima de 6/7 anos, parecem concordar com outros estudos que avaliam a neuromaturação como os estudos sobre a aquisição do VOT (voice onset time) e da duração no português. Esses estudos também indicam diferenças significativas somente a partir das faixas etárias acima de 6/7 anos, devido à maturação neurológica não estar completa até esta fase (Gama-Rossi, 1995, 1996; Aquino, 1997; Albano, 1999). Por isso, a maturação neurológica das vias auditivas parece ser um fator de interferência no padrão de respostas do LRF na medida em que, segundo Bellis (2003), o desenvolvimento do sistema auditivo central estará completo ao redor de 9 anos de idade. Essas considerações também são apoiadas por Lebel e Picard (1997).

Apesar da concordância dos valores de LRF médios obtidos, comparados à literatura (segundo Lebel e Lefebvre, 1991), ocorreram desempenhos extremos de alguns sujeitos, como resultados muito negativos (-10dBNS) ou muito positivos (+15dBNS), além de uma pequena tendência de resultados de LRF mais baixos na OE, 
principalmente, aos 5 anos de idade. Estes resultados são considerados inadequados na medida em que a diferença entre o LRF e a média tonal situa-se fora da faixa esperada, entre 0 e 10dBNS. Essa incompatibilidade de respostas está prevista na literatura (Coren, 1994; ASHA, 1998; Martim, 1997) apesar de não considerar-se possível que um indivíduo possa reconhecer, sem antes, detectar o sinal de entrada, como nos casos em que ocorreram valores de LRF negativos. Essa relação entre detecção e reconhecimento está descrita nos trabalhos clássicos psicofísicos que estudaram a relação do tipo de sinal com a intensidade de apresentação, a função desempenho-intensidade (PI), conforme Fletcher e Steinberg (1930), Hudgins (1947), Licklider e Miller (1951), Miller, Heise e Linchten (1951), Hirsch (1952) e Traul e Black (1965) segundo Penrod (1999). Olsen e Matkin (1979) sugerem que o limiar de reconhecimento da fala necessita de mais energia do que o limiar de detecção de fala, sendo esta diferença de 6 até $10 \mathrm{~dB}$, encontrada na curvas psicométricas. A quantidade exata de energia necessária ao reconhecimento varia de acordo com as características do estímulo de fala utilizado.

Para estes casos com resultados extremos, Coren (1994) e a ASHA (1988) sugerem algumas razões que poderiam provocar o aparecimento de uma discrepância entre a média dos limiares do tom puro e o Limiar de Reconhecimento da Fala. A primeira razão é a presença de problemas no equipamento; a segunda, o não entendimento da instrução da tarefa a ser realizada pelo sujeito, principalmente, no teste da medida do limar de tom puro, o que acarretaria resultados de limiar de tom puro, mais altos ou mais baixos, do que seriam na verdade. E portanto, o aparecimento de valores de LRF (dBNS) negativos ou 
positivos (acima de 10dBNS), e a terceira razão de resultados incompatíveis está relacionada à idade do sujeito sob teste.

Coren (1994) e a ASHA (1988) sugerem ainda outros fatores que podem produzir valores de LRF incompatíveis com a média dos limiares de tom puro, são eles: a presença de uma deficiência auditiva funcional, a presença de alterações auditivas retrococleares e centrais, a presença de alterações cognitivas e de linguagem associadas e a presença de configurações audiométricas irregulares.

Destas sugestões, considera-se que problemas no equipamento, o não entendimento da instrução e a idade do paciente, devido à faixa etária dos sujeitos, seriam os fatores preponderantes, neste estudo. Vale ressaltar que a presença de uma perda auditiva funcional, pode ser considerada, como uma conseqüência desta incompatibilidade, isto é, geralmente na clínica, a presença desta incompatibilidade é vista como a própria perda funcional ou pseudo-hipoacusia (disparidade nos resultados entre limiar de tom puro e fala causada pelo sujeito) independentemente do fator de causa, e não ela mesma como o fator desencadeante.

Diante destes resultados extremos obtidos, negativos e positivos, inicialmente, foi questionado se a obtenção desses resultados poderia estar relacionada a problemas no equipamento utilizado ou no local de realização do teste. Salientando que esses dados incompatíveis foram obtidos em instituições de ensino diferentes e com crianças de mesma série mas avaliadas em dias diferentes.

As questões técnicas que poderiam ter influenciado nos resultados, tais como variação de energia no local, variações do sinal enviado do dicsman ao audiômetro, a calibração do VUmeter e as 
condições do local de teste foram discutidas com o técnico responsável, que prestou suporte à pesquisa.

O audiômetro utilizado refere-se a um modelo do Tipo 1 ou mais conhecido como audiômetro clínico e possui uma fonte de alimentação de alta qualidade que aceita grandes variações de energia. Além disso, esteve conectado a um estabilizador de energia durante as avaliações, o que teria minimizado o aparecimento de problemas quanto a alimentação de energia do sistema. Assim, considerou-se que este item não provocou variações que pudessem ter modificado a energia, entre a medida do tom puro e a medida do LRF, na avaliação do mesmo sujeito, causando os achados incompatíveis.

Com relação a possíveis variações do sinal do discman enviados ao audiômetro, tendo utilizado a saída do tipo line out, não haveria como variar o envio do sinal, mesmo se movimentado o controle de volume do discman, e ainda, o sinal enviado foi monitorado todo o tempo no VUmeter, e por fim, este último foi calibrado a cada início de conjunto de sujeitos avaliados. Portanto, estes itens também foram descartados como prováveis influências nos resultados obtidos.

Quanto as salas de teste, elas apresentavam baixo nível de ruído, avaliado pela calibração biológica, a partir da audiometria de tom puro da avaliadora. Quando ocorreram eventuais aumentos do nível de ruído, como por exemplo, o horário de intervalo de lanche das crianças, as avaliações foram suspensas até que o nível de ruído retornasse a um patamar esperado. Sendo assim, a possibilidade de interferência de questões técnicas, no geral, não foi desconsiderada como causa das alterações nos resultados extremos obtidos.

Outro fator apontado como possível influência nas respostas relaciona-se com o tipo de tarefa solicitada e o entendimento à execução 
da própria tarefa pelo sujeito. Neste estudo, na avaliação da detecção de tom puro foi proposta a tarefa de levantar a mão ao ouvir o som, para favorecer um maior contato da examinadora com o sujeito, mantendo-se assim, contato de olho direto, e portanto, proporcionando mais atenção do sujeito ao teste. Tal estratégia pode ser criticada, do ponto de vista, dos estudos psicofísicos, na medida em que a atenção passa a ser dividida entre ouvir o som, olhar para a examinadora e cumprir a tarefa de levantar a mão. Mas, mesmo assim, esta é uma estratégia usualmente utilizada na prática clínica.

$\mathrm{Na}$ medida do LRF solicitou-se ao sujeito uma resposta oral. Este tipo de resposta implica em outros processos cognitivos mais complexos àqueles utilizados na medida do tom puro pelas próprias características dos estímulos. Lebel e Picard (1997) sugeriram que a variada possibilidade de escolha de respostas na tarefa de repetição (forma aberta) se opõe à tarefa de escolha de uma imagem e, assim, diminui a influência da decisão lexical e da necessidade de realizar a restauração fonêmica para o sujeito em teste. Este tipo de tarefa pode também aumentar a motivação da criança durante a realização, segundo Nittrouer e Boothroyd (1990).

Lebel e Picard (op.cit.) reportaram uma diminuição de 3 a 6,5 dB no LRF, em crianças de 6 a 12 anos, como resultado da restrição imposta pela tarefa de resposta fechada (apontar figuras) ao invés de resposta aberta (oral), sendo significantemente menor a diminuição do limiar do LRF, em todas as idades, quando a tarefa foi realizada através do apontar de figuras. Portanto, no que se refere a este trabalho, o uso da resposta aberta também pode ter contribuído na variabilidade das respostas nas três faixas etárias. 
Uma alternativa seria solicitar a resposta de apontar figuras, como sugerido por Elliot et al. (1979) e Lebel e Picard (1997) para tornar as repostas do LRF, em crianças, menos variáveis, principalmente, naquelas que tenham maior dificuldade de memória auditiva. Assim, sugere-se uma pesquisa que compare este corpus, utilizado no LRF, em tarefas de resposta aberta e fechada em grupos etários diferentes. Entretanto, sempre é necessário ter em mente o problema que a tarefa de resposta fechada traz no que diz respeito à relação entre o estímulo de fala e sua imagem. Apenas estímulos de fala correspondentes a referentes concretos podem ser representados visualmente sem gerar ambigüidade, por isso, a escolha do item-estímulo deve ser cuidadosa.

Outro fator que deve ter influenciado para o aparecimento de LRF extremos negativos e positivos foi o entendimento do sujeito à instrução do teste, isto é, há grande variabilidade individual no que se refere ao entendimento da resposta a ser dada ao tom puro bem como à fala.

É fato bastante comum na clínica audiológica o examinador "perceber" que o sujeito "ouve" o tom puro mas considera-o "baixo demais" para responder a ele, o que provocaria limiares de tom puro mais altos e LRF negativos ou quando o sujeito responde, mesmo quando não ouviu o estímulo, demandando limiares de tom puro mais baixos que os limiares reais e LRF mais altos. Ou então, na tarefa do LRF em que o sujeito não se dispõe a "adivinhar" o item (isto é, realizar o reconhecimento a partir de fragmentos do que foi percebido, vide avaliação qualitativa no item 5.2) mas somente o responde quando tem certeza do que ouviu, o que também demandaria valores de LRF (dBNA) mais altos. O julgamento individual do que deve ser o estimulo 
a ser respondido varia largamente entre os indivíduos, tanto em crianças como em adultos.

Por isso, Olsen e Matkin (1979) sugerem que os resultados obtidos durante um teste de percepção auditiva da fala com crianças reflete, muito mais o seu interesse e sua motivação, do que realmente indica suas habilidades de discriminação e reconhecimento. Eles apontam que em testes onde a instrução é manipulada de diferentes formas, os resultados do limiar de detecção de tom puro e de reconhecimento da fala se modificam, devido ao critério de resposta adotado pelo sujeito a partir da instrução dada, sugerindo que estes limiares são dependentes de variáveis não-auditivas.

Assim, a atenção, a motivação e o entendimento à instrução parecem ter sido os fatores de maior preponderância na ocorrência de LRF extremos, distantes da média geral dos grupos.

Todavia, outras questões são apontadas por Coren (1998) e ASHA (1988) como agentes de influência nas respostas do LRF, quando não compatíveis com os resultados da média tonal, além de problemas no equipamento e entendimento da instrução. As outras questões estão relacionadas diretamente com a idade do sujeito, como proposto por eles, mas não explicitado em suas citações, de que modo e em que graus eles estariam se relacionando. Os fatores relacionados à idade e que podem estar, juntos ou não, interferindo na qualidade das respostas do sujeito, são: (1) a motivação do sujeito em realizar a tarefa; (2) aspectos intrínsecos do sujeito, no que diz respeito ao funcionamento da via auditiva em relação às características do estímulo (influências acústicas) no processamento via bottom-up e às respostas do sistema auditivo no processamento top-down (influências semânticas e lexicais) e (3) a atenção e a memória auditiva. 
Relacionado aos fatores citados acima, a motivação das crianças para a realização do teste, neste estudo, deve ter sido uma das questões de interferência na resposta. Apesar de não ter sido medida objetivamente, a motivação foi evidente em solicitações do tipo: ir à sala de exame e permanecer lá após a avaliação para apreciar a "novidade" da atividade e perguntar ansiosamente quando seria sua vez no teste. Por outro lado, alguns sujeitos apresentaram comportamentos de "cara feia", medo do desconhecido e interesse em regressar, o mais breve possível, `a atividade que estavam realizando. Considerou-se que neste caso, pode ter havido motivações diferentes às respostas ao tom puro e à fala, sendo que algumas crianças podem ter se motivado ao tom puro por ser algo novo e outras não motivadas exatamente por esse motivo. Estes fatos demandariam, do mesmo modo, valores não reais para tom puro e fala, isto é, mais altos ou mais baixos do que na verdade o seriam. Uma possibilidade de minimizar esta questão seria, como já mencionado para o LRF, a tarefa de apontar figuras, além de estratégias especiais para a obtenção de tom puro, como a associação de diferentes atividades visuais ou motoras.

Outro fator, o funcionamento intrínseco da via auditiva, considera-se que há uma relação direta entre este funcionamento e o tipo de estímulo apresentado aos sujeitos, pois há diferenças fundamentais entre a tarefa de detecção de tom puro e reconhecimento de fala. A medida do tom puro se situa num nível mais baixo de processamento na análise acústica, o suficiente para assegurar a audibilidade do estímulo e contrapõe-se à medida do LRF que necessita de níveis de processamento mais complexos e hierárquicos, inerentes ao sinal acústico da fala, tais como: fonético-fonológico, semântico e lexical, além da memória de trabalho. 
O sistema auditivo funciona de modo diferenciado para as descargas das fibras nervosas para tons puros, em regiões de freqüência específicas, e para sons de fala (sons complexo) com descargas múltiplas, e ainda a seletividade das células nervosas na região cortical temporal para esses sons (Pickles, 1989). Além disso, nos sons de fala há a influência de outros aspectos ligados às características do próprio estímulo como, já citado, a interferência semântica e lexical, o que pode tornar mais fácil a atenção à fala do que ao tom puro, principalmente na avaliação dos sujeitos da faixa etária deste estudo. A fala é mais significativa às crianças do que um tom puro que não está presente em seu dia-a-dia.

Elliott et al. (1979) e Fallon et al. (2000) ressaltam que crianças jovens têm limiares tonais mais altos que crianças mais velhas e adultos. Este fator relaciona-se diretamente a atenção auditiva na realização do teste. Para eles, a tarefa de detecção requer mais atenção do que outras tarefas perceptivas, tais como, discriminação e reconhecimento.

Schneider e Trehub (1992) argumentaram que a atenção é um dos fatores que mais contribui para as diferenças de desempenho entre adultos e crianças em tarefas de detecção e discriminação. Pode-se supor também o mesmo, tanto na tarefa de tom puro como em tarefas de reconhecimento (escores), de crianças mais jovens (2 a 5 anos) em relação a crianças mais velhas e, por isso, Northern e Downs (1990) consideram que os limares tonais se equipararão aos limiares dos adultos somente após os 6 anos de idade. Picard et al. (1998) salientam que as dificuldades no reconhecimento do estímulo (por exemplo, apresentá-lo em níveis tão baixos como o próprio limiar de reconhecimento da fala), vão requerer da criança mais tempo e mais atenção para processá-lo e, 
assim, ela deverá utilizar, em maior número, as informações fonológicas e lexicais (Nittrouer e Boothroyd, 1990; Boothroyd e Nittrouer, 1988) na tarefa de reconhecimento.

$\mathrm{O}$ desempenho obtido na $\mathrm{OE}$, independentemente da lista utilizada, deve também estar relacionado, a atenção auditiva à tarefa da medida do limiar de tom puro. Os estudos sugerem que cada córtex auditivo governa as respostas ao estímulo na orelha contra-lateral, mas de modo muito mais intenso em tarefas na presença de estímulo em competição na orelha oposta à avaliada. Nesse caso, observa-se uma vantagem da orelha direita, porém Efron (1985) sugeriu que essa vantagem poderia ser observada também na estimulação com tons puros. Assim, neste estudo, pode-se supor, para alguns sujeitos (aqueles com média tonal em 10 e em 15dBNA), ocorreu uma desvantagem da $\mathrm{OE}$ para a tarefa de tom puro, o que teria ocasionado o aparecimento de limiares tonais mais altos nessa orelha e o aparecimento de LRF negativos (figuras 3 a 8).

Mas considera-se, entretanto, que esses resultados de LRF muito baixos na $\mathrm{OE}$ devem constituir, muito mais, um evento casual e aleatório. De qualquer modo, esses achados merecem uma posterior avaliação em outros grupos de sujeitos com as mesmas caracterisitcas deste estudo.

Por outro lado, também foram obtidos valores de LRF negativos, independentemente da orelha, em sujeitos em que a média tonal foi considerada baixa, como em 0 e 5dBNA. Pode ser que esses sujeitos sejam mais proficientes e experientes em sua língua do que os demais da mesma idade, conforme sugerido por Elliot et al. (1979), Lebel e Picard (1997) e Picard et al. (1998), incluindo aí suas experiências de exposição à língua no dia-a-dia, o nível de escolaridade 
dos pais e contato em casa com material escrito, além da estimulação da escola ou outros recursos que auxiliem na expansão do léxico. Essas experiências podem ter ocasionado LRF mais baixos pois a tarefa de reproduzir uma palavra se assemelha mais a tarefas do seu dia-a-dia, tanto em casa como na escola.

Picard et al. (1998) discutem que a diferença entre a relação do LRF e a média tonal em adultos, com perda auditiva induzida por ruído e que apresentaram LRF negativos, está relacionada à influência da habilidade do sujeito no reconhecimento da fala e do quanto ele se utiliza do processamento top-down. Os sujeitos com LRF negativos seriam mais proficientes que os demais no uso da língua.

Neste estudo, a qualidade do processamento top-down se relaciona à frequiência na língua do material de fala (palavras trissilábicas paroxítonas retiradas de um corpus formado por programas infantis) que deve aumentar a influência desse tipo de processamento. Essas influências são mais claras quando pensamos no individuo adulto com perda auditiva adquirida pois a perda funciona como um filtro de informações para o envio do sinal de fala pela via auditiva (processamento bottom-up) e, assim, outras estratégias devem ser utilizadas de modo a compensar essa falta de informação, sendo que nessa situação o processamento top-down torna-se mais preponderante, como a redundância lingüística e a familiaridade do material de fala.

Fallon et al. (2000), Elliot et al, (1979), Schneider et al. (1989); Nittrouer e Boothroyd (1990) e Boothroyd e Nittrouer (1988) concordam que palavras familiares são consideradas de alta previsibilidade e, por isso, demandam mais o uso de funções cognitivas do que sensoriais, ao passo que palavras menos familiares e menos previsíveis, demandariam mais informação sensorial do que cognitiva. 
De qualquer modo, essa proficiência na língua poderia estar refletida nas crianças mais velhas, como as de 7 anos, o que não ocorreu nesta analise, podendo ser mais bem visualizado nos resultados da analise qualitativa. Mesmo assim, não se pode descartar os outros fatores anteriores citados, como causas de influência também nestes casos (atenção e motivação, entendimento da instrução, processamento da via auditiva).

Para os sujeitos com LRF positivos, maiores que 10dBNS, Fallon et al. (2000) sugeriram que, inversamente, a experiência limitada de linguagem poderia ser um fator de influência podendo, ainda, indicar falhas no processamento fonológico (memória fonológica) e no acesso ao léxico mais restrito. Esse tipo de resultado pode ser obtido em sujeitos com alteração no processamento auditivo. Assim, o tipo de material de fala tem uma influência direta sobre o desempenho das crianças com maiores limitações lingüísticas. Por isso, a análise qualitativa das respostas pode ser um veículo para um melhor entendimento das estratégias utilizadas e das falhas no reconhecimento auditivo destes sujeitos. Por outro lado, mais uma vez, não se descarta para esses casos de LRF positivos (+10dBNS), a possibilidade de respostas inadequadas na medida do tom puro, relacionados aos outros fatores já citados.

E por fim, um outro aspecto não relacionado ao sujeito, seriam as diferenças no procedimento de medida do limiar de tom puro e no limiar de reconhecimento da fala. Essas distinções no procedimento utilizado deve ter gerado o aparecimento de pequenas diferenças nas respostas, tanto positivas, como no caso de +11 a +13 dBNS, como diferenças negativas, -1 a -3 dBNS pois, na medida do tom puro, foram utilizados degraus de $5 \mathrm{~dB}$ e, ainda, a influência no arredondamento da média tonal, e na medida do LRF, foram utilizados degraus de $2 \mathrm{~dB}$. 
Nota-se que na segunda fase do estudo piloto, com degraus de $5 \mathrm{~dB}$, não ocorreram respostas negativas.

Apesar dessa variabilidade de respostas obtidas (positivas e negativas) e dos fatores que influenciaram, tanto na medida do limiar de tom puro quanto na medida do LRF, é incontestável a importância clínica da correspondência e compatibilidade entre esses valores, a partir dos parâmetros já citados por_Lebel e Lefebvre (1991); Mendell e Danhauer (1997); Young et.al. (1982); Olsen e Maktin (1979) e Russo e Santos (1993). Essa correspondência é fundamental para a clínica audiológica como instrumento da consistência da audiometria tonal, de modo a confirmar seu valor para o diagnóstico.

Mas, os audiologistas devem estar cientes destas influências e limitações do método psicofísico adaptado, utilizado nestas medidas, de modo a prover estratégias para minimizar essa variabilidade. Algumas sugestões são apontadas para o clinico: (1) o fornecimento de instruções de modos variados no sentido de prover ao sujeito facilidade para o entendimento das tarefas; (2) o clínico estar pronto a possibilitar respostas através do apontamento de figuras para o LRF; (3) modificar a forma do procedimento do LRF em seus passos de atenuação de 5 para $2 \mathrm{~dB}$, se ele julgar que este método poderá ser mais sensível à medida do LRF para determinado sujeito; (4) estar atento a influências da atenção e motivação, durante a realização dos testes; (5) estar atento a questões técnicas do equipamento; e por fim, (6) estar atento a outros fatores intrínsecos do sujeito que poderiam influenciar nas respostas como alterações cognitivas, de linguagem e propriamente, auditiva associadas. A correlação entre a média dos limiares de tom puro e do LRF (dBNA) é a medida fundamental para avaliar-se a compatibilidade do resultado do tom puro através da fala, ou vice-versa, apesar das 
dificuldades em se comparar duas tarefas perceptuais tão distintas, que envolvem níveis de processamento diferentes, desde o nível mais baixo, o coclear, até todas as estruturas do lobo temporal e fora dele envolvidas neste processamento, e em última análise, as diferenças de local de chegada e avaliação do input, como para tom puro à direita e a fala à esquerda.

O consenso entre os estudos mostra que a correlação da média das frequiências de 500, 1000 e $2000 \mathrm{~Hz}$ é a que se apresenta mais próxima aos valores de LRF, na maioria dos casos, mesmo naqueles com perda auditiva (Cahart, 1971). O estudo nacional de Camargo et al. (1989) também sugeriu que a média de 500 a $2000 \mathrm{~Hz}$ foi a que apresentou alta relação com os valores de LRF.

A correlação da média tonal e do LRF, neste estudo, situouse entre $\Gamma=0,86$ e $0,71\left(p<0,001^{*}\right)$ para OD e entre $\Gamma=0,48$ e 0,54 $(\mathrm{p}=0,001 *)$ para $\mathrm{OE}$ na faixa etária de 5 anos, na OD para 6 e 7 anos obtivemos $\mathrm{r}=0,67$ e $0,70(\mathrm{p}<0,001 *)$ e para $\mathrm{OE} \Gamma=0,54$ e $0,57(\mathrm{p}=0,001 *)$ (tabela 15). A correlação indicada pela ASHA (1988) é o valor seja maior ou igual a 0,9 para adultos e Lebel e Lefebvre (1991) encontraram uma correlação de 0,22 a 0,55 para crianças. E ainda, Lebel e Picard (1997) obtiveram, como neste estudo, uma correlação significante entre a média tonal e o LRF, para crianças de 6 e 7 anos, tanto para a tarefa de resposta aberta como para fechada. Isto significa que para a maior parte dos sujeitos existe uma correlação entre a média tonal e o LRF apesar do aparecimento da variabilidade extrema negativa e positiva, como já discutida.

Outro dado obtido nesta análise é o valor de correlação para as crianças de 5 anos, na OE (média de 0,510), onde ocorreram os valores de LRF mais baixos. Esta correlação encontrada é a menor de 
todas as avaliadas, quando se compara à orelha direita de 5 anos $(0,785)$ e as outras idades. Este dado parece confirmar os achados anteriores sobre a $\mathrm{OE}$ em que as possíveis causas destes valores já foram discutidas anteriormente.

Esta análise da correlação também demonstra a consistência das listas. Os valores altos e os valores baixos, nas orelhas e idades, se mantêm entre as listas, mostrando uma sensibilidade dos instrumentos de medida propostos para medir o comportamento dos grupos e sua utilização na avaliação do LRF.

Dentre os estudos de correlação de tom puro e LRF, existe uma sugestão de Letowiski et al. (1992) para utilizar-se ruído branco e não estímulo de fala para a relação com a média das freqüências de 500,1000 e $2000 \mathrm{~Hz}$ com tons puros, isto é, o Limiar de Detecção para Ruído (LDR). Eles obtiveram uma correlação de $\Gamma=0,97$ (nível de confidência de limite) e as diferenças entre o LRF (com palavras) e o LDR, em relação à média tonal, foi de $2,3 \mathrm{~dB}$ com um desvio-padrão de 4,3dB. Apesar de não ter sido o objetivo deste trabalho em avaliar a correlação de diferentes médias tonais, sugere-se novas investigações, agora com material gravado, conjuntamente com o uso de algum tipo de ruído, para auxiliar na avaliação de indivíduos com comprometimentos (cognitivo, lingüístico, dentre outros) que possam influenciar seu desempenho nesta tarefa de modo significativo.

Por fim, quanto a variável sexo, na análise dos resultados da tabela 14 não houve diferenças estatisticamente significantes no desempenho entre os sujeitos do sexo feminino e masculino, na maior parte das situações avaliadas. Esta variável não tem sido relevante nos estudos anteriormente citados, dedicados ao LRF, como em Machado (1988); e Harris et al. (2001). Fragoso (1986) e Kumabe (1999) 
avaliaram esta variável e não obtiveram diferenças significantes entre os grupos de meninos e meninas concordante com Pereira (1993) para testes de fala no ruído. Não se observa o estudo desta variável também nos estudos de Zubick et al. (1983), Nilsson et al. (1994), Letowiski et al. (1992), Lebel e Picard (1997) e Rabin e Rosenhouse (2000).

\subsection{Sobre a análise qualitativa das respostas obtidas às palavras-alvo apresentadas}

A análise das respostas obtidas na apresentação da lista LE1 (quadro 6) teve como objetivo avaliar seus itens de forma a levantar aqueles que provocaram maior dificuldade de reconhecimento auditivo. Essa análise tem como objetivo verificar a possível interferência negativa desses itens na medida do LRF, isto é, proporcionando limiares, em dBNA, elevados.A medida utilizada foi o número de vezes em que a resposta verbal do sujeito não correspondeu diretamente à palavra apresentada, tal como se faz na medida do LRF.

Essa análise das possíveis estratégias que os sujeitos utilizaram para o reconhecimento, em suas respostas, contribui com subsídios ao audiologista na realização de uma avaliação mais aprofundada das respostas do LRF, indo além da contagem de itens adequados ou não, e fornecendo outros elementos ao processo de indicação de aparelho auditivo, implante coclear e reabilitação auditiva. Além disso, a análise qualitativa pode tornar-se importante nos casos em que não houve a correspondência esperada entre a média tonal e o LRF. Essa falta de correspondência resultará em um diagnóstico de perda auditiva funcional ou pseudo-hipoacusia, o que implicará condutas 
clínicas bastante diversas. Acredita-se que uma avaliação mais aprofundada nos casos de incompatibilidade de respostas (limiar tonal e LRF) pode, então, auxiliar o clínico a resolver esse dilema.

Como já comentado nos Resultados, não foi possível traçar, a curva logoaudiométrica para LE1 nas três intensidades $(5,10 \mathrm{e}$ $15 \mathrm{dbNS}$ ), porque o experimento foi aplicado numa única sessão para evitar resultados diferentes decorrentes de alterações auditivas ou outras alterações psico-fisiológicas, entre uma sessão e outra. Porém, a realização do teste em uma única sessão, causou reações de cansaço, falta de interesse e motivação de alguns sujeitos, uma vez que a aplicação das listas em diferentes intensidades foi realizada ao final da medida do LRF. Por isso, os resultados obtidos foram agrupados em número total de respostas por faixa etária, já que a maioria das respostas foi obtida nas intensidades de 5 e 10dBNS.

Segundo Lyregaard (1997) os erros na audiometria da fala geralmente apresentam as seguintes características relacionadas à similaridade fonética com o estímulo: (1) mesmo número de sílabas; (2) preservação das vogais do estímulo-alvo, com a utilização de outras consoantes ou (3) palavras com significante e significado totalmente diferentes em relação ao estímulo-alvo. Essa proposta de classificação de Lyregaard (op.cit.) mostrou-se restrita porque a análise realizada demonstrou que mais de um parâmetro pode ser mantido ao mesmo tempo como: o número de silabas e a preservação total ou parcial da vogal, paralelamente a isso, há uma tendência de manutenção do padrão acentual do estímulo-alvo, nas respostas. ${ }^{6}$

6 Warren e Marslen-Wilson (1988) e Marslen-Wilson (1996) destacaram a importância da coarticulação como facilitadora no processo de fechamento para o reconhecimento auditivo da palavra a partir de fragmentos percebidos pelo ouvinte. 
Por outro lado, outras vezes, observa-se a permanência de "pedaços" da palavra-alvo e a partir daí, ela é reorganizada em outra palavra. Esses pequenos pedaços podem variar entre traços fonológicos (por exemplo: nasalidade), fonemas, uma ou mais sílabas, rimas (vogal+ consoante seguinte pertencente à mesma sílaba), frase ou expressão (verdade por em fase) e o grupo interperceptual-center (GIPC). ${ }^{7}$

As tendências observadas nas respostas dos sujeitos, para a lista LE1, apresentaram características similares a essas descritas por Lyregaard (op.cit.), conforme o quadro 21.

A tendência de resposta mais comum foi a utilização de uma palavra por outra com o mesmo número de sílabas. Porém, em algumas essa tendência vem acompanhada da preservação das vogais do estímulo-alvo. Por exemplo:

- castelo por castanha;

- comigo por bolinha ou camisa ou comida;

- alguma por abelha ou almoço ou amigo e por sozinho;

- direito por espelho, comida, cliente e diego. Direito foi ainda repetido como silêncio, palavra que na fala pode ser reduzida a três sílabas, devido à redução a que está sujeita a pós-tônica -cio (conforme comunicação pessoal de Gama -Rossi a partir de Aquino (1997), GamaRossi (1996) e Barbosa (1999);

- verdade por cidade ou soldado ou fechado. Vale ainda notar que verdade foi repetida como em fase, o que denota uma preservação do

\footnotetext{
${ }^{7}$ de acordo com Barbosa (1999: pag.32) o grupo interperceptual-center (GIPC) refere-se a uma unidade delimitada por dois onsets (acusticamente definidos) vocálicos consecutivos (...) Devido a fato do onset vocálico ser o "point d'ancorage" por excelência para a percepção ou a produção da ritmicidade segundo os estudos em torno das noções de isocronismo e perceptual-center (Marcus, 1981; Morton, Macus e Franhish, 1976) - que representa o efeito acústico singular que seria usado pelos auditores para alinhar estímulos sonoros e perceber o isocronismo da fala-, essa unidade foi denominada grupo interperceptual-center ou GIPC. O GIPC é, então, composto pela rima de uma sílaba e o ataque da sílaba seguinte quando este é presente (por ex: sapato, o GIPC é início do "a" da sílaba "sa" e o inicio do "a" da silaba "pa").
} 
número de sílabas e das qualidades vocálicas. Como isso ocorreu para uma criança de 5 anos, supõem-se que deveu-se ao fato de nessa idade não haver contato suficiente com a língua escrita e por ser o fluxo continuo da fala ainda não-analisável em "palavras" ou unidades menores, como sílabas e fonemas (Scliar-Cabral, 2003); ${ }^{8}$

- bolinha por galinha, sozinho ou zoinho. No caso de bolinha por galinha, poder-se-ia ainda pensar que o sujeito "perdeu" o reconhecimento apenas da primeira sílaba da palavra-alvo, uma vez que a demais sílabas foram mantidas. Também aqui, bolinha foi repetida por uma seqüência de três palavras monossilábicas, a saber: faz de mim. É interessante notar ainda a manutenção do traço de nasalidade nas últimas sílabas:-nha e mim;

- amigo por palito com preservação do número de silabas e vogais;

- sozinho por bolinha ( da mesma forma que bolinha por sozinho);

- querido por perigo ou ferido, com preservação da sequiência de vogais do estímulo-alvo. Querido por comigo com a preservação das vogais das duas ultimas silabas. Querido por pêssego, devido ao provável alteamento da pós-tônica não-final, o que fez com que a mesma fosse pronunciada com [i] ao invés de [e];

- problema por ovelha, novela, coelho, espelho, governo, surpresa e programa. Nestas últimas observa-se a manutenção do grupo consonantal /pr/ na segunda e primeira sílabas respectivamente;

- desculpe por cantinho e pestico;

- caminho por amigo. Aqui vale notar que das respostas que não atingiram a palavra-alvo, 43 no total, 18 delas (42\%) foram amigo.

\footnotetext{
${ }^{8}$ Para melhor visualização dos tipos de resposta, elas estão marcadas de formas diferentes:

- itálico: quando há somente a preservação do número de sílabas

- itálico e negrito: quando há a preservação do número de sílabas e vogais

- sublinhado: a própria palavra -alvo

- outra fonte: quando a palavra tem menos de três sílabas.
} 
Caminho por tamanho, camelo, camisa e caminha, sendo que nessas duas últimas foram mantidas as duas primeiras sílabas, e na última, houve apenas a diferença em relação à vogal final. Por outro lado, todas as palavras referidas para caminho apresentam o traço de nasalidade em uma ou mais sílabas (Bisol, 2002). Embora não mantendo o mesmo numero de sílabas de caminho, é provável que as respostas mamãe e amém obtidas para essa palavra-alvo também tenham sido determinadas pela percepção do traço de nasalidade;

- porteiro por ponteiro, com manutenção das duas últimas sílabas e, de fato, apenas diferindo minimamente pela consoante final das primeiras sílabas: [R] e [N]. Porteiro por ursinho, miojo, confete e cozinha. Nestes casos, em relação a palavra-alvo, parece que a única semelhança referese ao número de silabas e ao padrão de acento, sempre paroxítono, apesar de este último não ser levado em conta por Lyregaard (1997). Houve ainda a resposta perfume para porteiro, indicando também a semelhança com a primeira sílaba. Também foram respondidos porte e portão, que apesar de duas sílabas mantêm grande semelhança fonológica e até mesmo semântica, no caso de portão;

- vergonha por legume, cebola, perfume, mordida e problema. No caso da resposta cebola, foram mantidas, além do número de sílabas, as vogais. No caso de perfume, houve a apreensão da rima (vogal+consoante, Bisol, 2002) da primeira sílaba. Vale notar que o sujeito parece apoiar-se em "pequeno pedaços" do que foi percebido para recompor a possível resposta.

- socorro por sufoco, sucrilho, surpresa e sofrendo. Nestas respostas dadas além da manutenção do número de 'silabas e do padrão de acento, chama a atenção a manutenção do primeiro fonema /s/ e de uma certa relação entre as vogais /o/ e /u/ (Bisol, 2002), classificadas no sistema 
vocálico do português brasileiro como posterior e altas. Numa outra resposta, suco, também o fonema /s/ e a relação entre /o/ e /u/ foi mantida, apesar da redução do número de sílabas;

- aonde por aranha e ao, havendo a preservação do número de sílabas do padrão de acento e da percepção da sílaba inicial da palavra /a/.

No que se refere ao GIPC, vale ressaltar o exemplo da palavra-alvo d/esc/ulpe que obteve como resposta esc/uto, esc/uro, esc/ova, esc/onde, p/esc/oço, b/isc/oito. Esta última torna-se uma resposta possível dentre o conjunto das demais palavras porque em quaisquer delas, com exceção de "pescoço", o /e/ pode ser produzido como /i/: disculpe, iscuto etc. Outro exemplo seria estranho, repetido como esp/era, estr/ela, esclonde, est/eira, esc/ola e esp/elho. Não foi anotado nas respostas dos sujeitos se eles repetiram es ou is, mas de toda forma ambas as pronúncias são possíveis. ${ }^{9}$

Ressalta-se ainda, na linha das respostas na quais os sujeitos pareceram basear-se no GIPC, as palavras-alvo iniciadas em vogal, como em alguma, aonde, abelha, ainda.

Há, por fim, as palavras-alvo que foram trocadas por palavras sem significado, tais como: alguma por alguto, desculpe por

\footnotetext{
${ }^{9}$ Lahiri e Marslen-Wilson (1991) avaliaram que não há necessidade do sujeito ouvir completamente a palavra para identificá-la e sim, basta ouvir a primeira sílaba. e deduzir os itens-estímulo a partir de seu arquivo fonológico e lexical. Charles-Luce e Luce (1990) e Walley (1988) argumentaram que a utilização da pista da sílaba inicial, só é realizada de modo adequado quando a criança já adquiriu um léxico substancial e por isso, para a identificação da palavra, ainda nesta fase ( em torno de 5 anos), devem realizar uma avaliação mais globalizada da mesma. Os autores sugerem também que, quando a informação da primeira sílaba não foi suficiente para o reconhecimento, a outra estratégia mais, freqüentemente, utilizada é a informação retirada da entonação, isto é, da sílaba de maior tonicidade. Outra questão apontada como um fator de influência no processo de reconhecimento é o funcionamento da memória de trabalho/fonológica. Segundo Gathercole e Baddeley (1989) há a presença de um armazenador fonológico que retém a informação recebida tempo suficiente para que ela seja avaliada e identificada. Seus achados mostram que a capacidade de armazenamento da memória de curto prazo é influenciada pelo aumento do léxico da língua, principalmente, a partir dos 5 anos de idade.
} 
banquismo, presente por ninquende. Nestes casos caberia uma análise acústica do sinal de fala do locutor que serviu como estímulo para a repetição, uma vez que causa estranheza que presente, por ex. tenha sido produzido como ninquende e pringuente por sujeitos diferentes, apesar de que tais palavras apresentam diferentes concentrações de numero de erros. Nestes casos, parece haver uma total disparidade entre a palavraalvo e a repetição pelo sujeito.

Considerando-se que a resposta correta ao LRF está baseada em seu correspondente direto da palavra-alvo, pode-se supor que uma análise qualitativa das respostas deve auxiliar esta avaliação fornecendo subsídios quanto aos processos que estão sendo realizados pelo sujeito, em especial, naqueles casos onde não houve compatibilidade de resultados entre o LRF e a média tonal.

É fato que o LRF não deve ser tomado como um indicativo final da qualidade de função comunicativa do indivíduo, pois somente o reconhecimento da palavra trissilábica é insuficiente para tal, por isso, a proposta de uma análise mais aprofundada, como esta apresentada, pode servir de meio para melhor entendimento dos processos utilizados pelo sujeito e aí, sim, indicar suas qualidades comunicativas, principalmente, naqueles em que haja a presença de alterações de linguagem, alterações de processamento auditivo ou a presença de uma perda auditiva. Esses dados servirão de suporte aos processos subseqüentes como a indicação de aparelho auditivo ou um implante coclear e suporte ao processo de reabilitação auditiva.

Além disso, como continuidade para este trabalho e para a análise dos resultados do LRF e suas correlações clínicas é necessário voltar-se para modelos de constituição e acesso lexical, ou seja, por quais unidades o léxico é composto (traço, fonema, morfema, GIPC, relação 
semântica,etc) e qual o papel dessas unidades no acesso e decisão lexical, baseado nas teorias de percepção da fala disponíveis.

\subsection{Sobre as Listas de Palavras Elaboradas para o Experimento}

O critério utilizado para a elaboração do material de fala que compôs as LE foi a freqüência das palavras em programas infantis. As palavras dessas listas foram selecionadas utilizando-se as 35 primeiras palavras de maior incidência no corpus obtido, retiradas da fala dos apresentadores e personagens dos programas infantis na época do levantamento. Essa forma foi empregada na confecção das listas LE porque pareceu contemplar a freqüência de ocorrência de palavras da linguagem infantil. Por outro lado, para as listas LRS não foi empregado nenhum critério objetivo na escolha do que seriam palavras familiares e freqüentes na composição das listas, a não ser o uso de trissílabos e substantivos, no geral.

O uso do critério da freqüência das palavras que compõem as listas audiométricas, em corpora da língua, é contemplado em estudos mais recentes de desenvolvimento de listas para audiometria da fala, como em Nsamba (1979); Ashoor e Prochazcka (1982), Zubick et al. (1983), Muraki e Said (1991), Mendel e Danhauer (1997), Rabin e Rosenhouse (2000), e para o português por Machado (1988) e Harris et al. (2001).

O presente estudo também se baseou nos trabalhos desenvolvidos por Silva et al. (1995) e Gama-Rossi e Silva (2000) sobre a incidência de palavras de maior freqüência no português brasileiro. 
Eles demonstraram que as palavras trissilábicas participam com $34,5 \%$ do total de ocorrência na língua e a tonicidade, do tipo paroxítona, está presente em mais de $54 \%$ da ocorrência de palavras no português. Estes trabalhos também discutiram as dificuldades de se realizar um balanceamento fonético em listas de palavras de qualquer extensão, além de questionarem a real necessidade de tal balanceamento em listas na audiometria da fala, também sugerido por Martin et al. (2000) quando seu objetivo é o diagnóstico clínico.

Os estudos recentes, acima citados, abandonaram o modelo que focava primordialmente o balanceamento fonético e têm utilizado palavras com alta ocorrência na língua, a partir de levantamentos dicionarizados ou levantamento em situações a que o grupo alvo dos testes de logoaudiometria esteja exposto.

A apresentação das quatro listas empregadas neste estudo (LE1, LE2, LRS1 e LRS2) ocorreu mediante sorteio antes da avaliação de cada orelha e cada sujeito. Na análise estatística, não foi encontrada diferença significante quanto à ordem de apresentação dessas listas.

Apesar das metodologias para a seleção das palavras nas listas LE (Lista Experimental) e LRS (Lista de Russo e Santos) terem sido diferentes, o principal critério empregado em ambas foi a utilização de trissílabos paroxítonos, por serem essas palavras as mais freqüentes na língua. Esta deve ser a razão pela qual não foram obtidas diferenças estatisticamente significantes entre elas, no total das situações avaliadas.

O trabalho de Harris et al. (2001) utilizou como critério para montagem de suas listas a freqüência das palavras na língua, sendo trissílabos paroxítonos e ainda, palavras com uma curva psicométrica de homogeneidade de audibilidade próxima de $8 \% / \mathrm{dB}$. Comparando-se as listas desenvolvidas neste trabalho com as de Harris (op.cit.), nota-se que 
há poucas palavras que coincidem entre LE (direito, idéia, primeiro e criança) e em LRS (banana e tapete).

No caso da Lista LE observa-se que duas palavras indicadas em Harris (op.cit.) como tendo a melhor relação de audibilidade com curva psicométrica à $50 \%$ de acerto entre 6 e 11dBNA, aparecem neste estudo dentre as palavras com maior número de erros. São elas: idéia $e$ primeiro o que talvez aponte para o fato de que na avaliação de crianças a curva de audibilidade não seja tão importante como na avaliação audiológica de adultos, ou ainda, o critério de audibilidade deva ser utilizado com maior preponderância para avaliar deficientes auditivos, como sugerido por Olsen e Matkin (1979).

Young et al. (1982) encontraram que listas com palavras psicometricamente homogêneas em audibilidade (selecionadas dentre aquelas cuja curva apresenta $8 \% / \mathrm{dB}$.), não apresentaram diferenças estatisticamente significantes para os valores de LRF em comparação a outras listas não homogêneas. Os autores sugerem que o próprio estímulo apresenta uma série de características de alta redundância como extensão, duração, entonação, familiaridade e alta ocorrência na língua que seriam muito mais críticos ao reconhecimento do que somente o critério de audibilidade e que a familiaridade seria um critério mais adequado. A esta situação, as questões que se levantam são: quais são as palavras familiares a um determinado grupo e que critério utilizar para escolhê-las. Para isso faz-se necessário um estudo em conjunto com a psicolingüística de modo a nortear o audiologista neste campo de estudo, a princípio, sugere-se a metodologia aqui empregada, como o levantamento de palavras a partir de determinado universo a que o grupo alvo está exposto. 
Outra questão inerente à construção das listas de LRF é o número de itens que elas devem conter. Os trabalhos de Beattie et al. (1975), Punch e Howard (1985) e Meyer e Bilger (1997) indicaram que listas com um número reduzido de palavras (como $2,4,9$, dentre outras) aumentaram a variabilidade dos resultados. Esses estudos sugeriram que uma lista contendo aproximadamente 35 palavras teria o tamanho suficiente para uso na avaliação do LRF. As listas aqui desenvolvidas seguiram, então, esse critério. Contudo, quando se leva em conta as avaliações realizadas na coleta dos dados, no geral, utilizou-se em média de 12 a 15 itens de cada lista. O trabalho de Young et al. (1982) já apontava para a necessidade de uso, em média, de 15 itens na medida do LRF.

Portanto, nem todas as palavras selecionadas foram utilizadas para a medida do LRF, pois algumas delas, nas duas listas, mantiveram-se fora do número total de palavras necessário. Para minimizar tal questão, sugere-se construir uma lista para cada sujeito, em muitas ordens aleatórias, para cada sessão de avaliação, ou pelo menos, criar 3 listas a partir de cada uma delas, sendo que 35 palavras seriam reordenadas e a lista teria três versões: uma iniciando na primeira palavra, outra, na décima terceira palavra e a última, na vigésima quinta.

A análise da incidência do número de erros por palavra (tabela 22) e também do número total de palavras necessárias à medida do LRF após a aplicação da lista LE1 sugere que as palavras que apresentaram até $40 \%$ de erros sejam retiradas (idéia, menina, ainda, caminho, porteiro, primeiro e certeza), mesmo que dentre elas haja palavras de alta freqüência no corpus, como porteiro e menina. Das 5 palavras com maior incidência de erro na fase piloto, 4 mantiveram-se na fase experimental (idéia, ainda, primeiro e menina) o que apóia a 
retirada delas da lista de modo a minimizar possíveis efeitos de número de erros nestas palavras e, assim, influenciar o resultado final do LRF. Vale ressaltar, entretanto, que apesar da presença destas palavras, também, foram obtidos valores de LRF, nas LE baixos.

A retirada dessas cincos palavras formaria uma nova lista composta por 28 palavras. Outra sugestão é que dessas 28 palavras podese considerar que: pessoas, moeda, teatro, crianças, presente, abelha, bolinha, castelo e amigo possam constituir um corpus de figuras a serem utilizadas para avaliar o LRF em crianças menores que 5 anos ou aquelas com dificuldades na resposta oral, conforme sugerido pela ASHA (1988) Nessa situação de avaliação são apresentadas de três a seis figuras, onde uma palavra é dita e deve ser relacionada com a figura correspondente. As listas formadas por figuras estão sugeridas no anexo 14.

A análise do número de erros de cada item e sua freqüência no corpus, não mostrou uma correlação estatisticamente significante, conforme a figura 9. Por exemplo, a palavra porteiro, tem incidência de 31 vezes no corpus, isto é, a quarta palavra de maior incidência mas, está classificada como a quinta palavra mais "difícil" da lista, com 38 erros no total das apresentações. O mesmo ocorre com a palavra aonde que não apresenta alta incidência no corpus (12 vezes) mas apresenta baixa incidência de erros ( 3 vezes). Um outro exemplo interessante de modo oposto a estes citados é a palavra agora que tem alta incidência no corpus (55 vezes) e baixa incidência de erros (3 vezes). Assim, os erros não parecem ter sido influenciados diretamente pela freqüência de ocorrência do item no corpus mas, sim, pelas razões já discutidas nas estratégias das respostas dos sujeitos nos itens 5.1 e 5.2.

A análise das categorias gramaticais das palavras que compõem as listas LE e LRS mostrou que, de acordo com a incidência 
na língua, os substantivos aparecem em maior número, seguidos pelos adjetivos. Na lista LE há o emprego, em menor porcentagem, de outras categorias gramaticais, tais como advérbios, pronomes, verbos e conjunções, conforme a tabela 21. Nota-se que o número de erros não está relacionado à categoria gramatical da palavra, mas à própria tarefa de reconhimento e às estratégias utilizadas pelos sujeitos para o seu reconhecimento. Como por exemplo, dentre as cinco palavras de maior incidência de erros temos idéia, menina, caminho e porteiro que são substantivos e ainda que é advérbio ou a palavra agora de maior freqüência e menor número de erros que é um advérbio. Essa avaliação também demonstrou que o tipo de critério utilizado na montagem das listas influenciou o aparecimento de diferentes tipos de palavras da língua.

De qualquer modo, o uso de um corpus apresenta a vantagem de que as palavras podem ser retiradas de acordo com diferentes critérios como categorias semânticas e gramaticais, ou ainda, podem ser inseridas dentro de sentenças carreadoras ou veículos segundo seu aparecimento no corpus. Esta é uma vantagem das listas $L E$ por terem sido produzidas deste modo, diferentemente das listas LRS, podendo aproveitá-las para um futuro desenvolvimento de listas de sentenças para o LRF.

Os achados deste estudo, concordam com as propostas feitas por Gama-Rossi e Silva (2000) que apontam para a necessidade de se utilizar um modelo mais psicolingüístico e sociolingüístico para a elaboração de listas para a clínica audiológica. Os resultados deste trabalho, apesar de não apontar diferenças significativas entre as listas com diferentes metodologias de estruturação, mostrou ao seu percurso, a necessidade do conhecimento mais estreito entre as áreas, de modo a 
favorecer a construção de listas ou outros materiais aplicados à clinica audiológica. Essas idéias também são apoiadas por outros autores, em diversas línguas, como Nsamba (1979), Ashoor e Prochazcka (1982) Mukari e Said (1991) dentre outros trabalhos já citados.

\subsection{Sobre a Gravação e a Edição do Material da Fala}

Desde 1970, os testes desenvolvidos para a audiometria da fala ganharam versões gravadas e, mais recentemente, com as tecnologias digitais, gravadas em compact disc. A gravação proporciona grande vantagem, principalmente pela estabilidade na apresentação do material e melhor reprodutibilidade dos resultados do teste (Kreul, Bell e Nixon (1969).

O levantamento bibliográfico realizado mostrou que, no Brasil, não há trabalhos ou materiais de fala gravados para uso específico na medida do LRF, para a faixa etária avaliada, salientando, assim, a importância do desenvolvimento desse tipo de material.

A metodologia de gravação deste estudo foi baseada em Wilson (1993, 1997) e Mendel e Danhauer (1997) que descreveram, de forma bastante completa, as vantagens e cuidados na utilização de material gravado. No presente trabalho, este item foi considerado de extrema importância, já que a intensidade de gravação tem influência no resultado final do LRF obtido, por isso, as gravações foram realizadas em estúdio de nível e renome nacional, com equipamentos de última geração, para garantir qualidade e fidelidade aos itens gravados. Considera-se que a metodologia utilizada produziu um material de qualidade e de baixa variabilidade, onde todos os itens apresentam picos 
máximos de intensidade no VU meter em torno de zero dBNA a partir do tom de calibração, sendo que as palavras possuem diferenças de energia de acordo com seus fonemas constituintes e sua energia total se espelha no funcionamento do VUmeter com picos que identificam as médias das intensidades (por exemplo, na medida do VUmeter para as palavras espondáicas que compõem o CIDW1, a média foi de $-4,42$ a $3,11 \mathrm{~dB})$.

Essa questão também foi sugerida por Picard et al. (1998) como um dos fatores mais importantes no desenvolvimento de materiais para o LRF. Eles consideram que as condições controladas de gravação e apresentação, além do método de medida do LRF (conforme discutido no item 5.1) provocará o aparecimento de medidas mais estáveis, fidedignas e confiáveis para uso no diagnóstico auditivo e otológico.

Outro item relevante neste tópico é o tom de calibração. Segundo sugestão de Wilson (1997) esse tom deve refletir o material da fala utilizado, de modo que a intensidade máxima no VU meter seja, aproximadamente, a mesma em todas as palavras apresentadas. A análise do material pelo limiter (do programa PRO TOOLS) proporcionou produzir um tom de calibração de $1000 \mathrm{~Hz}$ gravado na intensidade média do material de fala. De acordo com Sherwood e Fuller (1997) e a norma ISO 8253-3, o tom foi gravado em 3dB abaixo do pico de intensidade do material da fala.

Quanto à locução, a escolha da voz do sexo feminino, pareceu ser adequado pois é um tipo de voz muito presente no dia-a-dia das crianças, que são geralmente cuidadas pela mãe, professora, babá ou avó. Esta questão também foi sugerida e apoiada por Fallon et al. (2000). Todavia, estudos com indivíduos otologicamente normais não apresentaram diferenças significantes entre a apresentação de vozes 
masculinas ou femininas, como referem Sacaloski (1997) e Harris e col. (2001) e, também, no estudo de Peerce e Fowler (1992), Young et al. (1982) e Beattie et al. (1975). Uma sugestão é que o material seja gravado nos dois tipos de vozes conforme Harris et al. (2001) e o material desenvlvido pela Auditec Saint Louis e pela Brigham Young University.

A escolha por uma locução não-profissional foi baseada em Costa (1998) que também sugere ao locutor pronúncia clara e espontânea dos itens da lista. Young et al. (1982) sugeriram, também, que há pouco efeito do locutor nos testes de LRF, devido ao tipo de estímulo utilizado, palavras trissilábicas, que apresentam grande número de redundâncias quando comparadas a outros estímulos, como por exemplo, palavras monossilábicas.

A metodologia de gravação das palavras que compõem as listas LE e LRS foi realizada através de várias pronúncias da mesma palavra. Esta metodologia adotada proporcionou ao locutor um ritmo de fala adequado e com menor número de distorções de articulação e entonação. Entretanto, outra metodologia pode ser empregada, como a leitura seqüencial dos itens da lista.

Quanto ao tempo de intervalo de gravação utilizado, 4 segundos, mostrou-se como tempo suficiente para a obtenção das respostas do sujeito. Este intervalo de tempo é sugerido nos materiais da fala, já citados, como do Auditec Saint Louis e da Brigham Young University.

Vale ressaltar, ainda, a importância de um equipamento de qualidade (audiômetro e discman) e cuidados na calibração, conforme já indicados no método e na fase piloto. 


\section{CONSIDERAÇÕES FINAIS}


A partir da análise dos resultados obtidos na amostra estudada:

- Os resultados dos desempenhos dos sujeitos na medida do Limiar de Reconhecimento da Fala foram semelhantes quando comparadas as listas experimentais LE desenvolvidas por este trabalho às listas LRS de Russo e Santos (1993), tanto em relação à orelha avaliada como em relação às faixas etárias e ordem de aplicação das listas;

- Em relação ao sexo, somente na faixa etária de 5 anos foi encontrada diferença estatisticamente significante, na aplicação da lista LRS, na OE, em relação à faixa etária de 6 anos;

- Os resultados do LRF (dBNS) em relação ao número total de orelhas avaliadas nas três faixas etárias para a lista LE variaram entre -8 e $15 \mathrm{dBNS}$ e para a lista LRS variou entre -10 e 14dBNS. As médias gerais, computando-se os resultados de todas as listas, foram de 4,3 dBNS para a OD e 4,4 dBNS para a OE, concordantes com a literatura;

- A variabilidade das respostas do LRF está relacionada a vários fatores que podem ter interagido ou não, num mesmo sujeito, como: o funcionamento da via auditiva em relação às características do estímulo (influências acústicas) no processamento via bottom-up e às respostas do sistema auditivo no processamento top-down (influências semânticas e lexicais), além dos fatores da atenção auditiva e memória, fatores que se relacionam com a execução da própria tarefa e a motivação do sujeito em realizá-la;

- A correlação da média tonal e do LRF situou-se entre r=0,54 a $\mathrm{r}=0,86$ para as orelhas direitas e esquerdas; 
- A análise entre o número de erros cometidos nas palavras e a incidência das mesmas no corpus não foi estatisticamente significante além da comparação dos grupos em relação à faixa etária quanto à distribuição total dos erros por item da lista;

- Esses resultados indicam que as listas desenvolvidas são adequadas para uso na medida do LRF;

- Apesar da variabilidade das respostas, são incontestáveis a importância clínica e diagnóstica na correspondência do LRF e a média tonal. Para minimizar essa variabilidade, o clínico deve estar pronto e atento para propor estratégias diferenciadas. A proposta de uma avaliação qualitativa das respostas do LRF pode ser utilizada como forma de resolver a incompatibilidade entre o LRF e a média tonal;

- A análise qualitativa das estratégias para o reconhecimento da palavra realizada pelos sujeitos demonstrou que há uma inter-relação e sobreposição de diferentes estratégias, dentre elas: a similaridade fonética (palavra com o mesmo número de silabas, preservação total ou parcial das vogais do estimulo-alvo), manutenção de pedaços do estimulo-alvo que varia entre traço até frase ou expressão, além de relação semântica e a manutenção do GIPC. Por outro lado, mesmo as palavras sem significado parecem, na maior parte das vezes, manterem alguns destes parâmetros;

- É evidente que o audiologista que pretende dedicar-se ao desenvolvimento de listas, do ponto de vista clinico, para o diagnóstico deve ter conhecimento necessário na área da psicolingüística ou ser auxiliado por estudioso da área, a fim de prover materiais de fala válidos e adequados ao objetivo do teste a ser desenvolvido; 
- A medida do LRF é um processo complexo onde o ouvinte é solicitado a usar seu conhecimento lingüístico, para decidir o reconhecimento sob condições de informações auditivas limitadas pela intensidade. Assim, observa-se que a tarefa de realizar a medida do LRF, tanto para o examinador como para o examinado, abarca uma ampla discussão levando-se em consideração todos os aspectos pertinentes ao método, ao sujeito e ao estímulo que interagem de forma estreita e com variados níveis de entrelaçamento. Tais aspectos tornam a tarefa do desenvolvimento de listas de palavras extremamente árdua, principalmente, para a faixa etária desse estudo.

- Além da necessidade de valer-se de condições controladas para que se possa avaliar a correspondência entre o LRF e a média tonal: cuidados na apresentação do sinal (intensidade), padronização dos procedimentos de medida do limiar de tom puro e do reconhecimento da fala, uso de material gravado e a escolha do tipo de material de fala utilizado. 


\section{ANEXOS}




\section{ANEXO 1}

listas de palavras trissílabas paroxítonas do total do corpus em ordem decrescente (o número a frente indica sua ocorrência total no corpus)

$\begin{array}{rlrr}\text { agora } & 55 & \text { cabeça } & 9 \\ \text { castelo } & 44 & \text { comida } & 9 \\ \text { crianças } & 36 & \text { conheço } & 9 \\ \text { porteiro } & 31 & \text { dificil } & 9 \\ \text { amigo/a } & 31 & \text { escolha } & 9 \\ \text { estamos } & 26 & \text { gatinho } & 9 \\ \text { embora } & 25 & \text { história } & 9 \\ \text { cidade } & 22 & \text { imagens } & 9 \\ \text { desculpe } & 21 & \text { macaco } & 9 \\ \text { menina } & 21 & \text { maluco } & 9 \\ \text { menino } & 21 & \text { montanha } & 9 \\ \text { socorro } & 21 & \text { pensando } & 9 \\ \text { bolinha } & 20 & \text { vermelho } & 9 \\ \text { problema } & 20 & \text { adora } & 8 \\ \text { fazendo } & 19 & \text { artista } & 8 \\ \text { idéia } & 19 & \text { baralho } & 8 \\ \text { espere/a } & 18 & \text { bastante } & 8 \\ \text { querido } & 17 & \text { buraco } & 8 \\ \text { sozinho } & 17 & \text { podia } & 8 \\ \text { ainda } & 16 & \text { absurdo } & 7 \\ \text { estava } & 16 & \text { desenho } & 7 \\ \text { estranho } & 16 & \text { exemplo } & 7 \\ \text { certeza } & 15 & \text { pergunta } & 7 \\ \text { precisa } & 15 & \text { resposta } & 7 \\ \text { cansado } & 14 & \text { sobrinho } & 7 \\ \text { pedido } & 14 & \text { vontade } & 7 \\ \text { podemos } & 14 & \text { bacana } & 6 \\ \text { presente } & 14 & \text { bobagem } & 6 \\ \text { verdade } & 14 & \text { bonito } & 6 \\ \text { comigo } & 13 & \text { cantante } & 6 \\ \text { oitavo } & 13 & \text { chegamos } & 6 \\ \text { pessoas } & 13 & \text { chegaram } & 6 \\ \text { primeiro } & 13 & \text { coelho } & 6 \\ \text { vergonha } & 13 & \text { coragem } & 6 \\ \text { aonde } & 12 & \text { depressa } & 6 \\ \text { falando } & 12 & \text { inteira } & 6 \\ \text { alguma } & 11 & \text { morcego } & 6 \\ \text { direito } & 11 & \text { perfeitos } & 6 \\ \text { existe } & 11 & \text { princesa } & 6 \\ \text { parece } & 11 & \text { pulando } & 6 \\ \text { teatro } & 11 & \text { quieta } & 6 \\ \text { abelha } & 10 & \text { ratinho } & 6 \\ \text { aquela } & 10 & \text { soldado } & 6 \\ \text { caminho } & 10 & \text { trabalho } & 6 \\ \text { conhece } & 10 & \text { apaga } & 5 \\ \text { convite } & 10 & \text { aplauso } & 5 \\ \text { moeda } & 10 & 5\end{array}$




\begin{tabular}{|c|c|c|}
\hline surpresa & 10 & relógio \\
\hline palavra & 10 & saudades \\
\hline cachorro & 5 & segura \\
\hline caverna & 5 & \\
\hline concerto & 5 & senhora \\
\hline contrário & 5 & senhores \\
\hline deixaram & 5 & sumindo \\
\hline deserto & 5 & transporte \\
\hline estica & 5 & travesso \\
\hline estilo & 5 & ursinho \\
\hline floresta & 5 & viagem \\
\hline jaqueta & 5 & volume \\
\hline orquestra & 5 & acaba \\
\hline passeio & 5 & acaso \\
\hline perfume & 5 & adultas \\
\hline perigo & 5 & agosto \\
\hline pintado & 5 & aguente \\
\hline queria & 5 & antigo \\
\hline rainha & 5 & aperta \\
\hline responde & 5 & ataque \\
\hline tamanho & 5 & atraso \\
\hline tivesse & 5 & barquinho \\
\hline vestido & 5 & barriga \\
\hline visita & 5 & boneco \\
\hline abertos & 4 & brincando \\
\hline alegre & 4 & cabelos \\
\hline aposto & 4 & caixinha \\
\hline bexiga & 4 & ciume \\
\hline cantando & 4 & combate \\
\hline carona & 4 & comprida \\
\hline castigo & 4 & consigo \\
\hline cavalo & 4 & contente \\
\hline comando & 4 & contrato \\
\hline comece & 4 & correndo \\
\hline controle & 4 & delicia \\
\hline desejo & 4 & ensina \\
\hline desfile & 4 & entendo \\
\hline egito & 4 & escrito \\
\hline enorme & 4 & escute \\
\hline errada & 4 & espinha \\
\hline escola & 4 & estória \\
\hline esquece & 4 & estrela \\
\hline faísca & 4 & explica \\
\hline felizes & 4 & feitiço \\
\hline gostando & 4 & gravata \\
\hline manteiga & 4 & hamburguer \\
\hline mãozinha & 4 & impulso \\
\hline paquera & 4 & inverno \\
\hline perdido & 4 & lagarta \\
\hline perdoe & 4 & lembrança \\
\hline pescoço & 4 & linguiça \\
\hline piano & 4 & maneira \\
\hline possível & 4 & mentira \\
\hline potinho & 4 & minhoca \\
\hline preciso & 4 & momento \\
\hline prefiro & 4 & morrendo \\
\hline programa & 4 & famoso \\
\hline rasgada & 4 & fazemos \\
\hline orelha & 3 & figura \\
\hline
\end{tabular}




\begin{tabular}{|c|c|c|}
\hline ouvindo & 3 & filhinho \\
\hline passamos & 3 & fingindo \\
\hline passando & 3 & fizeram \\
\hline perdendo & 3 & furada \\
\hline pipoca & 3 & ganharam \\
\hline poderes & 3 & gostosa \\
\hline portanto & 3 & horrível \\
\hline pouquinho & 3 & humano \\
\hline procuro & 3 & importa \\
\hline sabiam & 3 & incrível \\
\hline seguinte & 3 & instante \\
\hline seguro & 3 & inventos \\
\hline sessenta & 3 & levanta \\
\hline sucesso & 3 & levante \\
\hline vejamos & 3 & madeira \\
\hline aberta & 2 & maldades \\
\hline acabe & 2 & mastigar \\
\hline acorda & 2 & materia \\
\hline ajude & 2 & medida \\
\hline alada & 2 & melado \\
\hline andando & 2 & mergulho \\
\hline assunto & 2 & metade \\
\hline batendo & 2 & moçada \\
\hline bichinhos & 2 & morava \\
\hline brilhante & 2 & mulheres \\
\hline brinquedo & 2 & naquela \\
\hline cadeira & 2 & nascido \\
\hline calçada & 2 & nenhuma \\
\hline cantora & 2 & olhada \\
\hline cebola & 2 & olhando \\
\hline cercada & 2 & ouvido \\
\hline chamada & 2 & ouviram \\
\hline chefinho & 2 & palhaço \\
\hline cinema & 2 & parada \\
\hline coberta & 2 & passaram \\
\hline colete & 2 & pedaço \\
\hline completos & 2 & pensado \\
\hline conselho & 2 & pequeno \\
\hline cozinha & 2 & perguntem \\
\hline criadas & 2 & picada \\
\hline culpado & 2 & piloto \\
\hline daquele & 2 & planeta \\
\hline demora & 2 & porquinho \\
\hline descubro & 2 & presença \\
\hline devemos & 2 & pretende \\
\hline duvido & 2 & proteja \\
\hline equipe & 2 & pudermos \\
\hline escapa & 2 & quarenta \\
\hline escrava & 2 & quebrada \\
\hline escreva & 2 & quiserem \\
\hline escreve & 2 & recibo \\
\hline esforço & 2 & bocado \\
\hline esperta & 2 & bombinha \\
\hline esperto & 2 & bonzinho \\
\hline estrada & 2 & brigando \\
\hline repórter & 2 & brincava \\
\hline revelam & 2 & burrinho \\
\hline saída & 2 & cabine \\
\hline sapato & 2 & caçula \\
\hline
\end{tabular}




\begin{tabular}{|c|c|c|}
\hline sapinho & 2 & caíram \\
\hline seguimos & 2 & camelo \\
\hline selvagem & 2 & canoa \\
\hline sorria & 2 & cansaço \\
\hline sorvete & 2 & cantinho \\
\hline soubesse & 2 & cãozinho \\
\hline sozinha & 2 & caramba \\
\hline tchauzinho & 2 & careta \\
\hline tentando & 2 & carinha \\
\hline tesoura & 2 & carrinho \\
\hline treinando & 2 & cartola \\
\hline vazio & 2 & casaca \\
\hline vencida & 2 & casulo \\
\hline vendendo & 2 & chamando \\
\hline ventando & 2 & chamaram \\
\hline voltinha & 2 & chegado \\
\hline abaixa & 1 & chegando \\
\hline abraço & 1 & chegava \\
\hline abriram & 1 & cheirosa \\
\hline aceito & 1 & chiquinho \\
\hline achasse & 1 & chorando \\
\hline achavam & 1 & circuito \\
\hline acima & 1 & circula \\
\hline açucar & 1 & cirquinho \\
\hline agouro & 1 & clareza \\
\hline aguda & 1 & cobrinha \\
\hline almoço & 1 & coisinhas \\
\hline altura & 1 & coitado \\
\hline anchovas & 1 & comendo \\
\hline andares & 1 & concorda \\
\hline apenas & 1 & confio \\
\hline aprendo & 1 & conforme \\
\hline arame & 1 & conosco \\
\hline arara & 1 & consegue \\
\hline aroma & 1 & consiga \\
\hline arqueiro & 1 & contava \\
\hline arquivo & 1 & conversa \\
\hline assina & 1 & convida \\
\hline assistem & 1 & corneta \\
\hline assuste & 1 & corrida \\
\hline bagunça & 1 & crescendo \\
\hline baleia & 1 & crescida \\
\hline bandido & 1 & danado \\
\hline banheiro & 1 & dançando \\
\hline barbante & 1 & decidem \\
\hline barracas & 1 & declaro \\
\hline barulho & 1 & depende \\
\hline bastasse & 1 & descansem \\
\hline batalha & 1 & garotos \\
\hline batata & 1 & garrafa \\
\hline bicudo & 1 & gigante \\
\hline bilhete & 1 & goiaba \\
\hline desprezo & 1 & gorila \\
\hline destaque & 1 & gostaram \\
\hline desvio & 1 & gostasse \\
\hline devia & 1 & gostoso \\
\hline devolva & 1 & goteiras \\
\hline diacho & 1 & gozado \\
\hline difíceis & 1 & gracinha \\
\hline
\end{tabular}




\begin{tabular}{|c|c|c|}
\hline dilatam & 1 & granada \\
\hline dispara & 1 & grandona \\
\hline disseram & 1 & granito \\
\hline distancia & 1 & gritando \\
\hline dizendo & 1 & grudento \\
\hline diziam & 1 & guerreiros \\
\hline doente & 1 & gulos $\mathrm{A}$ \\
\hline dormindo & 1 & honesta \\
\hline duquesa & 1 & iguais \\
\hline durante & 1 & imensa \\
\hline encontra & 1 & indica \\
\hline encontre & 1 & insiste \\
\hline encosta & 1 & interno \\
\hline engana & 1 & inutil \\
\hline enquanto & 1 & invejo \\
\hline enrola & 1 & inverso \\
\hline entraram & 1 & iremos \\
\hline entrasse & 1 & janela \\
\hline escada & 1 & lamento \\
\hline escrita & 1 & largada \\
\hline escuro & 1 & levados \\
\hline esfrega & 1 & levando \\
\hline espada & 1 & licença \\
\hline esporte & 1 & ligado \\
\hline estejam & 1 & lindinha \\
\hline estreito & 1 & listrada \\
\hline exato & 1 & loucura \\
\hline fajuto & 1 & magia \\
\hline falava & 1 & maldade \\
\hline faremos & 1 & maldito \\
\hline fechada & 1 & manteve \\
\hline fechando & 1 & medroso \\
\hline felinos & 1 & mesada \\
\hline feridas & 1 & mistura \\
\hline ficado & 1 & modelo \\
\hline ficando & 1 & moleza \\
\hline ficarmos & 1 & mudando \\
\hline ficava & 1 & muralha \\
\hline filhotes & 1 & naquele \\
\hline fininha & 1 & nasceram \\
\hline fizermos & 1 & negocio \\
\hline fofinho & 1 & nervoso \\
\hline fofoca & 1 & odeio \\
\hline fugiam & 1 & ofensas \\
\hline fugiram & 1 & sairam \\
\hline fumaça & 1 & segredo \\
\hline futuro & 1 & segundo \\
\hline garota & 1 & segure \\
\hline olhamos & 1 & segurem \\
\hline orgulho & 1 & semente \\
\hline ossinhos & 1 & sentado \\
\hline ouvia & 1 & sentido \\
\hline palpite & 1 & sentisse \\
\hline panela & 1 & seremos \\
\hline panelas & 1 & serrote \\
\hline parava & 1 & silencio \\
\hline parede & 1 & sinais \\
\hline parente & 1 & sincera \\
\hline assado & 1 & sistema \\
\hline
\end{tabular}




\begin{tabular}{|c|c|}
\hline \multicolumn{2}{|l|}{ gassagem } \\
\hline pedrona & \\
\hline pelado & \\
\hline pensaram & \\
\hline pepita & \\
\hline pertence & \\
\hline pesado & \\
\hline peteca & \\
\hline piada & \\
\hline pimeta & \\
\hline pintando & \\
\hline pintura & \\
\hline pirraça & \\
\hline pisando & \\
\hline piscina & \\
\hline poeira & \\
\hline posamos & \\
\hline preparem & \\
\hline profunda & \\
\hline projeto & \\
\hline prometo & \\
\hline prontinho & \\
\hline pulante & \\
\hline pulinhos & \\
\hline pulseira & \\
\hline pulseram & \\
\hline quatorze & \\
\hline queimados & \\
\hline querendo & \\
\hline quizeram & \\
\hline rachando & \\
\hline raizes & \\
\hline rajada & \\
\hline reage & \\
\hline recado & \\
\hline reforços & \\
\hline refresco & \\
\hline repita & \\
\hline resolve & \\
\hline retorna & \\
\hline roqueira & \\
\hline roubando & \\
\hline sabemos & \\
\hline sabendo & \\
\hline . & \\
\hline
\end{tabular}

$\begin{array}{rr}\text { sonhando } & 1 \\ \text { soninho } & 1 \\ \text { sugiro } & 1 \\ \text { suspeita } & 1 \\ \text { tecido } & 1 \\ \text { teimosa } & 1 \\ \text { tentado } & 1 \\ \text { tentaram } & 1 \\ \text { terceira } & 1 \\ \text { teremos } & 1 \\ \text { termine } & 1 \\ \text { terrivel } & 1 \\ \text { tigresa } & 1 \\ \text { tocando } & 1 \\ \text { tomado } & 1 \\ \text { tomara } & 1 \\ \text { tomate } & 1 \\ \text { topeira } & 1 \\ \text { torneira } & 1 \\ \text { trancada } & 1 \\ \text { tranquilo } & 1 \\ \text { trezento } & 1 \\ \text { tristinho } & 1 \\ \text { turistas } & 1 \\ \text { usamos } & 1 \\ \text { usava } & 1 \\ \text { vacina } & 1 \\ \text { valendo } & 1 \\ \text { vassoura } & 1 \\ \text { veneno } & 1 \\ \text { vermelha } & 1 \\ \text { vestiam } & 1 \\ \text { vibrante } & 1 \\ \text { vieram } & 1 \\ \text { vingança } & 1 \\ \text { visual } & 1 \\ \text { viveiro } & 1 \\ \text { vizinho } & 1 \\ \text { voador } & 1 \\ \text { voltarmos } & 1\end{array}$


Anexo 2A

\begin{tabular}{|c|c|c|c|c|}
\hline LISTA E1 & LRF & 5dBNS & 10dBNS & 15dBNS \\
\hline \multicolumn{5}{|c|}{ Castelo } \\
\hline \multicolumn{5}{|l|}{ Comigo } \\
\hline \multicolumn{5}{|l|}{ Alguma } \\
\hline \multicolumn{5}{|l|}{ Direito } \\
\hline \multicolumn{5}{|l|}{ Verdade } \\
\hline \multicolumn{5}{|l|}{ Bolinha } \\
\hline \multicolumn{5}{|l|}{ Amigo } \\
\hline \multicolumn{5}{|l|}{ Sozinho } \\
\hline \multicolumn{5}{|l|}{ Querido } \\
\hline \multicolumn{5}{|l|}{ Problema } \\
\hline \multicolumn{5}{|l|}{ Desculpe } \\
\hline \multicolumn{5}{|l|}{ Caminho } \\
\hline \multicolumn{5}{|l|}{ Porteiro } \\
\hline \multicolumn{5}{|l|}{ Vergonha } \\
\hline \multicolumn{5}{|l|}{ Socorro } \\
\hline \multicolumn{5}{|l|}{ Aonde } \\
\hline \multicolumn{5}{|l|}{ Espera } \\
\hline \multicolumn{5}{|l|}{ Menina } \\
\hline \multicolumn{5}{|l|}{ Presente } \\
\hline \multicolumn{5}{|l|}{ Estranho } \\
\hline \multicolumn{5}{|l|}{ Cidade } \\
\hline \multicolumn{5}{|l|}{ Abelha } \\
\hline \multicolumn{5}{|l|}{ Moeda } \\
\hline \multicolumn{5}{|l|}{ Aquela } \\
\hline \multicolumn{5}{|l|}{ Idéia } \\
\hline \multicolumn{5}{|l|}{ Teatro } \\
\hline \multicolumn{5}{|l|}{ Agora } \\
\hline \multicolumn{5}{|l|}{ Primeiro } \\
\hline Embora & & & & \\
\hline Ainda & & & & \\
\hline Crianças & & & & \\
\hline Pessoas & & & & \\
\hline Certeza & & & & \\
\hline Cansado & & & & \\
\hline Pedido & & & & \\
\hline Ordem: & & & & \\
\hline Orelha & : & & & \\
\hline
\end{tabular}


Anexo 2B

\begin{tabular}{|c|c|}
\hline LISTA E2 & LRF \\
\hline abelha & \\
\hline aonde & \\
\hline cidade & \\
\hline menino & \\
\hline bolinha & \\
\hline castelo & \\
\hline cansado & \\
\hline primeiro & \\
\hline socorro & \\
\hline ainda & \\
\hline pedido & \\
\hline aquela & \\
\hline embora & \\
\hline desculpe & \\
\hline idéia & \\
\hline amigo & \\
\hline certeza & \\
\hline agora & \\
\hline espera & \\
\hline problema & \\
\hline sozinho & \\
\hline direito & \\
\hline pessoas & \\
\hline caminho & \\
\hline estranho & \\
\hline crianças & \\
\hline comigo & \\
\hline presente & \\
\hline porteiro & \\
\hline vergonha & \\
\hline teatro & \\
\hline alguma & \\
\hline Moeda & \\
\hline verdade & \\
\hline querido & \\
\hline Ordem: & \\
\hline Orelha & \\
\hline
\end{tabular}


Anexo 3A

\begin{tabular}{|l|l|}
\hline LISTA RS1 & \\
\hline Cenoura & \\
\hline Galinha & \\
\hline Farofa & \\
\hline Guloso & \\
\hline Gemada & \\
\hline Cozinha & \\
\hline Novela & \\
\hline Torrada & \\
\hline Maleta & \\
\hline Sapato & \\
\hline Canhoto & \\
\hline Melado & \\
\hline Terraço & \\
\hline Mordida & \\
\hline Azeite & \\
\hline Favela & \\
\hline Chinelo & \\
\hline Janela & \\
\hline Banana & \\
\hline Bondade & \\
\hline Pacote & \\
\hline Telhado & \\
\hline Soldado & \\
\hline Toalha & \\
\hline Girafa & \\
\hline Vontade & \\
\hline Caderno & \\
\hline Tapete & \\
\hline Relógio & \\
\hline Tamanho & \\
\hline Varanda & \\
\hline Cabelo & \\
\hline Molhado & \\
\hline Travessa & \\
\hline Ordem: & \\
\hline
\end{tabular}


Anexo 3B

\begin{tabular}{|l|l|}
\hline \multicolumn{1}{|c|}{ Lista RS2 } & \\
\hline Torrada & \\
\hline Canhoto & \\
\hline Telhado & \\
\hline Cozinha & \\
\hline Janela & \\
\hline Novela & \\
\hline Cenoura & \\
\hline Terraço & \\
\hline Melado & \\
\hline Gemada & \\
\hline Tamanho & \\
\hline Varanda & \\
\hline Bondade & \\
\hline Guloso & \\
\hline Soldado & \\
\hline Pacote & \\
\hline Chinelo & \\
\hline Cabelo & \\
\hline Molhado & \\
\hline Girafa & \\
\hline Mordida & \\
\hline Galinha & \\
\hline Relogio & \\
\hline Farofa & \\
\hline Vontade & \\
\hline Azeite & \\
\hline Caderno & \\
\hline Banana & \\
\hline Tapete & \\
\hline Favela & \\
\hline Toalha & \\
\hline valeta & \\
\hline Sapato & \\
\hline travessa & \\
\hline maleta & \\
\hline torrada & \\
\hline
\end{tabular}




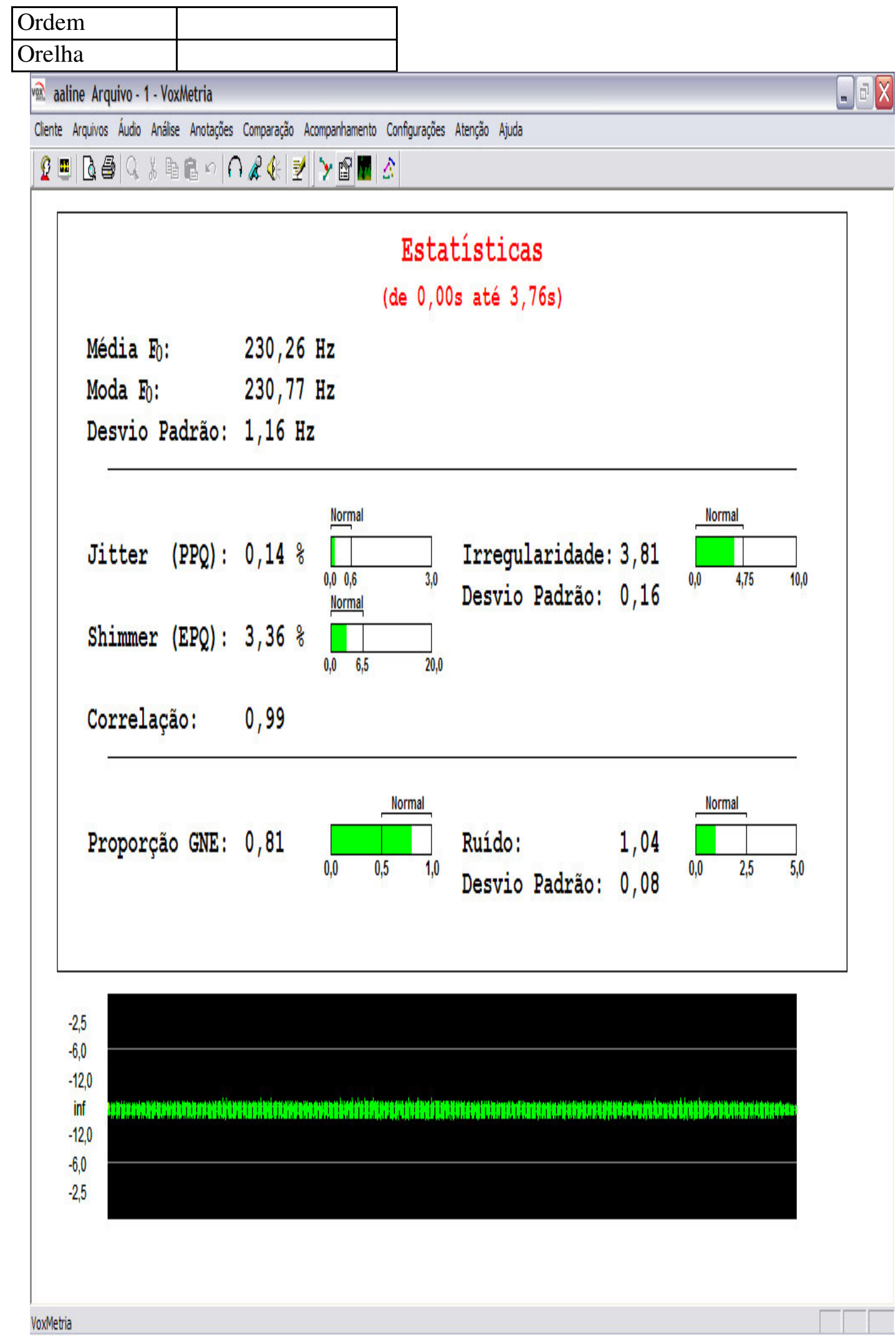

Anexo 4 
Anexo $5 \quad$ A

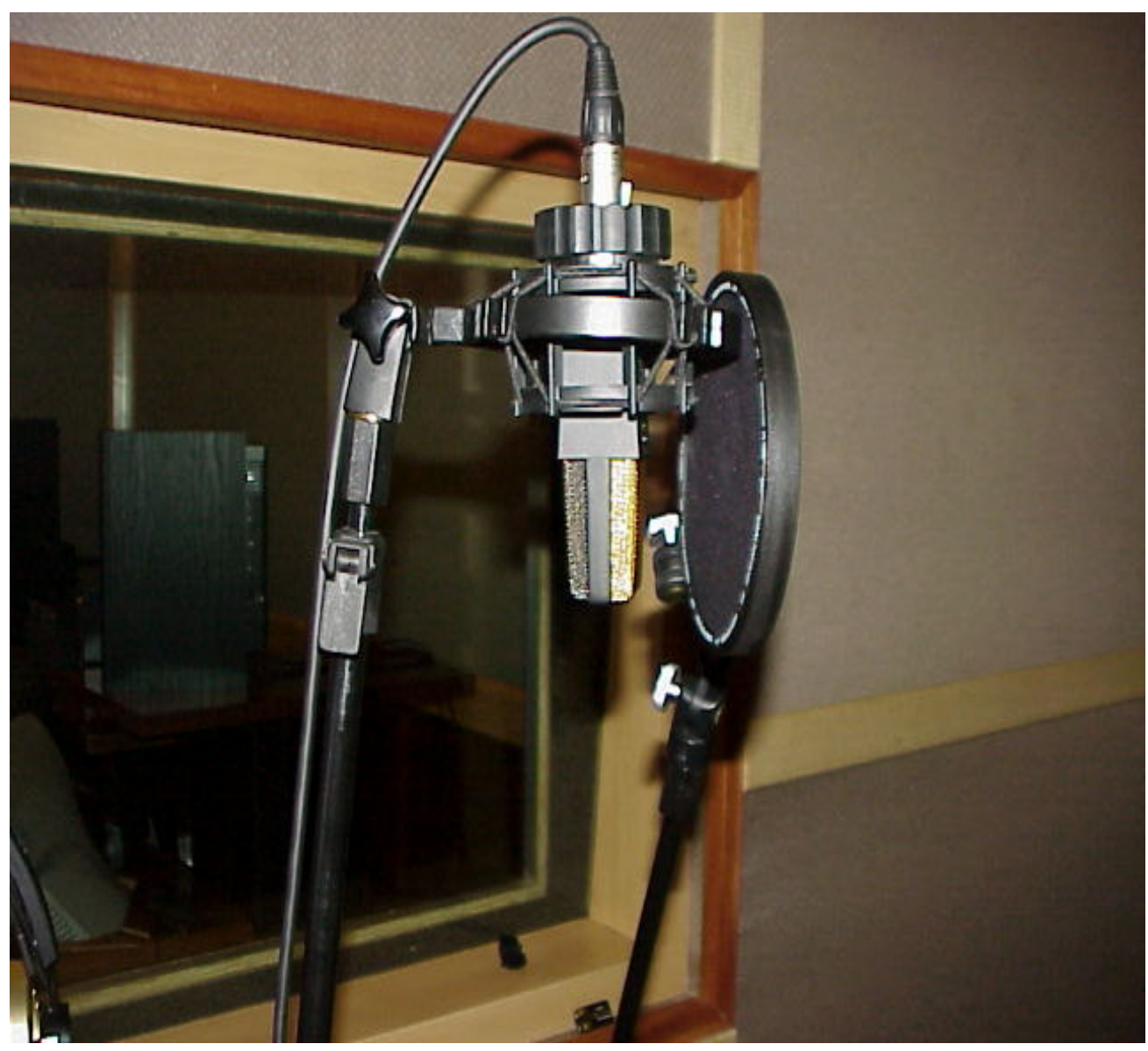


Anexo 5 B

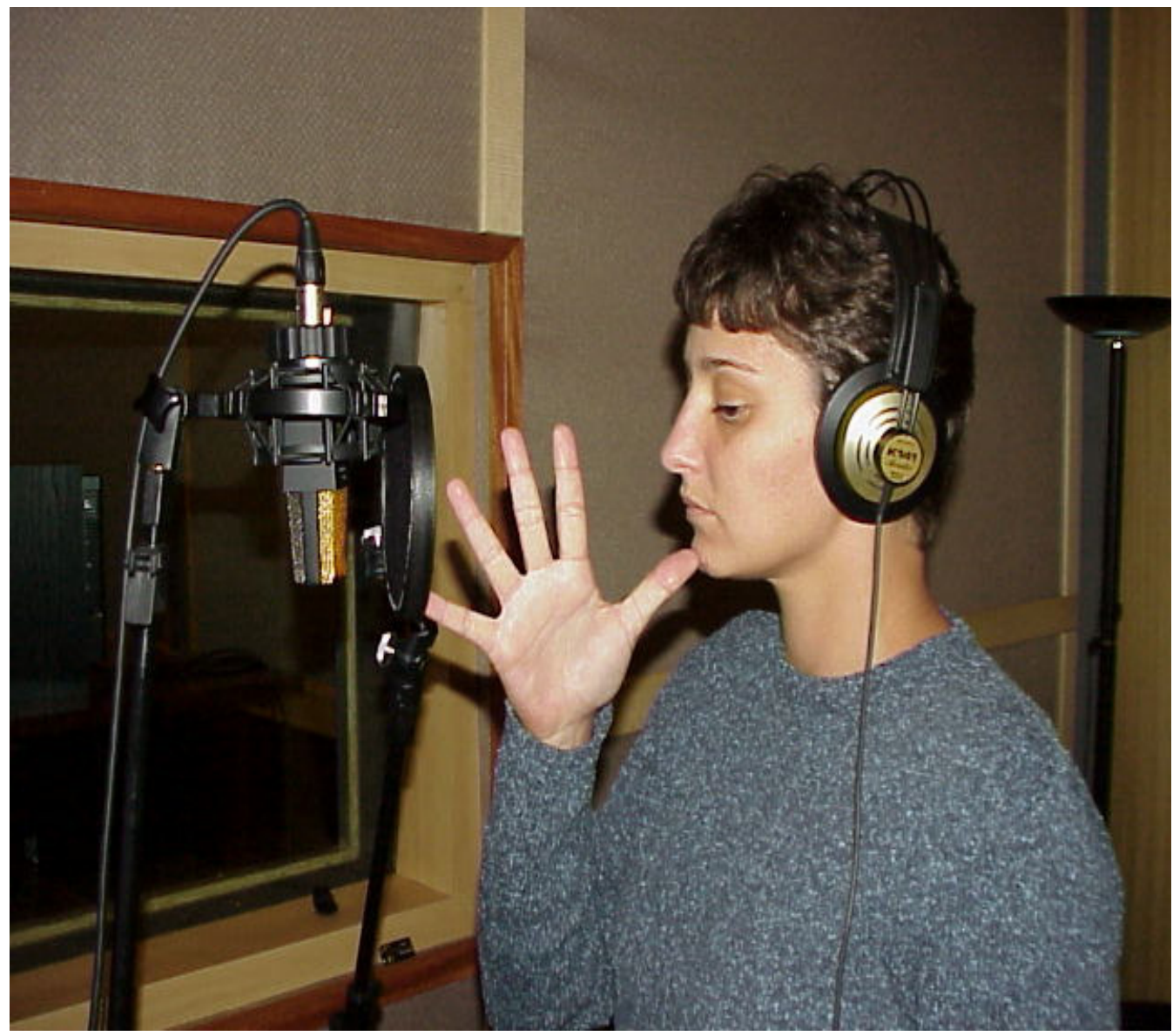




\author{
Anexo 6 \\ Universidade de São Paulo \\ Instituto de Ciências Biomédicas
}

TERMO DE CONSENTIMENTO LIVRE E ESCLARECIDO

(menores de 18 anos)

ESTUDO: DESENVOLVMENTO E ESTUDO COMPARATIVO DE LISTA DE

PALAVRAS PARA USO NA PESQUISA DO LIMIAR DE RECONHECIMENTO DA

FALA EM CRIANÇAS DE 5 A 7 ANOS DE IDADE

Seu filho está sendo convidado a participar do projeto de pesquisa acima citado. $O$ documento abaixo contém todas as informações necessárias sobre a pesquisa que estamos fazendo, então leia atentamente e caso tenha dúvidas, vou esclarece-las (se não souber ler, fique tranquilo(a) que leio para você). Se concordar, o documento será assinado e só então daremos início a pesquisa. Sua colaboração neste estudo será de muita importância para nós, mas se desistir a qualquer momento, isso não causará nenhum prejuízo a você, nem ao seu (sua) filho(a).

Eu RG , abaixo assinado(a), concordo de livre e espontânea vontade que meu(minha) filho(a) nascido(a) em I , seja voluntário do estudo" DESENVOLVMENTO E ESTUDO COMPARATIVO DE LISTA DE PALAVRAS PARA USO NA PESQUISA DO LIMIAR DE RECONHECIMENTO DA FALA EM CRIANÇAS DE 5 A 7 ANOS DE IDADE

Esclareço que obtive todas as informações necessárias e fui esclarecido(a) de todas as dúvidas apresentadas.

Estou ciente que:

I) O estudo se faz necessário para que possa desenvolver material de avaliação da percepção da fala específico para crianças na pesquisa do limiar de reconhecimento de fala. Este teste tem importante papel no diagnostico 
diferencial das mais variadas patologias auditivas, além de previsibilidade do desempenho comunicativo e informações ao processo de reabilitação auditiva e de linguagem.

II) Será realizada uma entrevista através de um questionário e posteriormente a aplicação de um teste de audição (audiometria tonal e imitanciometria), não invasivo e um teste de imitação de palavras.

III) Essas coletas serão feitas apenas para este estudo e em nada influenciará meu (minha) filho(a)

IV) A participação neste projeto não tem objetivo de se submeter a um tratamento terapêutico e será sem custo algum para mim;

V) Tenho a liberdade de desistir ou interromper a colaboração neste estudo no momento em que desejar, sem necessidade de qualquer explicação;

VI) A desistência não causará nenhum prejuízo a mim, nem ao(a) meu (minha) filho(a), e sem que venha interferir no atendimento ou tratamento médico;

VII) Os resultados obtidos durante este ensaio serão mantidos em sigilo, mas concordo que sejam divulgados em publicações científicas, desde que nem o meu nome nem o de meu filho sejam mencionados;

VIII) Caso eu desejar, poderei tomar conhecimento dos resultados ao final desta pesquisa

( ) Desejo conhecer os resultados desta pesquisa.

( ) Não desejo conhecer os resultados desta pesquisa.

Itatiba, de de 2002

Paciente l

Responsável

Testemunha 1:

Nome / RG / Telefone

Testemunha 2 :

Nome / RG / Telefone

Responsável pelo Projeto:

Marcia Regina Gama CRFA 3475/S 
Anexo 7

\section{QUESTIONARIO AOS PAIS}

INDENTIFICAÇÃO DA CRIANÇA

IDADE

D-N

\author{
SEXO \\ PAI-MÃE
}

1) Com que idade seu filho iniciou um processo de produção das primeiras palavras inteligiveis-claras?
( ) +10 meses
( ) +20 meses
( ) +15 meses
( ) +25 meses

2) Seu filho apresentou ou apresenta episódios de infecções de ouvido?

( ) $\operatorname{sim}$ ( ) não

se sim, com que freqüência
( ) 1 vez ao ano
( ) 6 vezes ao ano
( ) 3 vezes ao ano
( ) 12 vezes ao ano

3) Que outras doenças seu filho apresentou ou apresenta?
( ) caxumba
( ) sarampo
( ) bronquite
( ) rinite alérgica
( ) alterações neurológicas
( ) outras

4) Você considera que seu filho tem dificuldades para entender o que lhe é dito?
( ) $\operatorname{sim}$
( ) não

se sim, indique 1 ou mais alternativas

( ) distrai-se facilmente

( ) agitado

( ) concentrado mas mesmo assim com dificuldades

5) Você considera que seu filho apresenta alteração na sua fala?
( ) $\operatorname{sim}$
( ) não

se sim, que tipo?

( ) troca de letras-fonemas na fala

( ) fala não inteligível

( ) nível de fala abaixo da sua idade 
Anexo 8

\section{QUESTIONÁRIO AOS PROFESSORES}

IDENTIFICAÇÃO DA CRIANÇA:

IDADE

SÉRIE

ESCOLA

1) VOCÊ CONSIDERA QUE ESTE ALUNO TEM DIFICULDADES PARA ENTENDER O QUE LHE É DITO?
( ) SIM
( ) NÃO

SE SIM, INDIQUE 1 OU MAIS ALTERNATIVAS

( ) DISTRAI-SE FACILMENTE

( ) AGITADO

( ) CONCENTRADO MAS MESMO ASSIM COM DIFICULDADES

2) VOCÊ CONSIDERA QUE ESTE ALUNO APRESENTA ALTERAÇÃO NA SUA FALA ?
( ) SIM
( ) NÃO

SE SIM, QUE TIPO?

( ) TROCA DE LETRAS-FONEMAS NA FALA

( ) FALA ININTELIGIVEL

( ) NIVEL DE FALA INFERIOR A SUA IDADE

3) VOCÊ CONSIDERA QUE ESTE ALUNO APRESENTA ALTERAÇÃO NA ESCRITA?
( ) SIM
( ) NÃO

SE SIM, QUE TIPO:

( ) ESCREVE ININTELIGIVEL

( ) NÃO FAZ ASSOCIAÇÃO LETRA-SOM

( ) ESCREVE PALAVRAS COM ERROS DO TIPO: LETRAS ESPELHADAS 
Anexo 9

TESTE ABFW

FONOLOGIA. Protocolo de Registro - Imitação

\begin{tabular}{|lcc|}
\hline Nome: & Acerto: & Distorção: \\
Data do Exame: & Omissão: & \\
Idade: & Substituição: & \\
\hline
\end{tabular}

\begin{tabular}{|c|c|c|c|c|}
\hline Vocábulo & Transcrição & Fonema & Inicial & Final \\
\hline 01. Peteca & & $\mathrm{p}$ & & \\
\hline 02. Bandeja & & $\mathrm{b}$ & & \\
\hline 03. Tigela & & $\mathrm{t}$ & & \\
\hline 04. Doce & & $\mathrm{d}$ & & \\
\hline 05. Cortina & & $\mathrm{k}$ & & \\
\hline 06. Gato & & $\mathrm{g}$ & & \\
\hline 07. Foguete & & $\mathrm{f}$ & & \\
\hline 08. Vinho & & $\mathrm{V}$ & & \\
\hline 09. Selo & & $\mathrm{s}$ & & \\
\hline 10. Zero & & $\mathrm{z}$ & & \\
\hline 11. Chuva & & $\Sigma$ & & \\
\hline 12. Jacaré & & $\mathrm{Z}$ & & \\
\hline 13. Machado & & $\mathrm{m}$ & & \\
\hline 14. Nata & & $\mathrm{n}$ & & \\
\hline 15. Lama & & ) & & \\
\hline 16. Ônibus & & 1 & & \\
\hline 17. Prego & & $x$ & & \\
\hline 18. Café & & $\mathrm{P}$ & & \\
\hline 19. Alface & & $\mathrm{r}$ & & \\
\hline 20. Raposa & & $\mathrm{pR}$ & & \\
\hline 21. Borracha & & $\mathrm{bR}$ & & \\
\hline 22. Abelha & & $\mathrm{tR}$ & & \\
\hline 23. Carro & & $\mathrm{dR}$ & & \\
\hline 24. Branco & & $\mathrm{kR}$ & & \\
\hline 25. Travessa & & $\mathrm{gR}$ & & \\
\hline 26. Droga & & $\mathrm{fR}$ & & \\
\hline 27. Cravo & & $\mathrm{pl}$ & & \\
\hline 28. Grosso & & bl & & \\
\hline 29. Fraco & & $\mathrm{kl}$ & & \\
\hline 30. Plástico & & gl & & \\
\hline 31. Bloco & & $\mathrm{fl}$ & & \\
\hline 32. Clube & & Arqui/S/ & & \\
\hline 33. Globo & & Arqui/R/ & & \\
\hline \multicolumn{5}{|l|}{ 34. Flauta } \\
\hline \multicolumn{5}{|l|}{ 35. Pastel } \\
\hline \multicolumn{5}{|l|}{ 36. Porco } \\
\hline \multicolumn{5}{|l|}{ 37. Nariz } \\
\hline \multicolumn{5}{|l|}{ 38. Amor } \\
\hline 39. Roupa & & & & \\
\hline
\end{tabular}


Anexo $10 \mathrm{~A}$

Distribuição da amostra no grupo de crianças de 5 anos por idade, sexo, média total dos resultados por sujeito em relação à média tonal por orelha (em dBNA), o LRF (em dBNA) e a diferença entre a média tonal e o LRF (em dBNS) nas listas LE1 e LE2.

\begin{tabular}{|c|c|c|c|c|c|c|c|c|}
\hline \multirow[t]{2}{*}{ sujeito } & \multirow[t]{2}{*}{ sexo } & \multirow{2}{*}{$\begin{array}{c}\text { Ida } \\
d e\end{array}$} & \multicolumn{2}{|c|}{$M T(d B N A)$} & \multicolumn{2}{|c|}{$L R F(d B N A)$} & \multicolumn{2}{|c|}{$\operatorname{DIFLE}(d B N S)$} \\
\hline & & & OD & $\mathrm{OE}$ & OD & $\mathrm{OE}$ & OD & $\mathrm{OE}$ \\
\hline 1 & $\mathrm{f}$ & 5,1 & 10 & 5 & 20 & 15 & 10 & 10 \\
\hline 2 & f & 5,11 & 10 & 5 & 20 & 15 & 10 & 10 \\
\hline 3 & $\mathrm{f}$ & 5,1 & 5 & 10 & 15 & 20 & 10 & 10 \\
\hline 4 & $\mathrm{~m}$ & 5,6 & 10 & 10 & 10 & 15 & 0 & 5 \\
\hline 5 & $\mathrm{f}$ & 5,8 & 5 & 5 & 14 & 18 & 9 & 13 \\
\hline 6 & f & 5,9 & 10 & 10 & 19 & 19 & 9 & 9 \\
\hline 7 & $\mathrm{~m}$ & 5,7 & 5 & 5 & 11 & 9 & 6 & 4 \\
\hline 8 & $\mathrm{f}$ & 5,5 & 10 & 15 & 15 & 16 & 5 & 1 \\
\hline 9 & $\mathrm{~m}$ & 5,6 & 10 & 10 & 19 & 17 & 9 & 7 \\
\hline 10 & $\mathrm{f}$ & 5,8 & 5 & 5 & 3 & 1 & -2 & -4 \\
\hline 11 & $\mathrm{f}$ & 5,6 & 0 & 10 & 0 & 5 & 0 & -5 \\
\hline 12 & $\mathrm{f}$ & 5,7 & 0 & 5 & 0 & 2 & 0 & -3 \\
\hline 13 & $\mathrm{f}$ & 5,4 & 5 & 10 & 8 & 9 & 3 & -1 \\
\hline 14 & $\mathrm{~m}$ & 5,8 & 10 & 10 & 16 & 22 & 6 & 12 \\
\hline 15 & $\mathrm{~m}$ & 5,9 & 15 & 5 & 12 & 0 & -3 & -5 \\
\hline 16 & $\mathrm{~m}$ & 5,7 & 5 & 10 & 9 & 12 & 4 & 2 \\
\hline 17 & $\mathrm{f}$ & 5,9 & 10 & 10 & 12 & 17 & 2 & 7 \\
\hline 18 & $\mathrm{f}$ & 5,1 & 10 & 10 & 14 & 2 & 4 & -8 \\
\hline 19 & $\mathrm{f}$ & 5,5 & 10 & 10 & 7 & 12 & -3 & 2 \\
\hline 20 & $\mathrm{~m}$ & 5,6 & 5 & 5 & 2 & 0 & -3 & -5 \\
\hline 21 & $\mathrm{~m}$ & 5,1 & 5 & 5 & 7 & 10 & 2 & 5 \\
\hline 22 & $\mathrm{f}$ & 5 & 10 & 15 & 15 & 20 & 5 & 5 \\
\hline 23 & f & 5,9 & 10 & 10 & 15 & 20 & 5 & 10 \\
\hline 24 & $\mathrm{~m}$ & 5,1 & 15 & 10 & 20 & 20 & 5 & 10 \\
\hline 25 & $\mathrm{f}$ & 5 & 10 & 10 & 20 & 15 & 10 & 5 \\
\hline 26 & $\mathrm{f}$ & 5 & 10 & 10 & 18 & 10 & 8 & 0 \\
\hline 27 & f & 5 & 10 & 10 & 15 & 14 & 5 & 4 \\
\hline 28 & $\mathrm{~m}$ & 5,1 & 5 & 10 & 7 & 5 & 2 & -5 \\
\hline 39 & $\mathrm{~m}$ & 5,9 & 5 & 10 & 12 & 13 & 7 & 3 \\
\hline 30 & $\mathrm{~m}$ & 5,9 & 5 & 5 & 11 & 7 & 6 & 2 \\
\hline 31 & $\mathrm{~m}$ & 5,1 & 15 & 10 & 19 & 16 & 4 & 6 \\
\hline 32 & $\mathrm{~m}$ & 5,1 & 10 & 10 & 14 & 16 & 4 & 6 \\
\hline 33 & $\mathrm{~m}$ & 5,6 & 10 & 15 & 20 & 30 & 10 & 15 \\
\hline
\end{tabular}


Anexo 10 B

Distribuição da amostra no grupo de crianças de 5 anos por sexo, idade, média total dos resultados por sujeito em relação à média tonal por orelha $(\mathrm{em}$ dBNA), o LRF (em dBNA) e a diferença entre a média tonal e o LRF (em dBNS) nas listas LRS1 e LRS2.

\begin{tabular}{|c|c|c|c|c|c|c|c|c|}
\hline \multirow[t]{2}{*}{ sujeito } & \multirow[t]{2}{*}{ sexo } & \multirow[t]{2}{*}{ idade } & \multicolumn{2}{|c|}{ MT(dBNA) } & \multicolumn{2}{|c|}{ LRF (dBNA) } & \multicolumn{2}{|c|}{ DIFLRS(dBNS) } \\
\hline & & & OD & $\mathrm{OE}$ & OD & $\mathrm{OE}$ & OD & $\mathrm{OE}$ \\
\hline 1 & $\mathrm{f}$ & 5,1 & 10 & 5 & NR & NR & NR & NR \\
\hline 2 & $\mathrm{f}$ & 5,11 & 10 & 5 & NR & NR & NR & NR \\
\hline 3 & $\mathrm{f}$ & 5,1 & 5 & 10 & NR & NR & NR & NR \\
\hline 4 & $\mathrm{~m}$ & 5,6 & 10 & 10 & NR & NR & NR & NR \\
\hline 5 & $\mathrm{f}$ & 5,8 & 5 & 5 & 14 & 14 & 9 & 9 \\
\hline 6 & $\mathrm{f}$ & 5,9 & 10 & 10 & 16 & 15 & 6 & 5 \\
\hline 7 & $\mathrm{~m}$ & 5,7 & 5 & 5 & 12 & 10 & 7 & 5 \\
\hline 8 & $\mathrm{f}$ & 5,5 & 10 & 15 & 14 & 18 & 4 & 3 \\
\hline 9 & $\mathrm{~m}$ & 5,6 & 10 & 10 & 18 & 18 & 8 & 8 \\
\hline 10 & $\mathrm{f}$ & 5,8 & 5 & 5 & 2 & 2 & -3 & -3 \\
\hline 11 & f & 5,6 & 0 & 10 & 0 & 2 & 0 & -8 \\
\hline 12 & $\mathrm{f}$ & 5,7 & 0 & 5 & 6 & 0 & 6 & -5 \\
\hline 13 & $\mathrm{f}$ & 5,4 & 5 & 10 & 4 & 7 & -1 & -3 \\
\hline 14 & $\mathrm{~m}$ & 5,8 & 10 & 10 & 17 & 15 & 7 & 5 \\
\hline 15 & $\mathrm{~m}$ & 5,9 & 15 & 5 & 7 & 5 & -8 & 0 \\
\hline 16 & $\mathrm{~m}$ & 5,7 & 5 & 10 & 11 & 14 & 6 & 4 \\
\hline 17 & $\mathrm{f}$ & 5,9 & 10 & 10 & 12 & 14 & 2 & 4 \\
\hline 18 & $\mathrm{f}$ & 5,1 & 10 & 10 & 10 & 0 & 0 & -10 \\
\hline 19 & $\mathrm{f}$ & 5,5 & 10 & 10 & 10 & 12 & 0 & 2 \\
\hline 20 & $\mathrm{~m}$ & 5,6 & 5 & 5 & 2 & 10 & -3 & 5 \\
\hline 21 & $\mathrm{~m}$ & 5,1 & 5 & 5 & 11 & 12 & 6 & 7 \\
\hline 22 & $\mathrm{f}$ & 5 & 10 & 15 & 15 & 15 & 5 & 0 \\
\hline 23 & $\mathrm{f}$ & 5,9 & 10 & 10 & 20 & 23 & 10 & 13 \\
\hline 24 & $\mathrm{~m}$ & 5,1 & 15 & 10 & 20 & 15 & 5 & 5 \\
\hline 25 & $\mathrm{f}$ & 5 & 10 & 10 & 20 & 10 & 10 & 0 \\
\hline 26 & $\mathrm{f}$ & 5 & 10 & 10 & 10 & 10 & 0 & 0 \\
\hline 27 & $\mathrm{f}$ & 5 & 10 & 10 & 20 & 10 & 10 & 0 \\
\hline 28 & $\mathrm{~m}$ & 5,1 & 5 & 10 & 5 & 9 & 0 & -1 \\
\hline 39 & $\mathrm{~m}$ & 5,9 & 5 & 10 & 9 & 12 & 4 & 2 \\
\hline 30 & $\mathrm{~m}$ & 5,9 & 5 & 5 & 11 & 14 & 6 & 9 \\
\hline 31 & $\mathrm{~m}$ & 5,1 & 15 & 10 & 15 & 14 & 0 & 4 \\
\hline 32 & $\mathrm{~m}$ & 5,1 & 10 & 10 & 15 & 10 & 5 & 0 \\
\hline 33 & $\mathrm{~m}$ & 5,6 & 10 & 15 & 25 & 25 & 15 & 10 \\
\hline & $\begin{array}{l}\text { R: nãc } \\
T=m \\
R F=1 \\
F L E=\end{array}$ & $\begin{array}{l}\text { alizou } \\
\text { a tona } \\
\text { iar de } \\
\text { iferen } \\
\text { ensaça }\end{array}$ & $\begin{array}{l}\text { conh } \\
\text { da } m\end{array}$ & hen & $\begin{array}{l}\text { de fa } \\
\text { em r }\end{array}$ & ăo do & $\begin{array}{l}\text { el de } \\
\text { RF em }\end{array}$ & $\begin{array}{l}\text { ăo } \\
\text { ível de }\end{array}$ \\
\hline
\end{tabular}


$\mathrm{f}=$ feminino

$\mathrm{m}=$ masculino

Anexo $11 \mathrm{~A}$

- Distribuição da amostra no grupo de crianças de 6 anos por idade, sexo, média total dos resultados por sujeito em relação à média tonal por orelha $(\mathrm{em}$ dBNA), o LRF (em dBNA) e a diferença entre a média tonal e o LRF (em dBNS) nas listas LE1 e LE2.

\begin{tabular}{|c|c|c|c|c|c|c|c|c|}
\hline \multirow[t]{2}{*}{ NUM } & \multirow[t]{2}{*}{ Sexo } & \multirow[t]{2}{*}{ idade } & \multicolumn{2}{|c|}{ MT (dBNA) } & \multicolumn{2}{|c|}{ LRF (dBNA) } & \multicolumn{2}{|c|}{$\begin{array}{c}\text { DIFLRS } \\
\text { (dBNS) }\end{array}$} \\
\hline & & & OD & OE & OD & OE & OD & OE \\
\hline 1 & $\mathrm{~m}$ & 6,1 & 10 & 15 & 5 & 14 & -5 & -1 \\
\hline 2 & $\mathrm{~m}$ & 6,8 & 5 & 5 & 5 & 7 & 0 & 2 \\
\hline 3 & $\mathrm{~m}$ & 6,8 & 10 & 10 & 16 & 14 & 6 & 4 \\
\hline 4 & $\mathrm{~m}$ & 6,1 & 10 & 15 & 16 & 22 & 6 & 7 \\
\hline 5 & $\mathrm{~m}$ & 6,1 & 15 & 15 & 18 & 14 & 3 & -1 \\
\hline 6 & $\mathrm{~m}$ & 6 & 10 & 5 & 14 & 16 & 4 & 11 \\
\hline 7 & $\mathrm{~m}$ & 6,9 & 15 & 15 & 16 & 24 & 1 & 9 \\
\hline 8 & $\mathrm{~m}$ & 6,5 & 10 & 10 & 19 & 17 & 9 & 7 \\
\hline 9 & $\mathrm{f}$ & 6,1 & 10 & 10 & 16 & 19 & 6 & 9 \\
\hline 10 & $\mathrm{f}$ & 6,9 & 10 & 15 & 16 & 15 & 6 & 0 \\
\hline 11 & $\mathrm{f}$ & 6,6 & 10 & 10 & 20 & 18 & 10 & 8 \\
\hline 12 & $\mathrm{~m}$ & 6 & 10 & 10 & 15 & 15 & 5 & 5 \\
\hline 13 & $\mathrm{f}$ & 6 & 10 & 5 & 20 & 5 & 10 & 0 \\
\hline 14 & $\mathrm{f}$ & 6,2 & 5 & 10 & 5 & 15 & 0 & 5 \\
\hline 15 & $\mathrm{~m}$ & 6,6 & 10 & 5 & 15 & 10 & 5 & 5 \\
\hline 16 & $\mathrm{~m}$ & 6,6 & 15 & 10 & 15 & 20 & 0 & 10 \\
\hline 17 & $\mathrm{~m}$ & 6 & 15 & 15 & 25 & 25 & 10 & 10 \\
\hline 18 & $\mathrm{~m}$ & 6,1 & 10 & 10 & 15 & 20 & 5 & 10 \\
\hline 19 & $\mathrm{f}$ & 6,3 & 15 & 15 & 19 & 15 & 4 & 0 \\
\hline 20 & $\mathrm{~m}$ & 6,2 & 5 & 5 & 9 & 7 & 4 & 2 \\
\hline 21 & $\mathrm{f}$ & 6 & 5 & 5 & 0 & 9 & -5 & 4 \\
\hline 22 & $\mathrm{f}$ & 6,2 & 5 & 5 & 12 & 2 & 7 & -3 \\
\hline 23 & $\mathrm{~m}$ & 6,1 & 10 & 10 & 15 & 5 & 5 & -5 \\
\hline 24 & $\mathrm{~m}$ & 6,2 & 10 & 10 & 13 & 12 & 3 & 2 \\
\hline 25 & $\mathrm{f}$ & 6 & 10 & 15 & 10 & 17 & 0 & 2 \\
\hline 26 & $\mathrm{~m}$ & 6,1 & 5 & 5 & 10 & 13 & 5 & 8 \\
\hline 27 & $\mathrm{f}$ & 6,1 & 10 & 5 & 10 & 15 & 0 & 10 \\
\hline 28 & $\mathrm{f}$ & 6,3 & 15 & 15 & 20 & 20 & 5 & 5 \\
\hline 29 & $\mathrm{f}$ & 6,4 & 5 & 5 & 13 & 15 & 8 & 10 \\
\hline 30 & $\mathrm{f}$ & 6,1 & 5 & 5 & 13 & 15 & 8 & 10 \\
\hline 31 & $\mathrm{f}$ & 6,2 & 15 & 10 & 15 & 15 & 0 & 5 \\
\hline 32 & $\mathrm{~m}$ & 6,5 & 10 & 5 & 15 & 13 & 5 & 8 \\
\hline
\end{tabular}


Anexo $11 \mathrm{~B}$

$$
\begin{aligned}
& \mathrm{f}=\text { feminino } \\
& \mathrm{m}=\text { masculino }
\end{aligned}
$$

Distribuição da amostra no grupo de crianças de 6 anos por sexo, idade, média total dos resultados por sujeito em relação à média tonal por orelha $(\mathrm{em}$ dBNA), o LRF (em dBNA) e a diferença entre a média tonal e o LRF (em

\begin{tabular}{|c|c|c|c|c|c|c|c|c|}
\hline \multirow[t]{2}{*}{ NUM } & \multirow[t]{2}{*}{ idade } & \multirow[t]{2}{*}{ sexo } & \multicolumn{2}{|c|}{ MT (dBNA) } & \multicolumn{2}{|c|}{ LRF (dBNA) } & \multicolumn{2}{|c|}{ DIFLRS (dBNS) } \\
\hline & & & OD & OE & OD & OE & OD & $\mathbf{O E}$ \\
\hline 1 & 6,1 & $\mathrm{~m}$ & 10 & 15 & 5 & 14 & -5 & -1 \\
\hline 2 & 6,8 & $\mathrm{~m}$ & 5 & 5 & 7 & 14 & 2 & 9 \\
\hline 3 & 6,8 & $\mathrm{~m}$ & 10 & 10 & 11 & 15 & 1 & 5 \\
\hline 4 & 6,1 & $\mathrm{~m}$ & 10 & 15 & 14 & 24 & 4 & 9 \\
\hline 5 & 6,1 & $\mathrm{~m}$ & 15 & 15 & 16 & 11 & 1 & -4 \\
\hline 6 & 6 & $\mathrm{~m}$ & 10 & 5 & 12 & 12 & 2 & 7 \\
\hline 7 & 6,9 & $\mathrm{~m}$ & 15 & 15 & 18 & 20 & 3 & 5 \\
\hline 8 & 6,5 & $\mathrm{~m}$ & 10 & 10 & 16 & 19 & 6 & 9 \\
\hline 9 & 6,1 & $\mathrm{f}$ & 10 & 10 & 16 & 19 & 6 & 9 \\
\hline 10 & 6,9 & $\mathrm{f}$ & 10 & 15 & 16 & 22 & 6 & 7 \\
\hline 11 & 6,6 & $\mathrm{f}$ & 10 & 10 & 20 & 20 & 10 & 10 \\
\hline 12 & 6 & $\mathrm{~m}$ & 10 & 10 & 10 & 15 & 0 & 5 \\
\hline 13 & 6 & $\mathrm{f}$ & 10 & 5 & 15 & 5 & 5 & 0 \\
\hline 14 & 6,2 & $\mathrm{f}$ & 5 & 10 & 15 & 20 & 10 & 10 \\
\hline 15 & 6,6 & $\mathrm{~m}$ & 10 & 5 & 15 & 10 & 5 & 5 \\
\hline 16 & 6,6 & $\mathrm{~m}$ & 15 & 10 & 25 & 25 & 10 & 15 \\
\hline 17 & 6 & $\mathrm{~m}$ & 15 & 15 & 25 & 25 & 10 & 10 \\
\hline 18 & 6,1 & $\mathrm{~m}$ & 10 & 10 & 15 & 25 & 5 & 15 \\
\hline 19 & 6,3 & $\mathrm{f}$ & 15 & 15 & 19 & 15 & 4 & 0 \\
\hline 20 & 6,2 & $\mathrm{~m}$ & 5 & 5 & 12 & 7 & 7 & 2 \\
\hline 21 & 6 & $\mathrm{f}$ & 5 & 5 & 9 & 1 & 4 & -4 \\
\hline 22 & 6,2 & $\mathrm{f}$ & 5 & 5 & 14 & 0 & 9 & -5 \\
\hline 23 & 6,1 & $\mathrm{~m}$ & 10 & 10 & 15 & 8 & 5 & -2 \\
\hline 24 & 6,2 & $\mathrm{~m}$ & 10 & 10 & 15 & 12 & 5 & 2 \\
\hline 25 & 6 & $\mathrm{f}$ & 10 & 15 & 12 & 19 & 2 & 4 \\
\hline 26 & 6,1 & $\mathrm{~m}$ & 5 & 5 & 12 & 15 & 7 & 10 \\
\hline 27 & 6,1 & $\mathrm{f}$ & 10 & 5 & 12 & 17 & 2 & 12 \\
\hline 28 & 6,3 & $\mathrm{f}$ & 15 & 15 & 23 & 22 & 8 & 7 \\
\hline 29 & 6,4 & $\mathrm{f}$ & 5 & 5 & 13 & 17 & 8 & 12 \\
\hline 30 & 6,1 & $\mathrm{f}$ & 5 & 5 & 15 & 15 & 10 & 10 \\
\hline 31 & 6,2 & $\mathrm{f}$ & 15 & 10 & 17 & 15 & 2 & 5 \\
\hline 32 & 6,5 & $\mathrm{~m}$ & 10 & 5 & 15 & 15 & 5 & 10 \\
\hline
\end{tabular}
dBNS) nas listas LRS1 e LRS2. 
$\mathrm{m}=$ masculino

\section{Anexo 12 A}

Média dos resultados por sujeito em relação à média tonal por orelha (em dBNA), o LRF (em dBNA) e a diferença entre a média tonal e o LRF (em dBNS) no grupo de crianças de 7 anos nas listas LE1 e LE2

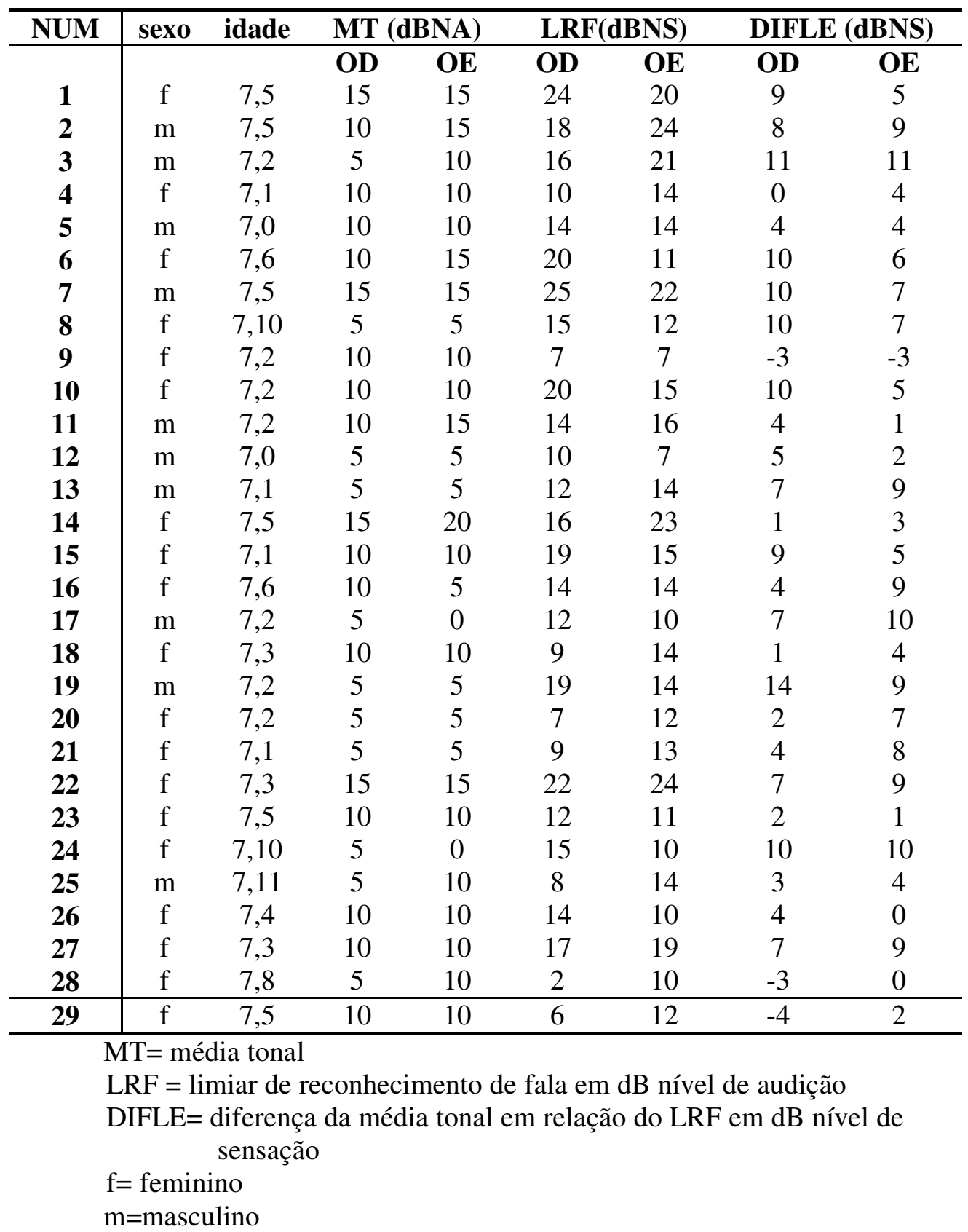




\section{Anexo 12 B}

Média dos resultados por sujeito em relação à média tonal por orelha (em dBNA), o LRF (em dBNA) e a diferença entre a média tonal e o LRF (em dBNS) no grupo de crianças de 7 anos nas listas LRS1 e LRS2.

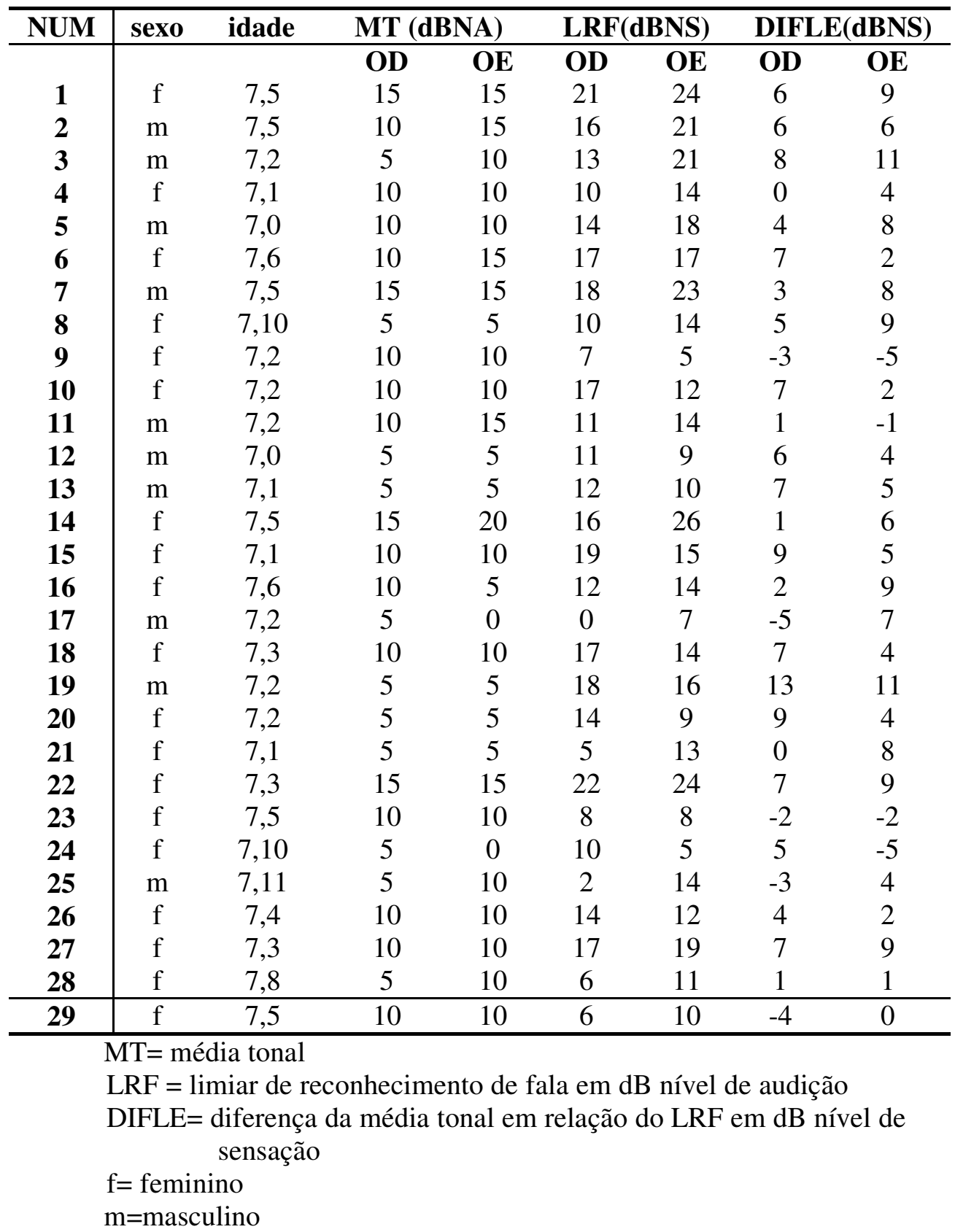




\section{Anexo 13}

distribuição dos resultados na aplicação dos questionários e ABFW em relação à indicação de fala alterada ou normal.

\begin{tabular}{c|c|c|c|c|c|c|c|c|c|c|c|c}
\hline & \multicolumn{4}{|c|}{ PAIS } & \multicolumn{3}{c|}{ PROFESSORES } & \multicolumn{4}{c}{ ABFW } \\
\hline & Normal & \multicolumn{2}{|c|}{ Alterado } & \multicolumn{2}{c|}{ Normal } & \multicolumn{2}{c}{ Alterado } & \multicolumn{2}{c}{ Normal } & \multicolumn{2}{c}{ Alterado } \\
\hline & $\mathrm{n}$ & $\%$ & $\mathrm{n}$ & $\%$ & $\mathrm{n}$ & $\%$ & $\mathrm{n}$ & $\%$ & $\mathrm{n}$ & $\%$ & $\mathrm{n}$ & $\%$ \\
\hline $\mathbf{5}$ anos & 2 & 18 & 0 & 0 & 2 & 17 & 1 & 25 & 2 & 17 & 1 & 25 \\
\hline $\mathbf{6}$ anos & 7 & 55 & 2 & 75 & 7 & 58 & 2 & 50 & 7 & 58 & 2 & 50 \\
\hline $\mathbf{7}$ anos & 3 & 27 & 1 & 25 & 3 & 25 & 1 & 25 & 3 & 25 & 1 & 25 \\
\hline subtotal & 13 & 100 & 3 & 100 & 12 & 100 & 4 & 100 & 12 & 100 & 4 & 100 \\
\hline
\end{tabular}


Anexo 14

Proposta de distribuição das palavras da lista LE na utilização da medida do LRF com figuras.

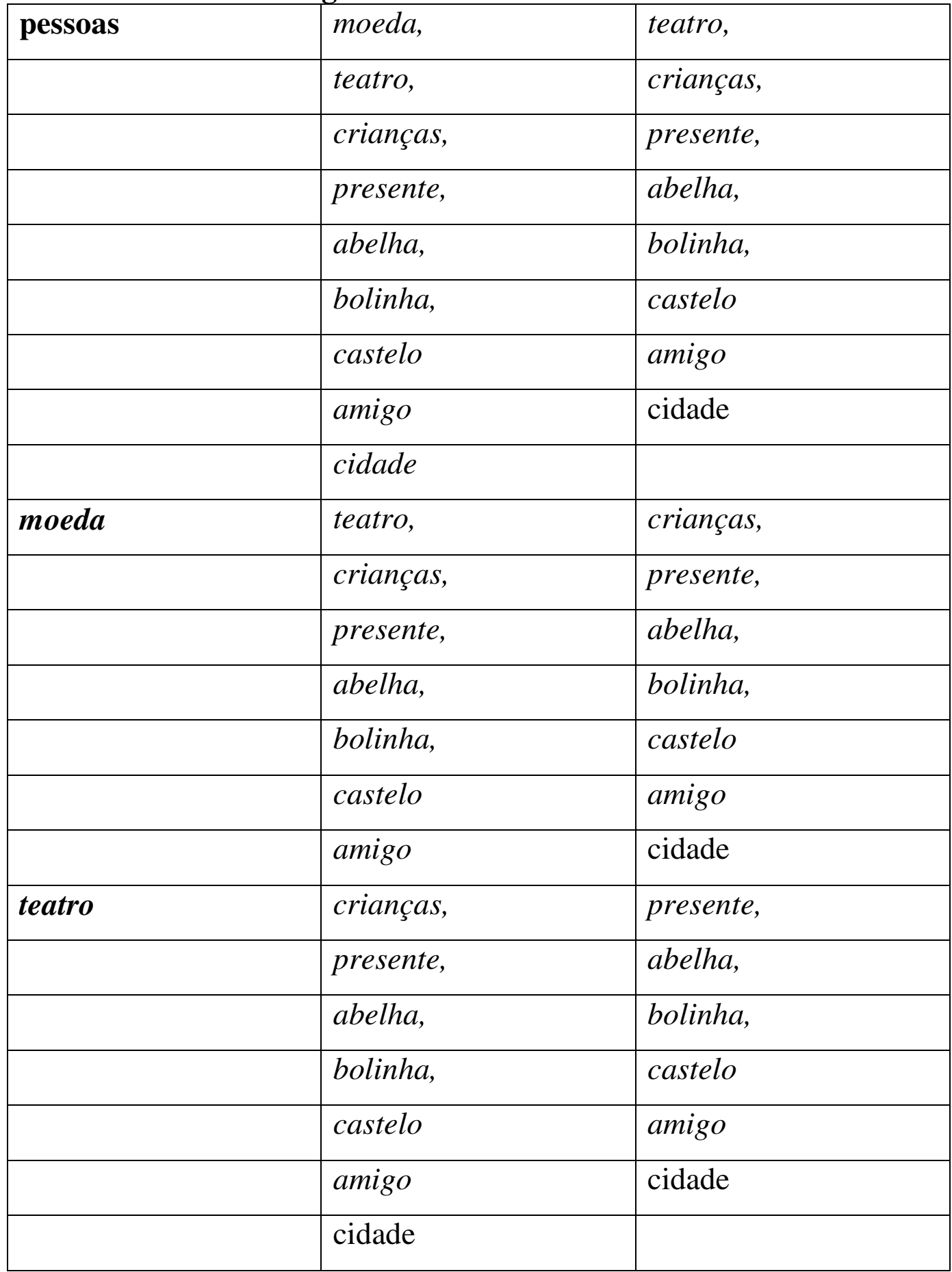




\begin{tabular}{|l|l|l|}
\hline crianças & presente, & abelha, \\
\hline & abelha, & bolinha, \\
\hline & bolinha, & castelo \\
\hline & castelo & amigo \\
\hline & amigo & cidade \\
\hline presente & cidade & \\
\hline & abelha, & bolinha, \\
\hline & bolinha, & castelo \\
\hline & castelo & amigo \\
\hline & amigo & cidade \\
\hline abelha & cidade & \\
\hline & bolinha, & castelo \\
\hline & castelo & amigo \\
\hline & amigo & cidade \\
\hline bolinha & cidade & \\
\hline & castelo & amigo \\
\hline & amigo & cidade \\
\hline castelo & cidade & cidade \\
\hline & amigo & \\
\hline & & \\
\hline
\end{tabular}


ANEXO 15 
REFERÊNCIAS BIBLIOGRÁFICAS 
ASOCIAÇÃO BRASILERA DE NORMAS TÉCNICAS. NBR 10520. Informação e documentação - Citações em documentos - Apresentação, no site www.abntdigital.com.br., (2002).

ALBANO, E. C.; MOREIRA, A. A; SILVA, A. H. P.; AQUINO, P. A.; KAKINOHANA, R. K. Um Conversor ortográfico-fônico e uma notação prosódica mínima para síntese de fala em língua portuguesa. In: E. SCARPA (org.). Estudos de Prosódia no Brasil. Campinas: Editora da UNICAMP, 1999 [1995].

ALMEIDA, C. I. R. Logoaudiometria. In: MANGABEIRA ALBERNAZ P. L., GANANÇA, M. M. Surdez Neurosensorial. São Paulo: Moderna, 1978, p. 18-20.

ALMEIDA, C. I. R.; CAMPOS, M. I.; ALMEIDA, R. R. Logoaudiometria pediátrica. Revista Brasileira de Otorrinolaringologia, v. 54, p. 73-76, 1988.

AMERICAN NATIONAL STANDARDS INSTITUTE. American National Standard Specification for Audiometers. ANSI S 3.1 V. New York , 1991.

AMERICAN NATIONAL STANDARDS INSTITUTE. American National Standard Specification for Audiometers. ANSI S 3.6 V. New York, 1996.

AQUINO, P. A. O papel das vogais reduzidas pós-tônicas na construção de um sistema de síntese concatenativa para o português brasileiro.Dissertação (Mestrado) - Laboratório de Fonética Acústica e Psicolingüística Experimental, Instituto de Estudos da Linguagem, Universidade Estadual de Campinas, 1997.

ASHA - AMERICAN SPEECH LANGUAGE HEARING ASSOCIATION COMMITTEE ON AUDIOMETRIC EVALUATION - Guidelines for determining the threshold level for speech, v. 21, p. $353-356,1979$.

ASHA - AMERICAN SPEECH LANGUAGE HEARING ASSOCIATION COMMITTEE ON AUDIOMETRIC EVALUATION - Guidelines for determining threshold level for speech, v. 30, p. 85-89, 1988.

ASHOOR, A. A.; PROCHAZKA, T. Saudi Arabic speech audiometry. Audiology, v. 21, n. 6, p. 493-508, Nov./ Dec. 1982.

BADDELEY A.; WILSON, B.A. A developmental deficit in short-term phonological memory: implications for language and reading. Cambridge, UK: MRCApplied Psychology Unit. Memory, v. 01, n. 01, p. 65-78, 1993.

BARBOSA, P.As vogais médias pótônicas: uma análise variacionsita in: BISOL,L; BRESCANCINI,C ORG. Fonologia e Vaiação:recortes do português brasileiro, Porto Alegre: PUCRS, 2002 .

BIAP. Recomendação para classificação audiométrica para deficiência auditiva, 1996. 
BISOL, L. (org.) Introdução a Estudos de Fonologia do Português Brasileiro. Porto Alegre: EDIPUCRS, 1996.

BEATTIE,R. C., SVIHOVEC D. V.; EDGERTON, B. J.Relative intelligibility of CID spondees as presented via monitored live voice. Journal of Speech and Hearing Disorders, v. 40, p. 84-91, 1975.

BELLIS, $\mathrm{T}$ Assessment and Management of Central Auditory Processing Disorders in the Educational. Singular: San Diego, 2003.

BESS, F. H.; HUMES, L. E. Fundamentos de Audiologia. São Paulo: Artmed, 1998.

BOOTHROYD, A. SPAC TEST: A speech pattern contrast manual, 1986.

BOOTHROYD, A.; NITTROUER, S. Mathematical treatment of context effects in phoneme and word recognition. Journal of the Acoustical Society of America, v. 84, p. 101-114, 1988.

BLUMSTEIN, S. E.; STEVENS, K. N.Acoustics invariance in speech production evidence from measurements of the spectral characteristics of stop consonants. Journal of the Acoustical Society of America, v. 66, p. 1001-1017, 1979.

BROADBENT, D. E.The role of auditory localization in attention and memory span. Journal of Experimental Psychology, v. 47, p. 191-6, 1954.

CAHART, R. Individual differences in hearing for speech. Ann. Otol. Rhinol. Laryngol., v. 55, p. 233-266, 1946.

CAHART, R.; PORTER, L. Audiometric configuration and prediction of threshold for spondees. Journal of Speech and Hearing Research, 14, p.486-495, 1971.

CAMARGO, M. B. B.; NEVES, F. N.; FAVARO, M. A.; LOPES, O.; REDONDO, M. C. Limiar da recepção da fala: estudo sobre a relação do limiar da recepção da fala e limiares tonais das freqüências de $250 \mathrm{~Hz}$ a $400 \mathrm{~Hz}$. Revista Brasileira de Otorrinolaringologia, v. 55, n. 1, jan./fev./mar. 1989.

COREN,S. Predicting Speech Recognition thresholds from pure tone hear thresholds. Perception Motor Skills, 79(2), 1003-1008,1994 .

CERVO, AL; BERVIAN,PA Metodologia Cientifica. Prentice Hall:SP, 2002.

CHAIKLYN, J. B. The relation among three selected audiometry speech thresholds. J. Speech Hearing Research, v. 2, p. 237-243, 1959. In KATZ, J. Logoaudiometria. Tratado de Audiologia Clínica. 4.ed. São Paulo: Manole, 1999. 
CHAIKLYN, J. B.; VENTRY, I. M. Spondee threshold measurement: A comparison to 2 and $5 \mathrm{~dB}$ methods. Journal of Speech and Hearing Disorders, v. 29 , p. 47$59,1964$.

CHARLES-LUCE, J.; LUCE, P. A.; Similarity neighbourhoods of words in young children's lexicons. Journal of Child Language, v. 17, p. 205-215, 1990.

CONN, M.; DANVER, J.; VENTRY, I. M. A spondee list for determining speech reception threshold without prior familiarization. Journal of Speech and Hearing Disorders, v. 40 , p. 376-388, 1975.

COSTA, E. A. Desenvolvimento de testes de reconhecimento da fala com ruído em português do Brasil para aplicação em audiologia ocupacional. 1998. 99 f. Tese ( Doutorado) - Universidade Estadual de Campinas, São Paulo. 1998.

COSTA, E. A. Os testes logoaudiométricos e sua aplicação em audiologia ocupacional. In: NUDELMAN, A. A.; COSTA, E. A.; SELIGMAN, R. N. Pair: perda auditiva induzida por ruído. Porto Alegre: Bagagem, p. 223-35, 1998.

DOMITZ, D. M.; SCHOW, R. L A new CAPD battery: multiply auditory assessment. American Journal of Audiology, v. 9, 2000.

EFRON,R The central auditory sistem auditory issues related of hemispheric specialization in ML Pinheiro, F MUsiek Assessment of centra auditory dysfunction, Baltimore: Williams and Wilkins, 1985, p. 143-154.

ELLIOT, L. L.; CONNORS, S.; KILLE, E.; LEVIN, S.; BALL, K.; KOTZ, D. Children's understanding of monosyllable nouns in quiet and in noise. Journal of the Acoustical Society of America, v. 66, p. 12-21, 1979.

EPSTEIN, A.; GIOLAS, T.C.; OWENS, E. Familiarity and intelligibility of monosyllabic word lists. Journal of Speech and Hearing Research, v. 11, p. 435438, 1968.

EVANS, P Speech audiometry for differential diagnosis.In: MARTIN, M. Speech audiometry. London: Whur Press, 1997.

EYSENK, M. W.; KENE, M. T. Psicologia Cognitiva: um manual introdutório. São Paulo: Artes Médicas, 1990.

FALLON, M.; ; THEHUB, S. E.; SCHNEIDER, B. A. Children's perception of speech in multitalker babble. Journal of the Acoustical Society of America, v. 106, n. 6, Dec. 2000.

FANT, G (1960). Theories of Speech Perception. In SANDERS, D. Auditory Perception of Speech. Nova Jersey: Prentice Hall, 1977. 
FERNALD, A.; SWINGLEY, D.; PINTO, J. P. When half a word is enough: infants can recognize spoken words using partial phonetic information. Child Development, v. 72, n. 4, p. 1003-1015, July/ Aug. 2001.

FRAGOSO, M. Limiar de audibilidade vocal: um estudo em escolares brasileiros. 1986. 102 f. Tese (Mestrado em Distúrbios da Comunicação) - UNIVERSIDADE FEDERAL DE SÃO PAULO, 1986.

FRAUENFELDER, V. F.; TYLER, L. K. The process of spoken word recognition: an introduction. Cognition, v. 25, n. 1, p. 1-20, mar. 1987.

FRAZA, M.; SILVA, M. L. G.: MUNHOZ, M. S. L.; CAOVILLA, H. H.; GANANÇA, M. M. Audiometria tonal e vocal. In SILVA, M. L. G.; MUNHOZ, M. S. L.; CAOVILlA, H. H.; GANANÇA, M. M. Audiologia Clínica, série Otoneurológica. São Paulo: Atheneu, 2000.

FROTA, S.; Sampaio, F. Fundamentos em Fonoaudiologia: Logoaudiometria. Rio de Janeiro: Guanabara, 2000. p. 61-113.

GAMA, M. R. Avaliação qualitativa da percepção de fala como auxílio no processo de seleção de aparelhos de amplificação sonora. 1991. Tese (Mestrado em Fonoaudiologia) - Pontifícia Universidade de São Paulo -SP, 1991.

GAMA, M. R. Percepção da fala: uma proposta de avaliação qualitativa. São Paulo: Pancast, 1994.

Gama-Rossi, A. Relações entre desenvolvimento lingüístico e desenvolvimento motor: A aquisição da duração no português brasileiro. Tese não publicada. Instituto de Estudos da Linguagem, Universidade Estadual de Campinas, Campinas, 1999.

GAMA-ROSSI, A.; SILVA, A. Critérios lingüísticos para a elaboração de listas de palavras no português brasileiro. Comunicação apresentada no XLVIII Seminário do GEL (Grupo de Estudos Lingüísticos do Estado de São Paulo), realizado em Assis, SP, de 18 a 20 de maio de 2000.

GATHERCOLE, S. E.; WILlIS, C. S.; EMSLIE, H.; BADDELEY, A. D. Development Psychology, v. 28, n. 5, p. 887-898, 1992.

GEERT, P. V. The Development of Perception, Cognition and Language. Londres: Routledge \& Kegan Paul, 1983.

GREEN, D. M.; WILLIANS, C.; KRYTER, K. D. Peak VU deflection and energy for monosyllabic words. Journal of the Acoustical Society of America , v. 31, p. 1264-1265, 1959.

GROSE, J. H.; HALL, J. W.; GIBBS, C. Temporal analysis in children. Journal of Speech and Hearing Research, v. 36, p. 351-356, 1993. 
HARRIS, R.; GOEF, M.V.; PEDALINI, M. E.; GYGI, M.; MERRIL, A. Palavras trissilábicas psicometricamente equivalentes faladas por indivíduo do sexo masculino e feminino. Pró-Fono, v. 13, n. 1, p. 37-53, 2001.

HIRSCH, J. J.; DAVIS, H.; SILVERMAN, S. R.; REYNOLDS, E. G.; ELDERTE BENSEN, R. W. Development of materials for speech audiometry. Journal of Speech and Hearing Disorders. p. 321-337, 1952. In MARTIN, M. Speech audiometry, San Diego: Singular, 1997.

HUDGINS, C. V.; HAWKINS, J. E.; KARLIN, J. E.; STEVENS, S. S. The development of recorded audiotory tests for measuring hearing loss . Laryngoscope, v. 57, p. 57-89, 1947.

ISO R389 . Acoustics - Audiometry test methods. Speech Audiometry, 1993.

ISO 8253-3. International organization for standardization. Acoustics - Audiometry test methods. Part 3: Speech Audiometry, 1993. 15 p.

JANHNER, J.A.; SCHLAUCH, R.A; DOYLE, T. A comparison of American Speech-Language Hearing Association guidelines for obtaining speech recognition thresholds. University of Minnesota, Minneapolis. Ear and Hearing, v. 15, n. 04, p. 324-329, Aug. 1994.

JAKOBSON, R.; FAnT,G.; HALlE, M. Preliminary to Speech Analysis. Cambridge: Mit Press, 1963.

JERGER, J. F.; JERGER, S.; MAULDIN, L. Studies in impedance audiometry I: normal and sensorineural ears. Archives of Otolaryngology., v. 96, p. 513-523, 1972.

JERGER, S. Speech Audiometry. In JERGER, J. (Ed.) Recent Advances Series in Speech, Hearing, and Language. San Diego-CA: College Hall Press, 1983.

Speech Audiometry. In JERGER, J. Pediatric Audiology. San DiegoCA: College Hall Press, 1984.

JYCZYK, P; LINCE, P Speech Perception and Spoken word recognition. Ear and Hearing, 23 (1), 2-40, 2002.

KEITH,RW Basic audiological evaluation in JL NORTEHRN. Hearing Disorders.Boston: Borw e Co., p 13-24, 1984.

KISHON-RABIN, L.; ROSENHOUSE, J. Speech reception test for Arabic speaking children. Audiology, v. 39, p. 269-277, 2000.

KOCH, D. B.; McGEE, T. J.; BRADLOW, A. R.; KRAUS, N. Acoustic-Phonetic Approach toward Understanding Neural Processes and Speech Perception. Journal of American Academy Audiology, v. 10, p. 304-318, 1999. 
KONKLE , D. F.; RINTELMANN, W. F. Principles of Speech Audiometry, Baltimore: Park Press, 1983.

KREUL E. J.; BELL D. W.; NIXON J. C. Factors affecting speech discrimination test difficulty. Journal of Speech and Hearing Research, v. 12, p. 281-287, 1969.

KRUGER, B.; KRUGER, F. Speech audiometry in USA In: MARTIN, M. Speech audiometry. San Diego: Singular 1997, p. 89.

KUMABE, E. M. A influência do material de fala na inteligibilidade de préescolares: variáveis que podem interferir. Tese (Mestrado em Distúrbios da Comunicação) - PUC - SP, 1999.

LACERDA, A. P. Audiologia Clínica. Rio de Janeiro, RJ: Guanabara Koogan S.A., 1976.

LAHIRI, A.; MARSLEN-WILSON, W. The mental representation of the lexical form: a phonological approach to the recognition lexicon. Cognition, v. 38, n. 5, p. 245-294, 1991.

LEBEL C.;LEFEBVRE,S. Test de seuil vocal en images pour enfants in LEBEL C.; PICARD, M. Influence du mode de réponse sur le seuil de reconnaissance de la parole chez l'enfant francias québécois d"âge scolarire. Journal of SpeechLanguage Patohology and audiology, 21, p.17-27,1997.

LEBEL C.; PICARD, M. Influence du mode de réponse sur le seuil de reconnaissance de la parole chez l'enfant francias québécois d"âge scolarire. Journal of Speech-Language Patohology and audiology, 21, p.17-27,1997.

LEHISTE, J.; PETERSON, G.E. Linguistic considerations in the study of speech inteligibility. In MENDEL, L.; DANHAUER, J. Audiologic evaluation and management and speech perception assessment. San Diego: Singular, 1997.

LIERBERMAN, P. On the Origin of Language: an Introduction of Human Speech. New York: MacMillan, 1975.

LILLY,D. J. Calibration of electroacoustic apparatus: disc reproduction systems. ASHA, 9 367, 1967.

LINQUIST, E. (1953). Test Administration and Interpretation. In MENDEL, L.; DANHAUER, J. Audiologic evaluation and management and speech perception assessment. San Diego: Singular, 1997.

LETOWISKI,T; HERGENREDER,P; TANG,H Relatonships between sppch recognition treshold, average, hearing level and speech importance noise dtection treshold, Amereican Speech Language Hearing Association, 35: 1131-1136, 1992. 
LIVELY, S.; PISONI, D. E.; GOLDINGER, S. Spoken Word Recognition. In: GERNSBACHER, M. Handbook of Psycholinguistics. New York: Academic Press, p. 265-301, 1994.

LOPES-FILHO, O. Tratado de Fonoaudiologia. São Paulo: Roca, 1997.

LOVRINIC, J. H.; BRUGI, E. J.; Curry, E. T. A comparative evaluation of five speech discrimination measures. Journal of Speech and Hearing Research, v. 11, p. 372- 381, 1968

LUCE, P. A.; PISONI, D. B.; GOLDINGER, S. D. Similarity neighborhoods of spoken words. In ALTMAN, G. T. M. Cognitive models of speech perception: psycholinguistic e competacional perspectives. Cambridge, MA: MIT Press, 1990.

LURIA, A. R. Fundamentos de Neuropsicologia. São Paulo: EDUSP, 1981.

LYREGAARD,P Towards a theory of speech audiometry tests in MARTIN, M Speech Audiometry. San Diego: Singular, 1997.

MACHADO, S.F. A lista de espondáicos e outros estímulos de fala na logoaudiometria. 1988. 95 f. Tese (Mestrado em Distúrbios de Comunicação) Pontifícia Universidade Católica, São Paulo. 1988.

MACHADO, S. F. Avaliação da Percepção de Fala - manual dos testes: S.S.W., C.E.S., fala no ruído, fala filtrada - fusão binaural. São Paulo: Plexus Editora Virtual Ltda, 1996.

MACHADO, S. F. Processamento Auditivo: Fundamentos e Avaliação. São Paulo: Plexus, 2003.

MARSHALL, L.; BACON, S. P. Prediction of speech discrimination scores from audiometric data. Ear and Hearing, v. 2, p. 148-155, 1981.

MARKIDES , A . Speech tests of hearing for children. In MARTIN, M. Speech Audiometry. San Diego: Singular, 1997.

MARSLEN-WILSON,W Perceptual distance and competition in lexica access. Journal of experimental psychology, 22:1376-1392, 1996.

MARTIN, F. N.; ARMSTRONG, T. W.; CHGSLEM, C. A. A severy of audiological pratices in the USA. Journal of the American Academy of Audiology, 1994.

MARTIN, F. N.; SIDES, D. G. Survey of current audiometric pratices. ASHA,v. 27, n.2, p. 29-36, 1985.

MARTIN, F.N.; PENNINGTON, C.D. Current trends in audiometric practices. ASHA, v. 13, n. 11, p. 671-677, 1971. 
MARTIN, F.N.; CHAMPLIN,C. A.; PEREZ, D. D. The Question of Phonetic Balance in Word Recognition Testing. Journal of the American Academy of Audiology, v.11, p. 489-493, 2000.

MARTIN, M. Speech Audiometry. $2^{\text {nd }}$. Ed. San Diego, CA: Singular Publishing Group Inc., 1997.

McCAULEY, R. J.; SWISHER, L. Psychometric review of language and articulation tests for preschool chiLdren. Journal of Speech and Hearing Disorders, v. 49, p. 34-42, 1984.

MENDEL, L.; DANHAUER, J. Audiologic evaluation and management and speech perception assessment. San Diego: Singular, 1997.

MESSICK, S. Meaning and values in test validation: the science and ethics of assessment. Educational Researcher, v. 18, p. 5-11, 1989.

MEYER , T. A.; BILGER , R.C. Effect of set size and method on speech reception threshold in noise. Ear and Hearing, v. 18, p. 202-209, 1997.

MILLS, J. N. Noise and children: a review of literature. Journal of Acoustical Society of America, v. 18, p. 767-779, 1985.

MUKARI, S. Z M.; SAID, H. The development of Malay speech audiometry. The Medical Journal of Malaysia, v. 46, n.3, p. 262-8, Sept, 1991.

MUELLER, H. G.; BRIGTH, K. E. Testes centrais: procedimentos utilizando monossílabos. In: KATZ, J. Tratado de audiologia clínica. São Paulo: Manole, 1999, p. 146-162.

NSAMBA, C. Luganda speech audiometry. Audiology, v.18, n.6, p.513-21, Nov./Dec, 1979.

NILSSON, M. J.; SOLI, S. D; SULlIVAN, J. A. Development of the hearing in noise test for the measurement of speech reception thresholds in quiet and noise. Journal of the Acoustic Society of America, v. 95, n. 2, p. 1085-1999, 1994.

NITTROUER,S; BOOTHROYD,A. Context effects in phoneme and word recognition by young children and older adults. Journal Acoustical Society of America, 87:2705-2715,1990.

OLSEN, W. O.; MATKIN, N. D. Speech audiometry. In: RINTELMAN, W.F. (Ed). Hearing Assessment. Baltimore: University Park Press, 1979.

OSTERNE, F. J. V. Limiares logoaudiométricos para palavras e sentenças. In: PEREIRA, L. D.; SCHOCHAT, E. Processamento Auditivo Central - manual de avaliação. São Paulo: Lovise, 1997. 
OWENS, E. E. Intelligibility of words varying in familiarity. Journal of Speech and Hearing Research, v. 4, n. 2, p. 113-129, 1961.

OWENS E. E.; SCHUBERT, E. O. Development of the California Consonant Test. Journal of Speech and Hearing Research, v. 20, p. 463-474, 1977.

PAVLOVIC, C. N.; ROSSI, M.; ESPESSER, R. Use of the magnitude estimation technique for assessury the performance of speech syntheses system. Journal of Acoustical Society of America, v. 87, n. 1, p. 373-382, 1990.

PEN, M.G.; MANGABEIRA ALBERNAZ, P.L. Desenvolvimento de teste para logoaudiometria: discriminação vocal. Anais do II Congresso Pan Americano de Otorrino. e Brancoes.. Lima- Peru, v.12, p.223-226, 1973.

PENROD, J. Logoaudiometria. In: KATZ, J. Tratado de audiologia clínica. 4. ed. São Paulo: Manole, 1999, p. 146-162.

PEREIRA, L D. Audiometria verbal: teste de discriminação vocal com ruído. 1993. 121p. Tese (Doutorado em Distúrbios da Comunicação) - UNIVERSIDADE FEDERAL DE SÃO PAULO, 1993.

PICARD, M.; BANVILLE, R.;BARBAROSIE, T.; MANOLACHE, M. Speech audiometry in noise exposed workers: the SRT-PTA relationship revisited. Ecole d'orthophonie et audiologie, Universite de Montreal, Quebec, Canada. Audiology, v. 38, n.01, p.30-43, Jan.-Feb. 1998.

PINHEIRO,M.; MUSIEK,F. Assessment of central auditory dysfunction. Baltomore: Williams and Wilkins, 1985.

PLOMP, R.; MIMPEN, A. M. Improving the reliability of testing the speech reception threshold for sentences. Audiology, v. 18, p. 43-52, 1979.

PREECE, JP; FOWLWE,CG Relationship of pure tone averages to speech reception treshold for male and female speakers. Journal American Academy of audiology, 3:221-224, 1992.

PUNCH, J. L.; HOWARD, M.T. Spondee recognition threshold as a function of set size. Journal of Speech and Hearing Disorders, v.50, p. 120-125, May 1985.

REDONDO, M. C.; LOPES-FILHO, O. Tratado de Fonoaudiologia. São Paulo: Roca, 1997.

RUSSO, I. C. P.; SANTOS, T. M. M. A Prática da Audiologia Clínica. 4. ed. rev. e aum.. São Paulo: Cortez, 1993, p.25.

RUBINSteIN, S. L Princípios da Psicologia Geral. Lisboa : Estampa, v. I, 1972. 
SÁ, G. Análise fonética da língua portuguesa falada no Brasil e a sua aplicação na logoaudiometria. Revista Brasileira Médica, 1952.

SACALOSKI, M. Limiar de Reconhecimento de Fala: Estudos com diferentes tipos de estímulo verbais. 1997. ???????f. Tese (Mestrado em Distúrbios da Comunicação Humana: Campo Fonoaudiológico) - Universidade Federal de São Paulo - Escola Paulista de Medicina. São Paulo, 1997.

SANDERS, D. Auditory Perception of Speech. New Jersey: Prentice Hall, 1977.

SCHOCHAT, E.; PEREIRA, L. D. Processamento Auditivo Central - manual de avaliação. São Paulo: Lovise. p. 39-42, 1997.

SCHWARTZ, A.H.; GOLDMAN, R. Variables influencing performance on speechsound discrimination tests. Journal of Speech and Hearing Research, v. 17, p. 2225, 1974.

SHERWOOD, T.; FULLER, H. Equipment for speech audiometry and its calibration. In: MARTIN, M. Speech audiometry. London:Whur P., 1997, p. 89.

SHOORENBURG, G.F.; BORMAN, A. Choosing speech materials to assess hearing impairment. In DAUEER, A. H.; HENDERSON, D.; SALVI, R. J.; HAMERNIK, R. P. Noise hearing loss. St. Louis: Mosby, 1992. p. 288292.

SIEGENTHALER, B. M.; STRAND, R. Audiogram average methods and SRT scores. Journal of Acoustical Society of America, v. 36, p. 589-593, 1964.

SILVA, A.H.P.; GAMA-ROSSI, A.J.A.; ALBANO, E.C.; MOREIRA, A.; KAKINOHAMA, M. Discussão sobre o balanceamento fonético de uma lista de palavras. Anais do X Enc. Inter. de Audiologia, Bauru, 1995.

SILVA, A. H. P.; GAMA-ROSSI, A. J. A.; ALBANO, E. C. Parecer sobre a Avaliação de Listas de palavras quanto ao Balanceamento Fonético- LFAPE Instituto de Estudos da Linguagem - Unicamp - Campinas, 1997.

SILVERMAN, S. R.; HIRSH, I. J. Problems related to the use of speech audiometry. AN. Otol. Rhin. Laryn., v. 64, p. 1234-1244, 1956.

SPEAKS, C.; JERGER, S.; JERGER, S. Performance intensity characteristics of synthetic sentences .Journal of Speaking and Hearing Research, v. 9, p. 305-312, 1966.

STEVENS, K.N.; HOUSE,A.S. Speech Peception in TOBIAS,J. Foundations of Modern Audoitory Theory. NY: Academic Press, 1972.

STUDEBAKER, G. A.; PAVlOVIC, C. V.; SHERBECOE, R. L. A frequency importance function for continuous discourse. Journal of the Acoustical Society of America, v. 81, p. 1130-1138, 1987. 
TARALlO, F. A Pesquisa Socio-Lingüística. São Paulo: Ática, 1985.

TURRINI, M. ; CUTUGNO, F.; MATURI, P.; PROSSER, S.; LEONI, F. A.; ARSLAN, E. Bisyllabic words for speech audiometry: a new Italian material. Acta Otorhinolaryngol. Ital., v. 13, n. 05, p. 467, 1993.

VENTRY, I. M. Pure tone-spondee threshold relationship in functional hearing loss: a hypothesis. Journal of Speech and Hearing Disorders, v. 41, p. 16-22, 1976.

VERSFELD, N. J.; DAALDER, L.; FESTEN, J. M.; HOUTGAST, T. Method for the selection of sentence materials for efficient measurement of the speech reception threshold. Journal of the Acoustical Society of America, v. 107, n. 3, March 2000.

WAGENER, K.; JOSVASSEN, J. L.; ARDENKJAER, R. Design, optimization and evaluation of a Danish sentence test in noise. International Journal of Audiology, v. 42 , p. 10-17, 2003.

WALDEN, B. E. Validity issues in speech recognition testing. In ELKINS, E. (Ed.). Speech recognition by the hearing-impaired. Asha Reports , v. 14 , p. 16-18, 1984.

WALLEY, A. C. Spoken word recognition by young children ans adults. Cognitive Development, v. 3, p. 137-165, 1988.

WEBSTER, D. B. Neuroscience of Communication. San Diego: Singular, 1999.

WERTZNER, H. F. Fonologia (Parte A). In: ANDRADE, C. R. F.; BEFI-LOPES, D. M.; FERNANDES, M. D. M.; WERTZNER, H. F. ABFW - Teste de Linguagem Infantil nas Áreas de Fonologia, Vocabulário, Fluência e Pragmática. Carapicuíba: Pró-Fono Departamento Editorial, 2000.

WHALEN, D. H. Three lines of evidence for direct links between production and perception in speech. In: Proceedings of the International Congress of Phonetic Science. San Francisco, 1999.

WARREN,P; E MARSLEN-WILSON,W Cues to lexical choice:dicriminating place and voice. Perceptions \& Psychophysics, 31:21-30, 1988.

.WILSON, R. H.; MORGAN, D. F.; DIRKS, D. A proposed SRT procedure and its statistical precedent. Journal of Speech and Hearing Disorders, v. 38, p. 184-191, 1973.

WILSON, R. H. Development and use of auditory Compact Discs in auditory evaluation. Journal of Rehabilitation Research and Development, v. 30, n. 3, p. 342-351, 1993.

WILSON, R. H. Speech and other materials on Compact Disc for use in Auditory Assessment. In MENDEL, L.; DANHAUER, J. Audiologic evaluation and management and speech perception assessment. San Diego: Singular, 1997. 
WINGFIELD, A.; LINDFIELD, K. C.; GOODGLASS, H. Effects of age and hearing sensibility on the use of prosodic information in spoken word recognition. Journal of Speech, Language, and Hearing Research, v. 93, p. 915-925, Aug. 2000.

YOUNG, L. L.; DUDLEY, B.; GUNTER, M. B. Thresholds and psychometric functions of the individual spondaic words. Journal of Speech and Hearing Research, v. 25, p. 586-593, 1982.

ZAIDAN, E. Desenvolvimento de uma bateria de testes de triagem da função auditiva central em pré-escolares e escolares na faixa etária de 6 a 11 anos. Tese. (Mestrado) Instituto de Psicologia da Universidade de São Paulo, 2001.

ZEIGELBOIM, B. S.; Borges, A. C. L. C.; PEREIRA, L. D. Triagem auditiva: estudo do limiar de inteligibilidade em crianças de 4 a 7 anos de idade. ACTA AWHO, v. 13, n. 1, jan./abril 1994. p. 17-20.

ZUBICK, H. H.; IRIZARRY, L. M.; ROSEN, L.; FEUDO, P.; KELLY, J.; STROME, M. Development of speech audiometric materials for native Spanishspeaking adults. Audiology, v. 22, n. 1, p. 88-102, Jan./Feb., 1983. 
